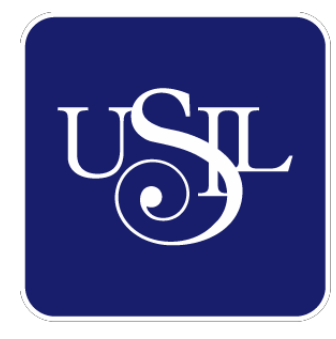

UNIVERSIDAD

SAN IGNACIO

DE LOYOLA

ESCUELA DE POSTGRADO

\title{
PLAN DE NEGOCIO PARA LA CREACIÓN DE UNA ESCUELA DE MARKETING DIGITAL, LIMA, 2018.
}

Trabajo de Investigación para optar el grado de:

\author{
RICARDO AUGUSTO LLANOS POLIANICH \\ Maestro en Ciencias Empresariales \\ ROSA LIZ MOSQUITO GUILLÉN \\ Maestro en Ciencias Empresariales
}

\author{
Asesor: \\ Mag. Flor Elvira Ríos Rivero \\ Lima - Perú \\ 2019
}


Dedicatoria/Agradecimiento

A Dios, por habernos permitido llegar hasta aquí superando retos que por momentos nos parecían imposibles.

A nuestras familias, por su amor y comprensión durante este año.

A nuestra asesora, Flor Ríos, por su paciencia y consejo, por inspirarnos, guiarnos y motivarnos a seguir adelante. 


\section{Resumen Ejecutivo}

La idea de crear una Escuela de Marketing Digital surgió a raíz de la experiencia e interés de los integrantes de este grupo en el marketing digital, así como en la educación y en la gestión de instituciones dedicadas a la enseñanza.

Con esta idea en mente, se analizó la demanda existente para este tipo de negocio, se hizo el estudio de mercado y se definieron estrategias. Se optó por la personalización de los cursos, por enseñar de manera individual, así como también a grupos reducidos, de manera que el conocimiento se genere de manera más eficiente. En el primer caso, dándole al alumno un curso flexible, tanto en horario como en contenido; en el segundo, formando grupos de máximo 15 alumnos, a los cuales se les ofrecerá cursos cortos, con contenido y objetivos de aprendizaje ya establecidos, pero que podrá ser presentado y adaptado de acuerdo con sus necesidades específicas, de manera que el alumno se sienta motivado a aprender y pueda, al finalizarlos, aplicarlos en su trabajo o para los fines que lo requiera.

Se eligió crear una Escuela que ofrezca cursos que pudieran ser diseñados en el corto plazo y de acuerdo con la demanda y tendencias del sector, pues en esta época donde la tecnología evoluciona a diario es necesario evolucionar con ella. La Escuela se ubicará en el distrito de Miraflores, contará con cuatro aulas, tres de ellas para clases grupales y una para clases individuales. Los cursos se dictarán en distintos horarios, en las mañanas, noches y también los sábados. Finalmente, cabe resaltar que se determinó que el negocio resultaba viable, pues así lo señalan los indicadores financieros utilizados. Se obtuvo un VAN de S/. 520,380.29 y la TIR resultó ser $117 \%$.

Palabras clave: plan de negocios, escuela de marketing, marketing digital 


\section{Abstract}

The idea of creating a Digital Marketing School arose from the experience and interest of this Digital Marketing group, as well as in the education and management of institutions dedicated to teaching.

Taking this idea into account, the current demand for this kind of business was analyzed, a market study was performed and strategies were defined. We opted for customizable courses, individual teachings and small study groups, so that knowledge is spread with better efficiency. In the first case, giving the student a flexible course, both in schedule and in content; in the second, forming groups of maximum 15 students, which will be offered short courses, with content and learning objectives already established, but that can be presented and adapted according to their specific needs, so that the student sits motivated to learn and can, upon completion, apply them in your work or for the purposes that require it.

It was chosen to create a School that offers courses that could be designed in the short term and according to the demand and trends of the sector, because in this era where technology evolves daily it is necessary to evolve with it. The School will be located in the district of Miraflores, will have four classrooms, three of them for group classes and one for individual classes. The courses will be taught at different times, in the mornings, evenings and also on Saturdays. Finally, it should be noted that it was determined that the business was viable, as indicated by the financial indicators used. A NPV of S /. 520,380.29 and the IRR turned out to be $117 \%$.

Keywords: business plan, marketing school, digital marketing, digital school 


\section{Tabla de Contenido}

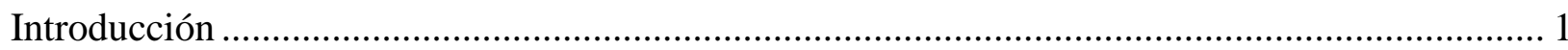

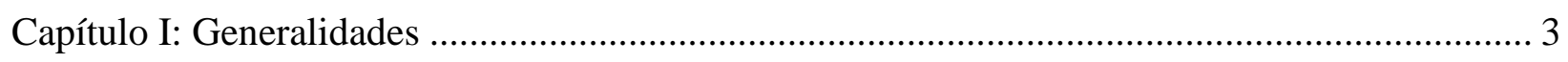

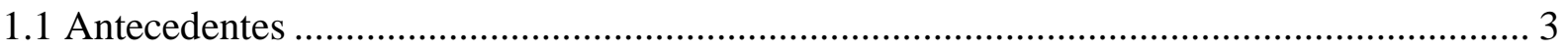

1.2 Determinación del problema u oportunidad......................................................... 6

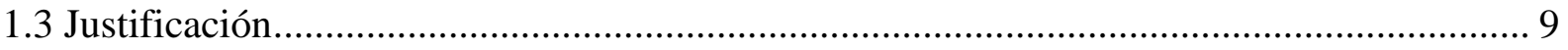

1.4 Objetivos generales y específicos ….............................................................. 10

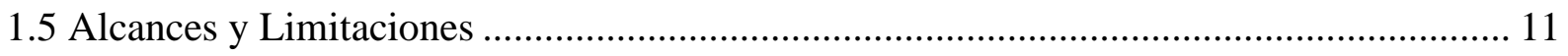

Capítulo II: Estructura Económica del Sector ................................................................ 12

2.1 Descripción del estado actual de la Industria ......................................................... 12

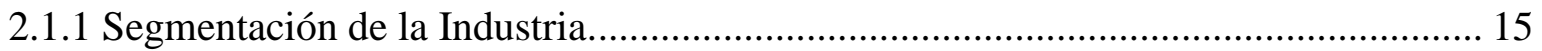

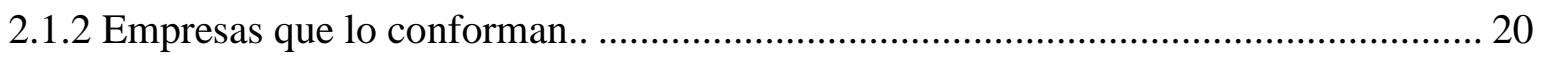

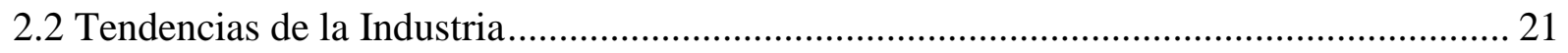

2.3 Análisis estructural del Sector Industrial ........................................................... 22

2.4 Análisis de la Competencia .............................................................................. 30

2.4.1 Empresas que ofrecen el mismo servicio................................................. 30

2.4.2 Participación de mercado de cada uno de ellos. ................................................. 35

2.4.3 Matriz de Perfil Competitivo........................................................................... 37

2.5 Análisis del Contexto Actual y Esperado............................................................. 45

2.5.1 Análisis Político- Gubernamental.................................................................. 45

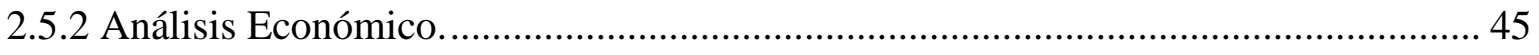

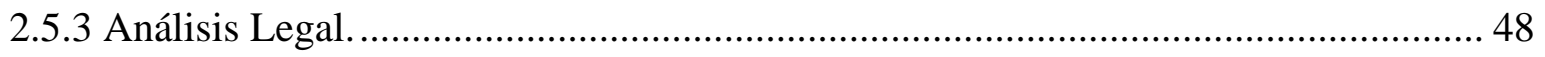


vi

2.5.4 Análisis Cultural......................................................................................... 50

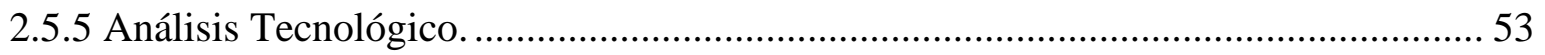

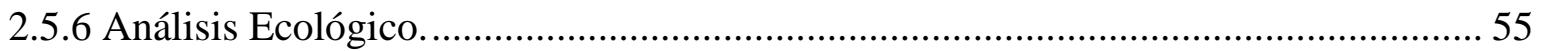

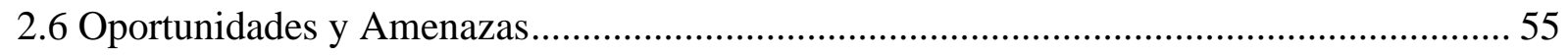

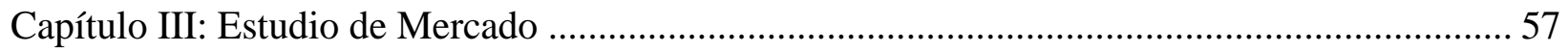

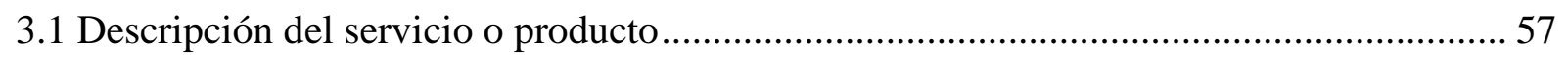

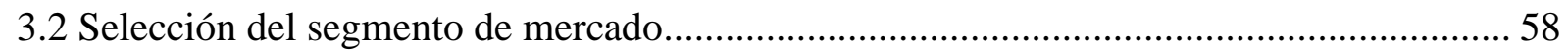

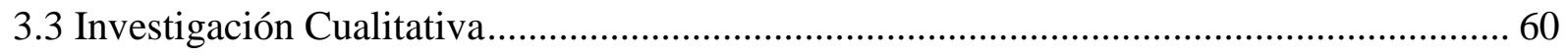

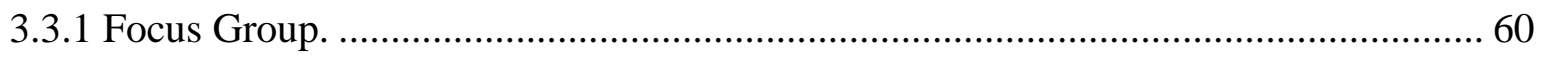

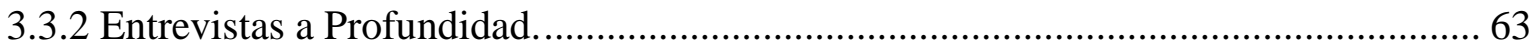

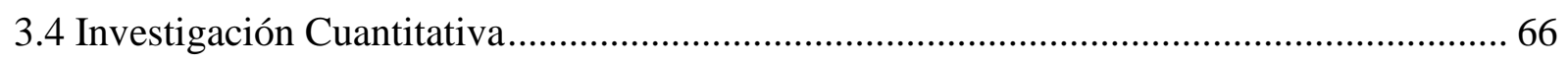

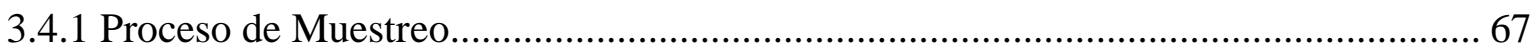

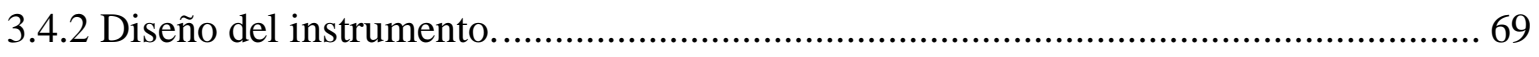

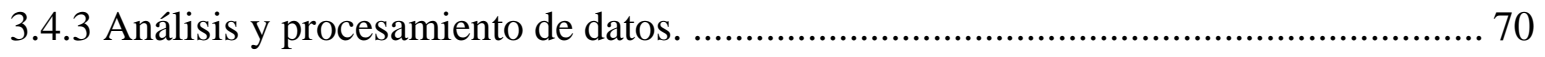

3.5 Conclusiones y recomendaciones del Estudio Cualitativo y Cuantitativo....................... 77

3.6 Perfil del consumidor tipo y sus variantes ........................................................ 78

Capítulo IV: Proyección de la demanda ....................................................................... 79

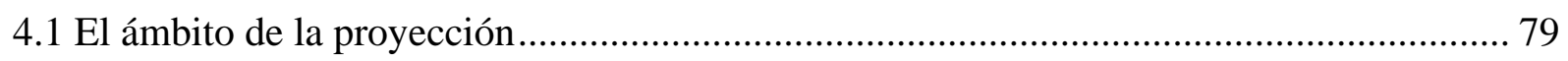

4.2 Selección del método de proyección........................................................................ 79

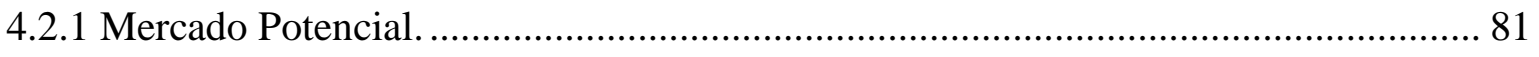

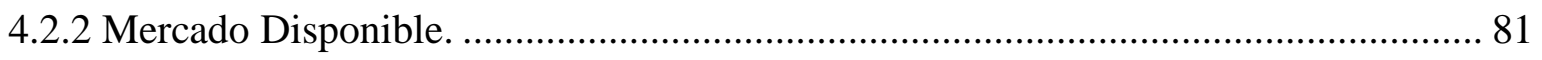

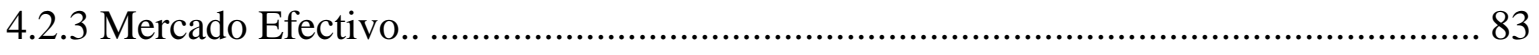

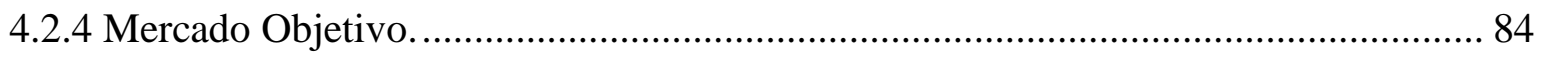




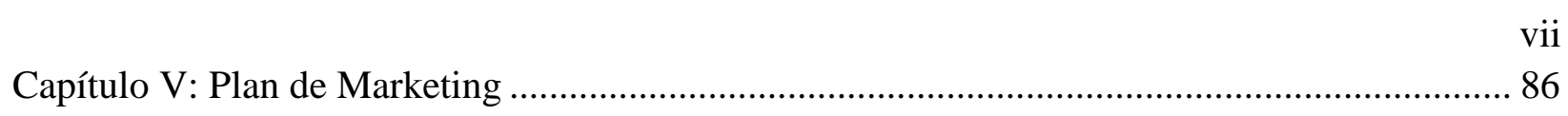

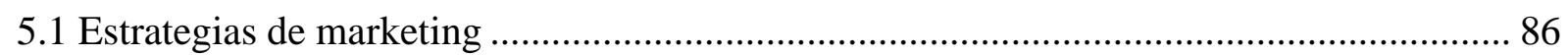

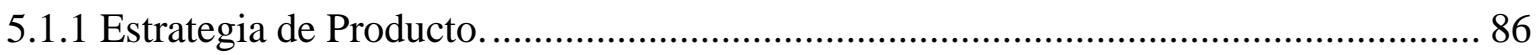

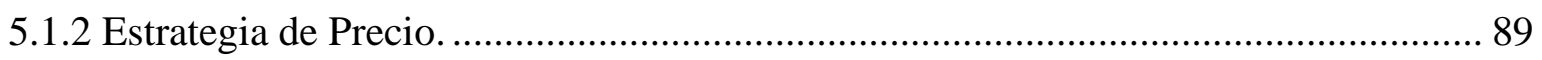

5.1.3 Estrategia de Plaza y Distribución............................................................................. 91

5.1.4 Estrategia de Promoción y Publicidad............................................................................ 91

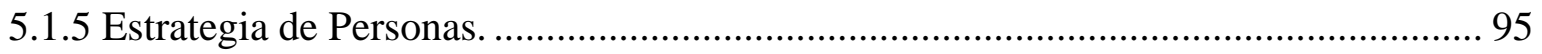

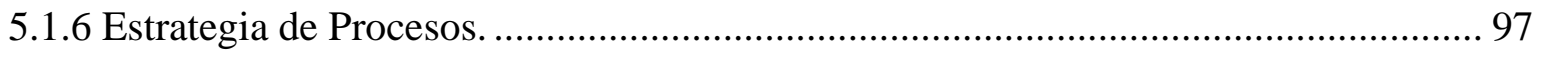

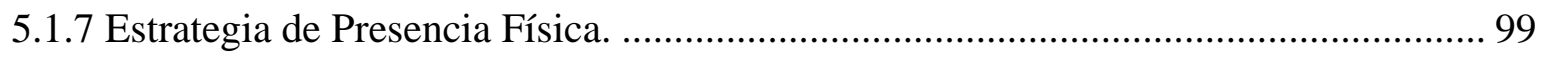

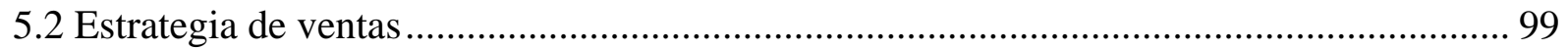

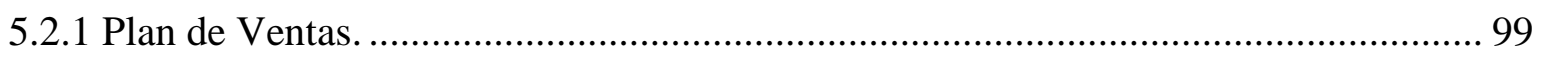

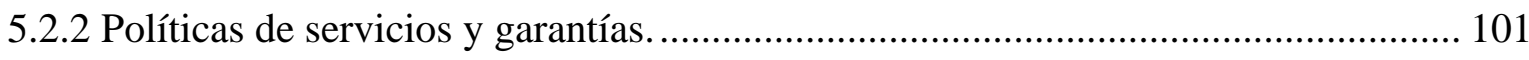

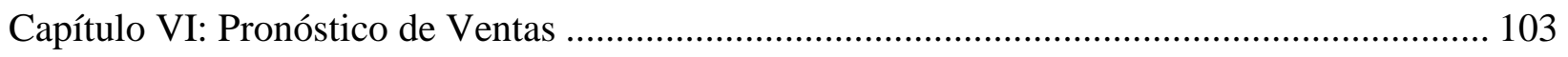

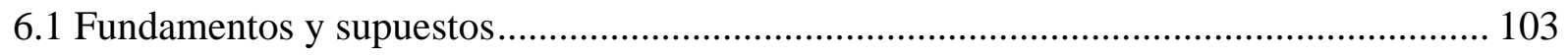

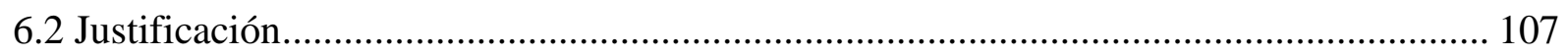

6.3 Análisis de los riesgos y aspectos críticos que impactan en el pronóstico........................ 108

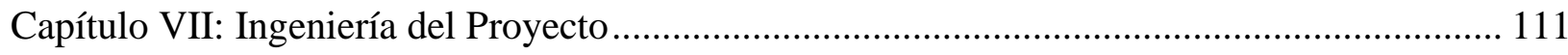

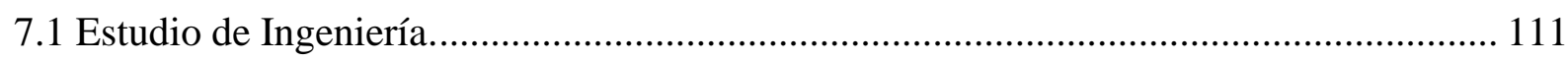

7.1.1 Modelamiento y selección de procesos productivos. ............................................... 111

7.1.2 Selección de equipamiento.................................................................................... 111

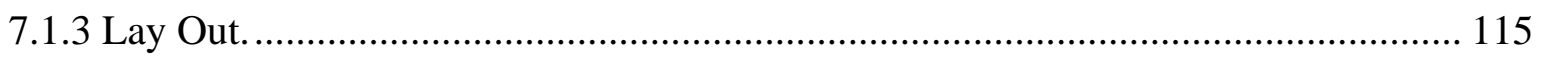

7.1.4 Distribución de equipos y maquinaria....................................................................... 115

7.2 Determinación del tamaño .................................................................................. 116 
viii

7.2.1 Proyección de crecimiento. ........................................................................... 118

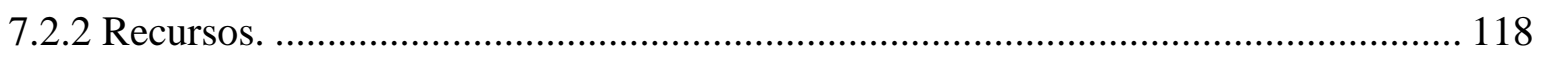

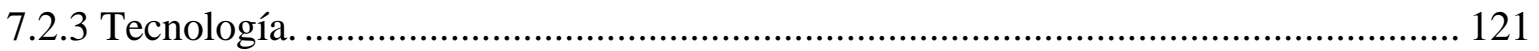

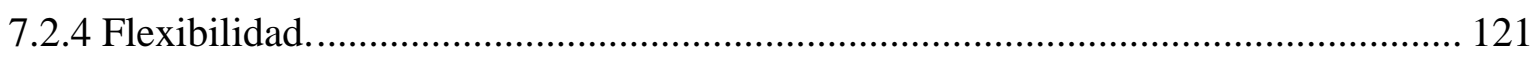

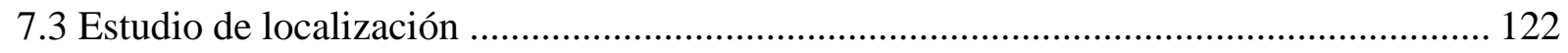

7.3.1 Definición de factores locacionales............................................................. 123

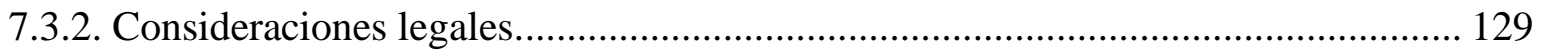

7.4. Determinación de la localización óptima ............................................................... 137

Capítulo VIII: Aspectos Organizacionales ............................................................... 141

8.1. Caracterización de la cultura organizacional deseada ............................................. 141

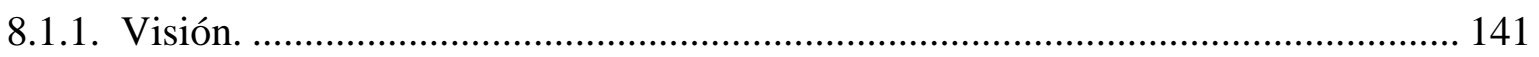

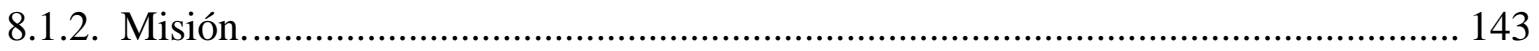

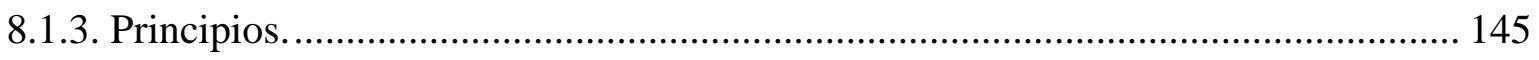

8.2. Formulación de Estrategias del Negocio.............................................................. 146

8.3. Determinación de las ventajas competitivas críticas ............................................. 147

8.4. Diseño de la estructura organizacional deseada ............................................... 150

8.5. Diseño de los perfiles de puestos clave ............................................................. 150

8.6. Remuneraciones, compensaciones e incentivos.................................................. 153

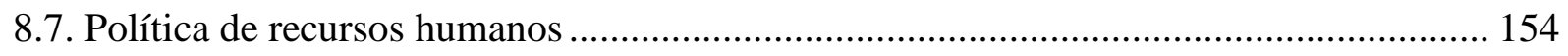

Capítulo IX: Planificación Financiera ….................................................................. 155

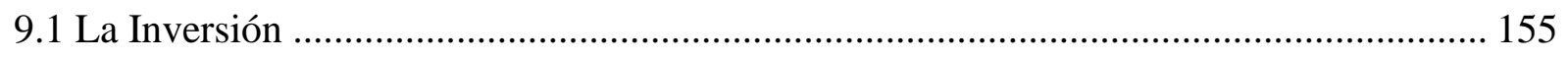

9.1.1 Inversión preoperativa ............................................................................ 155

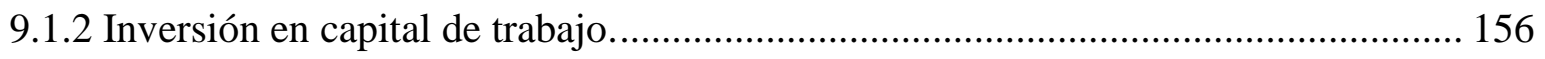


ix

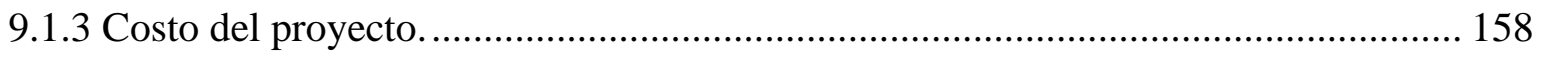

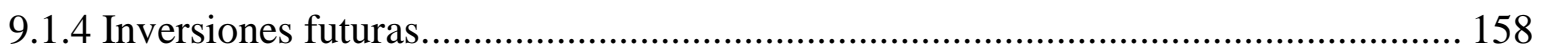

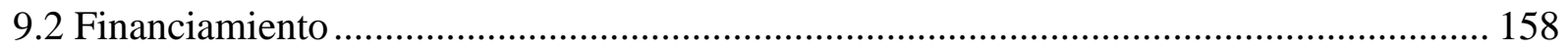

9.2.1. Endeudamiento y condiciones................................................................. 158

9.2.2 Capital y costo de oportunidad................................................................... 160

9.2.3 Costo de capital promedio ponderado........................................................... 160

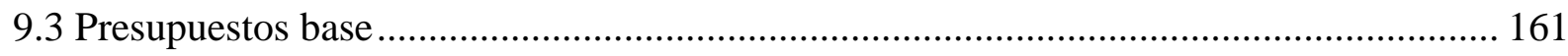

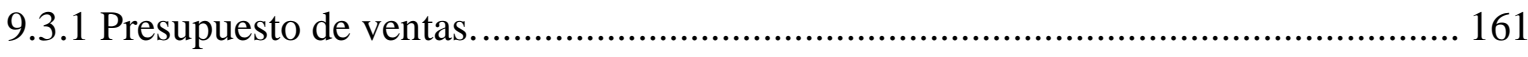

9.3.2 Presupuesto de costos de producción. ............................................................ 162

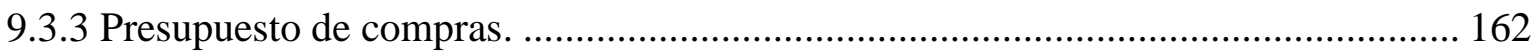

9.3.4 Presupuesto de costo de ventas.................................................................... 163

9.3.5 Presupuesto de gastos administrativos. ........................................................ 163

9.3.6 Presupuesto de marketing y ventas............................................................... 164

9.3.7 Presupuesto de gastos financieros. ........................................................ 164

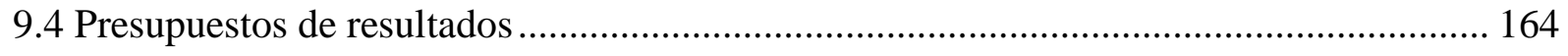

9.4.1 Estado de ganancias y pérdidas proyectado. ................................................. 164

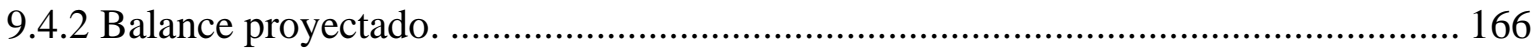

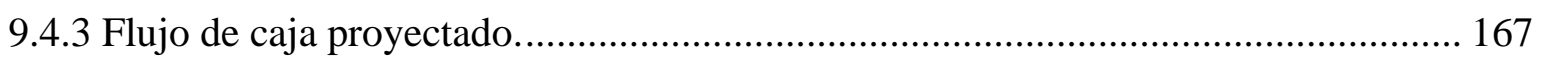

Capítulo X: Evaluación Económico Financiera.................................................................. 168

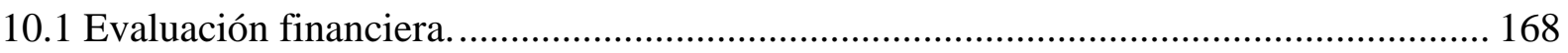

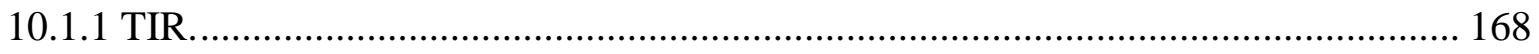

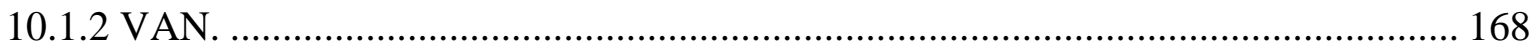

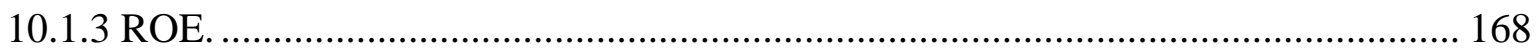




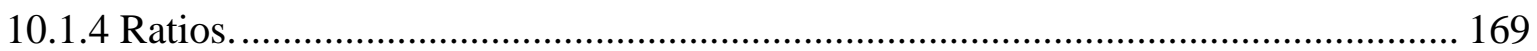

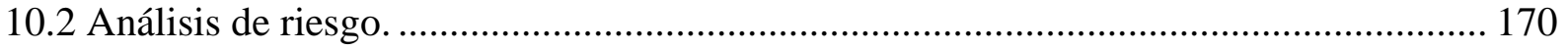

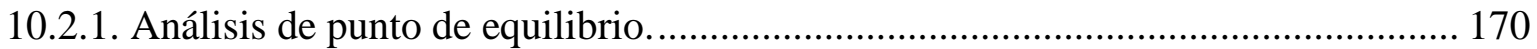

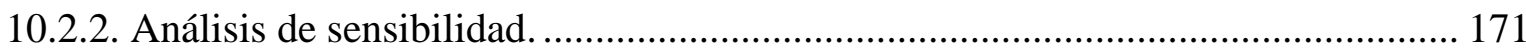

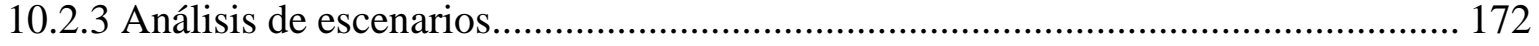

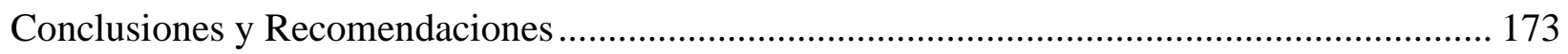

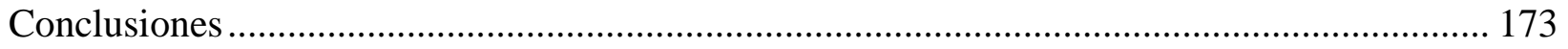

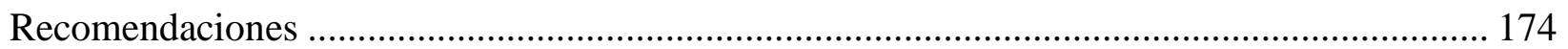

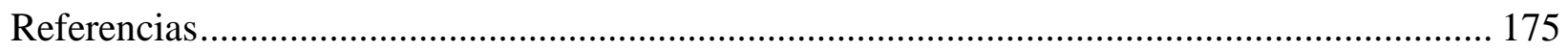

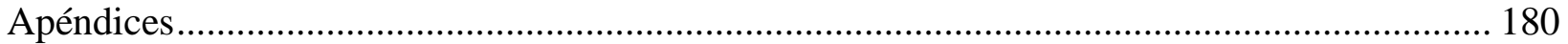




\section{Lista de Tablas}

Tabla 1. Evolución de las inversiones publicitarias en los medios a nivel nacional .................... 4

Tabla 2. Universidades donde se enseña Marketing Digital ................................................. 7

Tabla 3. Otras instituciones donde se enseña Marketing Digital........................................... 8

Tabla 4. Carreras que estudiaron quienes trabajan en el Área de Marketing Digital ................. 13

Tabla 5. Egresados de Pregrado de Universidades Públicas y Privadas por Familia de Carreras

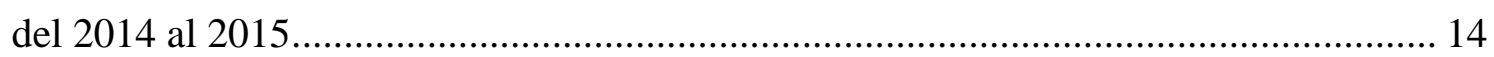

Tabla 6. Empresas que dictan cursos de marketing digital - Competidores Directos ................ 19

Tabla 7. Institutos que dictan cursos de marketing digital................................................... 19

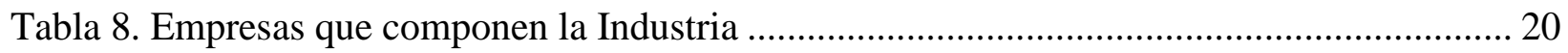

Tabla 9. Diferencias y similitudes de los competidores con el proyecto................................. 35

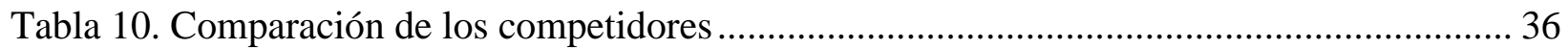

Tabla 11. Instituciones educativas que dictan carreras de marketing por distrito..................... 39

Tabla 12. Ponderación de factores críticos de éxito ........................................................ 43

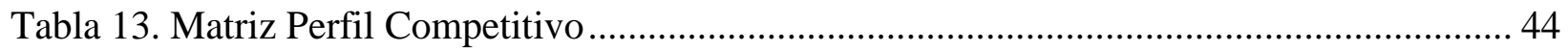

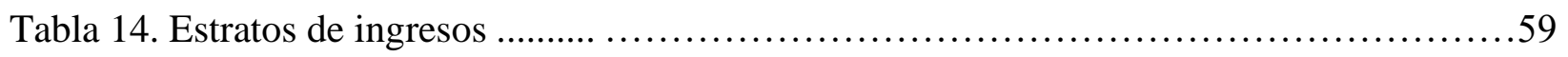

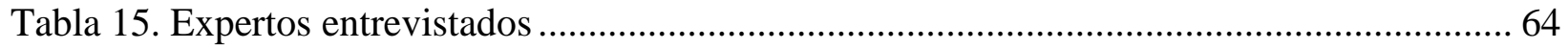

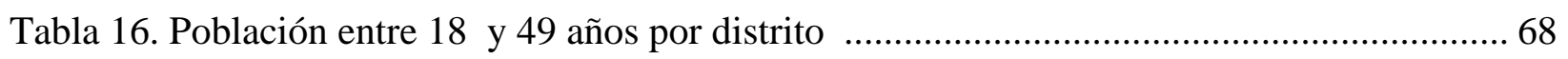

Tabla 17. Conocimiento de escuelas o institutos de marketing digital.................................... 71

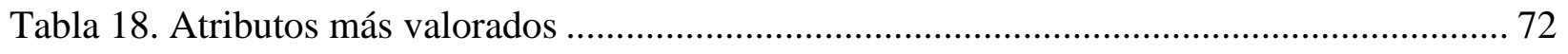

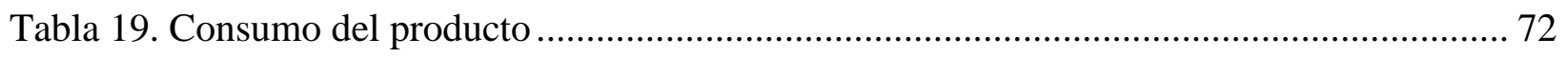

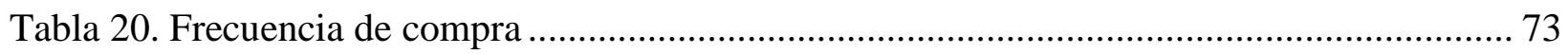

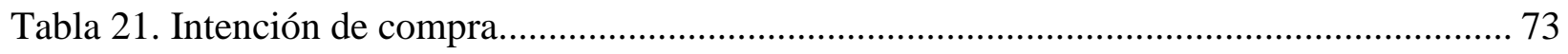


xii

Tabla 22. Modalidades de estudio preferidas. ................................................................ 74

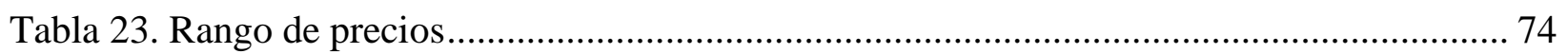

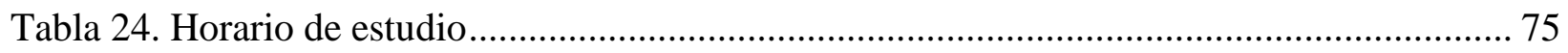

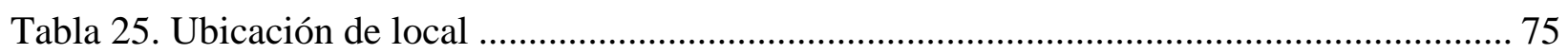

Tabla 26. Atributos más valorados en los profesores ........................................................ 76

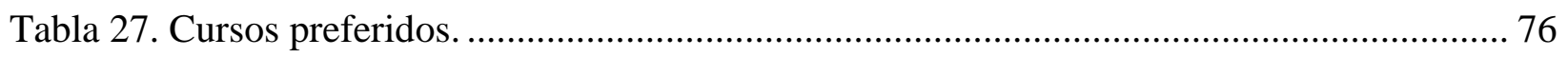

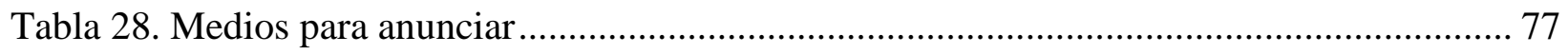

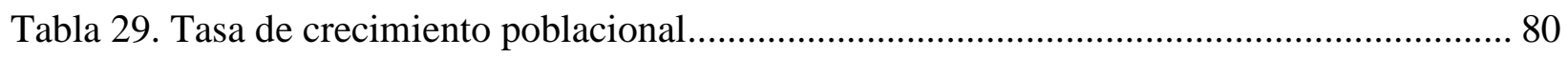

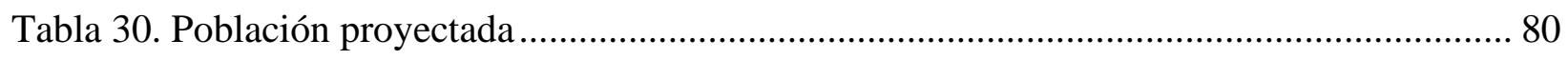

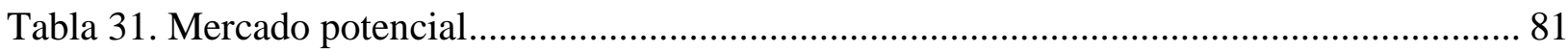

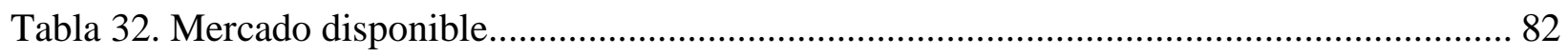

Tabla 33. Cálculo del índice de Mc Daniel.......................................................................... 83

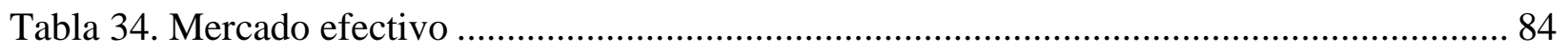

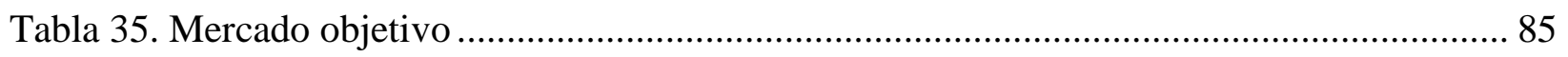

Tabla 36. Comparación precios de la competencia ........................................................... 90

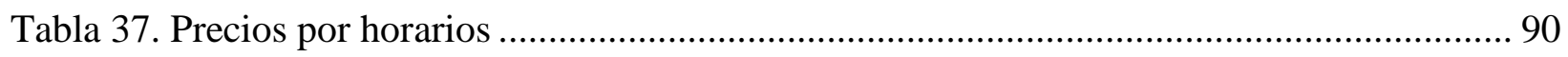

Tabla 38. Ventas en número de alumnos durante el primer año........................................... 100

Tabla 39. Ventas en soles para el primer año de funcionamiento ........................................ 101

Tabla 40. Pronóstico de alumnos inscritos durante el primer año ......................................... 105

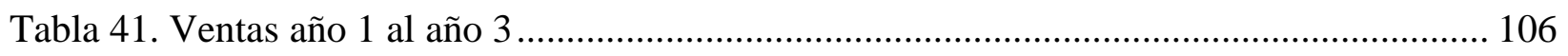

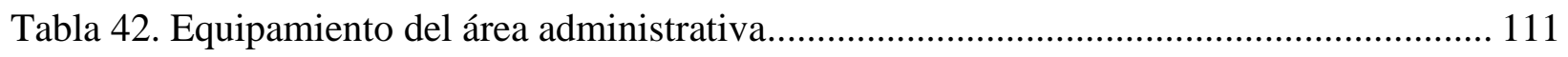

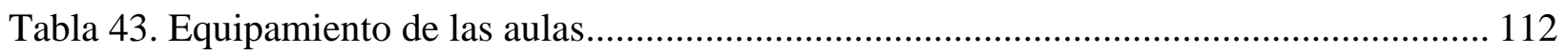

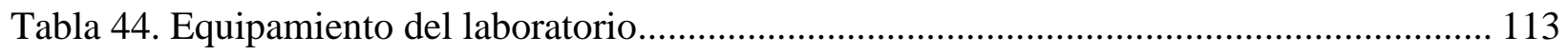


xiii

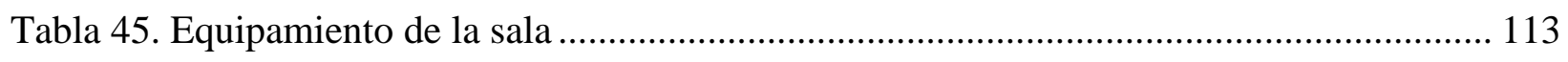

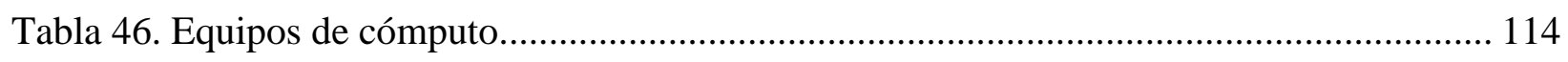

Tabla 47. Equipos de comunicación .............................................................................. 114

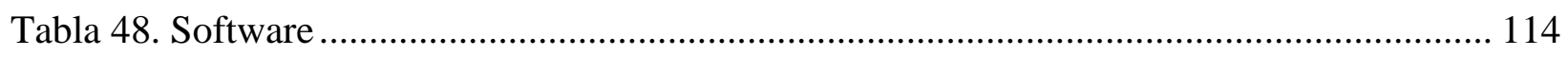

Tabla 49. Capacidad de cursos por salón .......................................................................... 116

Tabla 50. Programación de cursos por salón ................................................................... 117

Tabla 51. Horas de dictado por mes............................................................................ 118

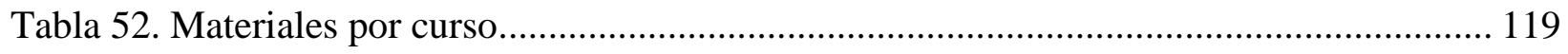

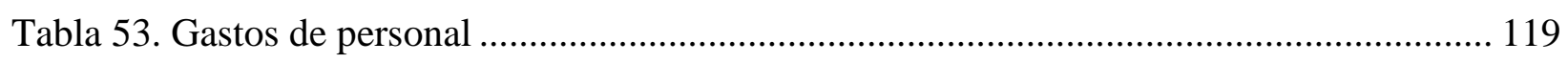

Tabla 54. Inversión en activo intangible.................................................................... 120

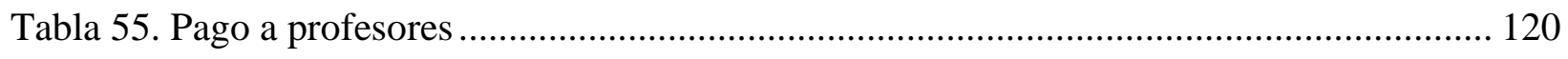

Tabla 56. Factores de localización .................................................................................. 126

Tabla 57. Valoración del puntaje ............................................................................... 126

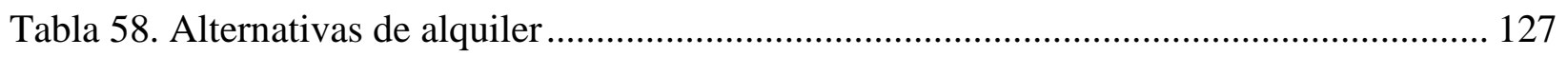

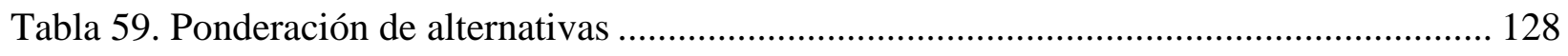

Tabla 60. Criterios para evaluar la visión ....................................................................... 142

Tabla 61. Nueve componentes de la misión ...................................................................... 144

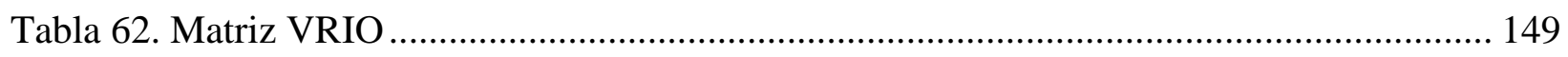

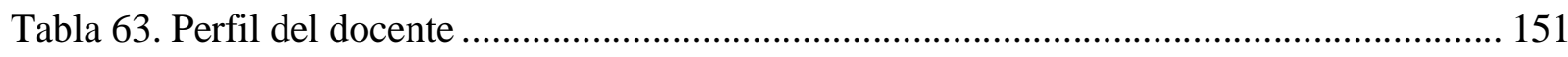

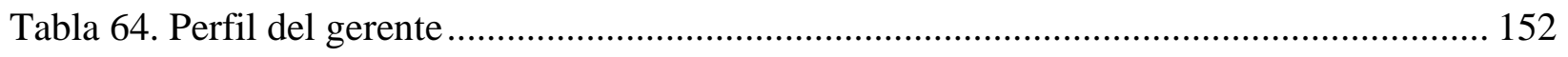

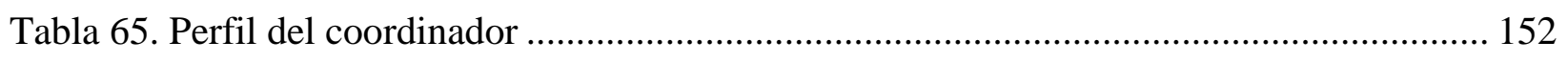

Tabla 66. Perfil de recepcionista / agentes de ventas..................................................... 153

Tabla 67. Remuneración bruta mensual del personal ..................................................... 154 
xiv

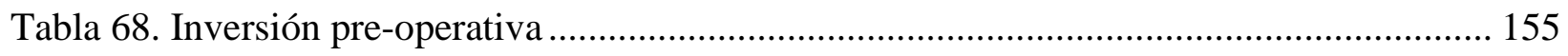

Tabla 69. Cálculo del capital de trabajo según el método del máximo déficit acumulado......... 157

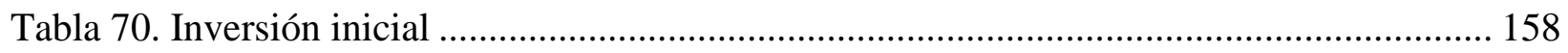

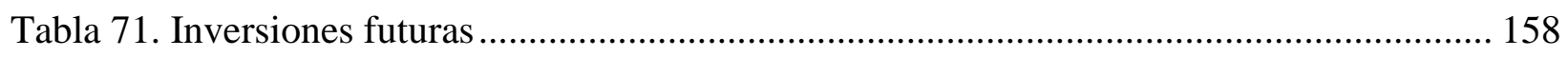

Tabla 72. Costo de capital......................................................................................... 160

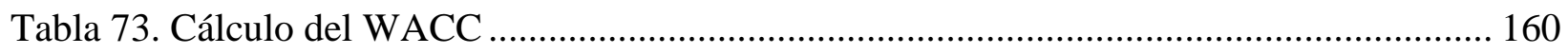

Tabla 74. Presupuesto de ventas por año .................................................................... 161

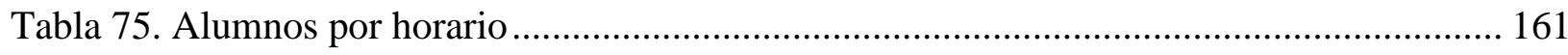

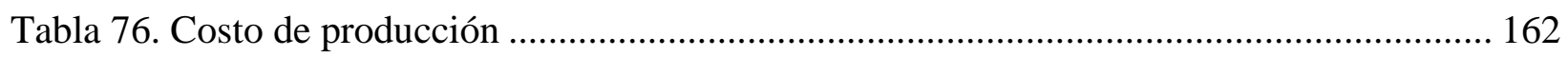

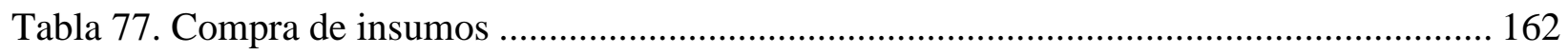

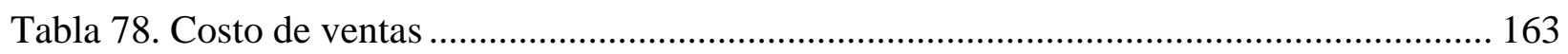

Tabla 79. Presupuesto de gasto administrativos ................................................................ 163

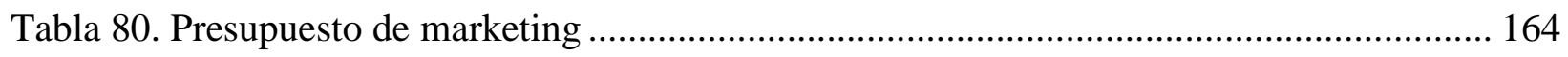

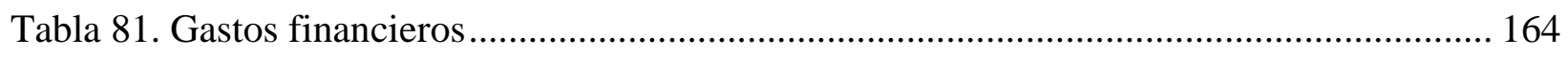

Tabla 82. Estado de Ganancias y pérdidas proyectado ...................................................... 165

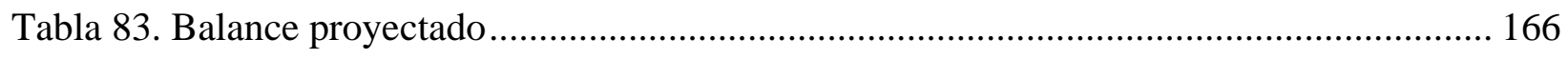

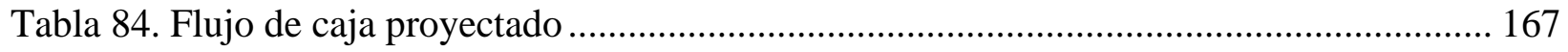

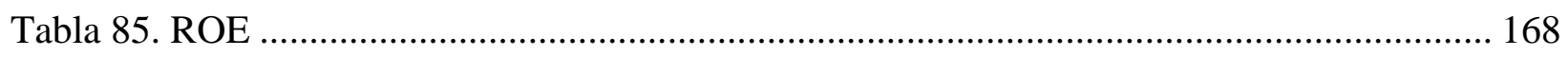

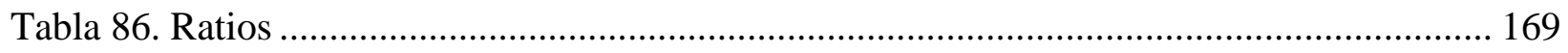

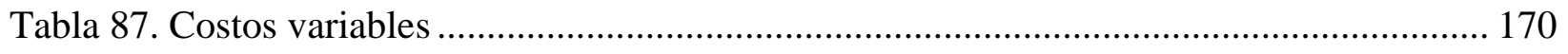

Tabla 88. Punto de equilibrio en unidades .................................................................. 170

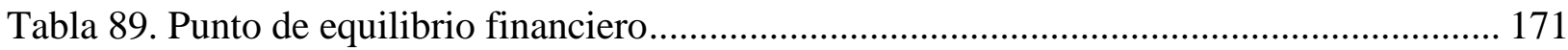

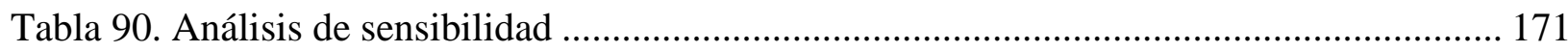




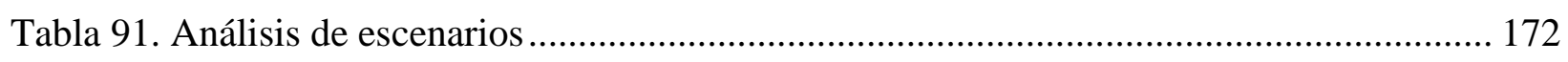




\section{Lista de Figuras}

Figura 1. Características de cada actor que hoy contribuye a la formación de la industria.......... 15

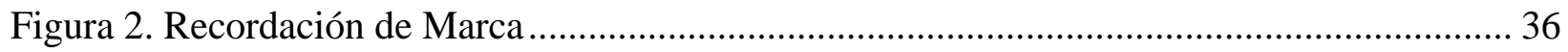

Figura 3. Ubicación de agencias de marketing digital ...................................................... 37

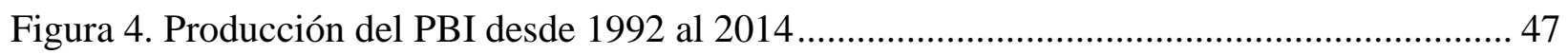

Figura 5. Tipo de cambio promedio anual del 2010 al 2017 ............................................. 47

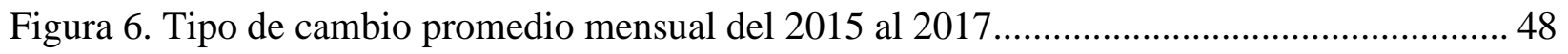

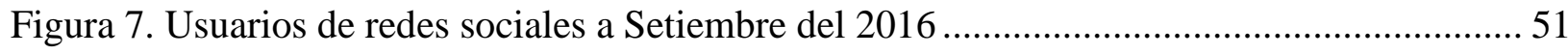

Figura 8. Tenencia de dispositivos para conexión a Internet................................................ 52

Figura 9. Líneas móviles que accedieron a internet - Junio 2017 ....................................... 54

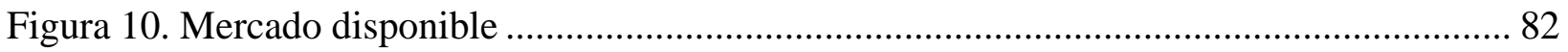

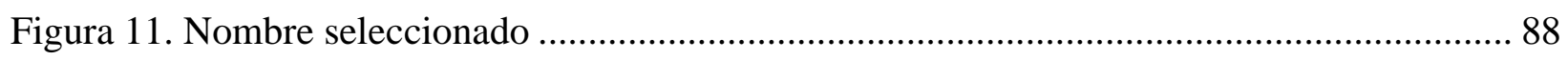

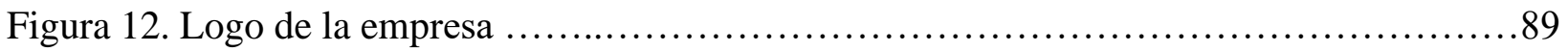

Figura 13. Proceso de Inscripción y Finalización del curso ............................................... 111

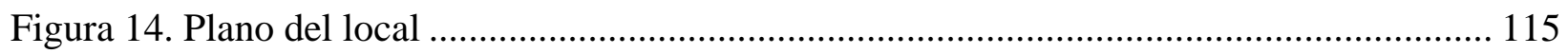

Figura 15. Distribución de Equipos y Muebles de la Escuela ............................................... 116

Figura 16. Plano de zonificación de Miraflores ............................................................... 124

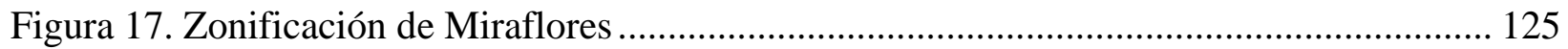

Figura 18. Proceso de obtención de licencia en Miraflores ............................................... 131

Figura 19. Local Comercial 117,5 m2 Miraflores ...................................................... 138

Figura 20. Plano Local Comercial en Miraflores............................................................. 139 


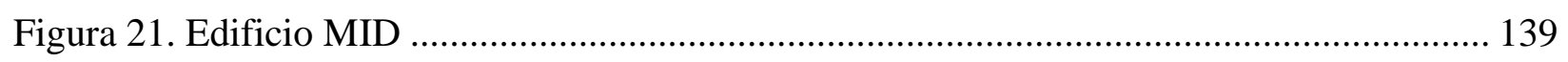

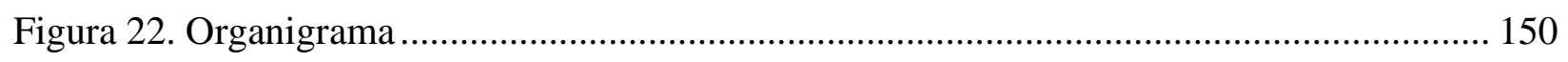

Figura 23. Simulación de préstamo …....................................................................... 159 


\section{Introducción}

A lo largo de este documento, se presenta el plan de negocios para la creación de una Escuela de Marketing Digital en la ciudad de Lima, la cual tendrá como finalidad atender parte de la creciente demanda por instituciones donde aprender sobre este tema.

En el primer capítulo se mencionan los antecedentes del marketing digital y de su estrecha relación con la masificación del uso de la Internet. Así también se ha resaltado la oportunidad que representa la inexistencia en el mercado de una Escuela de Marketing Digital como la propuesta, es decir enfocada en dictar cursos personalizados o a grupos de hasta 15 alumnos. Del mismo modo, se detallan los alcances y limitaciones del presente plan de negocios.

En el segundo capítulo, se analiza la estructura económica del sector educación.

Seguidamente, se desarrolla el análisis la competencia, indicando las semejanzas y diferencias que tienen con el presente proyecto. Por último, se analizan las variables del sector que pueden afectar, de alguna manera, el negocio.

El tercer capítulo corresponde al estudio de mercado. Primeramente, se presenta la descripción del servicio educativo que ofrecerá la Escuela de Marketing Digital. Luego, se explica cómo se realizó la selección del segmento de mercado al que estará dirigido el servicio. Seguidamente, se reseña tanto la investigación cualitativa como la cuantitativa que se realizaron. Finalmente se exponen las conclusiones y recomendaciones de ambos estudios.

En el cuarto capítulo se explica cómo se realizó la proyección del mercado objetivo. Incluyendo el ámbito de la proyección y el método de proyección utilizado para determinar el mercado potencial, mercado disponible, mercado efectivo y mercado objetivo.

En el quinto capítulo se expone el plan de marketing. Como primer punto se ha definido la estrategia general de marketing, la cual comprende las estrategias de producto, precio, plaza y 
promoción. Asimismo, por tratarse de un servicio se han incluido las estrategias de personas, procesos y presencia física. El segundo punto que se presenta son las estrategias de ventas, incluyendo el plan de ventas.

El sexto capítulo muestra el pronóstico de ventas. Se mencionan sus fundamentos y supuestos, su justificación y un análisis de los riesgos y aspectos críticos que podrían impactar en el pronóstico.

El estudio de ingeniería se desarrolla en el sétimo capítulo, así como también el estudio de localización. En base a ambos se determinó la localización óptima al final del capítulo.

El octavo capítulo trata de los aspectos organizacionales, se formulan la visión, misión y principios de la organización. También se formulan las estrategias del negocio, se determinan las ventajas competitivas críticas y se presentan el organigrama, los perfiles de los puestos clave, así como la política de recursos humanos.

En el capítulo noveno se trata todo el aspecto financiero del negocio, desde la inversión, pasando por el financiamiento y el presupuesto de base, hasta el presupuesto de resultados. Se presentan de manera detallada cada uno de los presupuestos y estados financieros.

El décimo y último capítulo es el referido a la evaluación económico-financiera. Incluye el cálculo e interpretación de los indicadores financieros más utilizados como TIR, VAN, ROE y otras ratios, así como también el análisis de riesgo.

Luego de analizados todos los aspectos desarrollados a lo largo de los diez capítulos se presentan las conclusiones y recomendaciones finales al proyecto. 


\section{Capítulo I: Generalidades}

En este capítulo se mencionan principalmente los antecedentes, es decir, la información relevante con la que se cuenta hasta el momento sobre el tema, así como también la oportunidad de negocio que se ha identificado, los objetivos y las limitaciones para el presente proyecto.

\subsection{Antecedentes}

Durante las últimas décadas se ha visto cómo se ha difundido rápidamente el uso de la Internet, el tráfico global de Internet creció por un factor de 30 entre 2000 y 2014, conectando a cuatro de cada diez personas en el mundo (Kotler, Kartajaya, \& Setiawan, 2017). Según la Internet World Stats, en 2016 se estimaba en 3,600 millones la cantidad de usuarios de internet lo cual equivalía, según el Banco Mundial, a más del 40\% de la población mundial (Cámara Americana de Comercio de la República Dominicana, 2016).

En el Perú también hay una aceleración del desarrollo digital. Hoy en día el 72\% de los limeños, es decir 13 millones de habitantes se conectan a Internet por lo menos seis veces a la semana y el $25 \%$ de ellos ha efectuado la compra de algún producto a través de la web (Nuñez, 2017). Es dentro de este contexto que nuevas herramientas de marketing han aparecido, es así como ya no sólo se habla del marketing, sino también del marketing digital, es decir de la aplicación de las estrategias de comercialización en los medios digitales (Velásquez, 2017).

El concepto de marketing digital fue usado por primera vez en los años noventa, aunque en ese entonces se refería principalmente a hacer publicidad hacia los clientes. Sin embargo, durante las dos décadas siguientes, con el surgimiento de nuevas herramientas sociales y móviles ese paradigma se amplió. Poco a poco se fue transformando de hacer publicidad, al concepto de crear una experiencia que involucre a los usuarios, de modo que cambie su concepto de lo que es ser cliente de una marca (Velásquez, 2017). 
Una muestra de la importancia que está tomando el marketing digital es el aumento de la inversión publicitaria en Internet, que en el año 2017 alcanzó los 96 millones de dólares creciendo un $11.62 \%$ respecto del año anterior, tal como se puede observar en la tabla 1. Este es un resultado bastante interesante si se toma en cuenta que la inversión publicitaria total (a través de todos los medios de comunicación) decayó en 7.8\%, de 725 millones de dólares en 2016 a 668 millones de dólares en 2017. Por otro lado, el porcentaje de la inversión en publicidad en Internet con respecto del total de la inversión publicitaria total fue de $14.4 \%$ en 2017 mientras que en 2016 había sido de 11.9\%. Este crecimiento es constante año a año desde el 2013

(Compañía Peruana de Estudios de Mercados y Opinión Pública, 2018).

Tabla 1

Evolución de las inversiones publicitarias en los medios a nivel nacional

\begin{tabular}{|c|c|c|c|c|c|c|c|c|c|c|}
\hline \multicolumn{11}{|c|}{$\begin{array}{c}\text { Estimado a costo real - Tarifa Neto } 2013-2017 \\
\text { Millones de dólares }\end{array}$} \\
\hline & \multicolumn{2}{|c|}{2013} & \multicolumn{2}{|c|}{2014} & \multicolumn{2}{|c|}{2015} & \multicolumn{2}{|c|}{2016} & \multicolumn{2}{|c|}{2017} \\
\hline & US \$ & $\%$ & US \$ & $\%$ & US \$ & $\%$ & US \$ & $\%$ & US \$ & $\%$ \\
\hline Televisión & 352 & 49.9 & 373 & 50.0 & 351 & 49.4 & 368 & 50.8 & 320 & 47.9 \\
\hline Internet & 44 & 6.2 & 66 & 8.8 & 77 & 10.8 & 86 & 11.9 & 96 & 14.4 \\
\hline Radio & 79 & 11.2 & 81 & 10.9 & 74 & 10.4 & 83 & 11.4 & 85 & 12.7 \\
\hline Diarios & 106 & 15.0 & 107 & 14.3 & 94 & 13.2 & 81 & 11.2 & 69 & 10.3 \\
\hline Vía Pública & 71 & 10.1 & 72 & 9.7 & 68 & 9.6 & 64 & 8.8 & 59 & 8.8 \\
\hline Cable & 39 & 5.5 & 33 & 4.4 & 34 & 4.8 & 31 & 4.3 & 28 & 4.2 \\
\hline Revistas & 14 & 2.0 & 14 & 1.9 & 13 & 1.8 & 12 & 1.7 & 11 & 1.6 \\
\hline Total & 705 & 100.0 & 746 & 100.0 & 711 & 100.0 & 725 & 100.0 & 668 & 100.0 \\
\hline $\begin{array}{c}\text { Participación } \\
\text { del PBI }\end{array}$ & \multicolumn{2}{|c|}{0.35} & \multicolumn{2}{|c|}{0.37} & \multicolumn{2}{|c|}{0.37} & \multicolumn{2}{|c|}{0.38} & \multicolumn{2}{|c|}{0.31} \\
\hline $\begin{array}{c}\text { Crecimiento } \\
\text { del PBI }\end{array}$ & \multicolumn{2}{|c|}{$5.9 \%$} & \multicolumn{2}{|c|}{$2.4 \%$} & \multicolumn{2}{|c|}{$3.3 \%$} & \multicolumn{2}{|c|}{$3.9 \%$} & \multicolumn{2}{|c|}{$2.5 \%$} \\
\hline
\end{tabular}

Nota. Tomado de Inversiones Publicitarias 2017, por Compañía Peruana de Estudios de Mercado y Opinión Pública, 2018, Perú, Lima: Editorial. Copyright 2018 por Compañía Peruana de Estudios de Mercado y Opinión Pública. 
Ahora es cuando las empresas deben comunicarse con las personas de una manera que se adapte a su estilo de vida y sus preferencias, uniendo el mundo físico con el digital. Es por ello por lo que se presenta como una oportunidad y una necesidad saber de marketing digital. La mayoría de los clientes cree más en el Factor F, entendido como amigos, familiares, fans de Facebook, seguidores en Twitter, que en la publicidad y las opiniones de expertos (Kotler, Kartajaya, \& Setiawan, 2017).

La llegada de la Internet y de nuevas tecnologías al mercado hacen cada vez aún más atractiva la carrera de Marketing para muchos jóvenes. En un estudio realizado por la Superintendencia Nacional de Educación Superior Universitaria sobre las principales carreras con proyección al futuro, la carrera de Marketing obtuvo el cuarto puesto de 150 carreras analizadas (Universia Perú, 2017).

En Lima, luego de revisar la oferta del mercado en lo que respecta a instituciones donde aprender marketing digital, se puede afirmar que existe sólo un instituto, el Toulouse Lautrec, en el que se puede estudiar la carrera técnica profesional de Publicidad y Marketing Digital en cuatro años. En cuanto a diplomados en Marketing Digital, son diez las instituciones que lo ofrecen, entre universidades e institutos. Estas mismas instituciones también ofrecen cursos de un año o más cortos, en una de ellas se puede encontrar también un Taller de Marketing Digital.

Los cursos más dictados son Marketing Digital, Community Manager, Publicidad Digital, Social Media, E-Commerce y Analítica Web. Los sílabos de los cursos ya están establecidos, no se han encontrado ofertas de cursos personalizados, donde el cliente elija los temas específicos que desee aprender. Asimismo, el número de horas por curso, en el caso de aquellos dictados de manera presencial, ya está establecido y para el inicio del curso, las instituciones señalan que se debe alcanzar un número de mínimo de alumnos matriculados. 
En estas instituciones, la enseñanza si bien conjuga la teoría con la práctica, no se ha visto alguna que ofrezca, o al menos publicite, el aprendizaje realizando campañas reales en empresas existentes. Sólo en el caso de Pandemia, que es también una agencia, ofrecen el servicio de publicidad digital a empresas, pero como otra unidad de negocio, no como escuela.

Luego de analizar el sector y las empresas que compiten en éste, se determinó que la presente Escuela se enfocará en ofrecer cursos cortos, que puedan ser aplicados en el corto plazo en el ámbito profesional y a bajo costo en distintas modalidades. La Escuela no formará parte del sistema educativo tradicional por lo cual no se regirá por la Ley General de Educación. Esto debido a que, dentro de un entorno tecnológico altamente cambiante, se hace necesario adaptarse rápidamente creando y ofreciendo cursos nuevos de acuerdo con la demanda.

\subsection{Determinación del problema u oportunidad}

En el Perú, la inversión en publicidad digital se está incrementando, más aún la inversión publicitaria en Internet es la segunda más importante luego de la televisión. Sin embargo, la industria digital publicitaria en el Perú es aún menor con respecto a países como Brasil, México, Chile y Colombia. El Perú ocupa el puesto cinco en el ranking de países latinoamericanos que invierten más en publicidad digital. (El Comercio Perú, 2017a).

Por otro lado, como se ha descrito en los antecedentes, existe una variada oferta de cursos de marketing digital, que son ofrecidas por diversas instituciones educativas, tales como institutos y universidades; es por ello que se observa que hay mercado suficiente para crear una Escuela de Marketing Digital. En la tabla 2 se listan las universidades que tienen programas de Marketing Digital. 
Tabla 2

Universidades donde se enseña Marketing Digital

\begin{tabular}{ll}
\hline Universidad & Programa \\
\hline UPC & Curso marketing digital \\
Universidad de Piura & Diplomado Marketing Digital \\
Universidad del Pacífico & Diplomado Marketing Digital \\
Universidad San Pablo & Diplomado Marketing Digital \\
Universidad de Lima & Diplomado Marketing Digital \\
Universidad del Pacífico & Diplomado Marketing Digital \\
USMP & Diplomado Data Driven Marketing \\
Universidad Nacional de Trujillo & Carrera de Publicidad y Marketing Digital \\
Universidad Ricardo Palma & Curso Redes Sociales \\
\hline
\end{tabular}


En la tabla 3 se pueden observar los diplomados y cursos que dictan los institutos sobre Marketing Digital

Tabla 3

Otras instituciones donde se enseña Marketing Digital

\begin{tabular}{ll}
\hline Institución & Programa \\
\hline ISIL & Diplomado Marketing Digital \\
& Técnico en Marketing Digital \\
& Diplomado de innovación y estrategia digital \\
Neo Consulting - futuro Labs & Estrategias para Google AdWords \\
& Workshop Google Analytics \\
Instituto Toulouse Lautrec & Diplomado en Community Management \\
IPAD & Diplomado Marketing Digital \\
Zegel IPAE & Curso marketing digital \\
MOTT & Diplomado Marketing Digital \\
IAB Perú & Diplomado Marketing Digital \\
APEM & Seminario Marketing Digital \\
\hline
\end{tabular}


La Escuela se orientará a ofrecer cursos del área del marketing digital a grupos reducidos de máximo quince alumnos en los horarios más convenientes para ellos, los cuales se han determinado en base al estudio de mercado realizado. Las clases serán dictadas por profesores reconocidos en el medio, con experiencia en el área de marketing digital.

Otro servicio que brindará la Escuela serán los cursos personalizados o a la medida, el alumno podrá adquirir un paquete de horas durante las cuales se le asignará un profesor que le enseñará temas que el alumno solicite. Este servicio estará orientado a personas que deseen aprender sobre temas específicos.

Más adelante, se establecerán alianzas con empresas del mercado local, ofreciéndoles la elaboración de campañas gratuitas en Internet, las que serán elaboradas por los alumnos bajo la supervisión y con la asesoría de los profesores.

\subsection{Justificación}

Este trabajo tiene por objeto integrar los conocimientos sobre administración, marketing y finanzas adquiridos en la Maestría en Ciencias Administrativas con la experiencia laboral adquirida en el sector educación. Cabe mencionar, en este aspecto, que uno de los miembros del grupo desarrollador de este proyecto es actualmente docente de publicidad digital, cuenta con experiencia organizando talleres y se desempeña actualmente como jefe de SEO y SEM en el área de marketing, mientras que otro miembro del grupo trabaja en el sector educación.

Este proyecto tendrá además un impacto económico, pues contribuirá con las empresas, poniendo en el mercado, personal con conocimiento sobre temas actuales y específicos de marketing digital, de modo que estas puedan optar por contratar personal idóneo para el manejo de nuevas herramientas que les ayuden a ser más competitivas en el mercado actual. 
También tendrá un impacto social, pues se ofrecerá un servicio educativo de calidad. Se brindará a través de la Escuela, la oportunidad de adquirir una educación personalizada y acorde a las necesidades del mercado laboral.

\subsection{Objetivos generales y específicos}

En cuanto a los objetivos para el presente trabajo, se ha determinado el objetivo general, así como otros específicos para cada aspecto del proyecto.

\section{Objetivo general}

Elaborar el plan de negocios para determinar la viabilidad económica del proyecto de creación de una Escuela de Marketing Digital en Lima, 2018.

\section{Objetivos específicos}

- Analizar la estructura económica del sector educación, especialmente las tendencias y el crecimiento proyectado para los siguientes años.

- Realizar el estudio de mercado para determinar la demanda de mercado para el servicio ofrecido.

- Proyectar el mercado objetivo con precisión.

- Formular el plan de marketing para la Escuela.

- Hacer el pronóstico de ventas, analizando los riesgos y otros aspectos que puedan causar impacto en éstas.

- Diseñar la estructura organizacional adecuada para poder brindar el servicio educativo y formular la visión, misión y principios que guiarán a la organización. Al ser un servicio de educación lo ofrecido a los clientes, este se enfocará en el capital humano, creando la política más adecuada. 
- Determinar el nivel de inversión del proyecto y elaborar los presupuestos, así como estados financieros proyectados.

- Calcular el VAN, TIR, ROE y otros ratios con el fin de determinar la viabilidad del proyecto.

\subsection{Alcances y Limitaciones}

Luego del análisis respectivo, se determinaron los alcances y limitaciones para el presente proyecto.

\section{Alcances}

El presente trabajo se elaborará con las siguientes consideraciones:

- El público objetivo habita en los distintos distritos de Lima Metropolitana y con edades entre 18 y 49 años.

- Estará dirigido a personas interesadas o ligadas a las áreas de marketing, relaciones públicas, ventas y publicidad.

- Los cursos que se ofrecerán serán aquellos que permitan desarrollarse a los alumnos en el área de marketing digital de una empresa o emprendedores que deseen realizar negocios en un entorno on-line.

\section{Limitaciones}

- La inexactitud y/o falta de datos sobre la competencia.

- La falta de estudios de mercado previos sobre este tema. 


\section{Capítulo II: Estructura Económica del Sector}

En el presente capítulo se presentan la investigación y análisis de la industria y las principales tendencias.

\subsection{Descripción del estado actual de la industria}

Según la información difundida en el CADE Educación 2018, actualmente en el Perú una de cada tres personas se encuentra matriculada en algún tipo de programa educativo. Asimismo, en cuanto a la educación superior, existen más de 2,700 instituciones educativas entre Centros de Educación Técnica Productiva, Institutos y Universidades. (IPAE, 2018)

Otro dato importante señalado en el CADE fue que los estudiantes provienen de todos los estratos sociales y en su mayoría son jóvenes. Estos nativos digitales, nacidos a partir de 1980, se comunican a través de redes sociales y tienden a buscar una aplicación rápida de aquello que aprenden. Ellos conformarán más del $60 \%$ de la fuerza laboral dentro de diez años. Por ello se requieren instituciones que ofrezcan una formación práctica y en concordancia con las demandas del entorno. (IPAE, 2018)

Como parte del presente trabajo se realizó un estudio previo (ver Apéndice 1) analizando 100 perfiles de profesionales de Marketing Digital en LinkedIn y se determinó que la mayoría de los profesionales que actualmente se dedican al rubro provienen de carreras de Comunicaciones, Administración, Publicidad, Marketing entre otras. La lista de las carreras se puede observar en la tabla 4 . 
Tabla 4

Carreras que estudiaron quienes trabajan en el Área de Marketing Digital

\begin{tabular}{ll}
\hline Carrera que estudio & Nro. de Profesionales \\
\hline Comunicaciones & 38 \\
Administración & 12 \\
Publicidad & 11 \\
Marketing & 11 \\
Informática & 6 \\
Periodismo & 5 \\
Diseño & 3 \\
Economía & 3 \\
No Especifica & 2 \\
Bibliotecología & 2 \\
Estadística & 1 \\
Soporte Técnico & 1 \\
Contabilidad & 1 \\
Química & 1 \\
Ingeniería & 1 \\
Literatura & 1 \\
Hotelería & 1 \\
\hline Total general & 100 \\
\hline
\end{tabular}

Conforme se aprecia en la tabla 4, a partir de la información extraída de LinkedIn (ver Apéndice 1), se pudo verificar que quienes han realizado estudios de Marketing Digital son, principalmente, profesionales de las especialidades de Comunicación, Administración, Publicidad, Informática y Periodismo. La presencia de profesionales de Administración y Marketing dentro del Marketing Digital se explica debido a que estas carreras están relacionadas con las áreas comerciales de las empresas:

La presencia de profesionales formados como informáticos, ingenieros de sistemas o programadores se debe a que esta área del Marketing requiere un uso intensivo de plataformas tecnológicas y requiere un mínimo de conocimientos de código y programación. 
Con base en dicha información se analizó el número de egresados de estas carreras universitarias del 2014 al 2016 y se observó que hay un crecimiento de $6.29 \%$ del 2015 al 2016 y de $14.96 \%$ del 2014 al 2015, tal como se observa en la tabla 5.

Tabla 5

Egresados de Pregrado de Universidades Públicas y Privadas por Familia de Carreras del 2014 al 2015

\begin{tabular}{|c|c|c|c|c|c|c|c|}
\hline & & & & $\%$ & & $\%$ & \\
\hline & & & 2016 & Crecimiento & 2015 & Crecimiento & 2014 \\
\hline & & Número de & & & & & \\
\hline & Número de & programas de & Nro. de & & Nro. de & & Nro. de \\
\hline \multicolumn{8}{|l|}{ Ciencias Administrativas y } \\
\hline Comerciales & 103 & 276 & 23140 & $3.71 \%$ & 22312 & $20.66 \%$ & 18492 \\
\hline \multicolumn{8}{|l|}{ Ingeniería de sistemas y } \\
\hline comunicaciones & 93 & 119 & 4811 & $4.79 \%$ & 4591 & $4.75 \%$ & 4383 \\
\hline Ciencias de la comunicación & 45 & 77 & 3550 & $28.53 \%$ & 2762 & $-5.64 \%$ & 2927 \\
\hline Informática & 7 & 7 & 133 & $35.71 \%$ & 98 & $11.36 \%$ & 88 \\
\hline Total & & Total & 31634 & $6.29 \%$ & 29763 & $14.96 \%$ & 25890 \\
\hline
\end{tabular}

Nota. Tomado de SUNEDU (SIBE) Perú, Lima: Editorial. Copyright 2016 por SUNEDU.

Conforme se observa en la tabla 5, a nivel de la educación superior universitaria, se consideró que las carreras afines al marketing digital mantienen tasas de crecimiento positivos; así, las Ciencias Administrativas y Comerciales han aumentado su demanda. Cabe destacar que, a nivel de la educación superior técnica, según el portal web Ponte en Carrera (Ministerio de Educación, 2018), la carrera de Marketing es la tercera mejor pagada a nivel nacional. En el caso de las carreras universitarias, Marketing es la décimo cuarta mejor pagada. (Ministerio de Trabajo y Promoción del Empleo, 2016). 


\subsubsection{Segmentación de la Industria.}

Según Eyzaguirre (2016), docente del diplomado de marketing digital de la Universidad de Piura, el mercado de la enseñanza de marketing digital está dividido entre los siguientes actores: (a) Universidades (Pregrado y Postgrado), (b) Institutos, (c) Agencias, (d) Talleres y (e) Cursos Online. En la figura 1 se pueden observar las características de cada uno de los actores.

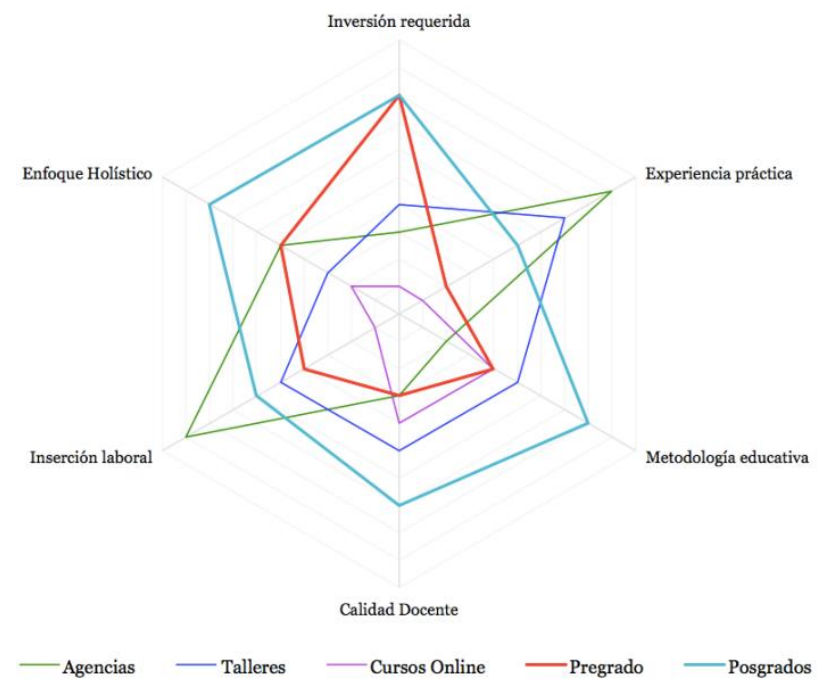

Figura 1. Características de cada actor que hoy contribuye a la formación de la industria. Tomado de Formación en marketing digital, por Eyzaguirre, Marco, 2016, Perú, Lima: Editorial. Copyright 2016 por Semana Económica.

\section{Universidades Postgrado}

Las universidades brindan cursos cortos de marketing digital como cursos de extensión, así como programas especializados, tales como diplomaturas, de seis meses y un año en la materia. Estos programas ofrecen cursos de marketing general, considerando que no todos los estudiantes han recibido formación básica en la materia para, posteriormente, incluir formación en social media o publicidad online, entre otros. 
Es importante destacar que una característica de este tipo de programas es su alta calidad de docentes y apropiada metodología educativa; además, algunas instituciones brindan doble certificación con universidades extranjeras y la posibilidad de hacer viajes por una semana para llevar charlas en otras universidades y visitar negocios directamente relacionados con el marketing digital.

Cabe destacar que estos programas tienen un alto costo y, según Eyzaguirre (2016), ofrecerían limitada experiencia práctica, es decir, tiene un mayor componente teórico, tal es el caso de la Universidad de Piura, que ofrece un Programa especializado en Marketing Digital.

\section{Universidades Pregrado}

En el caso del Pregrado, a la fecha de corte de la presente investigación, no se encontró ninguna carrera de pregrado especializada estrictamente en marketing digital, sin embargo, se han incorporado algunos cursos de marketing digital dentro de la malla de la especialidades de Marketing.

\section{Institutos}

Se ha observado que algunos institutos han implementado la carrera de marketing digital. Por ejemplo, IPAD implementó la carrera de un año de publicidad y marketing digital, y Toulouse ha sido el único instituto que brinda la carrera de publicidad y marketing digital de tres años.

La ventaja de los institutos respecto a las universidades radica en el menor precio y el enfoque más práctico de su malla curricular. Consideraríamos que este sería uno de los sectores que brindaría los productos sustitutos más cercanos a lo que ofreceríamos en la Escuela de Marketing Digital. 
Ejemplos de Institutos que brindan estos programas:

- Toulouse Lautrec: Carrera de Publicidad y Marketing Digital http://tls.edu.pe/

- IPAD: Carrera Corta de Publicidad y Marketing Digital http://www.ipad.edu.pe

\section{Talleres}

Actualmente se dictan talleres de un día o unas horas sobre temas específico de marketing digital. Estos talleres son dictados a veces por una persona particular relacionada al tema y otras veces a nombre de una agencia. Estos talleres no garantizan necesariamente una buena calidad docente, ya que no tendrían el respaldo académico de una institución, pero debido a su bajo costo y corta duración cubren la demanda de los profesionales que necesitan saber temas específicos y solo pueden dedicar unas horas para aprender sobre ellos. Este tipo de talleres se promociona a través de eventos por Facebook o a través de páginas especializadas como Joinnus:

https://www.joinnus.com

\section{Cursos Online}

Existen una amplia variedad de plataformas online extranjeras que brindan cursos de marketing digital, entre otros temas. Algunos de estos cursos destacan por su bajo precio y buena calidad que, además, brindan la posibilidad de desarrollarlos conforme a los tiempos y necesidades de los participantes.

Si bien es cierto estos cursos dan importantes ventajas, tienen la desventaja de que muchos de ellos se impartes solo en idioma extranjero, existe una alta tasa de deserción; y, en la mayoría de casos, los certificados solo acreditan la participación en el curso, no pudiendo ser 
convalidados con institutos o universidades peruanas, por ende, carecen de valor oficial. Algunas plataformas con ofertas relevantes en cursos de marketing digital son:

En el extranjero:

- Coursera: https://es.coursera.org/

- Edx : https://www.edx.org/

En Perú:

- CentrumX: https://www.centrumx.com/

- Campus Virtual Romero: https://www.campusromero.pe/

\section{Escuelas (Agencias):}

Otro segmento de la industria son las escuelas de marketing digital. Estas escuelas son por lo general agencias que empezaron dictando cursos y se convirtieron en escuelas de marketing digital. Las características de estas escuelas es que, a diferencia de los institutos, se encuentran orientadas a personas que ya tienen una profesión y necesitan capacitarse en marketing digital pero no pueden pagar los precios que brindan universidades e institutos y requieren una formación más práctica. Este tipo de escuelas brindan cursos cortos, diplomados y talleres. Así se tiene:

- Mott: https://mott.pe/

- Pandemia: http://www.pandemia.me/

- Negzy: http://negzy.com/

Como este tipo de escuelas no son institutos, se revisó el rubro de cada una de ellas (ver tabla 6), identificándose que solo una de ellas ha consignado a la prestación de servicios de educación en las actividades económicas en las que se desempeña. 
Tabla 6

Empresas que dictan cursos de marketing digital-Competidores Directos

\begin{tabular}{lll}
\hline Escuela & \multicolumn{1}{c}{ Razón Social } & \multicolumn{1}{c}{ Actividad Económica } \\
\hline Negzy & Negzy SAC & $9609-$ Otras actividades de servicios \\
& & personales N.C. P. \\
Mott & Mott Centro de Especialización & $7310-$ Publicidad \\
& Digital S.A.C. & \\
Pandemia & Social Media Academy E.I.R.L. & $74145-$ Act. de Asesoramiento \\
& & \\
& & Empresarial \\
& & \\
& & \\
& &
\end{tabular}

A diferencia de los Institutos, que sí tienen asignada una actividad económica relacionada con la enseñanza, lo cual se puede observar en la tabla 7.

Tabla 7

Institutos que dictan cursos de marketing digital

\begin{tabular}{lc}
\hline Razón Social & Actividad Económica \\
\hline Instituto Peruano de Publicidad & $8530-$ Enseñanza Superior. \\
Toulouse Lautrec & $8549-$ Otros tipos de enseñanza N.C.P. \\
Instituto Peruano de Arte y Diseño. & $8530-$ Enseñanza Superior.
\end{tabular}


Según palabras del experto Marco Eyzaguirre, lo que hace falta son programas que brinden, además de la base teórica, una buena experiencia práctica con una alta calidad docente y precios más asequibles para el mercado (Eyzaguirre, 2016). Considerando estas características es que para el presente trabajo se determinó que la modalidad de Escuela es la más apropiada para la oferta de cursos de marketing digital.

\subsubsection{Empresas que lo conforman.}

En base al estudio realizado (ver Apéndice 1) se identificaron las empresas que componen la industria, tal como se muestra en la tabla 8 .

\section{Tabla 8}

Empresas que componen la Industria

\begin{tabular}{lll}
\hline Institutos & Escuelas & Otros \\
\hline ISIL & MOTT & The Atomic Garden \\
Instituto Toulouse Lautrec & Pandemia & Neo Consulting \\
IPAD & Negzy & APEM \\
Zegel Ipae & & \\
IAB Perú & & \\
IPM & & \\
\hline
\end{tabular}

Nota: Elaboración propia a partir del estudio realizado (ver Apéndice 1) y búsquedas realizadas en Google. 


\subsection{Tendencias de la Industria.}

En el sector de la industria educativa, se identificaron las siguientes tendencias:

\section{Cursos online}

Para el especialista Paul Neira (El Economista América, 2018), educador y consultor, "Las universidades tienen la responsabilidad de generar conocimientos en contextos y tiempos específicos. Actualmente, el ambiente es profundamente digital y tecnológico. Contar con una malla curricular con cursos online es nuestra tarea fundamental como educadores".

Según Neira, los cursos online desarrollan en los jóvenes habilidades y competencias básicas para ámbito laboral. Los cursos online, los empoderan, les permiten innovar, generan nuevos espacios para compartir conocimiento, les permiten desarrollar sus competencias digitales, los dotan de sentido de responsabilidad e independencia.

Esta forma de enseñanza permite a los jóvenes manejar sus tiempos, trabajar con autonomía, responsabilizarse de su propio crecimiento y sentar las bases para un aprendizaje continuo como profesionales competitivos.

Según Ricardo Greco Guiñazo, presidente de Aden Business School (El Comercio Perú, 2017b), las escuelas tienen que adaptarse a las nuevas generaciones que están acostumbradas a lo virtual en todas las facetas de su vida. Greco señala que la calidad de las maestrías online es igual o incluso superior a las maestrías presenciales en base a la cantidad de herramientas con las que cuenta.

\section{Movimiento Maker}

Este movimiento se basa en el conocimiento compartido, el acceso a recursos y el desarrollo de ideas orientadas a mejorar la vida de toda la sociedad. En el ámbito educativo, su aplicación se produce a través de "metodologías activas en línea con el aprendizaje basado en 
proyectos, siendo las preguntas (y no tanto las respuestas) las que determinan la forma en que se adquiere el conocimiento. El trabajo colaborativo, la adaptación de espacios apropiados para el desarrollo de proyectos y el acceso a recursos compartidos son señas de identidad de esta tendencia educativa." (Realinfluencers, 2017)

\section{Especialización del conocimiento}

Según Giuliana Leguía, directora de Maestrías de la Escuela de Posgrado de la Universidad del Pacífico (El Comercio Perú, 2017b), hay otra gran tendencia en el aprendizaje: la especialización del conocimiento. Indica que el mercado laboral requiere profesionales con competencias muy diferentes a las que se requerían hace 15 años, por lo que se han creado varias maestrías especializadas, pero sin embargo la oferta todavía no está satisfecha.

\section{Cursos cortos}

Otra tendencia en el sector educativo es la proliferación de cursos cortos. Muchos ejecutivos no poseen el tiempo para llevar programas largos por lo que buscan cursos cortos para capacitarse rápidamente. Según Garro, director de IE Business School para el Perú (El Comercio Perú, 2017b) menciona lo siguiente: "Hay muchos ejecutivos de 40 años en la dirección general de grandes empresas y en otros altos cargos; y ellos demandan cursos cortos y especializados para reforzar las áreas en que todavía no han adquirido experiencia”

\subsection{Análisis estructural del Sector Industrial}

La competencia por obtener beneficios en una industria, no solo abarca a los competidores directos, sino que alcanza a otras fuerzas: los clientes, proveedores, posibles aspirantes y los productos sustitutos. Comprender las fuerzas competitivas es importante para determinar la rentabilidad de una industria, así como el nivel de competencia que se encontrará a lo largo del tiempo (Porter, 2009). 


\section{Poder de los Clientes}

Según Porter (2009) los clientes ejercen una fuerte influencia si cumplen algunos de los siguientes requisitos:

1. Existen pocos compradores o si cada uno de ellos realiza compras en volúmenes muy grandes en relación con el tamaño de un solo vendedor.

2. Los productos de la industria no se diferencian entre sí o están muy estandarizados.

3. Los compradores no enfrentan costes significativos al cambiar de vendedor.

4. Los compradores tienen la posibilidad de retirarse y producir ellos mismos el producto o servicio.

En base a los requisitos mencionados por Porter se ha determinado que el poder de los clientes es medio por los siguientes motivos:

- El número de posibles clientes es grande, por lo que la pérdida de un posible cliente no tiene una influencia significativa para la Escuela.

- Los cursos se diferencian con los cursos de los competidores ya que, aparte de tener un sílabo diferente, tiene otros profesores, cuyos perfiles orientarán la enseñanza al ámbito práctico. Además, se van a ofrecer cursos personalizados por lo que serían a la medida del cliente.

Se ha considerado un poder medio ya que hay dos factores que podrían utilizar los compradores para ejercer su poder:

- No existen costos significativos en cambiar de proveedor. Una vez que un cliente ha llevado un curso libre puede llevar otro curso en alguna otra institución sin problemas.

- Los clientes tienen la posibilidad de aprender por su cuenta. Considerando que existen libros y cursos gratuitos en internet, la posibilidad de que un cliente decida aprender por 
su cuenta es alta si el cliente no encuentra lo que está buscando en calidad, precio y otros factores.

La única forma de reducir estos dos riesgos es brindando un excelente servicio que incluiría la flexibilidad en la modalidad de estudio, variedad de cursos, docentes especializados y otros factores que permitan diferenciar a la Escuela de la competencia.

\section{Competidores Potenciales}

Según Porter (2009) la amenaza de entrada de competidores potenciales depende de lo elevadas que son las barreras de acceso y de las posibles reacciones de los principales miembros de la industria. Existen siete barreras de entradas principales que pueden dificultar el ingreso de un nuevo competidor:

- Economías de escala por parte de la oferta: Esta barrera se da cuando uno o varios miembros de la industria logran obtener costos fijos bajos en base a su alto nivel de producción. En el caso de la Escuela de Marketing Digital, este tipo de barrera de entrada es baja ya que hay un límite de alumnos por clase que se puede incorporar por clase sin afectar metodología de enseñanza.

- Beneficios de escala por parte de la demanda: También conocida como "efecto de red", surge cuando la disposición de un comprador a pagar por el producto o servicio se incrementa al haber otros compradores que adquirieron ese producto a la misma empresa. Aunque esta barrera de entrada puede ser más notoria en productos ligados con redes de usuarios como consolas de videojuegos, teléfonos móviles, redes sociales, etc., se considera que en este caso también se podría aplicar ya que es más probable que un posible comprador se inscriba en una escuela donde han estudiado sus amigos o conocidos que en una donde no se ha inscrito ningún conocido. 
- Coste por el cambio de clientes: Son costes fijos que asumen los clientes al cambiar de proveedor. Estos costes pueden ser altos en algunos productos como en un ERP o CRM con altos costos de implementación. En el caso de la Escuela esta barrera es muy baja.

- Requisitos de Capital: Se refiere al monto de inversión necesario para poner en marcha el negocio. En el caso de la escuela sería una barrera relativamente baja ya que la Escuela podría comenzar con un local pequeño o alquilado.

- Beneficios para los miembros independientemente del tamaño: Se refiere a beneficios con los cuentan las empresas actuales que pueden dar una ventaja sobre la calidad o costes. Estos beneficios pueden ser: fuentes de materia prima, propiedad intelectual, acceso a ciertas zonas geográficas. En este caso la barrera seria baja.

- Acceso desigual a los canales de distribución: Esta barrera se da especialmente en productos como alimentos en los que diferentes empresas se pelean por espacio en los canales de distribución que serían los anaqueles de los supermercados. En el caso de la Escuela los canales de distribución son prácticamente inexistentes.

- Política restrictiva del gobierno: Se refiere a leyes que promueve el gobierno que podrían limitar o promover la entrada de nuevos competidores. Considerando las nuevas leyes que se han venido implementando respecto a institutos y universidades limitando el ingreso de nuevos participantes, podríamos considerar que esta es una barrera de nivel medio por lo menos.

Conclusión: Actualmente existe un regular número de profesionales que brindan talleres, así como agencias que tienen la capacidad de brindar este tipo de cursos. Ambos podrían convertirse en un futuro en otra escuela de marketing digital. 
Sin embargo, hay que considerar que para que una agencia se dedique a ser una escuela tiene que cambiar su modelo de negocio. El modelo de negocio de la agencia se sostiene sobre la base que los clientes no saben mucho de marketing digital o no tienen tiempo de dedicarse a realizar campañas por su cuenta. Al poner una escuela y enseñar a otros cómo realizar campañas estaría yendo en contra de su modelo. En base a lo analizado se considera que en este caso la barrera es intermedia.

\section{Poder de los proveedores}

Según Porter (2009) los proveedores son influyentes si tienen alguna de las siguientes características:

- Está más concentrado que la industria a la que provee, en ejemplo de esto son los proveedores de sistemas operativos respecto a los productores de computadoras y dispositivos móviles. En el caso de la Escuela los principales proveedores son los profesionales que van a dictar los cursos y los locales donde se dictarían los mismos. En ambos casos existe una amplia variedad de opciones en el mercado.

- Los proveedores no dependen mucho de la industria para obtener beneficios. Esto se da en el caso de que los proveedores pueden brindar sus productos a varias industrias. En el caso de los profesores estarían limitados a dictar en un número limitado de escuelas que brindan estos cursos por lo que no se cumpliría esta característica.

- Es complicado y costoso cambiar de proveedor. Esto se da en el caso de inversiones en maquinarias, sistemas empresariales y otros productos. En el caso de la Escuela es poco costoso el cambio.

- Los proveedores ofrecen productos que están diferenciados entre sí: Esto se podría dar en el caso de que se contratara influenciadores famosos o profesionales con mucho 
reconocimiento en la industria. Como los profesores que se piensan contratar serian profesionales con experiencias sin ser famosos esta característica no se aplicaría.

- No existe sustituto alguno del producto que ofrece el grupo proveedor. Tampoco aplica ya que cualquier profesor con experiencia y buena metodología estaría en capacidad de brindar los cursos.

- El grupo proveedor puede decidir integrarse a la industria. Aunque un profesor puede dictar un taller personal que sería un producto sustituto, no es tan probable que decida crear su propia escuela. Lo más probable es que decida dictar en otra o de forma independiente.

- Estos docentes van a trabajar bajo la modalidad part time, es decir no estarían a tiempo completo con la empresa.

El perfil que se esperaría de los docentes que van a brindar los cursos es que cuenten por lo menos con cuatro años de experiencia en el área de marketing digital. Se considera que el poder de negociación de los docentes seria medio ya que actualmente se cuenta con una amplia oferta de profesionales que trabajan en agencias y pueden cumplir con estas características. Sin embargo una vez que el profesor se ha dado a conocer y es valorado y reconocido por los alumnos, es complicado prescindir de él. Respecto a los proveedores de suministros de oficinas y espacios para dictar cursos existe una amplia oferta haciendo que este poder sea bajo.

\section{Amenaza de servicios sustitutos}

Según Porter (2009) los productos sustitutos son influyentes si tienen alguna de las siguientes características:

- Ofrecen una atractiva equiparación entre precio y prestaciones al producto de la industria; así, si el producto sustituto tiene un valor bajo respecto al producto de la industria puede 
afectar el margen de beneficio de la industria. Por ejemplo, uno de los productos sustitutos más relevantes serían los cursos gratuitos online.

- Para el comprador, el costo del cambio a un producto sustituto es muy bajo.

Para el caso de la Escuela de Marketing Digital, existe una amplia variedad de productos sustitutos tales como diplomados en universidades, carreras cortas en institutos, cursos online e inclusive la posibilidad de formación autodidacta a través de cursos gratis y libros. Sin embargo, uno de los principales temas que les falta a estos productos sustitutos es la capacidad de transmitir la experiencia práctica y la posibilidad de aplicar los conocimientos a casos reales o casos propios lo cual sería uno de los factores en los que se haría más énfasis en la Escuela.

La amenaza de productos sustitutos es alta, sin embargo, se puede combatir con las siguientes características del producto:

- Precios asequibles: Esta característica serviría para disminuir el riesgo de reemplazo por productos de precios más altos como diplomados en universidades.

- Cursos personalizados y cortos: Esta característica sería una ventaja para personas que quieren aprender rápido y no desean ocupar seis meses a un año en diplomados o programas parecidos.

- Experiencia práctica y caso reales: Este tipo de experiencia no la brindan los cursos gratuitos y los cursos online y en el caso de los cursos que brindan las universidades, se enfocan mucho en la teoría, por lo que sería un diferenciador importante.

- Pertenencia a una comunidad: Usando las técnicas de gamificación se podría lograr una comunidad de estudiantes y exestudiantes que compartan conocimiento y compitan para obtener beneficios. Además, a través de esta red pueden obtener trabajos. Esto no lo 
brindan los cursos gratuitos y si lo brindan las universidades, pero de una manera limitada.

\section{Rivalidad entre empresas competidoras}

Según Porter (2009) la rivalidad entre competidores adopta varias formas tales como descuentos en los precios, mejoras en el producto y servicio, campañas de publicidad, entre otras. Una rivalidad alta disminuye el rendimiento y rentabilidad de una industria. La rivalidad entre competidores es fuerte si se cumplen los siguientes factores:

- Los competidores son numerosos o muy parecidos en tamaño e influencia.

- El crecimiento de la industria es lento por lo que hay una fuerte lucha por la cuota del mercado.

- Las barreras de salida son elevadas. Esto sucede cuando hay activos altamente especializados que son difíciles de vender.

- Los rivales están comprometidos con el negocio y tienen objetivos que van más allá de la rentabilidad económica lo cual puede hacer que se resistan a dejar el mercado aun no sea rentable.

- Las empresas no pueden interpretar correctamente las señales de sus competidores lo que podría hacer que entren en una guerra de precios u otro tipo de competencia que afecta a la industria.

- Existe la posibilidad de entrar en una guerra de precios. Esto puede suceder cuando se dan las siguientes condiciones:

○ Los productos o servicios son casi idénticos

○ Los costes fijos son elevados

- Se necesita producir volúmenes grandes para lograr la eficiencia 
- El producto es perecedero.

Tomando en cuenta los factores mencionadas, prácticamente ninguno se ajusta al sector de escuelas de marketing digital por lo que se considera que la rivalidad entre competidores es baja.

\subsection{Análisis de la Competencia}

\subsubsection{Empresas que ofrecen el mismo servicio.}

Las empresas que ofrecen el mismo servicio, es decir la capacitación en marketing digital, a través de cursos cortos y sobre temas específicos, sin ser instituciones educativas regidas por la Ley General de Educación, son las siguientes: MOTT, Pandemia y Negzy.

\section{MOTT:}

- Dirección: Av. Alfredo Benavides 768 Centro Empresarial El Reducto, Av. Alfredo Benavides 768, Miraflores.

- RUC: 20600323394 / Razón Social: MOTT Centro de Especialización Digital S.A.C.

- Sitio Web: https://mott.pe/

- Nro. de trabajadores: Según SUNAT, a julio del 2018 cuentan con 14 trabajadores en planilla y con 23 personas que le prestan servicios recibos por honorarios (Sunat, 2018). Según su página web cuentan con 31 docentes activos.

- Inicio de actividades: La empresa inició actividades el 4 de mayo del 2015 (Sunat, 2018).

- Presencia Online:

○ Visitas Web: MOTT recibió más de 295, 830 visitas durante el último mes (Similar Web, 2018). 
- Fuentes de Tráfico: Su principal fuente de tráfico ha sido a través de búsquedas orgánicas (Similar Web, 2018). También cuentan con campañas en AdWords y presencia en Facebook.

○ Página Facebook: Su página fue creada el 23 de agosto del 2010 y actualmente cuentan con 259,085 fans (Facebook, 2018).

- Cursos: Actualmente MOTT cuenta con la siguiente oferta de cursos:

○ Ocho cursos de Fotografía

- Catorce cursos de Marketing Digital

○ Doce cursos de Diseño

- Cuatro diplomados de tres meses de duración cada uno. Estos diplomados se dictan una vez a la semana durante tres horas por sesión por lo que tienen una duración aproximada de 36 horas.

- Características Principales (según su página web)

- Docentes certificados en Google, Facebook y Adobe

○ Presencia digital en Perú, México y Argentina

- Cuentan con una plataforma online de cursos

○ Brindan certificados online que pueden ser verificados por terceros

- Opinión de los alumnos:

○ Cuentan con veinte comentarios positivos (4.6 sobre 5) en Google. En los comentarios se menciona entre las caracterices principales:

- Cursos son puntuales y didácticos

- Buen ambiente, infraestructura y ubicación 


\section{Pandemia}

Se ha podido obtener la siguiente información sobre Pandemia:

- Dirección: Calle Las Camelias $\mathrm{N}^{\circ} 891$ - $4^{\circ}$ piso - San Isidro

- RUC: 20554383743 / Razón Social: Social Media Academy E.I.R.L.

- Sitio Web: https://www.pandemia.me/

- Nro. de trabajadores: Actualmente cuenta con tres personas que le prestan servicios recibos por honorarios (Sunat, 2018). Según su página web cuentan con ocho docentes activos.

- Inicio de la empresa: Se encuentra registrado en Sunat (Sunat, 2018) que la empresa inició actividades el 3 de octubre del 2013. Anteriormente la empresa se llamaba Social Media Academy y su página web era http://www.academysm.com (Internet Archive, 2018).

- Presencia Online:

○ Visitas Web: No hay información disponible del tráfico web (Similar Web, 2018).

- Fuentes de Tráfico: Según Similar Web su principal fuente de tráfico ha sido a través de buscadores de forma orgánica (Similar Web, 2018). También cuentan con Presencia en Facebook.

- Página Facebook: Su página fue creada el 9 de Julio del 2012 y actualmente cuentan con 183,274 fans (Facebook, 2018).

- Cursos: Actualmente Pandemia cuenta con la siguiente oferta de cursos:

- Seis cursos de Marketing Digital. Los precios de los cursos van desde S/.599 soles hasta S/1,090 soles y su duración está entre 20 y 60 horas. 
○ Quince talleres de Marketing Digital. Los talleres tienen precios entre S. /90 y S/. 500 soles y su duración oscila entre dos a 18 horas.

- Características Principales (según su página web)

- Brindan servicio de consultoría a empresas

- Cuentan con un programa de franquicias para extender sus locales

- Variedad de cursos

- Dictan cursos innovadores como el taller de Chatbot

- Opinión de los alumnos:

- Cuentan con nueve comentarios positivos (4.8 sobre 5) en Google. En los comentarios se menciona entre las características principales: Buenos profesores.

\section{Negzy:}

Se ha podido obtener la siguiente información sobre Negzy:

- Dirección: Av. Benavides 195 Oficina 205, Miraflores

- RUC: 20601903181 / Razón Social: NEGZY SAC

- Sitio Web: https://negzy.com/

- Nro. de trabajadores: Según Sunat, cuentan con dos trabajadores en planilla y con seis personas que cobran a través de recibos por honorarios (Sunat, 2018). Según su página web, cuentan con cinco docentes activos.

- Inicio de la empresa: En Sunat (Sunat, 2018) figura que la empresa inició actividades el 1 de marzo del 2017. El director Académico Carlos Hoempler tenía su consultora http://hoempler.com/ y dictaba cursos desde varios años antes que la academia empezara a funcionar.

- Presencia Online: 
○ Visitas Web: No hay información disponible del tráfico web (Similar Web, 2018).

- Fuentes de Tráfico: Su principal fuente de tráfico ha sido a través de redes sociales (Similar Web, 2018). También cuentan con una gran cantidad de tráfico a través de buscadores.

○ Página Facebook: Su página fue creada el 12 de febrero del 2016 y actualmente cuentan con 10,600 fans (Facebook, 2018).

- Cursos: Actualmente Negzy cuenta con la siguiente oferta de cursos:

○ Dos talleres de Marketing Digital. Los talleres los ofrecen a S/600 soles cada uno.

- Dos programas de especialización digital que cuyos precios fluctúan entre S/1,200 a $\mathrm{S} / 1,800$ soles.

- Características Principales (según su página web)

- Asesoría personalizada

- Preparados para brindar examen de certificación de Google

- Uso de plantillas de trabajo

- Opinión de los alumnos:

- Cuentan con 66 comentarios positivos (4.8 sobre 5) en Facebook y 19 (5 sobre 5) en Google. En los comentarios se menciona entre las caracterices principales:

○ Buenos profesores

- Profesores expertos en su tema

- Buena metodología

- Clases prácticas

En la tabla 9 se muestra un resumen de las diferencias y similitudes de los competidores con el proyecto. 
Tabla 9

Diferencias y similitudes de los competidores con el proyecto.

\begin{tabular}{|c|c|c|c|c|}
\hline Características & Proyecto & MOTT & Pandemia & Negzy \\
\hline $\begin{array}{l}\text { Variedad de } \\
\text { Cursos }\end{array}$ & Alta & Alta & Alta & Baja \\
\hline $\begin{array}{l}\text { Otros cursos } \\
\text { (fotografía y } \\
\text { programación) }\end{array}$ & No & Sí & Sí & No \\
\hline $\begin{array}{l}\text { Presencia fuera } \\
\text { de Perú }\end{array}$ & No & Sí & No & No \\
\hline $\begin{array}{l}\text { Plataforma } \\
\text { online }\end{array}$ & Sí & Sí & No & No \\
\hline Franquicia & No & No & Sí & No \\
\hline $\begin{array}{l}\text { Servicio de } \\
\text { Consultoría }\end{array}$ & No & No & Sí & No \\
\hline $\begin{array}{l}\text { Ubicación } \\
\text { céntrica }\end{array}$ & Miraflores & Miraflores & San Isidro & Miraflores \\
\hline
\end{tabular}

\subsubsection{Participación de mercado.}

No se cuenta con los datos sobre cantidad de cursos vendidos ni los ingresos de cada una de las escuelas por lo que se preparó un comparativo de los tres competidores (ver tabla 10). 
Tabla 10

Comparación de los competidores

\begin{tabular}{llll}
\hline & MOTT & Pandemia & Negzy \\
\hline Nro. de visitas la a la web (mes anterior) & 295,839 & -- & -- \\
Nro. Fans & 259,085 & 183,274 & 10,600 \\
Nro. Docentes & 31 & 8 & 5 \\
Año de lanzamiento & 2011 & 2013 & 2016 \\
Nro. cursos & 38 & 21 & 4 \\
Encuestados que conocen la escuela & 192 & 103 & 37 \\
\hline
\end{tabular}

Revisando los factores anteriores se puede concluir que el líder del mercado sería MOTT, seguido de Pandemia en segundo lugar y Negzy en tercero. Tomando las respuestas a la pregunta 4 de la encuesta mostrada en el capítulo 3 del presente plan de negocios (ver tabla 17), se elaboró un cuadro de recordación de marca que se puede observar en la figura 2.

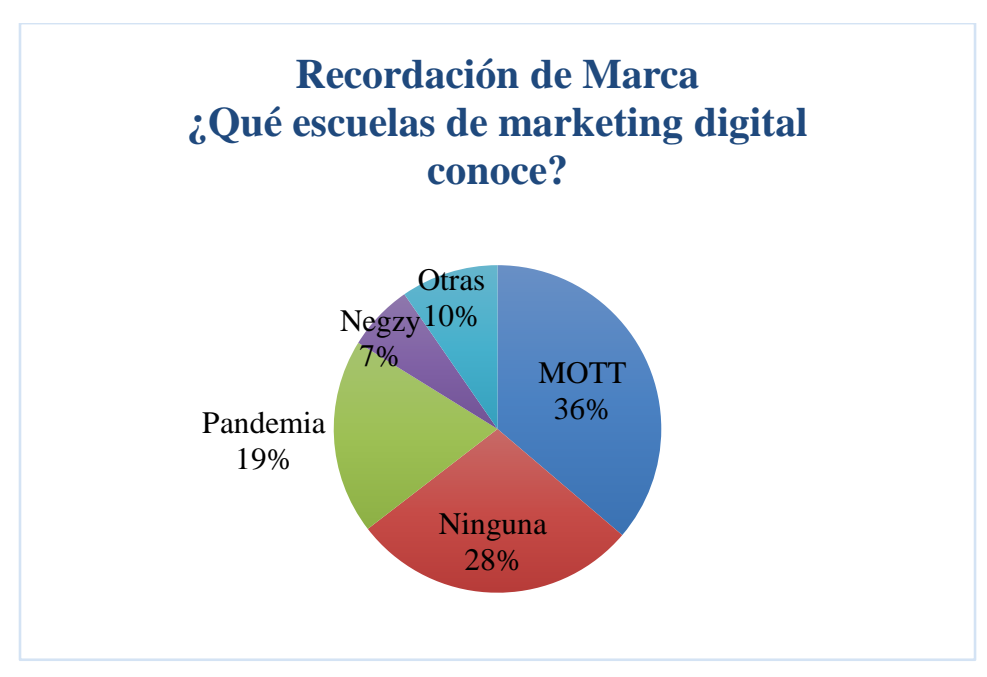

Figura 2. Recordación de Marca 


\subsubsection{Matriz de Perfil Competitivo.}

En base a la teoría sobre la Matriz de Perfil Competitivo (David, 2013) y a la experiencia profesional de los miembros del grupo desarrollador de este proyecto, se han identificado los siguientes factores claves de éxito: (a) Ubicación, (b) Prestigio de la institución, (c) Prestigio de los profesores, (d) Precio, (e) Horario, (f) Variedad de cursos, (g) Aplicación a casos reales, (h) Computadores Modernos y alta velocidad de conexión, (i) Bolsa de trabajo, (j) Otros servicios y (k) Emisión de Certificados. Los factores mencionados fueron validados por los expertos Marcos Fonruge (ver Apéndice 7) y Miguel Calderón (ver Apéndice 8) durante las entrevistas realizadas por los autores de la presente tesis.

1. Ubicación del local: Se considera que la ubicación es un factor clave de éxito por los siguientes motivos.

1.1 Un segmento de posibles clientes trabaja en agencias dedicadas al marketing digital y la mayoría de estas agencias se encuentran ubicadas en distritos céntricos de la ciudad tales como Miraflores y San Isidro (Google Maps, 2018) como se puede ver en la figura 3 . 


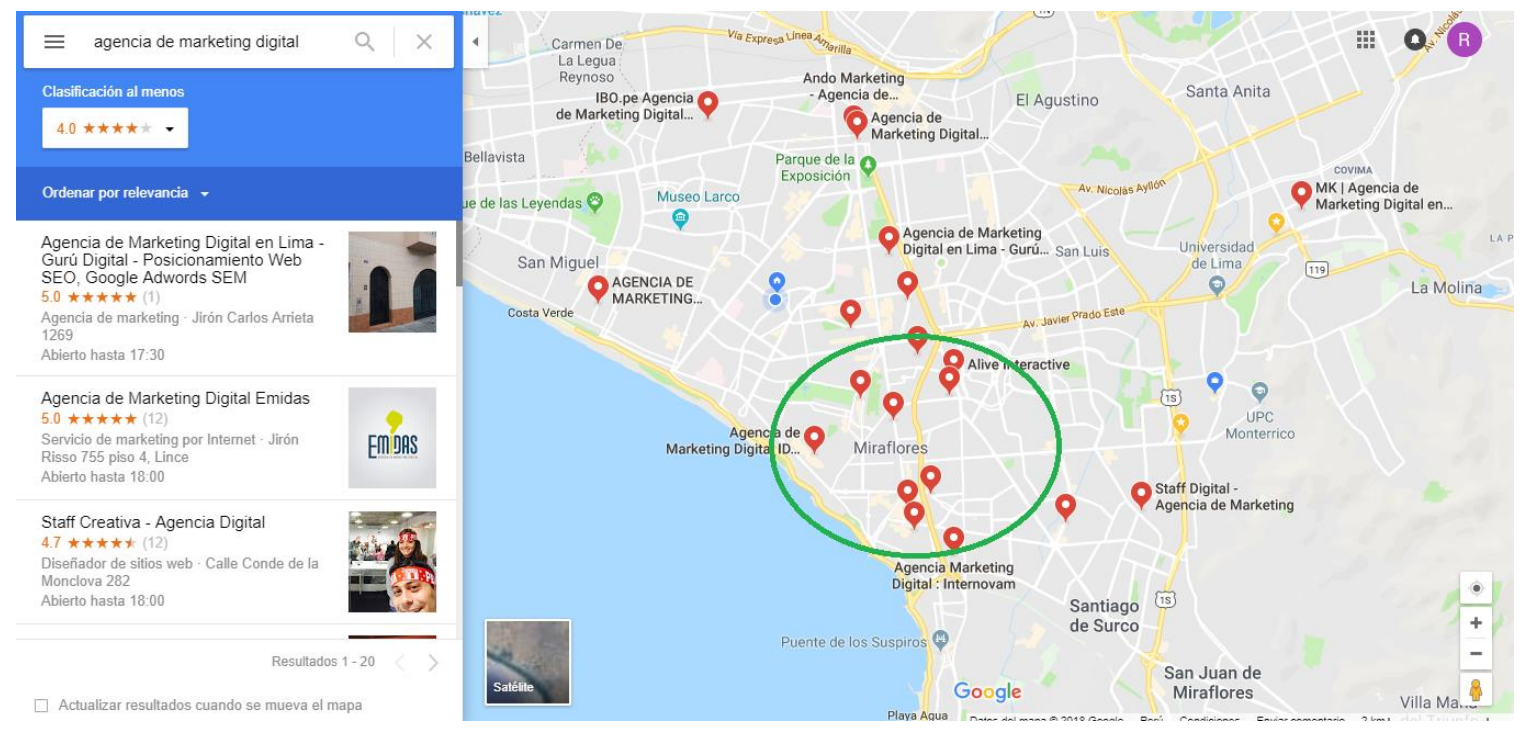

Figura 3. Ubicación de agencias de marketing digital

1.2 Uno de los segmentos a los cuales se espera atender es el de profesionales que trabajen en el área de marketing digital de empresas grandes y medianas. El 64.4\% de las empresas grandes se encuentran en Lima Centro (INEI, 2016a) . Los distritos que incluye Lima Centro son los siguientes: Barranco, Breña, Cercado de Lima, Jesús María, La Victoria, Lince, Magdalena del Mar, Miraflores, Pueblo Libre, Rímac, San Borja, San Isidro, San Miguel, Santiago de Surco y Surquillo.

1.3 Otro posible segmento de clientes son las personas que están estudiando o han terminado de estudiar en institutos y universidades, especialmente en carreras de Marketing. Según el portal Ponte en Carrera (Ministerio de Educación, 2018) los institutos o universidades donde se enseña Marketing se pueden apreciar en la tabla 11. 
Tabla 11

Instituciones educativas que dictan carreras de marketing por distrito.

\begin{tabular}{|c|c|c|}
\hline Distritos & Institución & $\begin{array}{l}\text { Nro. } \\
\text { Instituciones }\end{array}$ \\
\hline Jesús María & $\begin{array}{l}\text { Universidad del Pacífico, Universidad de San Martin } \\
\text { de Porres }\end{array}$ & 2 \\
\hline La Molina & $\begin{array}{l}\text { Universidad San Ignacio de Loyola, Universidad de } \\
\text { San Martin de Porres }\end{array}$ & 2 \\
\hline Lince & $\begin{array}{l}\text { Instituto de Tecnología Von Braun, Instituto Leo } \\
\text { Design, Universidad César Vallejo, Instituto Superior } \\
\text { Norbert Wiener }\end{array}$ & 4 \\
\hline Magdalena & $\begin{array}{l}\text { Universidad San Ignacio de Loyola, Instituto Peruano } \\
\text { de Publicidad, Instituto Toulouse Lautrec }\end{array}$ & 3 \\
\hline Pueblo Libre & $\begin{array}{l}\text { Pontificia Universidad Católica del Perú, Zegel IPAE, } \\
\text { Instituto de Educación Superior Tecnológico Perú } \\
\text { Pacífico }\end{array}$ & 3 \\
\hline & $\begin{array}{l}\text { Universidad de Piura, Instituto Superior Tecnológico } \\
\text { Cibertec, Universidad de San Martín de Porres, } \\
\text { Instituto Superior Sise, Instituto Peruano de Marketing } \\
\text { - IPM, Universidad Científica del Sur, Instituto }\end{array}$ & 7 \\
\hline Miraflores & Peruano de Arte y Diseño - IPAD & \\
\hline San Borja & Adex & 1 \\
\hline San Isidro & $\begin{array}{l}\text { Universidad Peruana de Ciencias Aplicadas, } \\
\text { Universidad Tecnológica del Perú, Instituto Superior } \\
\text { Tecnológico Cibertec, Universidad de San Martín de } \\
\text { Porres, Instituto Chio Lecca }\end{array}$ & 5 \\
\hline San Miguel & $\begin{array}{l}\text { Universidad Peruana de Ciencias Aplicadas; } \\
\text { Universidad Pontificia Católica del Perú }\end{array}$ & 2 \\
\hline Surco & $\begin{array}{l}\text { Universidad Peruana de Ciencias Aplicadas, } \\
\text { Universidad ESAN, Universidad de Lima, } \\
\text { Universidad de San Martín de Porres, Universidad } \\
\text { Científica del Sur, Instituto Toulouse Lautrec }\end{array}$ & 6 \\
\hline
\end{tabular}


2 Prestigio de la Institución: El prestigio de la institución es muy importante ya que influye en la posibilidad de ser contratado o reconocido por el mercado. Los empleadores no consideran a todas las instituciones iguales y tienden a valorar más a profesionales que estudiaron en alguna institución específica. Por ejemplo, según el portal Ponte en Carrera (Ministerio de Educación, 2018), los profesionales de marketing que en promedio tienen los sueldos más altos vienen de la Universidad Peruana de Ciencias Aplicadas y de la Universidad de Lima siendo estas las más valoradas para las carreras de Marketing. Para el caso de la Escuela que compite con centros de enseñanza que no son Institutos ni Universidades se considera que se aplica el mismo criterio, el cual fue validado por medio del estudio de mercado y por el experto entrevistado.

3 Prestigio de los profesores: En base a la información obtenida del focus group se identificó como otro factor crítico de éxito el prestigio de los profesores. A los alumnos les interesa que les enseñe un buen profesor, y el prestigio del profesor es un indicador de ello. Para evaluar el prestigio se puede recurrir a las siguientes fuentes:

- Comentarios de amigos que han llevado los cursos

- Comentarios en redes sociales. Se puede considerar especialmente valioso los comentarios dejados en LinkedIn.

○ Currículum Vitae del profesor.

- Artículos publicados por el profesor en redes y especialmente en medios masivos: periódicos, revistas, entrevistas en tv, blogs, etc.

4 Precio: El precio es un factor importante en la mayoría de productos y servicios. Según la información obtenida en el Focus los precios que se está dispuesto pagar para este tipo de 
cursos se encuentran entre $\mathrm{S} / 300$ a S/1,500 soles dependiendo del curso y número de horas que dure el mismo.

5 Horario: Los horarios también son importantes. Considerando que una parte del público objetivo trabaja, los horarios de noche durante el fin de semana o los fines de semana son más demandados. También es importante que los cursos comienzan a una hora adecuada. Si comienzan muy temprano los alumnos pueden tener dificultades para llegar debido al tráfico.

6 Variedad de cursos: Se consideró que la variedad de cursos es importante ya que se puede cubrir una mayor cantidad de requerimientos del mercado. Según los resultados de los Focus Group, al público objetivo le interesa una escuela que brinde cursos novedosos, sobre todo si son cursos que pueden diferenciar el estudiante en el mercado y no son brindados por otras escuelas. Por ejemplo, hace poco Pandemia fue una de las pocas escuelas que brindó talleres de Chatbot. El taller se llenó por lo que se pudo observar que ya existía una demanda potencial para ese tipo de cursos.

7 Aplicación a casos reales: Otra característica detectada en los Focus Group es la importancia de que los conocimientos sean aplicados de forma práctica y si es en casos reales se considera mucho más efectivo.

8 Computadores Modernos y alta velocidad de conexión: Debido a que el marketing digital se refiere al uso de canales digitales para llegar a públicos definidos es importante contar con computadores suficientemente potentes y una buena velocidad de conexión. La elaboración de campañas de publicidad no requiere computadoras tan potentes como las que se necesita para diseño gráfico, producción multimedia y programación, por lo que la importancia de este factor es moderada. 
9 Bolsa de trabajo: De las personas que llevarían los cursos un cierto porcentaje podría estar aprendiendo los cursos con el objetivo de lograr cambiar de trabajo, por lo que la bolsa de trabajo puede ser muy importante para esa parte del público objetivo.

10 Otros servicios: estacionamiento, cafetería, biblioteca, etc., a pesar de no ser imprescindibles en la decisión de escoger un curso, sí influenciarían en la percepción del estudiante respecto a la escuela una vez que está llevando el curso. Especialmente el estacionamiento puede llegar a ser un factor muy importante para el público que viene en auto y puede ser determinante si no existen estacionamientos cercanos al local donde funciona la escuela.

11 Emisión de certificados: Según el experto entrevistado Miguel Calderón (Ver Apéndice 8), cualquier empresa puede emitir certificados y constancias a nombre propio. En el caso de la escuela al no ser un instituto licenciado por el ministerio de educación, el certificado se emitiría a nombre de la escuela y no tendría ninguna validez en el sistema educativo. Sin embargo se ha considerado la importancia de la emisión de los certificados ya que participantes en el Focus han considerado la emisión de un certificado como uno de los motivos que la animaría a inscribirse en la escuela de marketing digital. El peso e importancia de este certificado se irá incrementando conforme la escuela se haga más conocida.

\section{Ponderación de los Factores}

En base a la entrevista con el experto Marcos Fonruge (ver Apéndice 7) y el experto Miguel Calderón (ver Apéndice 8) se realizó la ponderación para los factores críticos de éxito. Los resultados de este cálculo se pueden observar en la tabla 12. 
Tabla 12

Ponderación de factores críticos de éxito

\begin{tabular}{lll}
\hline Factor Crítico de Éxito & Importancia (1-20) & Ponderación \\
\hline Ubicación & 9 & $10 \%$ \\
Prestigio de la Institución & 20 & $23 \%$ \\
Prestigio de los profesores & 18 & $21 \%$ \\
Precio & 14 & $16 \%$ \\
Horario & 12 & $14 \%$ \\
Variedad de cursos & 1 & $1 \%$ \\
Aplicación a casos reales & 1 & $1 \%$ \\
Computadores Modernos y Alta & 6 & $7 \%$ \\
velocidad de conexión & 1 & $1 \%$ \\
Bolsa de trabajo & 5 & $6 \%$ \\
Otros servicios: Estacionamiento, & 1 & $1 \%$ \\
cafetería, biblioteca & 87 & $100 \%$ \\
Emisión de certificados & & \\
\hline Total & &
\end{tabular}

Tomando en cuenta la información que se obtuvo sobre los competidores se procedió a elaborar la Matriz de Perfil Competitivo, la cual se puede observar en la tabla 13. 
Tabla 13

Matriz Perfil Competitivo

\begin{tabular}{|c|c|c|c|c|c|c|c|}
\hline & & \multicolumn{2}{|l|}{ MOTT } & \multicolumn{2}{|c|}{ Pandemia } & \multicolumn{2}{|l|}{ Negzy } \\
\hline Factores Claves del Éxito & Ponderación & Puntaje & $\begin{array}{l}\text { Resultado } \\
\text { Ponderado }\end{array}$ & Puntaje & $\begin{array}{l}\text { Resultado } \\
\text { Ponderado }\end{array}$ & Puntaje & $\begin{array}{l}\text { Resultado } \\
\text { Ponderado }\end{array}$ \\
\hline Ubicación & $10.23 \%$ & 5 & 0.51 & 4 & 0.41 & 5 & 0.51 \\
\hline Prestigio de la Institución & $22.73 \%$ & 5 & 1.14 & 4 & 0.91 & 4 & 0.91 \\
\hline Prestigio de los profesores & $20.45 \%$ & 4 & 0.82 & 4 & 0.82 & 5 & 1.02 \\
\hline Precio & $15.91 \%$ & 4 & 0.64 & 5 & 0.80 & 4 & 0.64 \\
\hline Horario & $13.64 \%$ & 4 & 0.55 & 5 & 0.68 & 3 & 0.41 \\
\hline Variedad de cursos & $1.14 \%$ & 5 & 0.06 & 5 & 0.06 & 3 & 0.03 \\
\hline Aplicación a casos reales & $1.14 \%$ & 4 & 0.05 & 4 & 0.05 & 4 & 0.05 \\
\hline $\begin{array}{l}\text { Computadores Modernos y } \\
\text { Alta velocidad de conexión }\end{array}$ & $6.82 \%$ & 5 & 0.34 & 5 & 0.34 & 3 & 0.20 \\
\hline Bolsa de trabajo & $1.14 \%$ & 4 & 0.05 & 4 & 0.05 & 4 & 0.05 \\
\hline Otros servicios: & & & & & & & \\
\hline $\begin{array}{l}\text { Estacionamiento, cafetería, } \\
\text { biblioteca }\end{array}$ & $5.68 \%$ & 5 & 0.28 & 3 & 0.17 & 3 & 0.17 \\
\hline Emisión de certificados & $1.14 \%$ & 5 & 0.06 & 5 & 0.06 & 5 & 0.06 \\
\hline Total & $100.00 \%$ & & 4.48 & & 4.33 & & 4.05 \\
\hline
\end{tabular}

En función a los resultados de la matriz del perfil competitivo, validada por el experto entrevistado (ver Apéndice 7), dos de los factores más fuertes de los competidores son el prestigio de la institución y el prestigio de los profesores. Por lo que estos factores son sumamente importantes para el éxito de la Escuela. 


\subsection{Análisis del Contexto Actual y Esperado}

\subsubsection{Análisis Político- Gubernamental.}

La estabilidad política es un factor relevante en el desarrollo de los emprendimientos empresariales. En tal sentido, la inestabilidad política genera falta de predictibilidad respecto a las reglas y leyes emitidas por el Estado y por lo tanto desanima a inversores los cuales necesitan estabilidad y reglas claras para competir en el mercado.

El Perú se encuentra en el puesto 63 de 160 economías del Ranking de Competitividad Global 2018 del World Economic Forum, habiendo retrocedido tres ubicaciones respecto del año anterior, relacionándose este retroceso con las dificultades y los problemas que se han suscitado en el entorno político.

Durante el desarrollo de la presente investigación (2017- 2018) el país entero, se vio sacudido por diversos escándalos de corrupción en los cuales se ha identificado actividad ilícita de las más altas autoridades (ex presidentes), líderes políticos, altos funcionarios, grandes empresarios, entre otros, lo cual ha generado serios enfrentamientos políticos y un preocupante estancamiento no solo a nivel económico sino del proceso de modernización del estado.

En consecuencia, la estabilidad política y económica son condiciones indispensables para incentivar al ecosistema emprendedor, en tanto es parte del tejido empresarial que dinamiza la economía, brinda empleo y diversifica la matriz económica; en ese sentido, como bien refiere la presidenta de la Cámara de Comercio de Lima, Yolanda Torriana: "La inestabilidad política y la incertidumbre que se generan por el enfrentamiento entre los poderes del Estado están afectando la dinámica económica del país. Las inversiones privadas comienzan a detenerse ante la incertidumbre y son ellas las que constituyen un 
elemento clave si queremos mantener nuestro crecimiento" (Andina Agencia Peruana de Noticias, 2018)

\subsubsection{Análisis Económico.}

De acuerdo con el portal BBVA Research (2019) sobre la situación económica del país durante el 2018, se vio un incremento en la actividad económica en el cuarto trimestre del 2018 llegándose a producir un crecimiento de 4.6\% en los últimos tres meses del año. Sin embargo, como los primeros tres cuartos del año el crecimiento económico fue más lento, se estimó el crecimiento de todo el año en 3.9\%.

Según BBVA Research (2019) se prevé un entorno externo no muy favorable debido a que se proyecta una moderación del crecimiento mundial, una caída de los precios del petróleo y los metales. Sin embargo, la situación interna se prevé más positiva debido a los siguientes factores: incremento de la inversión y normalización de la producción en el sector minero, se acelerará el gasto de reconstrucción del país y un ánimo empresarial positivo que puede incrementar la inversión privada. En base a estos factores se tiene una previsión de crecimiento de $3.9 \%$ para el 2019 y $3.7 \%$ para el 2020. El tipo de cambio cerró el 2018 en S/3.37 soles por dólar y la tasa de inflación del 2018 fue de 2.2\%. Se prevé terminar el 2019 con un tipo de cambio de S/3.30 soles por dólar y una tasa de inflación de $2.3 \%$.

\section{PBI}

El PBI en el 2017 ha sido cerca de 211.4 miles de millones de dólares, observándose un crecimiento acelerado desde el 2002. (Ver figura 4) 
Producción del PIB (dólares estadounidenses actuales) ?

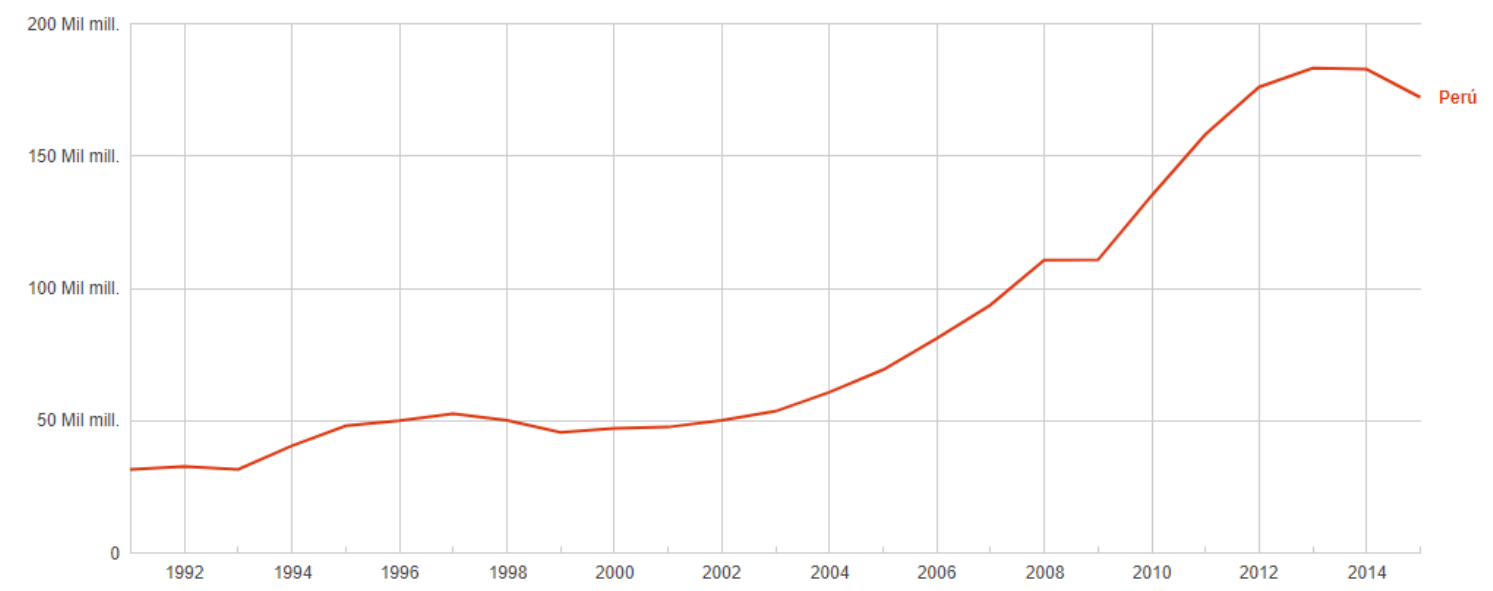

Figura 4. Producción del PBI desde 1992 al 2014. Recuperado de https://www.google.com.pe/publicdata/. Tomado de Producto Interior Bruto por Banco Mundial, 2018. Copyright 2018 por Banco Mundial.

Tipo de cambio promedio anual: El tipo de cambio promedio anual en los últimos tres años ha fluctuado desde 2.64 en su punto más bajo en el 2012 a 3.38 en su punto más alto en el 2016. (ver figura 5)

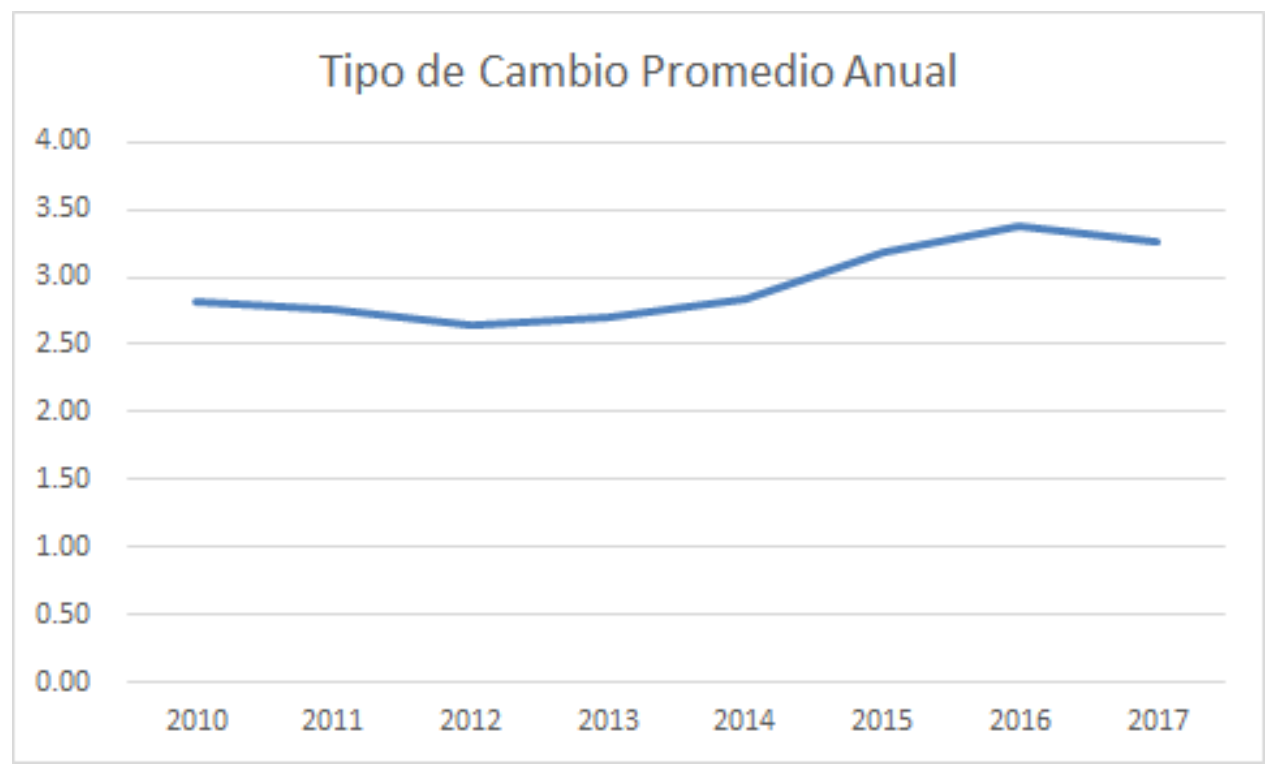

Figura 5. Tipo de cambio promedio anual del 2010 al 2017 
Revisando el tipo de cambio de los últimos tres años se puede observar que el tipo de cambio en el 2017 ha disminuido respecto al 2016 manteniéndose relativamente estable. (ver figura 6)

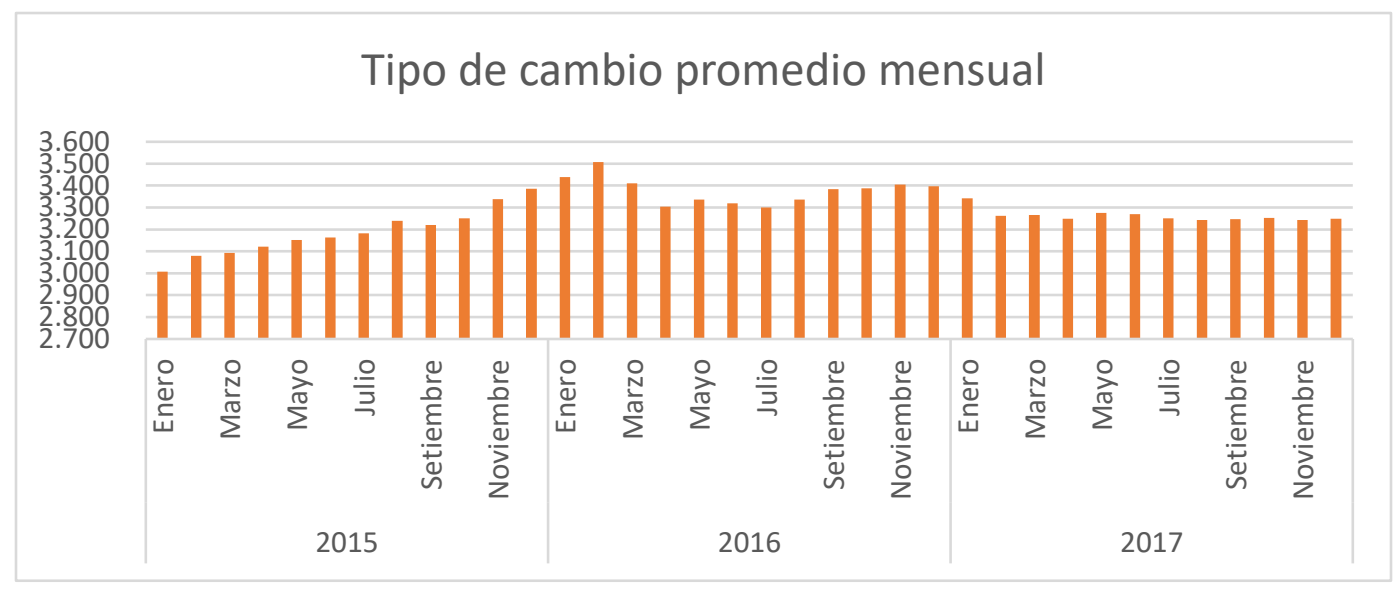

Figura 6. Tipo de cambio promedio mensual del 2015 al 2017

\subsubsection{Análisis Legal.}

Debido a que la empresa no se va a constituir como un Instituto o Universidad no le resultan aplicables ni la Ley Universitaria, Ley $N^{\circ} 23733$, ni la Ley de Institutos y Escuelas de Educación Superior, Ley N 30512; así, la empresa se regiría por la Constitución y la Ley General de Sociedades, por lo que deberá cumplir con los requisitos necesarios para implementar cualquier empresa (SUNARP, 2018):

- Búsqueda y reserva de nombre

- Elaboración de la minuta de constitución de la empresa o sociedad

- Aporte de capital.

- Elaboración de escritura pública ante el notario

- Inscripción de la empresa o sociedad en el Registro de Personas Jurídicas de la Sunarp

- Inscripción al RUC para persona jurídica 
- Una vez activa la empresa el último paso pendiente seria obtener la licencia municipal y de defensa civil.

Sin embargo sería importante considerar los requisitos de la ley de Institutos considerando la posibilidad de que en algún momento se decida transformar a la Escuela de Marketing Digital en un Instituto de Marketing Digital.

Según el experto entrevistado Miguel Calderón (ver Apéndice 8), cualquier empresa puede dictar cursos o emitir certificados y constancias a nombre propio. Solo los títulos a nombre de la Nación o los certificados a nombre del Ministerio de Educación pueden ser emitidos por Institutos licenciados por esta entidad. Asimismo, existen restricciones en el nombre de la empresa, por ejemplo los siguientes nombres solo pueden ser usados por universidades o institutos con licencia: universidad, escuela de educación superior tecnológica, escuela de educación superior pedagógica, escuela superior de formación artística, instituto de educación superior.

Una de las principales ventajas de que se pueda obtener la licencia para implementar un instituto es la opción de brindar títulos validados por el ministerio de educación. Según el artículo 5 de la Ley de Institutos y Escuelas de Educación Superior y de la Carrera Pública de sus Docentes (Ministerio de Educación, 2016), los institutos pueden brindar los títulos de bachiller técnico y los títulos de técnico y de profesional técnico a nombre de la Nación. También se puede brindar los certificados de estudios técnicos y de auxiliar técnico.

Sin embargo para acceder a esta ventaja la empresa debe cumplir con los siguientes requisitos según el artículo 25 de la Ley de Institutos (Ministerio de Educación, 2016):

- Contar con una gestión institucional que demuestre la solidez organizativa del modelo educativo propuesto. 
- La gestión académica y los programas de estudios deben estar alineados a las normas del Ministerio de Educación.

- Deberá contar con infraestructura física y equipamiento adecuado para brindar un buen servicio tales como bibliotecas, laboratorios, talleres, entre otros

- Se deberá disponer de personal docente adecuado para los cursos y carreras ofrecidas. Se requiere que por lo menos el veinte por ciento de los docentes contratados estén en la modalidad de tiempo completo.

- Se debe contar con una previsión económica y financiera compatible con los objetivos de la institución.

\subsubsection{Análisis Cultural.}

Existe una creciente demanda del aprendizaje de marketing digital como parte de la capacitación esencial de un trabajador de las áreas de marketing, publicidad o ventas. Esto fortalecido por el deseo de superación constante que existe en la actualidad por parte de los jóvenes ejecutivos y emprendedores.

Actualmente, el uso de las redes sociales está bastante extendido. Según una encuesta de la empresa GFK (2017), la principal red social usada por los usuarios es Facebook seguida de YouTube. De los cursos que se revisaron y tratan sobre social media la mayoría de ellos se enfoca en Facebook. Sin embargo, existen otras redes como WhatsApp, Google+, Twitter, Instagram, Snapchat y LinkedIn que no son cubiertas por los cursos actuales. Estas redes podrían ser interesantes para muchos empresarios ya que van a nichos determinados de mercados, tienen un volumen considerable de usuarios y cuenta con una competencia más baja que en el caso de Facebook (ver figura 7) 
Usuarios de Internet - Perú urbano

¿Cuál de las siguientes redes usa:...?

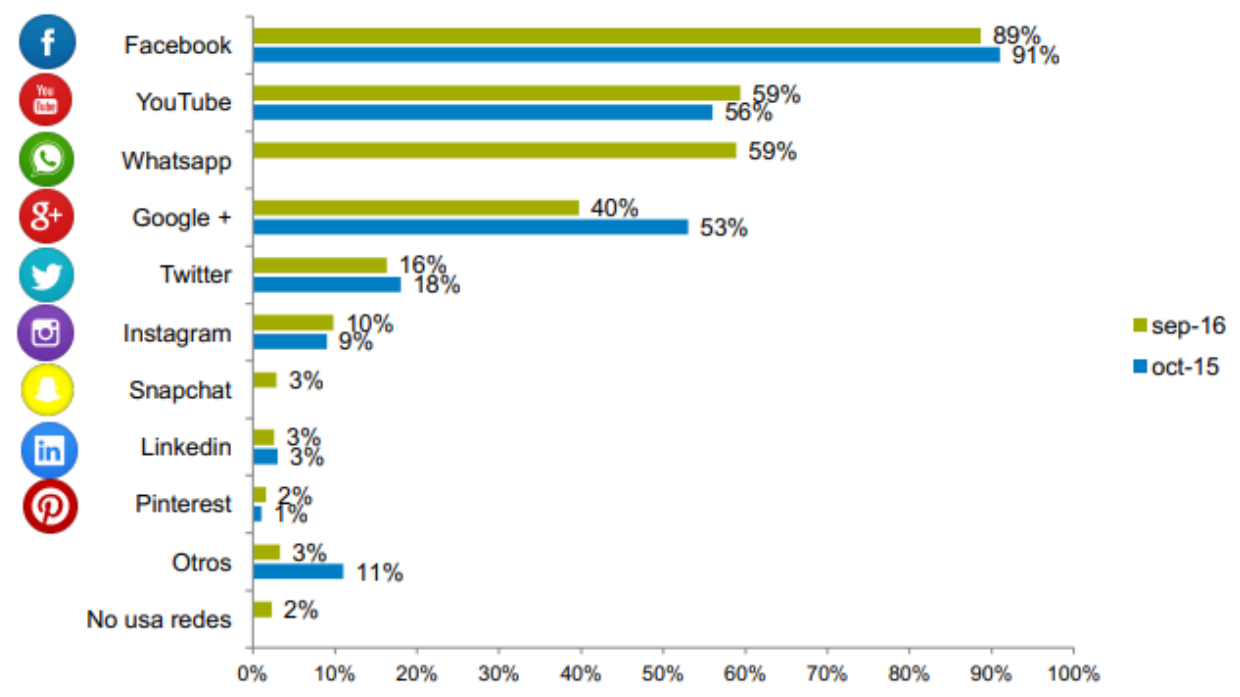

Figura 7. Usuarios de redes sociales a Setiembre del 2016. Tomado de GfK Kit de planeamiento digital Perú 2017, por GFK Perú, 2017, Perú, Lima: Editorial. Copyright 2017 por GFK Perú.

\section{Tenencia de dispositivos}

Según un estudio de la empresa GFK (2017) ha aumentado el uso de dispositivos móviles tales como Smartphones y Laptops. Por otro lado, ha disminuido ligeramente el uso de computadoras de escritorio y en una gran medida el uso de celulares simples. Se puede observar que el uso de otros tipos de dispositivos como con consolas de videojuegos o Smartphone todavía es bajo (ver figura 8). 
Perú urbano - Total población

¿Cuál de los siguientes dispositivos tiene usted? (RESPUESTA MÚLTIPLE)

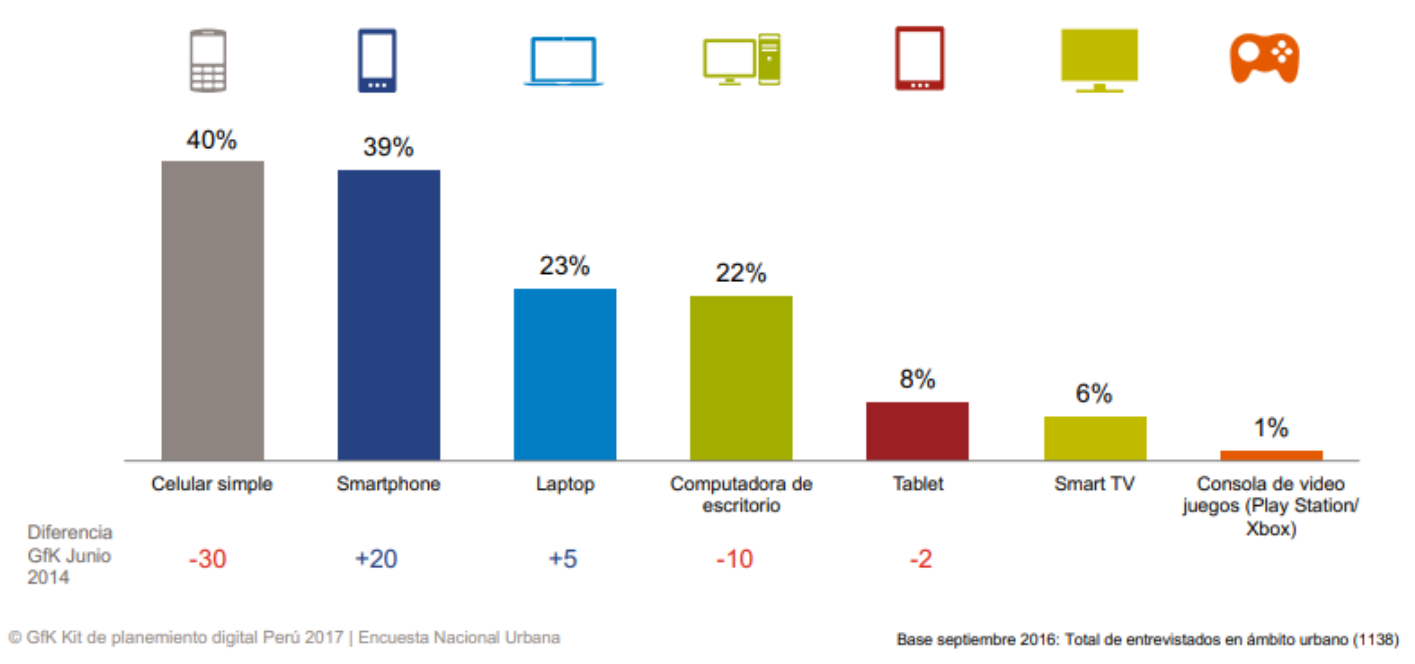

Figura 8. Tenencia de dispositivos para conexión a Internet. Tomado de GfK Kit de planeamiento digital Perú 2017, por GFK Perú, 2017, Perú, Lima: Editorial. Copyright 2017 por GFK Perú.

\section{Uso de los Smartphones}

Otra de las tendencias sociales y culturales más importantes es el uso de los smartphones para casi todas las actividades. Según una encuesta de GFK Perú (2017):

- El 66\% de los participantes del estudio usaron un smartphone para escuchar música la última vez.

- El $51 \%$ lo uso para compartir fotos, el $48 \%$ para acceder a redes sociales, el $39 \%$ para consultar noticias, $33 \%$ lo uso para informarse de un evento y 32\% calificó un producto a través de un smartphone la última vez que lo hizo.

\section{Nuevas formas de aprender}

La actual generación tiene necesidades e intereses de aprendizaje distintos, están convencidos de que pueden aprender a través de una computadora y del internet. Sin 
embargo, no se trata sólo de contar con la infraestructura, sino también de adaptar los contenidos de las clases y contar una nueva metodología que permita al alumno entender, aprender y reflexionar. (Ferreyro, 2008)

Las tecnologías de la información y comunicación (TIC) son hoy en día un recurso imprescindible en la educación. Si bien en el Perú existen factores que pueden limitar su uso, como, por ejemplo, problemas técnicos, de seguridad, culturales y económicos, es necesario que los docentes se encuentren capacitados para utilizar las TIC en el aula. El docente está pasando a ser considerado un facilitador del aprendizaje y debe aplicar una metodología que aproveche las herramientas tecnológicas. (Hernández, Orrego, \& Quiñonez, 2018)

\subsubsection{Análisis Tecnológico.}

Aumento del uso de Internet: Un total de cinco millones 712 mil 244 hogares

peruanos tienen conexión a Internet fijo o móvil, y tres de cada cuatro familias cuentan con más de un servicio de telecomunicaciones, según los resultados que arrojó la Encuesta Residencial de Servicios de Telecomunicaciones al 2016 (Osiptel, 2016), realizada por el Organismo Supervisor de la Inversión Privada en Telecomunicaciones (OSIPTEL) a nivel nacional.

Aumento del uso de teléfonos móviles inteligente por parte de la población: La encuesta de ERESTEL indicó al 2016, que la tasa de acceso a Telefonía móvil entre los hogares rurales ya supera el 90\% (Osiptel, 2016). 
Aumento de las compras en línea: Según la Cámara Peruana de Comercio

Electrónico, las ventas por Internet llegaron a los US\$ 2,800 millones en el año 2016, lo que significa un crecimiento del 198\% durante los últimos dos años. (Revista Gestión, 2017)

Aumento de Uso de Internet Móvil: Según Osiptel (Osiptel, 2016), el uso de internet móvil ha aumentado los últimos cuatro años. Desde el 2014 al 2017 la cantidad de líneas móviles que accedieron a internet ha aumentado en un 56.3\% (ver figura 9).

\section{Total de Líneas Móviles que accedieron a}

\section{Internet: Junio 2017}

\section{(En Millones)}

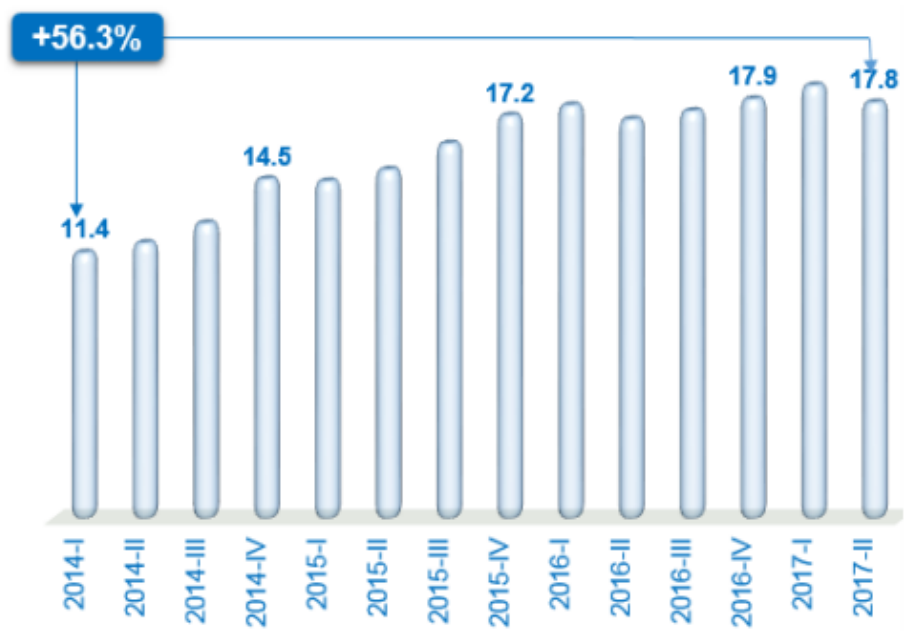

Figura 9. Líneas móviles que accedieron a internet - Junio 2017. Tomado de Propuesta tarifaria de la red de transporte y acceso de los proyectos regionales de Internet de banda ancha, por OSIPTEL, 2016, Perú, Lima: Editorial. Copyright 2016 por OSIPTEL.

Aparte de la cantidad de usuarios, ha aumentado el consumo por cada usuario. Por ejemplo, el tráfico promedio por línea en el 2017 ha superado los 5,000 Megabytes por línea celular. No solo el volumen de tráfico sino también la velocidad, por ejemplo, en el 2017 el 36\% de los usuarios usa el estándar 4G (36\%) casi duplicando el porcentaje del año pasado que era de $19 \%$. 


\subsubsection{Análisis Ecológico.}

Una de las tendencias ecológicas que siguen diversas instituciones es la reducción del uso de papel. Según el experto Jorge Cortés, Gerente de Ventas de la empresa Stansa Digital, el ahorro del 15\% en costos operativos es posible con la reducción del consumo físico del papel. El experto recomienda junto con la utilización del papel por ambos lados, la digitalización de documentos (Gestión, 2012).

Con el fin de desarrollar conciencia ecológica se procederá a publicar los siguientes materiales en la plataforma online que sería parte del proyecto:

- Sílabo

- Brochure de los cursos

- Constancias y certificaciones

- Material de lectura, entre otros.

\subsection{Oportunidades y Amenazas}

\section{Oportunidades}

- Del análisis económico: El PBI nacional continúa siendo más alto que el promedio mundial desde más de 10 años, este crecimiento favorece para que las empresas decidan invertir o crecer, es entonces donde surge la necesidad de mantenerse empleables y esto se relaciona con capacitarse continuamente en las nuevas tecnologías y su uso.

- Del análisis legal: Al no estar regulada por el Ministerio de Educación la Escuela de Marketing Digital contará con mayor flexibilidad para crear y lanzar nuevos cursos en función a la demanda y las tendencias tecnológicas. 
- Del análisis sociocultural: La tenencia y uso de smartphones, se ha generalizado de tal manera, que hoy en día se considera necesario que los docentes empleen la tecnología en el aula.

- Del análisis tecnológico: El aumento del tráfico de internet, sobre todo a través de equipos celulares, así como el aumento del volumen de compras por internet contribuyen a que las empresas se orienten hacia los canales digitales para lanzar su publicidad, existiendo la necesidad de gente capacitada en marketing digital.

- Del análisis ecológico: En un mundo donde cada vez se valora más el cuidado del medio ambiente, el ser una empresa eco-amigable contribuirá de manera positiva a la imagen de la institución. Por otro lado, la digitalización de documentos permitirá ahorros en papel, tóner y espacio.

\section{Amenazas}

- Del análisis económico: Dado que la economía se mantiene en crecimiento, otros empresarios podrían decidir invertir en el mismo sector, aumentando la competencia. 


\section{Capítulo III: Estudio de Mercado}

En este capítulo se presenta el estudio de mercado para la Escuela de Marketing Digital. Después de analizar los estudios cualitativo y cuantitativo se procederá a analizar la información obtenida con el objetivo de determinar la demanda.

Para desarrollar este estudio de mercado se realizó una investigación cualitativa utilizando técnicas de focus group y entrevistas a profundidad. Así mismo se realizó un estudio cuantitativo como parte del cual se realizaron encuestas a una muestra de la población.

\subsection{Descripción del servicio o producto}

Se creará una Escuela de Marketing Digital, la cual se ubicará en un distrito de Lima Metropolitana. Se orientará a personas entre 18 y 49 años, que vivan en los distritos de Jesús María, La Molina, Lince, Magdalena, Pueblo Libre, Miraflores, San Borja, San Isidro, San Miguel y Surco y que estudien o hayan estudiado una carrera relacionada a las áreas de marketing, relaciones públicas, ventas o publicidad.

La Escuela se especializará en ofrecer cursos cortos, de un mes de duración, sobre temas específicos relacionados al marketing digital. Los alumnos de la Escuela podrán elegir llevar cursos tales como:

- Publicidad Digital

- AdWords

- Social Media

- Analítica Web

Los cursos se dictarán en dos modalidades: 
Cursos grupales: cursos de un mes de duración, con un total de 18 horas de clase.

Los cursos serán dictados de manera presencial, es decir, los alumnos asistirán a la Escuela. Los horarios estarán establecidos con anticipación para que el alumno pueda elegir aquel que le resulte más conveniente.

Cursos individuales: el alumno podrá adquirir un paquete de 10 horas de clase durante las cuales se le asignará un profesor que le enseñará aquellos temas que el alumno especifique. Este servicio estará orientado a personas que deseen complementar sus conocimientos en algún tema específico, y que no cuente con disponibilidad para asistir a clases en los horarios establecidos para las clases grupales.

\subsection{Selección del segmento de mercado}

"Podemos definir a la Segmentación como una estrategia que emplean las empresas para concentrar, y por tanto optimizar, sus recursos dentro de un mercado general." (Rodríguez, 2002)

Según Stanton, Walker y Etzel (2007), la segmentación del mercado es beneficiosa para las empresas que la aplican porque les permite:

- Orientar sus productos, precios, promoción y canales de distribución hacia los clientes.

- Aprovechar mejor sus recursos de mercadotecnia al enfocarlos hacia segmentos realmente potenciales para la empresa.

- Competir más eficazmente en determinados segmentos en los que les es posible utilizar sus fortalezas.

- Ayudar a sus clientes a encontrar productos o servicios mejor adaptados a sus necesidades o deseos. 


\section{Proceso de segmentación}

En primer lugar, se definirán los criterios de segmentación, es decir aquellas variables que se utilizarán para dividir el mercado en segmentos fácilmente accesibles, medibles, sustanciales y diferenciables. (Kotler \& Armstrong, 2012)

Para el presente trabajo, las variables a utilizarse serán:

Geográficas, es decir, tomándose como base la ubicación, se dividirá el territorio en regiones fácilmente identificables. En este caso de toda Lima Metropolitana se eligieron diez distritos: Jesús María, La Molina, Lince, Magdalena, Pueblo Libre, Miraflores, San Borja, San Isidro, San Miguel y Surco, por ser aquellos donde por lo menos el $80 \%$ de la población pertenece a los niveles socioeconómicos alto y medio alto. (INEI, 2016b)

Según el informe del INEI citado en el párrafo anterior, se definen cinco estratos de ingresos. El estrato medio alto lo conforman aquellos cuyo ingreso per cápita es mayor a S/. 2192.20 y el estrato alto lo conforman aquellos con un ingreso entre 1330.10 y S/.2192.19. Los rangos de ingresos de estos estratos se muestran en la tabla 14.

Tabla 14

Estratos de ingresos

\begin{tabular}{lc}
\hline Estrato & Rango de ingresos per cápita (soles) \\
\hline Alto & 2192.20 a más \\
Medio alto & $1330.10-2192.19$ \\
Medio alto & $899-1330.09$ \\
Medio bajo & $575.70-898.99$ \\
Bajo & hasta 575.69 \\
\hline
\end{tabular}

Nota: Rango de ingresos per cápita. Tomado de Planos Estratificados de Lima Metropolitana a Nivel de Manzana 2016, por INEI, 2016b, Perú, Lima: Editorial. Copyright 2016 por INEI. 
- Demográficas, lo que significará dividir el mercado en grupos utilizando como variable la edad. Para fines del presente estudio, se está considerando a la población entre 18 y 49 años. (INEI, Perú: Indicadores de Educación por departamento, 2007-2017, 2018)

\subsection{Investigación Cualitativa}

La investigación cualitativa resulta conveniente para conocer las razones por las que los individuos actúan de la manera en que lo hacen. (Rodriguez Jaume \& Garrigos, 2017)

Para el presente estudio se utilizaron dos métodos de investigación cualitativa: focus group y entrevistas a profundidad.

\subsubsection{Focus Group.}

Este método consiste en reunir un grupo de personas, generalmente entre seis y doce, para que den sus opiniones acerca de un tema específico. Un moderador hace preguntas que conlleven a obtener información sobre determinado tema y los guía para que no se desvíen de este. Generalmente estas sesiones son grabadas. (McDaniel \& Gates, 2016)

\section{Objetivos del Focus Group:}

Tuvo como objetivos los siguientes:

- Determinar hábitos de estudio (horario, modalidad, frecuencia y duración)

- Definir el precio que los alumnos estarían dispuestos a pagar por las distintas modalidades de cursos.

- Establecer los cursos que tienen mayor demanda

- Determinar los atributos que valoran más las personas a la hora de elegir en que institución estudiar. 
- Determinar en qué zona de Lima debería ubicarse la Escuela

\subsubsection{Proceso de Muestreo.}

Se realizó un muestreo de tipo no probabilístico por conveniencia. Este proceso consistió en seleccionar una muestra de la población por el fácil acceso a ésta, sin que haya un criterio estadístico. Las ventajas de trabajar con este tipo de muestra son la facilidad operativa y el bajo costo, mientras que su principal desventaja es que no permite hacer afirmaciones de tipo estadístico sobre la población. Sin embargo, los resultados obtenidos sirven para obtener tendencias y resultados que más adelante puedan ser utilizados para trabajar con una muestra probabilística. (Ochoa, 2015)

\section{Definición de la Población}

Para la realización de los focus group, se ha determinado el perfil de la población:

- Habitantes de los distritos de Jesús María, La Molina, Lince, Magdalena, Pueblo Libre, Miraflores, San Borja, San Isidro, San Miguel y Surco.

- Hombres y mujeres, entre 18 y 49 años.

- Con estudios o experiencia laboral en las áreas de marketing, relaciones públicas, ventas y publicidad.

El cumplimiento de esta última condición se validó con la Ficha de Reclutamiento (ver Apéndice 2), pues fue una pregunta filtro.

\section{Tamaño de muestra}

Para el presente trabajo se realizaron dos focus group de siete personas cada uno.

\section{Selección de los elementos de la muestra}

En el caso los focus group, se invitó a participar a personas que trabajan en el área de marketing, ventas y publicidad para realizar con ellos el primer focus group. Asimismo, 
se convocó a personas que hayan estudiado marketing o carreras afines a ésta para el segundo focus group.

\subsubsection{Diseño de instrumento.}

Se elaboraron los siguientes documentos:

- Ficha de reclutamiento (ver Apéndice 2)

- Guía de indagación para Focus Group (ver Apéndice 3)

La guía de indagación se alineó con los objetivos investigación cualitativa, estimando un tiempo promedio de 40 minutos por sesión. Los integrantes del grupo actuaron como moderadores buscando obtener la mayor información posible y tratando que no hubiera desviaciones del tema.

\subsubsection{Análisis y Procesamiento de datos.}

Se realizó la transcripción de los dos focus group realizados (ver Apéndice 4 y 5). Asimismo, se analizó la data obtenida, obteniéndose la siguiente información:

- Sobre los hábitos de estudio, los horarios preferidos para estudiar son por las noches, dos o tres veces por semana y también los sábados. Los cursos presenciales fueron los preferidos, pues los entrevistados señalaron que los cursos online los pueden encontrar de manera gratuita en la web.

- El precio que las personas están dispuestas a pagar varía entre 300 a 1500 soles.

- Los cursos por los que se tiene mayor interés o los más demandados son aquellos sobre nuevas tendencias en el marketing digital. Relacionados también con métricas, publicidad digital y estrategia.

- El prestigio de la institución y de sus profesores junto con el precio, el horario, las opiniones de conocidos y la ubicación son factores que evalúan al momento 
de tomar la decisión de compra. El poder realizar proyectos para empresas reales también es un factor que consideran importante para optar por una escuela.

- La ubicación que preferirían sería el distrito de Miraflores o algún otro distrito céntrico.

\subsubsection{Entrevistas a Profundidad.}

También se utilizó esta técnica para obtener información para el presente proyecto.

El método consiste básicamente en preparar una guía de preguntas que puedan ser formuladas a un experto o conocedor de un tema específico, al cual se debe motivar para que conteste con libertad. (Ochoa, 2015)

\section{Objetivos de las entrevistas a profundidad}

- Determinar si es posible constituir una Escuela de Marketing Digital que no esté supervisada por el MINEDU.

- Confirmar que es posible emitir certificados y/o constancias de estudio.

- Es posible utilizar la denominación "Escuela"

- Determinar cuáles son los cursos más dictados actualmente y las nuevas tendencias.

- Conocer el perfil del alumno de cursos de marketing digital.

- Confirmar qué tipo de factores influyen en las personas al momento de decidir si matricularse o no en determinada institución.

\section{Definición de la población:}

Se entrevistó a los siguientes expertos (ver tabla 15):

- Miguel Calderón, Director General de Educación Superior del Ministerio de Educación del Perú, sobre temas administrativos y legales. 
- Marcos Fonruge, Coordinador del Área de Marketing Digital en el IPP e IPAD, sobre temas académicos y comerciales.

\section{Tabla 15}

Expertos entrevistados

\begin{tabular}{|c|c|c|}
\hline & Área de experiencia: & Temas por consultar \\
\hline Miguel & Sector Educación - Área & Constitución de empresas \\
\hline Calderón & Administrativa & educativas. Temas legales. \\
\hline Marcos & Sector Educación - Área & Cursos con más dictados, \\
\hline Fonruge & Académica y Comercial & $\begin{array}{l}\text { nuevas tendencias. } \\
\text { Perfil del alumno. } \\
\text { Características de los } \\
\text { cursos dictados en otras } \\
\text { instituciones. } \\
\text { Factores que influyen en la } \\
\text { toma de decisión al } \\
\text { momento de matricularse } \\
\text { (infraestructura, plana } \\
\text { docente, precio, entre } \\
\text { otros) }\end{array}$ \\
\hline
\end{tabular}

Tamaño de la muestra

Se entrevistó a un experto de cada una de las áreas mencionadas. 


\section{Selección de la muestra}

Se seleccionó a los expertos por conveniencia, por el acceso que se tenía a ellos a través de conocidos en común, pero, sobre todo, por su conocimiento del sector y específicamente de los temas de interés.

\section{Diseño del Instrumento}

Antes de cada entrevista, se preparó una guía de entrevista semi estructurada con preguntas abiertas, adaptada para cada experto. (ver Apéndice 6)

\section{Análisis y procesamiento de datos}

Para el respectivo análisis de datos se procedió a transcribir la entrevista. Posteriormente se analizó en función a los objetivos planteados, con los siguientes resultados:

- Los cursos más demandados actualmente son Community Manager y Pauta Publicitaria. La tendencia es la micro especialización, es decir, especializarse en el manejo de sólo una red social y la publicidad en redes de mensajería como el WhatsApp.

- Los alumnos son generalmente emprendedores, community managers, estudiantes universitarios de marketing o de cursos relacionados que desean complementar lo aprendido en su carrera.

- Los atributos más valorados son el prestigio de la institución, de los docentes, horarios, precios, referencias de conocidos, la imagen.

- Sí es posible formar una escuela que no esté supervisada por la SUNEDU, siempre y cuando esté constituida de acuerdo con la Ley General de Sociedades. 
- Se confirmó que es posible entregar certificados a nombre de la institución, más no a nombre de la Nación.

- El nombre instituto o escuela puede ser usado indistintamente, pero no universidad, escuela de formación artística o instituto de educación superior, entre otros nombres oficiales.

\subsection{Investigación Cuantitativa}

Es una investigación cuyo objetivo es obtener información que describa hechos que puedan ser cuantificables a través de técnicas más estructuradas que las cualitativas. Los datos que se obtienen resultan medibles y es posible extrapolarlos al total de la población que se está analizando. (Merino, Pintado, Sanchez, \& Grande, 2015)

\section{Objetivos de la investigación}

- Determinar la demanda por cursos de marketing digital a dictarse en la Escuela.

- Determinar el precio que los alumnos están dispuestos a pagar por los cursos en las modalidades ofrecidas.

- Conocer cuáles son los atributos que los alumnos potenciales valoran más en una Escuela de Marketing Digital.

- Establecer la ubicación más adecuada para el local de la Escuela.

- Conocer los hábitos de estudio y la frecuencia con la que los alumnos toman cursos cortos de marketing digital.

- Establecer cuáles son los medios preferidos para revisar anuncios sobre la Escuela. 


\subsubsection{Proceso de Muestreo.}

Existen varios tipos de muestreo, los cuales se dividen en probabilísticos y no probabilísticos. Una muestra probabilística es aquella en la que cada elemento de la población tiene una probabilidad conocida de selección distinta a cero. Con una muestra probabilística los resultados pueden proyectarse a la población total. Sin embargo, tienen también desventajas tales como el costo elevado y el tiempo que toma ejecutar el estudio. (McDaniel \& Gates, 2016).

La técnica utilizada fue el muestreo estratificado, en cual las muestras probabilísticas se distinguen porque la población original se divide en subconjuntos mutuamente excluyentes y se eligen muestras representativas obtenidas de manera aleatoria simple de elementos de dichos subconjuntos. (McDaniel \& Gates, 2016).

La muestra tomada no fue probabilística, ya que por motivo de tiempo y recursos no se pudo cumplir con todos los requerimientos necesarios para que se defina como probabilística. Sin embargo por motivos académicos se decidió asumir la muestra como probabilística.

\section{Población}

Para el estudio de mercado se ha considerado como población a los habitantes de los distritos de Jesús María, La Molina, Lince, Magdalena, Pueblo Libre, Miraflores de los estratos económicos alto y medio alto. Se consideró como población a los habitantes de los distritos seleccionados cuyas edades se encuentra entre 18 y 49 años. En la tabla 16 se puede observar la población y la cantidad de muestras a considerar por cada distrito. 
Tabla 16

Población entre 18 y 49 años por distrito

\begin{tabular}{lccccc}
\hline Población & $\begin{array}{c}\% \text { de } \\
\text { Proyectada } \\
\text { por Distrito } \\
\text { 2016 (18 a 49 } \\
\text { años) }\end{array}$ & $\begin{array}{c}\text { Población } \\
\text { Estrato de } \\
\text { Ingresos Alto } \\
\text { y Medio Alto }\end{array}$ & $\begin{array}{c}\text { Población } \\
18 \text { a 49 años } \\
\text { Ingresos alto y } \\
\text { medio alto }\end{array}$ & Proporción & $\begin{array}{c}\text { Muestra por } \\
\text { distrito }\end{array}$ \\
\hline Jesús María & 32,964 & $100 \%$ & 32,964 & $7 \%$ & \\
La Molina & 85,238 & $92 \%$ & 78,419 & $16 \%$ & 26 \\
Lince & 22,789 & $87 \%$ & 19,826 & $4 \%$ & 61 \\
Magdalena & 25,295 & $93 \%$ & 23,524 & $5 \%$ & 15 \\
Pueblo Libre & 34,418 & $96 \%$ & 33,041 & $7 \%$ & 26 \\
Miraflores & 37,217 & $100 \%$ & 37,217 & $8 \%$ & 29 \\
San Borja & 52,041 & $98 \%$ & 51,000 & $10 \%$ & 39 \\
San Isidro & 23,275 & $100 \%$ & 23,275 & $5 \%$ & 18 \\
San Miguel & 65,069 & $87 \%$ & 56,610 & $11 \%$ & 44 \\
Surco & 170,856 & $82 \%$ & 140,102 & $28 \%$ & 108 \\
\hline Total & 549,161 & $90 \%$ & 495,978 & $100 \%$ & 384 \\
\hline
\end{tabular}

Nota. Elaborado tomando como fuente Población total al 30 de junio, por grupos quinquenales de edad, según departamento, provincia y distrito, por Instituto Nacional de Estadística e Informática, 2015, Perú, Lima. Copyright 2015 por INEI y Planos Estratificados de Lima Metropolitana a Nivel de Manzana 2016 (INEI, 2016b)

\section{Muestra}

Para calcular el tamaño de la muestra se consideró los siguientes datos:

- $\quad \mathrm{N}=$ Tamaño de la población: 549,161 personas

- $Z=$ Nivel de confianza: $95 \%$

- $\mathrm{P}=$ Probabilidad de éxito: $50 \%$

- $\mathrm{Q}=$ Probabilidad de fracaso: $50 \%$

- $\mathrm{D}=$ Error aceptable: $5 \%$

En base a la fórmula para determinar el tamaño de la encuesta se obtiene que el número de encuestas debe ser de 384 personas. 


$$
n=\frac{N \times Z_{a}{ }^{2} \times p \times q}{d^{2} \times(N-1)+Z_{a}{ }^{2} \times p \times}=384
$$

\section{Selección de la muestra}

La técnica de muestreo probabilístico utilizada fue el muestreo estratificado como se mencionó anteriormente. En primer lugar, se determinó el número de personas a encuestar por distrito. Luego, ubicó en el mapa de cada distrito (ver Apéndice 10) las manzanas que cumplían con los criterios de segmentación, es decir cuyos habitantes pertenecieran a los niveles socioeconómicos alto y medio alto, seleccionándose de algunas de estas viviendas.

\subsubsection{Diseño del instrumento.}

El instrumento utilizado fue el cuestionario, el cual tiene 14 preguntas, las cuales debían ser respondidas por cada uno de los encuestados de la población seleccionada. Las preguntas son cerradas, politómicas y con escala de Likert. (ver Apéndice 9)

Para la prueba piloto o pretest se encuestó a 20 personas que estaban dentro del público objetivo. La finalidad de este pretest era enfrentar el cuestionario con un grupo de personas que calificaban como posibles entrevistados para detectar errores (Fernandez Nogales, 1999) y poder evitar ambigüedad o confusión con la forma en cómo se plantearon las preguntas.

En base al resultado y sugerencias que se recibieron de la prueba piloto se procedió a modificar el cuestionario que se aplicó a la muestra. 


\section{Trabajo de Campo}

Se utilizó como instrumento de recolección de datos, un cuestionario (ver Apéndice 9) diseñado para ser aplicado en entrevistas cara a cara por el encuestador al encuestado. Se eligieron al azar las manzanas de los distritos de Jesús María, La Molina, Lince, Magdalena, Pueblo Libre, Miraflores, San Borja, San Isidro, San Miguel y Surco en las que se aplicaría la encuesta. Se utilizaron los planos a nivel manzana obtenidos del INEI (ver Apéndice 10).

Se les indicó a los encuestadores el número de encuestas que debían obtener de cada distrito. El equipo de encuestadores estuvo conformado por 4 personas, las cuales fue capacitadas durante una reunión en cuanto a los objetivos del estudio y la manera como llevar a cabo las encuestas. Durante la capacitación, se practicó con los encuestadores simulando encuestas entre ellos.

El cuestionario fue aplicado durante el mes de julio de 2019. Durante el primer día de trabajo de campo los encuestadores fueron supervisados in locus.

\subsubsection{Análisis y procesamiento de datos.}

Para esta parte del estudio se utilizó el procedimiento que señalan Mc Daniel y Gates (2016):

- Validación y edición. Se confirmó que los encuestados hubieran sido aplicados según lo especificado, de manera presencial y en su totalidad. Se revisaron las encuestas para ver que se hubieran respetado los patrones de saltos.

- Proceso de codificación. Se consolidaron preguntas abiertas.

- Entrada de datos. Los cuestionarios validados, editados y codificados se ingresaron al Excel. 
- Depuración de datos. Se revisó la base de datos en busca de posibles incongruencias.

- Tabulación y análisis estadístico. Se trabajó en con la base datos, se cruzó información y se elaboraron cuadros.

A continuación, se analizaron los datos obtenidos de la encuesta:

Para conocer sobre el mercado actual, se realizó la pregunta 4 de la encuesta, la cual estaba diseñada para saber cuáles son los institutos o escuelas que la gente conoce o recuerda. Como resultado se obtuvo que el 36\% conocía la escuela Mott, el 19\% a Pandemia y el $7 \%$ a Negzy. Hubo un $28 \%$ que no conocía ninguna escuela de marketing digital. Los resultados de esta pregunta se muestran en la tabla 17.

Tabla 17

Conocimiento de escuelas o institutos de marketing digital

\begin{tabular}{lc}
\hline Respuestas & Porcentaje \\
\hline Mott & $36 \%$ \\
Pandemia & $19 \%$ \\
Negzy & $7 \%$ \\
Otras & $10 \%$ \\
Ninguna & $28 \%$ \\
\hline Total & $100 \%$ \\
\hline
\end{tabular}

En la pregunta 5 se consultó por los factores o atributos que consideraban los encuestados como los más importantes al momento de elegir una escuela. Se determinó que los atributos más valorados son el prestigio de la institución, así como el prestigio de los docentes que laboran en ella. El 10\% de los encuestados consideraron al precio como el atributo más importante, tal como se puede observar en la tabla 18. 
Tabla 18

Atributos más valorados

\begin{tabular}{lc}
\hline Respuestas & Porcentaje \\
\hline Prestigio de la institución & $58 \%$ \\
Prestigio de los profesores & $21 \%$ \\
Precio de los cursos & $10 \%$ \\
Ubicación & $5 \%$ \\
Horarios de estudio & $5 \%$ \\
\hline Total & $100 \%$ \\
\hline
\end{tabular}

A través de la pregunta 6, se determinó que, del total de la muestra, el 79\% suele tomar cursos de capacitación, mientras que el $21 \%$ nunca lo hace (ver tabla 19).

Tabla 19

Consumo del producto

\begin{tabular}{lc}
\hline Respuestas & Porcentaje \\
\hline Una vez & $50 \%$ \\
Dos veces & $21 \%$ \\
Tres o más veces & $8 \%$ \\
Nunca & $21 \%$ \\
\hline Total & $100 \%$ \\
\hline
\end{tabular}

Para cuantificar la demanda de manera más precisa, se les preguntó a aquellos que tomaban cursos de capacitación, cuántos cursos no gratuitos relacionados con el marketing digital tomaban al año, en total el 64\% de los encuestados los tomaba. La gran mayoría, el $46 \%$, toma cursos una vez al año. El $8 \%$ lo hace 2 veces al año y el $8 \%$ se capacita tres veces al año. Aquellos que se capacitan cuatro o cinco veces al año alcanzan un $2 \%$. En la tabla 20 se puede observar la frecuencia de compra de estos cursos. 
Tabla 20

Frecuencia de compra

\begin{tabular}{lc}
\hline Respuestas & Porcentaje \\
\hline 1 vez & $46 \%$ \\
2 veces & $8 \%$ \\
3 veces & $8 \%$ \\
4 veces & $1 \%$ \\
5 veces & $1 \%$ \\
Nunca & $36 \%$ \\
\hline Total & $100 \%$ \\
\hline
\end{tabular}

En la pregunta 7 (ver tabla 21) se consultó si estarían dispuestos a tomar un curso en este proyecto de escuela. Se les mencionaron brevemente las características de la escuela y a través de una escala de Likert se determinó el mercado efectivo para producto. El resultado fue que un $78 \%$ probablemente sí se matricularía en un curso en la Escuela.

Tabla 21

Intención de compra

\begin{tabular}{lc}
\hline Respuestas & Porcentaje \\
\hline Definitivamente sí & $19 \%$ \\
Probablemente sí & $59 \%$ \\
Indeciso & $14 \%$ \\
Probablemente no & $7 \%$ \\
Definitivamente no & $1 \%$ \\
\hline Total & $100 \%$ \\
\hline
\end{tabular}

Para determinar la demanda de cada uno de los productos que se ofrecería en la Escuela se hizo la pregunta 7b (en cuál de las modalidades se matricularía). Se determinó que los cursos con mayor demanda eran los regulares y los individuales con $46 \%$ y $41 \%$ respectivamente, como se puede observar en la tabla 22. 
Tabla 22

Modalidades de estudio preferidas

\begin{tabular}{lc}
\hline Respuestas & Porcentaje \\
\hline Regular & $46 \%$ \\
Individual & $41 \%$ \\
Blended & $14 \%$ \\
\hline Total & $100 \%$ \\
\hline
\end{tabular}

Se consultó también por los precios que estarían dispuestos a pagar los encuestados por un curso en la modalidad elegida. El 36\% eligió precios entre S/. 200 y S/. 300. El 26\% prefirió precios entre S/. 301 y S/. 400. El 13\% pagaría entre S/. 401 y S/.500. En la tabla 23 se muestra la distribución de los rangos de precios preferidos por cada tipo de modalidad.

Tabla 23

Rango de precios

\begin{tabular}{lcccc}
\hline Respuestas & Blended & Individual & Regular & Total por precio \\
\hline Menos de S/. 200 & $15 \%$ & $7 \%$ & $10 \%$ & $10 \%$ \\
Entre S/. 200 y S/. 300 & $37 \%$ & $32 \%$ & $38 \%$ & $36 \%$ \\
Entre S/. 301 y S/. 400 & $28 \%$ & $25 \%$ & $27 \%$ & $26 \%$ \\
Entre S/. 401 y S/ 500 & $11 \%$ & $19 \%$ & $9 \%$ & $13 \%$ \\
Entre S/. 501 y S/.600 & $7 \%$ & $11 \%$ & $11 \%$ & $10 \%$ \\
De S/.601 a más & $2 \%$ & $6 \%$ & $6 \%$ & $5 \%$ \\
\hline Total por modalidad & $100 \%$ & $100 \%$ & $100 \%$ & $100 \%$ \\
\hline
\end{tabular}

Sobre los hábitos de estudio, se determinó que la mayoría prefiere tomar cursos por las noches de lunes a viernes, seguidamente están aquellos que prefieren estudiar los sábados y en tercer lugar, aquello que buscan estudiar los días domingo, los resultados de esta pregunta se pueden visualizar en la tabla 24 . 
Tabla 24

Horario de estudio

\begin{tabular}{lc}
\hline Respuestas & Porcentaje \\
\hline L-V Noches & $40 \%$ \\
Sábados & $32 \%$ \\
Domingos & $12 \%$ \\
L-V Mañanas & $11 \%$ \\
L-V Tardes & $5 \%$ \\
\hline Total & $100 \%$ \\
\hline
\end{tabular}

En cuanto a la ubicación de la Escuela, la mayoría de los encuestados (el 33\%), indicó que ésta debería estar localizada en el distrito de Miraflores (ver tabla 25).

Tabla 25

Ubicación del local

\begin{tabular}{lc}
\hline Respuestas & Porcentaje \\
\hline Miraflores & $33 \%$ \\
Surco & $27 \%$ \\
San Isidro & $20 \%$ \\
Lince & $9 \%$ \\
La Molina & $2 \%$ \\
San Borja & $1 \%$ \\
San Miguel & $1 \%$ \\
Magdalena del Mar & $1 \%$ \\
Otros & $4 \%$ \\
\hline Total & $100 \%$ \\
\hline
\end{tabular}

Con referencia a los atributos de los profesores, la mayoría, es decir el $41 \%$, considera que éstos deberían tener amplia experiencia en el área marketing. En la tabla 26 se observa el orden de estos atributos siguiendo en preferencia, la experiencia en la docencia y reconocimiento en el medio. 
Tabla 26

Atributos más valorados en los profesores

\begin{tabular}{lc}
\hline Respuestas & Porcentaje \\
\hline Amplia experiencia en el área de marketing & $41 \%$ \\
Experiencia en la docencia & $24 \%$ \\
Reconocidos en el medio & $23 \%$ \\
Graduados de instituciones de prestigio & $11 \%$ \\
Otros & $1 \%$ \\
\hline Total & $100 \%$ \\
\hline
\end{tabular}

En cuanto a los cursos, los más votados fueron Publicidad Digital, Social Media, Diseño de Contenidos, Analítica Web, SEO y SEM y Adwords (ver tabla 27).

Tabla 27

Cursos preferidos

\begin{tabular}{lc}
\hline Respuestas & Porcentaje \\
\hline Publicidad Digital & $22 \%$ \\
Social Media & $17 \%$ \\
Diseño de contenidos & $17 \%$ \\
Analítica web & $16 \%$ \\
SEO y SEM & $15 \%$ \\
Adwords & $12 \%$ \\
Otros & $1 \%$ \\
\hline Total & $100 \%$ \\
\hline
\end{tabular}

Sobre los medios preferidos para que la Escuela realice publicidad, en primer lugar, se encuentran las redes sociales con $45 \%$, seguido de Adwords con $21 \%$ y el Mailing con 17\%. La lista completa de estos medios se observa en la tabla 28 
Tabla 28

Medios para anunciar

\begin{tabular}{lc}
\hline Respuestas & Porcentaje \\
\hline Redes Sociales & $45 \%$ \\
Adwords & $21 \%$ \\
Mailing & $17 \%$ \\
Revistas o diarios & $10 \%$ \\
Radio & $6 \%$ \\
Otros & $1 \%$ \\
\hline Total & $100 \%$ \\
\hline
\end{tabular}

\subsection{Conclusiones y recomendaciones del Estudio Cualitativo y Cuantitativo}

Luego de aplicadas cada una de las técnicas de investigación. Se pudo obtener las siguientes conclusiones:

- Existe demanda para una escuela de marketing digital en Lima, se ha confirmado a través de la encuesta que hay muchas personas interesadas en tomar cursos cortos de marketing digital tanto de forma grupal como individual.

- Los cursos blended no tienen la misma aceptación que aquellos cursos dictados íntegramente de manera presencial. Existe la idea que los cursos online los pueden encontrar gratuitamente en la web según manifestaron los participantes de los focus group.

- El atributo más valorado es el prestigio, tanto de la institución como de los docentes. Por esta razón se debería optar por contratar personal altamente calificado y con experiencia.

- Los horarios preferidos para estudiar son por las noches, dos o tres veces por semana y en segundo lugar los sábados. Se encontró que también hay personas 
que desean cursos los domingos. Si se optara por ofrecer cursos los domingos, habría que considerar un mayor costo de personal, debido a que se tendría que contratar personal administrativo que cubra el día de descanso. Así como también habría que ofrecer una tarifa más alta a los docentes para motivarlos a dictar clases en domingo.

- La mayoría está dispuesta a pagar precios entre S/.200 y S/. 300. Sólo el 28\% de los encuestados está dispuesto a pagar más de S/.400 por un curso.

- La ubicación que preferirían sería el distrito de Miraflores.

- La forma preferida para recibir publicidad o anuncios sobre la Escuela es a través de las redes sociales.

\subsection{Perfil del consumidor tipo y sus variantes}

El consumidor es en general una persona joven, hombre o mujer, que ha estudiado o estudia una carrera afín al marketing o que trabaja en esta área. Con deseos de aprender más sobre marketing digital a través de cursos específicos que puedan completarse en corto tiempo.

El consumidor tipo realiza diferentes actividades, por lo cual generalmente tiene tiempo para estudiar un curso corto por las noches o los sábados, cuando no está trabajando o estudiando en la universidad.

El consumidor tipo considera el prestigio de la institución un atributo que influye en la toma de decisión al momento de contratar el servicio. 


\section{Capítulo IV: Proyección de la demanda}

El presente capítulo muestra la proyección del mercado para el plan de negocios. Se elaboró esta proyección basada en la información del INEI así como con la información obtenida de la encuesta realizada y explicada en el capítulo anterior.

\subsection{El ámbito de la proyección}

Para determinar la proyección estadísticamente válida para el estudio del presente proyecto, se utilizó la información histórica sobre la población de 18 a 49 años edad de los distritos de Jesús María, La Molina, Lince, Magdalena, Pueblo Libre, Miraflores, San Borja, San Isidro, San Miguel y Surco, tomándose como base la información elaborada por el Ministerio de Salud (MINSA, 2015) basada en los resultados obtenidos del estudio del INEI: Perú: Población total al 30 de junio, por grupos Quinquenales de Edad, según Departamento, provincia y distrito, 2015. (INEI, 2015). Se consideró la información del MINSA ya que la información del INEI presentaba la población entre 15 a 19 años de forma unificada mientras en el MINSA estaba información estaba desglosada, lo que nos permitía eliminar el segmento de 15 a 17 años.

\subsection{Selección del método de proyección}

El método utilizado para la proyección fue el de regresión lineal, con este se proyectó la población de los distritos seleccionados en base a una tendencia lineal la cual se obtuvo en base a datos históricos. Para efectos de la proyección se utilizó datos históricos de la población desde el año 2005 hasta el 2015.

En la tabla 29 se muestra el cálculo de la tasa de crecimiento promedio: 
Tabla 29

Tasa de crecimiento poblacional

\begin{tabular}{lcccc}
\hline Distritos & $\begin{array}{c}\text { Población } \\
\text { al 2005 }\end{array}$ & $\begin{array}{c}\text { Población al } \\
2015\end{array}$ & $\begin{array}{c}\text { Tasa de } \\
\text { crecimiento } \\
(2005-2015)\end{array}$ & $\begin{array}{c}\text { Tasa de } \\
\text { crecimiento } \\
\text { promedio } \\
(2005-2015)\end{array}$ \\
\hline Jesús María & 37,591 & 33,341 & $-11.31 \%$ & $-1.13 \%$ \\
La Molina & 75,925 & 84,307 & $11.04 \%$ & $1.10 \%$ \\
Lince & 39,581 & 23,739 & $-40.02 \%$ & $-4.00 \%$ \\
Magdalena & 30,082 & 25,671 & $-14.66 \%$ & $-1.47 \%$ \\
Pueblo Libre & 44,301 & 35,144 & $-20.67 \%$ & $-2.07 \%$ \\
Miraflores & 52,579 & 38,259 & $-27.24 \%$ & $-2.72 \%$ \\
San Borja & 70,913 & 53,362 & $-24.75 \%$ & $-2.48 \%$ \\
San Isidro & 39,284 & 24,204 & $-38.39 \%$ & $-3.84 \%$ \\
San Miguel & 71,607 & 65,618 & $-8.36 \%$ & $-0.84 \%$ \\
Surco & 140,338 & 167,600 & $19.43 \%$ & $1.94 \%$ \\
\hline Total & 602,201 & 551,245 & $-8.46 \%$ & $-0.85 \%$ \\
\hline
\end{tabular}

Una vez calculada la tasa se realizó la proyección para los siguientes años. En la tabla 30 se observa la proyección del 2016 al 2021.

Tabla 30

Población proyectada

\begin{tabular}{lccccccc}
\hline Distritos & $\begin{array}{c}\text { Población al } \\
2015\end{array}$ & $\begin{array}{c}\text { Población al } \\
2016\end{array}$ & $\begin{array}{c}\text { Población } \\
\text { al } 2017\end{array}$ & $\begin{array}{c}\text { Población al } \\
2018\end{array}$ & $\begin{array}{c}\text { Población al } \\
2019\end{array}$ & $\begin{array}{c}\text { Población al } \\
2020\end{array}$ & $\begin{array}{c}\text { Población al } \\
\text { Jesús María }\end{array}$ \\
33,341 & 32,964 & 32,591 & 32,223 & 31,859 & 31,498 & 31,142 \\
La Molina & 84,307 & 85,238 & 86,179 & 87,130 & 88,092 & 89,065 & 90,048 \\
Lince & 23,739 & 22,789 & 21,877 & 21,001 & 20,161 & 19,354 & 18,579 \\
Magdalena & 25,671 & 25,295 & 24,924 & 24,558 & 24,198 & 23,843 & 23,494 \\
Pueblo Libre & 35,144 & 34,418 & 33,706 & 33,009 & 32,327 & 31,659 & 31,005 \\
Miraflores & 38,259 & 37,217 & 36,203 & 35,217 & 34,258 & 33,325 & 32,418 \\
San Borja & 53,362 & 52,041 & 50,753 & 49,497 & 48,272 & 47,077 & 45,912 \\
San Isidro & 24,204 & 23,275 & 22,381 & 21,522 & 20,696 & 19,902 & 19,138 \\
San Miguel & 65,618 & 65,069 & 64,525 & 63,985 & 63,450 & 62,919 & 62,393 \\
Surco & 167,600 & 170,856 & 174,175 & 177,558 & 181,008 & 184,524 & 188,108 \\
\hline Total & 551,245 & 549,161 & 547,315 & 545,702 & 544,321 & 543,166 & 542,236 \\
\hline
\end{tabular}


Para los siguientes cálculos se aplicará el 90\%, el cual es el porcentaje de la población de estos distritos que pertenece a los estratos alto y medio alto (ver tabla 16).

\subsubsection{Mercado Potencial.}

Según Kotler y Armstrong (2012) el mercado potencial es el conjunto de posibles consumidores que tienen un interés suficientemente elevado por el producto o servicio. El mercado potencial se basa solo en el interés por lo que incluye público que a pesar de que quiere el producto no tiene los ingresos suficientes para comprarlo o las facilidades para adquirirlo.

Para hallar el mercado potencial se consideró a todos aquellos que contestaron en la encuesta que sí toman cursos de capacitación (pregunta 6 del cuestionario) es decir el 79\% de la muestra. El resultado del cálculo es el que se muestra en la tabla 31.

Tabla 31

Mercado potencial

\begin{tabular}{lrrr}
\hline Año & 2019 & 2020 & 2021 \\
\hline Población & 489,889 & 488,850 & 488,013 \\
Mercado potencial & 387,012 & 386,191 & 385,530 \\
\hline
\end{tabular}

\subsubsection{Mercado Disponible.}

De acuerdo con Kotler y Armstrong (2012) el mercado disponible está formado por el conjunto de posibles consumidores que aparte del interés tienen los ingresos y las facilidades de acceso para adquirir el producto.

Para determinar el mercado disponible se consideró a aquellos que contestaron que tomaban cursos de capacitación relacionados al marketing digital no gratuitos más de una vez al año, los cuales sumaban el 64\% de los encuestados (ver figura 10). 
Ante la ausencia de un marco muestral y solo con fines académicos se decidió asumir la muestra no probabilística como si fuera probabilística.

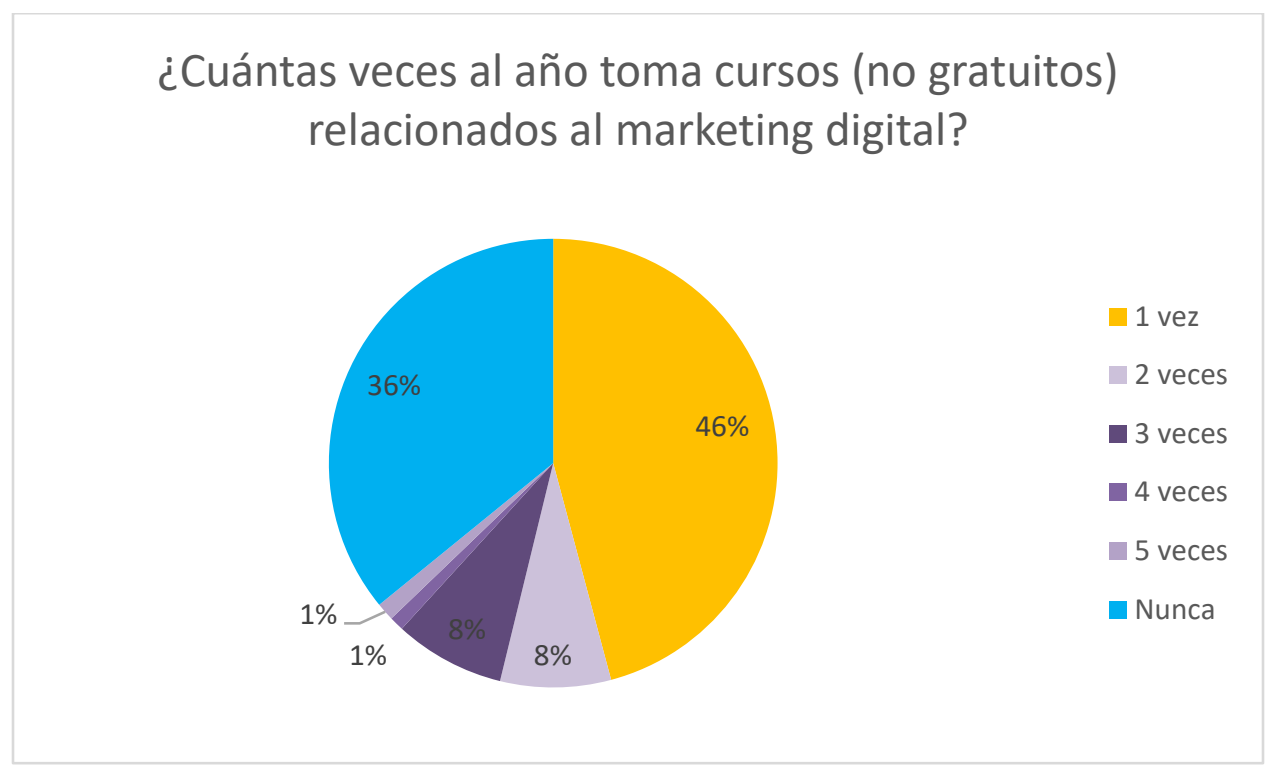

Figura 10. Mercado disponible

El resultado del cálculo del mercado disponible se muestra en la tabla 32.

Tabla 32

Mercado disponible

\begin{tabular}{lccc}
\hline Año & 2019 & 2020 & 2021 \\
\hline Mercado Potencial & 387,012 & 386,191 & 385,530 \\
Mercado disponible & 247,688 & 247,162 & 246,739 \\
\hline
\end{tabular}




\subsubsection{Mercado Efectivo.}

Es una parte del mercado disponible y lo forma el conjunto de consumidores que tiene la intención de comprar el bien o servicio que ofrece la nueva empresa. Se considera a los posibles consumidores que están muy interesados en la oferta que ofrece el nuevo negocio.

Para el mercado efectivo se han considerado a aquellas personas del mercado disponible que contestaron que "Definitivamente sí" y "Probablemente sí" se matricularían para tomar un curso en la Escuela del presente proyecto. Cabe mencionar que previamente se le aplicó el factor de McDaniel (McDaniel \& Gates, 2016) a las respuestas obtenidas, tal cual se explicó en el capítulo 3, dando como resultado que sólo el 34\% se matricularía en la escuela, como se puede ver en la tabla 33.

Tabla 33

Cálculo del índice de McDaniel

\begin{tabular}{lcr}
\hline Respuestas & Cantidad & Porcentaje \\
\hline Definitivamente sí & 49 & $13 \%$ \\
Probablemente sí & 77 & $21 \%$ \\
\hline Total & 126 & $34 \%$ \\
\hline
\end{tabular}

De este porcentaje, se trabajará solamente con aquellos que eligieron cursos en las modalidades Regular e Individual que fueron aquellas con mayor aceptación, las prefirieron el $46 \%$ y $41 \%$ de los encuestados respectivamente (ver tabla 22); es decir, el $87 \%$.

Por otro lado, dado que el servicio ofrecido será un servicio de calidad, dictado en un ambiente agradable, por profesionales con experiencia y basado en la personalización, es decir un servicio que se adapte a las necesidades de los alumnos, que tenga en cuenta lo que ellos esperan del curso, el precio será en un inicio S/. 450 para los cursos regulares. Por lo 
cual se tomó el porcentaje de la población que está dispuesta a pagar a partir del rango de S/. 401 a S/.500, esto equivale al 25\%. En la tabla 34 se muestra el mercado efectivo del 2019 al 2021.

Tabla 34

Mercado efectivo

\begin{tabular}{lccc}
\hline Año & 2019 & 2020 & 2021 \\
\hline Mercado efectivo & 84,214 & 84,035 & 83,891 \\
\hline
\end{tabular}

\subsubsection{Mercado Objetivo.}

Según Stanton, Etzel y Walker (2007), existen cuatro normas que rigen la manera de determinar si debe elegirse un segmento como mercado meta:

- El mercado meta debe ser compatible con los objetivos y la imagen de la organización.

- Debe haber concordancia entre la oportunidad de mercado que presenta el mercado meta y los recursos de la organización.

- Se debe elegir segmentos de mercado que generen un volumen de ventas suficiente y a un costo lo bastante bajo como para generar ingresos que justifiquen la inversión requerida. Es decir, que sea rentable.

- Se debe buscar segmentos de mercado en el que los competidores sean pocos o débiles.

Tomando en cuenta estas normas, para el primer año se ha proyectado alcanzar una cifra conservadora del 5\% del mercado efectivo. 
En primer lugar, por la imagen que proyectará la escuela. Esta ofrecerá cursos personalizados, individuales y grupales, que se adapten en lo posible a las necesidades y expectativas de los alumnos. En segundo lugar, se ha tenido en cuenta la disponibilidad de fondos de los accionistas para invertir en el negocio y su capacidad de endeudamiento en el sistema financiero. En tercer lugar, con el porcentaje de mercado señalado se logra la rentabilidad del negocio. Finalmente, se está teniendo en cuenta que hay otros competidores que también buscarán entrar al mercado en los próximos años.

Posteriormente, gracias a las campañas de marketing y a la publicidad boca a boca que puedan realizar los egresados y que algunos de ellos podrían continuar tomando cursos, se espera alcanzar el $10 \%$ del mercado efectivo al segundo año y $13 \%$ al tercero. En la tabla 35 se muestra el tamaño del mercado efectivo del 2019 al 2021.

Tabla 35

Mercado objetivo

\begin{tabular}{lccc}
\hline Año & 2019 & 2020 & 2021 \\
\hline$\%$ del Mercado Efectivo & $5 \%$ & $10 \%$ & $13 \%$ \\
Mercado Objetivo & 4,211 & 4,202 & 4,195 \\
\hline
\end{tabular}




\section{Capítulo V: Plan de Marketing}

El plan de marketing tiene como finalidad llevar a la organización a alcanzar sus objetivos de manera rentable a través de la mezcla de marketing, la cual originalmente se conoce como las 4 P: precio, producto, plaza y promoción. Para ser exitoso, según Kotler (2012) el plan de marketing debe enfocarse en el cliente, estudiando sus necesidades y ofreciéndole un valor mayor que el que le ofrecen los competidores.

Fueron Lovelock, Huete y Reynoso (2010), quienes orientaron la mezcla de marketing original al sector servicios, añadiendo otros tres factores a tener cuenta: personas, procesos y presencia física, lo cual dio como resultado las $7 \mathrm{P}$.

\subsection{Estrategias de marketing}

Como estrategia básica de marketing el proyecto considerará la diferenciación, la cual es consistente con la estrategia de negocio señalada en el capítulo VIII. En cuanto a la estrategia de crecimiento de negocio, basándonos en la Matriz de Ansoff (1976), la estrategia a seguir será la de penetración de mercado.

\subsubsection{Estrategia de Producto.}

Según Kotler y Armstrong (2012), el producto es una parte esencial de la mezcla de marketing y todo plan debería iniciar con una oferta de valor al mercado meta. En el presente trabajo, el producto o, mejor dicho, servicio ofrecido, es la enseñanza de marketing digital mediante de cursos cortos ofrecidos en distintas modalidades a través de una Escuela de Marketing Digital. 
De acuerdo con los mismos autores, existen cuatro aspectos a considerar cuando se crea una estrategia de marketing para un servicio:

- Intangibilidad: Se debe encontrar la manera de hacer tangible el servicio y de dar señales de la calidad de este.

- Inseparabilidad: El servicio no puede separarse de quien lo provee, en este caso, al tratarse de un servicio educativo, los profesores como proveedores, así como los alumnos, no pueden separarse del servicio. Esta interacción es una característica de los servicios.

- Variabilidad: Se refiere a la variación que puede haber en la calidad de servicio dependiendo de la persona que lo preste. Es decir, cada profesor, por ejemplo, podría tener una manera distinta de dictar la misma clase.

- Caducidad: Dado que no es posible almacenar los servicios, puede haber fluctuaciones en la demanda. Por ejemplo, en el caso, de una escuela, puede haber horarios con mayor demanda que otros. Así también la caducidad se refiere al horario, si un cliente tiene un curso programado a determinada hora y llega más tarde, habrá perdido la clase por no estar presente durante el horario de dictado establecido.

La estrategia de servicio que se aplicará será la diferenciación. Se ofrecerá más por lo mismo, es decir un servicio con características innovadores a un precio similar al de la competencia:

- Clases dictadas por profesores con amplia experiencia en el área de marketing.

- Los profesores estarán capacitados para enseñar a través de talleres de metodología. 
- El ambiente de las clases presenciales estará acondicionado especialmente, contará con equipos modernos y en perfectas condiciones. Se contará con internet de la más alta velocidad disponible.

- Los alumnos podrán matricularse presencialmente o vía online.

\section{Marca y Logo}

Para la Escuela de Marketing Digital se ha considerado la Marca: Mossaiqo. El término Mosaico se refiere a una obra elaborada por pequeñas piezas de cerámica u otros materiales que forman composiciones. En el caso de la Escuela los cursos están formados por temas que están estructurados en módulos. Todos los temas en conjunto forman un curso y una persona que lleve varios cursos estaría preparado para desempeñarse como un experto en marketing digital. En base a este concepto modular se escogió el nombre de la empresa.

Se buscó la palabra mosaico en Godaddy (2018) para ver si el dominio estaba disponible. Al ser un término común se observó que el dominio ya estaba tomado. Por lo que se escogió un nombre que sonara como la palabra original pero se escribiera de otra forma (ver figura 11). De ahí surgió Mossaiqo.

mosaico

¡Lo sentimos! mosaico.com está tomado.

\section{Buscar nuevamente}

Continuar al carrito

\section{¡Si! El dominio está disponible.}

\section{mossaiqo.com}

s/.54.99: S/. 3.9.*

\section{Agregar al carrito}

Figura 11. Nombre seleccionado

Para el logo de la empresa se solicitó a un diseñador que creara un logo el cual se puede ver en la figura 12 . 


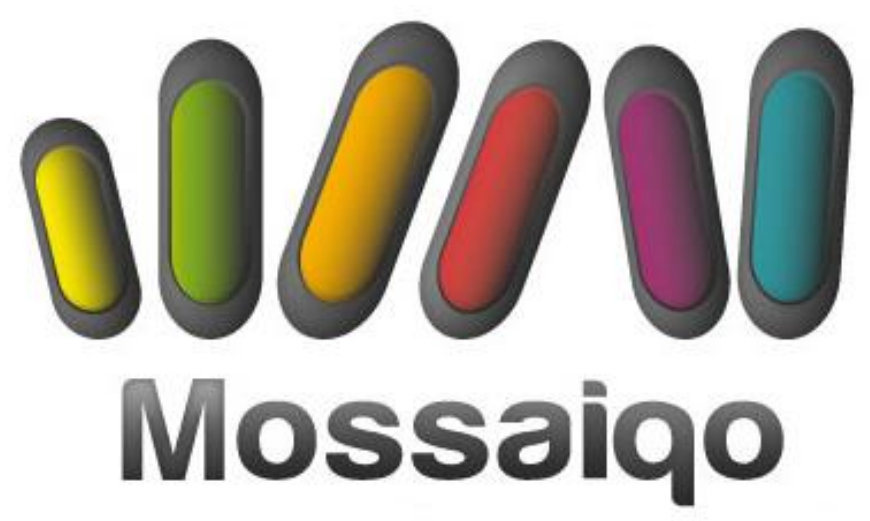

Figura 12. Logo de la empresa

\subsubsection{Estrategia de Precio.}

Los autores Kotler y Armstrong (2012) afirman que el precio, es uno de los factores que más influye en la decisión de compra. De igual modo, el precio puede determinar la participación de mercado y la rentabilidad de un negocio.

Los factores que limitan el precio son la demanda y los costos. Los factores de la demanda, como la fijación de precios basados en el valor, establecen el precio máximo; mientras que los costos de la compañía establecen el precio mínimo.

En el caso de la fijación de precios basados en el valor, la empresa establece las necesidades y la percepción de valor que tienen los clientes del valor del servicio. Para el caso de la Escuela de Marketing Digital, se adoptará la fijación de precios por valor agregado, lo cual significará brindar un servicio diferenciado a los clientes, de manera que el precio se vea justificado y los clientes motivados por lo que reciben al pagar.

\section{Determinación de los precios}

Para determinar los precios se realizó primero un análisis de los precios de los competidores. Los precios variaban por tipo de cursos y la cantidad de horas dictadas. Analizando el precio por hora se tiene que varían desde S/13.89 soles por hora en algunos 
talleres de Pandemia hasta S/46.20 por hora en cursos de MOTT que es el competidor más reconocido en el mercado. En la tabla 36 se muestra un comparativo de precios por hora de los principales competidores.

Tabla 36

Comparación precios de la competencia

\begin{tabular}{lcrrll}
\hline Competidor & Precio por Curso & Nro. Horas & Precio/ Hora & Tipo de Curso \\
\hline Pandemia & S/ 490.00 & 20 & S/ & 24.50 & Curso \\
\hline Pandemia & S/ 990.00 & 40 & S/ & 24.75 & Curso \\
\hline Pandemia & S/ 250.00 & 18 & S/ & 13.89 & Taller \\
\hline Negzy & S/ 900.00 & 30 & S/ & 30.00 & Curso \\
\hline Mott & S/ 693.00 & 15 & S/ & 46.20 & Curso \\
\hline
\end{tabular}

En base a la definición del mercado objetivo, la Escuela de Marketing Digital tendrá como objetivo el público interesado en llevar los cursos que esté dispuesto a pagar más de S/450 soles. Se ha establecido una tabla de precios por horarios (ver tabla 37).

Tabla 37

Precios por horarios

\begin{tabular}{lcc}
\hline Horario & Horas por curso & Precio \\
\hline Martes y Jueves de 7 a $10 \mathrm{pm}$ & 18 & $\mathrm{~S} / 450.00$ \\
\hline Lunes y Miércoles de 7 a 10pm & 18 & $\mathrm{~S} / 450.00$ \\
\hline Sábados de 9 am a 1:30 pm & 18 & $\mathrm{~S} / 450.00$ \\
\hline Sábados 2 a 6:30 pm & 18 & $\mathrm{~S} / 450.00$ \\
\hline Lunes y Miércoles de 9 am a 12 pm & 18 & $\mathrm{~S} / 450.00$ \\
\hline Martes y Jueves de 9 am a 12 pm & 18 & $\mathrm{~S} / 450.00$ \\
\hline
\end{tabular}

\section{Cursos Personalizados}

Uno de los diferenciadores de la Escuela son los cursos personalizados que se pueden dictar a una sola persona. Estos cursos se adaptan a las necesidades del cliente por lo que el contenido es flexible. El precio de un curso personalizado seria de S/650 soles. 


\subsubsection{Estrategia de Plaza y Distribución.}

La estrategia de plaza y distribución consiste en determinar los canales de distribución para el servicio. Usualmente se trata de negocios con los que se forman alianzas a largo plazo con otros negocios que actúan como intermediarios entre el productor o fabricante y el cliente.

La estrategia de distribución que se utilizará en la Escuela de Marketing Digital será directa, es decir, no habrá intermediarios. La venta se hará a través de la fuerza de venta de la empresa quienes tendrán como función: dar información a clientes potenciales sobre los servicios que ofrece la Escuela, promocionar los cursos a través de correos electrónicos y llamadas telefónicas y concretar las ventas, matriculando a los alumnos en los cursos que se ofrecerán.

\subsubsection{Estrategia de Promoción y Publicidad.}

La estrategia de promoción tendrá tres etapas: a) Una campaña de pre lanzamiento b) Una campaña de lanzamiento que se ejecutará el primer mes de funcionamiento y c) una campaña permanente.

\section{Campaña Pre lanzamiento}

Antes del lanzamiento de los cursos se publicará la página web de la empresa y se creará perfiles en las principales redes sociales: Facebook, LinkedIn, Twitter, Instagram y YouTube.

Se realizarán las siguientes acciones:

- Un plan de publicaciones en redes sociales mencionadas. El plan de publicaciones incluye una publicación diaria por Facebook, LinkedIn, Twitter e Instagram y dos publicaciones de video mensuales por YouTube. 
- Se contratará un Community Manager y un diseñador para que creen las publicaciones mencionadas. El Community Manager también se encargaría de responder a las consultas realizadas por el público interesado.

- Con el objetivo de llegar a una mayor cantidad de público se realizarán campañas pagadas en Facebook e Instagram. Así también se realizará campañas en Google AdWords que incluiría la aparición en las búsquedas, así como en YouTube.

\section{Campaña Lanzamiento}

Para la campaña de lanzamiento se contratará una empresa de relaciones públicas que nos pueda conseguir notas de prensa en medios impresos, radiales o televisivos. Se realizará un cóctel en el que se invitará a gerentes de agencia o de empresas, influenciadores y otros tipos de contactos que consideramos que podrían ayudar a difundir y hacer más conocida la empresa.

Para los primeros cursos se seguirá las siguientes estrategias para obtener más visibilidad entre los medios y posibles clientes:

- Una campaña de descuento para las personas que se inscriban a las primeras clases.

- Se invitará a personas claves del área de marketing de empresas grandes o ejecutivos y directivos de agencia con el fin de que conozcan nuestra metodología. Con esta estrategia podríamos captar futuros clientes de estas empresas o agencias claves.

\section{Campañas Permanentes}

Desde el primer mes de funcionamiento se realizará las siguientes actividades de marketing de forma permanente:

- Publicaciones en redes sociales y blog: Se ha considerado lo siguiente: 
- Realizar cinco publicaciones semanales (una publicación diaria de lunes a viernes) en Facebook y LinkedIn. A través de estos medios se difundirán noticias y conocimiento sobre marketing digital.

- Publicación de un artículo semanal en el blog de la empresa. Este artículo podrá ser sobre noticias de la industria, tendencias, análisis de un servicio o producto, casos empresariales entre otros. Se actualizará la página web con la información y los cronogramas de los cursos

- También se ha considerado la publicación de mínimo un video al mes en YouTube. Los videos mensuales serían clases gratuitas de 10 minutos sobre diferentes temas con el objetivo de hacer conocidos a los docentes y la metodología.

- Campaña de posicionamiento en buscadores: Usando estrategias de posicionamiento en buscadores se tendrá como objetivo aparecer en los primeros lugares de búsqueda ante búsquedas claves de posibles clientes en Google y otros buscadores. Un ejemplo de este tipo de palabras claves es "cursos de marketing digital" o "aprender marketing digital". Para lograr este objetivo se contratará a una agencia o persona que se dedique a este tipo de campañas.

- Campañas de publicidad en redes sociales y buscadores: A través de Facebook y Google AdWords se realizarán campañas publicitarias para llegar al público objetivo mediante campañas en Facebook y en las redes de AdWords: Búsqueda, Display y YouTube. 
- Se participará mínimo en una feria al año relacionada con el Marketing. Un ejemplo de este tipo de feria es Expo Marketing que se realiza todos los años en el Swissotel Lima.

- Se tendrá una persona asignada a ventas directas. Esta persona contactará con gerentes, ejecutivos y personal de recursos humanos de empresas grandes y agencias para ofrecer paquetes de cursos para sus trabajadores. Los medios de comunicación que utilizara serán los siguientes:

○ Comunicación por correo electrónico, llamadas telefónicas o visitas directas a ejecutivos. Se contactaría a los gerentes de Recursos Humanos de empresas reconocidas, utilizando la base de datos de empresas Top 10,000 así también, datos de contactos directos o los que provienen de recomendaciones de alumnos y la base de datos conseguida en ferias.

- Contacto directo a través de LinkedIn. Para esto se empleará uno de los planes pagados de LinkedIn que permiten realizar contacto con personas que no son contactos directos del personal de la empresa o que no son seguidores del perfil empresarial.

- Eventos y Talleres gratuitos: Dos veces al mes se dictará talleres gratuitos de una hora con el objetivo de hacer conocida la empresa a público que todavía no se ha animado a inscribirse en un curso. También se ha considerado que estos talleres pueden ayudar a aumentar la base de datos de clientes potenciales. 


\subsubsection{Estrategia de Personas.}

Según Lovelock y Wirtz (2015), los puestos más demandantes en un negocio que brinda un servicio son los de contacto directo con los clientes. Los empleados que establecen contacto con el cliente son factores claves para poder brindar un servicio excelente y obtener una ventaja competitiva que diferencie de la competencia.

Con el objetivo de brindar un servicio excelente se procederá a tener los siguientes procesos cuyo objetivo sería tener un personal muy motivado y eficiente:

\section{Contratación de Personal:}

Según Collins (2011), el personal correcto es el activo más importante de la empresa y el personal incorrecto es un pasivo del cual es difícil liberarse. Por eso se ha considerado dar un peso importante al proceso de contratación para conseguir el mejor personal posible.

\section{Proceso de Contratación:}

El proceso de contratación seguirá los siguientes pasos:

1. Publicación de ofertas laborales en redes sociales como Facebook y LinkedIn. Considerando que el personal deberá estar orientado y ser un usuario asiduo de redes sociales se considera que uno de los mejores canales para captar estos perfiles es a través de las redes sociales.

2. Proceso de entrevistas: Consideramos que es necesario que cada persona pase por lo menos dos entrevistas, una de ellas con quien sería su jefe directo.

3. Aplicación de pruebas de personalidad: En base a las características deseadas de los trabajadores se procederá a aplicar pruebas de personalidad para ver si cumplen con dichas características. 


\section{Facultar al Personal}

Una vez que se ha realizado un proceso de contratación efectivo el siguiente paso es la capacitación del personal. Según Lovelock y Wirtz (2015) para que el personal este alineado con los objetivos de la empresa consideramos que la capacitación debería considerar los siguientes puntos:

- La cultura y el propósito de la organización: Es importante que los empleados interioricen los valores y la cultura de la organización para que estén alineados con los objetivos y sean unos representantes efectivos de la marca.

- Habilidades técnicas e interpersonales: En el caso de los trabajadores que están en contacto con el cliente las habilidades interpersonales son muy importantes ya que repercuten en la experiencia del servicio que tiene el usuario final. Algunas de las habilidades interpersonales que se pueden desarrollar son: contacto visual, lenguaje corporal, escucha activa, etc. También es importante desarrollar las habilidades técnicas requeridas por el puesto.

- Conocimiento del producto o servicio: Se consideró que es necesario que el personal sobre todo el de ventas y de marketing conozca muy bien los productos que se ofrecen. Como parte de la capacitación se podría considerar que este tipo de personal lleve las clases que ofrecería la Escuela. La mejor forma de conocer el producto seria haber consumido el mismo.

\section{Empowerment}

Otra parte del proceso de capacitación es empoderar a los empleados para que puedan resolver problemas o conflictos que pudieran surgir con los clientes. Según Lovelock y Wirtz (2015) el otorgamiento de facultades a los empleados es más efectivo en empresas que quieren 
brindar un servicio personalizado y buscan diferenciarse de la competencia por lo que se aplicaría a la Escuela de Marketing Digital.

\section{Motivación del Personal}

Una vez que se tiene el personal correcto y adecuadamente capacitado el siguiente paso es establecer un sistema de recompensas que mantenga motivado al trabajador. Las principales recompensas que podría recibir un buen trabajador son las siguientes:

- Recompensa económica: Se pagará un salario acorde a los precios de mercado.

- Satisfacción con el trabajo: Para que un trabajo sea satisfactorio debe estar bien definido y resultar retador a los trabajadores.

- Retroalimentación y reconocimiento: El reconocimiento de un buen trabajo por parte de la gerencia es importante. Se establecerán programas de reconocimiento.

- Logro de metas: Es importante tener metas bien definidas ya que las metas ayudan a enfocar la energía de las personas. Las metas que son específicas y que constituyen un reto alcanzable producen una mayor motivación que las metas vagas, inexistentes o imposibles de lograr.

\subsubsection{Estrategia de Procesos.}

Según Lovelock y Wirtz (2015) los servicios son experiencias para los clientes, pero desde el punto de vista de la organización, son procesos que deben diseñarse para brindar la experiencia deseada. Los procesos describen la secuencia de pasos que se deben realizar para brindar un servicio. Los procesos mal diseñados resultan en una entrega de servicios lenta y de mala calidad lo que tiende a disgustar a los clientes.

Los procesos se dividen en los siguientes tipos: 
1. Procesamiento hacia las personas: Este tipo de proceso es el más utilizado en la Escuela de Marketing Digital en el que ingresan alumnos que no saben mucho de un tema específico y egresan con conocimientos y experiencia.

2. Procesamiento hacia las posesiones: Son los procesos típicos de centros de relación de vehículos o electrodomésticos.

3. Procesamiento como estímulo mental.

4. Procesamiento de la información

Puntos de falla:

Según Lovelock y Wirtz (2015) para diseñar procesos eficientes es importante identificar los puntos en el proceso donde hay mayores posibilidades de fallas o donde la falla pueda comprometer la calidad y experiencia del servicio. Estos posibles puntos son:

- Puntos de fallas graves: Son aquellos que impiden al cliente el acceso o disfrute del servicio básico.

- Momentos de espera: Son puntos en el proceso donde el cliente está obligado a esperar, por lo que una espera excesivamente larga molestaría al cliente y en caso más extremos podría hacer que el cliente desista de contratar el servicio.

- Monitoreo de los procesos: Para diseñar procesos eficientes se debe definir indicadores de calidad del servicio. Estos indicadores deben ser medibles con el objetivo de poder realizar un seguimiento. Para identificar un meta a alcanzar se debería considerar las expectativas de los clientes y la capacidad real de la empresa de cubrir la meta definida. Esta meta se debería posteriormente comunicar a los clientes para que sus expectativas del servicio sean realistas. Un 
ejemplo de esto es cuando una empresa promete una respuesta en 24 horas o menos.

\subsubsection{Estrategia de Presencia Física.}

Según Lovelock y Wirtz (2015) el entorno físico tiene un papel muy importante en la experiencia del servicio y en el incremento o disminución de la satisfacción del consumidor. Según la entrevista con el experto Marcos Fonruge (ver Apéndice 7), el entorno podría no ser el factor principal para que un posible cliente escoja la Escuela. Sin embargo, una vez que se ha inscrito si el entorno es desfavorable por más que se tenga buenos profesores y una buena metodología, la percepción general acerca del servicio podría ser de insatisfacción. Por lo cual, es importante brindar un ambiente confortable, limpio y ordenado.

\subsection{Estrategia de ventas}

La estrategia de ventas se enfocará en lograr un crecimiento rápido de las mismas por lo que tendrá los siguientes objetivos.

- Dar a conocer el producto al mercado objetivo.

- Lograr relaciones a largo plazo con clientes y proveedores

- Realizar análisis del mercado de forma constante

- Informar al público objetivo de los nuevos servicios y productos

- Tener un eficiente servicio post venta

\subsubsection{Plan de Ventas.}

En base al estudio de mercado y los supuestos sustentados en el capítulo 6 se ha elaborado un plan de ventas para el primer año de funcionamiento de la empresa. Se ha pronosticado lograr 141 alumnos a finales del primer año, lo que representaría lograr el uso del 
100

$34 \%$ de la capacidad del local. En la tabla 38 se puede observar el plan de ventas por cantidad de alumnos para los primeros 12 meses de funcionamiento del proyecto.

Tabla 38

Ventas en número de alumnos durante el primer año

\begin{tabular}{|c|c|c|c|c|c|c|c|c|c|c|c|c|c|c|}
\hline Días & Horario & Salón & Ene & Feb & Mar & Abr & May & Jun & Jul & Ago & Sep & Oct & Nov & Dic \\
\hline Lun-Mie & Mañana & $\mathrm{Lab}$ & ( & ( & 0 & 0 & 0 & 0 & 0 & 0 & 0 & 0 & 0 & 0 \\
\hline Lun-Mie & Mañana & Aula 1 & ( & ( & 0 & 0 & 0 & 0 & 0 & 0 & 0 & 0 & 0 & 0 \\
\hline Lun-Mie & Mañana & Aula 2 & ( & ( & 0 & 0 & 0 & 0 & 0 & 0 & 0 & 0 & 0 & 0 \\
\hline Mar-Jue & Mañana & $\mathrm{Lab}$ & ( & 10 & 10 & 10 & 10 & 10 & 15 & 15 & 15 & 15 & 15 & 15 \\
\hline Mar-Jue & Mañana & Aula 1 & ( & ( & 0 & 0 & 0 & 0 & 10 & 10 & 10 & 10 & 10 & 10 \\
\hline Mar-Jue & Mañana & Aula 2 & ( & ( & $\underline{0}$ & 0 & 0 & 0 & 10 & 10 & 10 & 10 & 10 & 10 \\
\hline Lun-Mie & Noche & $\mathrm{Lab}$ & ( & ( & 0 & 0 & 0 & 0 & 10 & 10 & 10 & 10 & 10 & 10 \\
\hline Lun-Mie & Noche & Aula 1 & ( & ( & 0 & 0 & 0 & 0 & 10 & 10 & 10 & 10 & 10 & 10 \\
\hline Lun-Mie & Noche & Aula 2 & ( & ( & 0 & 0 & 0 & 0 & 0 & 0 & 0 & 0 & 0 & 0 \\
\hline Mar-Jue & Noche & $\mathrm{Lab}$ & ( & 10 & 10 & 10 & 10 & 10 & 15 & 15 & 15 & 15 & 15 & 15 \\
\hline Mar-Jue & Noche & Aula 1 & ( & 15 & 15 & 15 & 15 & 15 & 15 & 15 & 15 & 15 & 15 & 15 \\
\hline Mar-Jue & Noche & Aula 2 & ( & ( & 0 & 0 & 0 & 0 & 10 & 10 & 10 & 10 & 10 & 10 \\
\hline \multirow{2}{*}{$\begin{array}{l}\text { Sábado } \\
\text { Sábado }\end{array}$} & Mañana & Lab & ( & 10 & 10 & 10 & 10 & 10 & 15 & 15 & 15 & 15 & 15 & 15 \\
\hline & Mañana & Aula 1 & ( & ( & 0 & 10 & 10 & 10 & 15 & 15 & 15 & 15 & 15 & 15 \\
\hline Sábado & Mañana & Aula 2 & ( & ( & 0 & 5 & 5 & 5 & 5 & 5 & 5 & 5 & 5 & 5 \\
\hline Sábado & Tarde & $\mathrm{Lab}$ & ( & ( & 0 & 0 & 0 & 0 & 5 & 5 & 5 & 5 & 5 & 5 \\
\hline \multirow{2}{*}{ Sábado } & Tarde & Aula 1 & ( & ( & 0 & 0 & 0 & 0 & 0 & 0 & 0 & 0 & 0 & 0 \\
\hline & Tarde & Aula 2 & ( & ( & 0 & 0 & 0 & 0 & 5 & 5 & 5 & 5 & 5 & 5 \\
\hline & Personalizado & Sala A & ( & 1 & 0 & 1 & 0 & 1 & 1 & 1 & 1 & 1 & 1 & 1 \\
\hline Total & & & ( & 46 & 45 & 61 & 60 & 61 & 141 & 141 & 141 & 141 & 141 & 141 \\
\hline
\end{tabular}


Debido a que el precio de los cursos regulares es de $\mathrm{S} / 450.00$ y el precio del curso personalizado estaría en $\mathrm{S} / 650.00$ soles multiplicando la cantidad de inscritos por el precio de los cursos permite obtener el pronóstico de venta en soles para el primer año que se muestra en la tabla39.

Tabla 39

Ventas en soles para el primer año de funcionamiento.

\begin{tabular}{|c|c|c|c|c|c|c|c|c|c|c|c|c|}
\hline \multicolumn{13}{|c|}{ Ventas en Soles (S/.) } \\
\hline Horario & Ene & Feb & Mar & Abr & May & Jun & Jul & Ago & Sep & Oct & Nov & Dic \\
\hline Mañana & 0 & 4,500 & 4,500 & 4,500 & 4,500 & 4,500 & 15,750 & 15,750 & 15,750 & 15,750 & 15,750 & 15,750 \\
\hline Noche & 0 & 11,250 & 11,250 & 11,250 & 11,250 & 11,250 & 27,000 & 27,000 & 27,000 & 27,000 & 27,000 & 27,000 \\
\hline Sábados & 0 & 4,500 & 4,500 & 11,250 & 11,250 & 11,250 & 20,250 & 20,250 & 20,250 & 20,250 & 20,250 & 20,250 \\
\hline Personalizado & 0 & 650 & 0 & 650 & 0 & 650 & 650 & 650 & 650 & 650 & 650 & 650 \\
\hline Total Ingresos & 0 & 20,900 & 20,250 & 27,650 & 27,000 & 27,650 & 63,650 & 63,650 & 63,650 & 63,650 & 63,650 & 63,650 \\
\hline IGV & 0 & 3,762 & 3,645 & 4,977 & 4,860 & 4,977 & 11,457 & 11,457 & 11,457 & 11,457 & 11,457 & 11,457 \\
\hline $\begin{array}{l}\text { Total incluido } \\
\text { IGV }\end{array}$ & 0 & 24,662 & 23,895 & 32,627 & 31,860 & 32,627 & 75,107 & 75,107 & 75,107 & 75,107 & 75,107 & 75,107 \\
\hline
\end{tabular}

\subsubsection{Políticas de servicios y garantías.}

Como parte de la política de servicios que brindará la Escuela con el objetivo de garantizar un servicio de alta calidad se definirán las siguientes políticas:

- Implementación de un buzón de quejas por si algún alumno recibiera un servicio que no cumpliera con sus expectativas.

- Cuestionarios a la mitad del curso para evaluar a los docentes. Con estos cuestionarios se podrá evaluar la calidad de los cursos brindados y si hubiera una percepción negativa sobre el docente se podrá retroalimentar al mismo para que mejore su curso. También se realizará una evaluación del docente al final del grupo. 
- Realización de Focus Group con los alumnos que han estudiado en la Escuela con el objetivo de identificar los nuevos cursos que se pueden brindar, mejoras en el proceso o en la metodología de enseñanza entre otras mejores.

- Reuniones y capacitaciones periódicas con los docentes para compartir la visión y las políticas de la Escuela y para capacitar en técnicas pedagógicas.

- En el caso de los cursos si el alumno decidiera abandonar el curso por enfermedad, trabajo o alguna emergencia personal se le dará la posibilidad de volver a llevar el mismo sin costo alguno siempre y cuando el motivo de abandono esté justificado.

- En el caso de retirarse de un curso de forma definitiva se procedería a devolver el monto correspondiente a la parte faltante del curso. Esto se aplicaría cuando el retiro está justificado por un motivo de fuerza mayor. 


\section{Capítulo VI: Pronóstico de Ventas}

En este capítulo se presenta la proyección de ventas de los siguientes tres años mostrándose con detalle las ventas del primer año mes a mes. Asimismo, se analizan los supuestos que permiten justificar esta proyección, así como los factores que podrían afectar la proyección de ventas.

\subsection{Fundamentos y supuestos}

\section{Planificación Primer año}

Para el pronóstico de ventas del primer año (ver tabla 40) se han asumido los siguientes supuestos:

- Primer Mes (enero): Debido a que el primer mes se estaría terminando de implementar el local y se necesitaría por lo menos un mes para promocionar el primer curso se ha considerado que durante ese periodo no se brindaría clases por lo que no existiría ingresos en el primer mes.

- Segundo al Tercer mes (febrero a marzo): En estos dos meses se ha considerado abrir 4 horarios: (a) Martes y Jueves en la mañana, (b) Martes y Jueves en la noche - salón laboratorio, (C) Martes y Jueves en la noche - aula 1 y (d) Sábado en la mañana. En base a la entrevista brindada por Marcos Fonruge se ha considerado que los horarios en la noche sobre todo los de Martes y Jueves que serían los más demandados si se pueden llegar a llenar dependiendo de los profesores y el curso a dictarse. Para ser más conservadores se ha asumido que uno de los salones se llenaría al 100\% y otro al 66\%. También se ha considerado un salón en la mañana al 66\% y otro salón en la tarde al mismo porcentaje (66\%). Respecto a los cursos personalizados solamente se ha asumido un alumno en estos dos meses. 
- Cuarto al Sexto mes (abril a junio): En estos tres meses se abrirían dos horarios adicionales los días sábados: uno con 10 personas y el otro con cinco personas. Según la encuesta y el focus para algunas personas los sábados son los únicos días que pueden dedicar tiempo a llevar cursos. Si se utilizaran todos los horarios a la máxima capacidad se podrían atender a 271 alumnos al mes (18 horarios con 15 personas cada uno y un alumno personalizado). A finales de junio se tendrían 61 alumnos por lo que la capacidad utilizada del local sería de $61 / 271=22.50 \%$.

- Séptimo al Doceavo mes (julio a diciembre): Durante este periodo se tendría los siguientes pronósticos:

○ Turno Mañana: tres horarios abiertos. Capacidad utilizada del turno: $38.88 \%$

- Turno Noche: cinco horarios abiertos. Capacidad utilizada del turno: $66.66 \%$

o Turno sábados: cinco horarios abiertos. Capacidad utilizada del turno: $50.00 \%$

La capacidad utilizada del local al final del primer año será de 52\% En la tabla 40 se observa el pronóstico de ventas del primer año por cada horario y salón. 
Tabla 40

Pronóstico de alumnos inscritos durante el primer año

\begin{tabular}{|c|c|c|c|c|c|c|c|c|c|c|c|c|c|c|}
\hline Días & Horario & Salón & Ene & Feb & Mar & Abr & May & Jun & Jul & Ago & Sep & Oct & Nov & Dic \\
\hline Lun-Mie & Mañana & Lab & ( & c & 0 & 0 & 0 & 0 & 0 & 0 & 0 & 0 & 0 & 0 \\
\hline Lun-Mie & Mañana & Aula 1 & ( & c & 0 & 0 & 0 & 0 & 0 & 0 & 0 & 0 & 0 & 0 \\
\hline Lun-Mie & Mañana & Aula 2 & ( & c & 0 & 0 & 0 & 0 & 0 & 0 & 0 & 0 & 0 & 0 \\
\hline Mar-Jue & Mañana & Lab & ( & 10 & 10 & 10 & 10 & 10 & 15 & 15 & 15 & 15 & 15 & 15 \\
\hline Mar-Jue & Mañana & Aula 1 & c & c & 0 & 0 & 0 & 0 & 10 & 10 & 10 & 10 & 10 & 10 \\
\hline Mar-Jue & Mañana & Aula 2 & ( & c & 0 & 0 & 0 & 0 & 10 & 10 & 10 & 10 & 10 & 10 \\
\hline Lun-Mie & Noche & Lab & ( & c & 0 & 0 & 0 & 0 & 10 & 10 & 10 & 10 & 10 & 10 \\
\hline Lun-Mie & Noche & Aula 1 & ( & c & 0 & 0 & 0 & 0 & 10 & 10 & 10 & 10 & 10 & 10 \\
\hline Lun-Mie & Noche & Aula 2 & ( & c & 0 & 0 & 0 & 0 & 0 & 0 & 0 & 0 & 0 & 0 \\
\hline Mar-Jue & Noche & Lab & ( & 10 & 10 & 10 & 10 & 10 & 15 & 15 & 15 & 15 & 15 & 15 \\
\hline Mar-Jue & Noche & Aula 1 & ( & 15 & 15 & 15 & 15 & 15 & 15 & 15 & 15 & 15 & 15 & 15 \\
\hline Mar-Jue & Noche & Aula 2 & ( & $\mathrm{c}$ & 0 & 0 & 0 & 0 & 10 & 10 & 10 & 10 & 10 & 10 \\
\hline Sábado & Mañana & Lab & ( & 10 & 10 & 10 & 10 & 10 & 15 & 15 & 15 & 15 & 15 & 15 \\
\hline Sábado & Mañana & Aula 1 & ( & c & 0 & 10 & 10 & 10 & 15 & 15 & 15 & 15 & 15 & 15 \\
\hline Sábado & Mañana & Aula 2 & ( & c & 0 & 5 & 5 & 5 & 5 & 5 & 5 & 5 & 5 & 5 \\
\hline Sábado & Tarde & Lab & ( & c & 0 & 0 & 0 & 0 & 5 & 5 & 5 & 5 & 5 & 5 \\
\hline $\mathrm{S}$ & Tarde & Aula 1 & ( & ( & 0 & 0 & 0 & 0 & 0 & 0 & 0 & 0 & 0 & 0 \\
\hline & Tarde & Aula 2 & ( & c & 0 & 0 & 0 & 0 & 5 & 5 & 5 & 5 & 5 & 5 \\
\hline & Personalizado & Sala A & ( & 1 & 0 & 1 & 0 & 1 & 1 & 1 & 1 & 1 & 1 & 1 \\
\hline Total & & & ( & 46 & 45 & 61 & 60 & 61 & 141 & 141 & 141 & 141 & 141 & 141 \\
\hline
\end{tabular}


Planificación alumnos inscritos - Primeros tres años

Se ha proyectado el crecimiento de las ventas durante los primeros tres años obteniéndose los resultados que se muestran en la tabla 41:

Tabla 41

Ventas del año 1 al año 3

\begin{tabular}{lllccc}
\hline Días & Horario & Salón & Año 1 & Año 2 & Año 3 \\
\hline Lunes y Miércoles & Mañana & Laboratorio & 0 & 120 & 180 \\
Lunes y Miércoles & Mañana & Aula 1 & 0 & 120 & 180 \\
Lunes y Miércoles & Mañana & Aula 2 & 0 & 120 & 180 \\
Martes y Jueves & Mañana & Laboratorio & 140 & 120 & 180 \\
Martes y Jueves & Mañana & Aula 1 & 60 & 120 & 180 \\
Martes y Jueves & Mañana & Aula 2 & 60 & 120 & 180 \\
Capacidad Utilizada & Mañana & & $24 \%$ & $67 \%$ & $100 \%$ \\
\hline Lunes y Miércoles & Noche & Laboratorio & 60 & 180 & 180 \\
Lunes y Miércoles & Noche & Aula 1 & 60 & 120 & 180 \\
Lunes y Miércoles & Noche & Aula 2 & 0 & 120 & 180 \\
Martes y Jueves & Noche & Laboratorio & 140 & 180 & 180 \\
Martes y Jueves & Noche & Aula 1 & 165 & 180 & 180 \\
Martes y Jueves & Noche & Aula 2 & 60 & 180 & 180 \\
Capacidad Utilizada & Mañana & & $45 \%$ & $89 \%$ & $100 \%$ \\
\hline Sábado & Mañana & Laboratorio & 140 & 180 & 180 \\
Sábado & Mañana & Aula 1 & 120 & 180 & 180 \\
Sábado & Mañana & Aula 2 & 45 & 60 & 180 \\
Sábado & Tarde & Laboratorio & 30 & 120 & 180 \\
Sábado & Tarde & Aula 1 & 0 & 0 & 0 \\
Sábado & Aula 2 & 30 & 120 & 180 \\
Capacidad Utilizada & Mañana & & $34 \%$ & $61 \%$ & $83 \%$ \\
\hline Total & Personalizado & Sala A & 9 & 24 & 36 \\
Capacidad Utilizada & Todo Local & & $34 \%$ & $72 \%$ & $95 \%$ \\
\hline
\end{tabular}


Se ha considerado una utilización del 34\% del local durante el primer año. En base a la inversión en marketing, el crecimiento de la demanda y el prestigio que haya ganado la Escuela en el primer año se considera que se podría llegar a una utilización del 72\% en el segundo año y de $95 \%$ en el tercer año considerando que este mercado está en crecimiento (ver tabla 1).

\subsection{Justificación}

Para justificar la proyección presentada se presentan los siguientes supuestos y hechos:

- Como se observa en la tabla 1, la inversión en marketing digital se encuentra en crecimiento, habiendo crecido entre el año 2016 al 2017 un 11.62\%. Como todavía esta inversión es menor que en otros medios tales como la televisión, se considera que el crecimiento continuaría durante los siguientes tres años. El crecimiento en inversión en digital impulsa a que los profesionales actualicen sus conocimientos en dicha área.

- De acuerdo con la información obtenida por el experto Marcos Fonruge (ver Apéndice 7) si se contrata profesores reconocidos para dictar los cursos se puede llegar a completar la capacidad del salón. Además, según lo observado en los competidores la Escuela de Marketing Digital es la que tendría una menor cantidad de alumnos por salón lo que permitiría completar la capacidad del mismo.

- Los precios ofrecidos por la Escuela son competitivos siendo menor en el costo por hora respecto a la competencia.

- El mercado objetivo es de 4,211 personas que sería superior al mercado que estaríamos atendiendo a finales del tercer año que es de 3,099 alumnos atendidos durante ese año. Se debe considerar que para hallar el mercado objetivo solo se ha considerado las personas que viven en distritos céntricos de lima, que han estudiado carreras relacionadas con el marketing digital, han pagado por cursos de marketing digital, que les interesaría estudiar 
en la Escuela y que están dispuestos a pagar más de S/400 soles. No se ha considerado los siguientes perfiles que también podría entrar como parte del público y ampliarían el mercado objetivo:

○ Gerentes de pymes que no han estudiado marketing, pero les interesaría aprender a realizar sus campañas publicitarias.

- Personas de otras carreras como informáticos que se capacitarían en SEO y Adwords o Diseñadores que les interesaría estudiar un curso de Community Management.

- Personas que han estudiado marketing y les interesa el marketing digital, pero viven en Lima Norte y Sur y están dispuestos a movilizarse hasta Miraflores.

- Personas que no han pagado por cursos pero que se podrían animar a matricularse en uno si la currícula y el profesor es de su interés.

- Las personas que respondieron que no les interesaba probar la nueva Escuela podrían cambiar de opinión cuando sea conocida y gane prestigio.

\subsection{Análisis de los riesgos y aspectos críticos que impactan en el pronóstico}

Se ha determinado los siguientes factores que podrían impactar en el pronóstico de las ventas.

1. Crecimiento económico: Uno de los factores que podrían incidir en las ventas sería una disminución del ritmo de crecimiento económico. Sin embargo, aunque la tasa de crecimiento de la economía disminuya, según la información obtenida por la Compañía Peruana de Estudios de Mercado y Opinión Pública (ver tabla 1), la tasa de crecimiento de la inversión en marketing digital sigue siendo positiva. Se considera que el crecimiento en la inversión en este rubro va seguir aumentando. En el Perú la inversión 
en marketing digital todavía es menor que en la televisión y la tendencia tanto en Perú como en otros países es que se va a seguir distribuyendo la inversión destinada a medios tradicionales hacia el rubro digital debido a la efectividad de este medio (ver tabla 1).

2. Situación del Sector: Tal como se vio en el factor anterior el crecimiento del sector ha sido muy positivo en estos últimos años y la tendencia y los cambios en las empresas confirman que así se mantendrá en los próximos años.

3. Acciones de los competidores. Este es uno de los factores que podría afectar con mayor peso en las ventas. Si surgieran nuevos competidores o los competidores actuales decidieran incrementar sus campañas de promoción de una forma más agresiva podrían afectar el pronóstico de ventas. Las acciones que se podrían tomar para disminuir este riesgo serían las siguientes:

a. Ampliar la oferta de cursos y las modalidades de los mismos para tener una mayor gama de servicios que permitan destacar sobre los competidores.

b. Siendo los profesores uno de los factores críticos de éxito de la Escuela sería muy importante hacer todo lo posible por mantener a los profesores más destacados como parte permanente del staff.

c. Trabajar el tema de la imagen de la Escuela mediante recomendaciones de los alumnos, reportajes en medios de prensa, artículos en blog y todo tipo de estrategias que permitan que no solo los profesores, sino que el prestigio de la Escuela sea conocido.

4. Impacto Tecnológico.: Los cambios tecnológicos pueden afectar a los productos de la Escuela, ya que el contenido de los cursos puede quedar obsoleto rápidamente. Sin 
embargo, si la currícula de los cursos se actualiza constantemente podría ser un factor a favor de la Escuela sobre todo si la competencia no respondiera con la misma rapidez.

5. Nuevas Leyes: Hasta el momento ninguna ley restringe el dictado de cursos, siempre y cuando se especifique que los diplomas otorgados no tienen una validez como los títulos emitidos a nombre de la nación otorgados por otros institutos. Mientras las leyes permitan a cualquier empresa dictar cursos no deberían afectar el pronóstico de ventas. Sin embargo, siempre habría la posibilidad de que se emitiera una ley restringiendo el dictado de clases solamente a institutos y universidades. Lo único que se podría hacer contra este riesgo es hacer un seguimiento de las leyes que estén por aprobarse, que puedan afectar a la Escuela y preparar un plan de acción si en caso se restringiera el dictado de clases a las empresas y la única opción fuera formalizarse como un instituto. 


\section{Capítulo VII: Ingeniería del Proyecto}

En el presente capítulo se describirá el proceso de los servicios brindados por la Escuela de Marketing Digital, así como el análisis de los requerimientos de inversión, diseño y selección del local y requerimientos legales y técnicos necesarios para poner en funcionamiento la Escuela.

\subsection{Estudio de Ingeniería}

En el estudio de ingeniería se describirá el proceso de los servicios, requerimientos de equipos y el diseño del local.

\subsubsection{Modelamiento y selección de procesos productivos.}

En este diagrama se mostrará el flujo de los procesos desde que solicita la inscripción al curso hasta que termina su capacitación (ver figura 13):

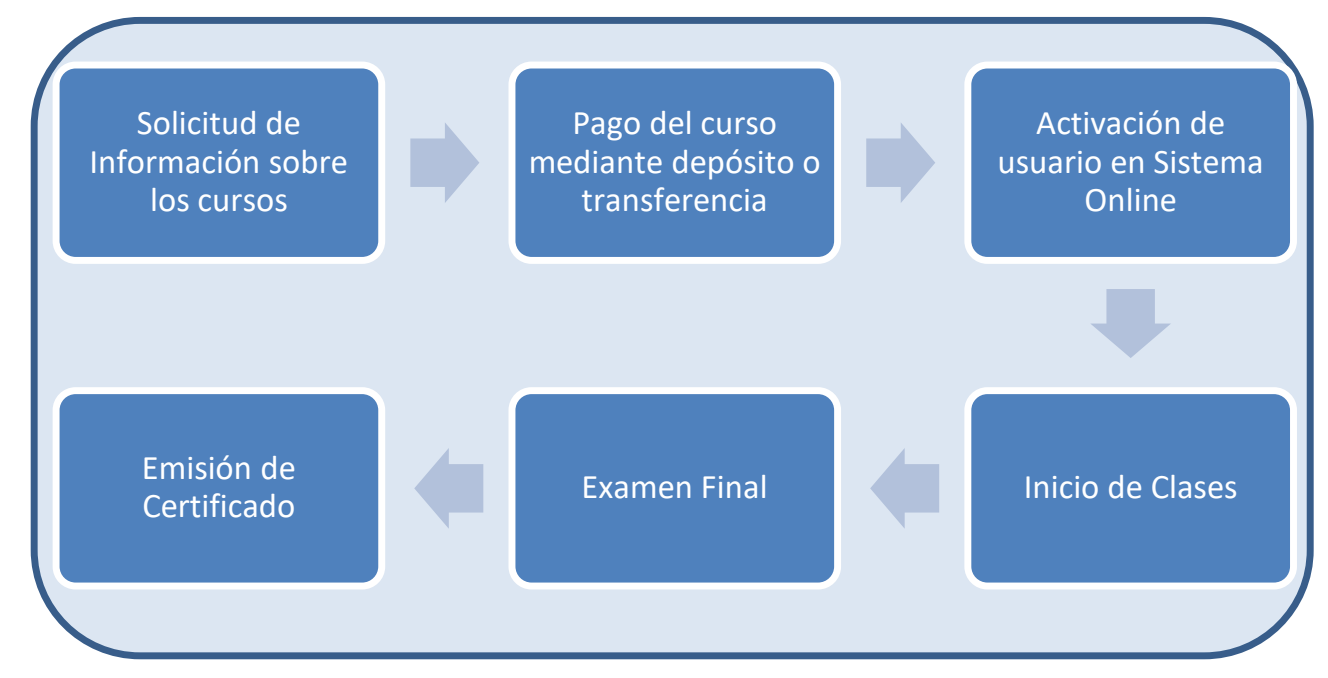

Figura 13. Proceso de Inscripción y Finalización del curso.

\subsubsection{Selección de equipamiento.}

La Escuela de Marketing Digital alquilará un local para llevar acabo la capacitación por lo que se necesitará equipos para el área administrativa y las áreas de clases.

En las tabla 42 se detallan los recursos necesarios para el área administrativa. 
Tabla 42

Equipamiento del área administrativa

\begin{tabular}{lllccc}
\hline Cantidad & Descripción & Costo Unit S/. & Valor de & IGV S/. & Precio de \\
& & & Compra S/. & & compra S/. \\
\hline 2 & Escritorios + Estante & S/ 761.86 & S/1,523.73 & S/274.27 & S/1,798.00 \\
\hline 2 & Sillas Giratorias & S/ 83.90 & S/ 167.80 & S/30.20 & S/ 198.00 \\
\hline 4 & Sillas Fijas & S/ 50.76 & S/ 203.05 & S/36.55 & S/ 239.60 \\
\hline & & Total & S/ $1,894.58$ & S/ 341.02 & S/ 2,235.60 \\
\hline
\end{tabular}

Para el equipamiento de las aulas se consideraron dos televisores, 35 sillas, dos pizarras y 12 mesas como se observa en la tabla 43.

Tabla 43

Equipamiento de las aulas

\begin{tabular}{llllll}
\hline Cantidad & Descripción & Costo Unit S/. & Valor de & IGV S/. & Precio de \\
& & & Compra S/. & & compra S/. \\
\hline 2 & Televisores 40' & S/ 1,100.85 & S/2,201.69 & S/ 396.31 & S/2,598.00 \\
\hline 30 & Sillas fijas & S/ 50.76 & S/1,522.88 & S/ 274.12 & S/1,797.00 \\
\hline 5 & Sillas giratorias & S/ 83.90 & S/ 419.49 & S/ 75.51 & S/495.00 \\
\hline & $\begin{array}{l}\text { Pizarra aulas, } \\
\text { laboratorio y salas }\end{array}$ & S/ 63.47 & S/ 126.95 & S/ 22.85 & S/149.80 \\
\hline 6 & Mesas 1.8 & S/ 288.14 & S/1,728.81 & S/ 311.19 & S/2,040.00 \\
\hline 6 & Mesas 1.2 & S/ 144.07 & S/ 864.41 & S/ 155.59 & S/1,020.00 \\
\hline & & Total & S/6,864.24 & S/ 1235.56 & S/ 8,099.80 \\
\hline
\end{tabular}

En la tabla 44 se describen los equipos necesarios para el equipamiento del laboratorio. 
Tabla 44

Equipamiento del laboratorio

\begin{tabular}{llllll}
\hline Cantidad & Descripción & Costo Unit S/. & Valor de & IGV S/. & Precio de \\
& & & Compra S/. & & compra S/. \\
\hline 1 & Televisores 40' & S/ 1,100.85 & S/1,100.85 & S/198.15 & S/1,299.00 \\
\hline 15 & Sillas fijas & S/ 50.76 & S/761.44 & S/ 137.06 & S/ 898.50 \\
\hline 1 & Sillas giratorias & S/ 83.90 & S/ 83.90 & S/ 15.10 & S/ 99.00 \\
\hline 1 & Pizarra & S/ 63.47 & S/ 63.47 & S/ 11.43 & S/ 74.90 \\
\hline 3 & Mesas 1.8 & S/ 288.14 & S/ 864.41 & S/ 155.59 & S/1,020.00 \\
\hline 3 & Mesas 1.2 & S/ 144.07 & S/ 432.20 & S/ 77.80 & S/ 510.00 \\
\hline & & Total & S/3,306.27 & S/ 595.12 & S/ 3901.40 \\
\hline
\end{tabular}

Para la sala donde se van a dictar los cursos personalizados se consideró dos televisores, cuatro sillas, dos pizarras y una mesa (ver tabla 45). Esta sala no solo serviría para dictar los cursos personalizados sino que es un espacio donde los alumnos pueden estudiar cuando no hay clases personalizadas programadas.

Tabla 45

Equipamiento de la sala

\begin{tabular}{llllll}
\hline Cantidad & Descripción & Costo Unit S/. & Valor de & IGV S/. & Precio de \\
& & & Compra S/. & & compra S/. \\
\hline 2 & Televisores 40' & S/ 1,100.85 & S/2,201.69 & S/396.31 & S/2,598.00 \\
\hline 4 & Sillas fijas & S/ 50.76 & S/203.05 & S/36.55 & S/239.60 \\
\hline 2 & Pizarra & S/ 63.47 & S/126.95 & S/22.85 & S/149.80 \\
\hline 1 & Mesas 1.8 & S/ 296.61 & S/296.61 & S/53.39 & S/350.00 \\
\hline & & Total & S/2,828.31 & S/509.09 & S/3,337.40 \\
\hline
\end{tabular}

En la tabla 46 se observan los equipos de cómputo que se comprarían para el proyecto los cuales incluyen 15 computadoras de escritorio, siete laptops y una impresora multifuncional 
Tabla 46

Equipos de cómputo

\begin{tabular}{llllll}
\hline Cantidad & Descripción & Costo Unit & Valor de & IGV S/. & Precio de \\
& & S/. & Compra S/. & & compra S/. \\
\hline 15 & $\begin{array}{l}\text { Computadoras } \\
\text { laboratorio }\end{array}$ & $\mathrm{S} / 1,804.24$ & $\mathrm{~S} / 27,063.56$ & $\mathrm{~S} / 4,871.44$ & $\mathrm{~S} / 31,935.00$ \\
\hline 7 & Laptops & $\mathrm{S} / 1,863.56$ & $\mathrm{~S} / 13,044.92$ & $\mathrm{~S} / 2,348.08$ & $\mathrm{~S} / 15,393.00$ \\
\hline & $\begin{array}{l}\text { Impresora } \\
\text { multifuncional }\end{array}$ & $\mathrm{S} / 507.63$ & $\mathrm{~S} / 507.63$ & $\mathrm{~S} / 91.37$ & $\mathrm{~S} / 599.00$ \\
\hline & & Total & $\mathrm{S} / 40,616.10$ & $\mathrm{~S} / 7,310.90$ & $\mathrm{~S} / 47,927.00$ \\
\hline
\end{tabular}

En la tabla 47 se muestran los equipos de comunicación y en la tabla 48 las licencias de software que se van a comprar.

Tabla 47

Equipos de comunicación

\begin{tabular}{llllll}
\hline Cantidad & Descripción & Costo Unit & Valor de & IGV S/. & Precio de \\
S/. & Compra S/. & & compra S/. \\
\hline 2 & $\begin{array}{l}\text { Teléfono fijo }+ \\
\text { internet }\end{array}$ & $\mathrm{S} / 541.53$ & $\mathrm{~S} / 1,083.05$ & $\mathrm{~S} / 194.95$ & $\mathrm{~S} / 1,278.00$ \\
\hline $\begin{array}{l}\text { Celular recepción } \\
\text { (coordinador) }\end{array}$ & $\mathrm{S} / 50.76$ & $\mathrm{~S} / 101.53$ & $\mathrm{~S} / 18.27$ & $\mathrm{~S} / 119.80$ \\
\hline & & Total & $\mathrm{S} / 1,184.58$ & $\mathrm{~S} / 213.22$ & $\mathrm{~S} / 1,397.80$ \\
\hline
\end{tabular}

Tabla 48

Software

\begin{tabular}{llllll}
\hline Cantidad & Descripción & Costo Unit S/. & Valor de Compra S/. & IGV S/. & Precio de compra S/. \\
\hline 22 & Licencias & S/13.98 & S/307.63 & S/55.37 & S/363.00 \\
\hline & & Total & S/307.63 & S/55.37 & S/363.00 \\
\hline
\end{tabular}




\subsubsection{Lay Out.}

El local tendrá un contrato de arrendamiento y su distribución se realizará de acuerdo con el siguiente plano en un área de $118 \mathrm{~m}^{2}$ (ver figura 14).

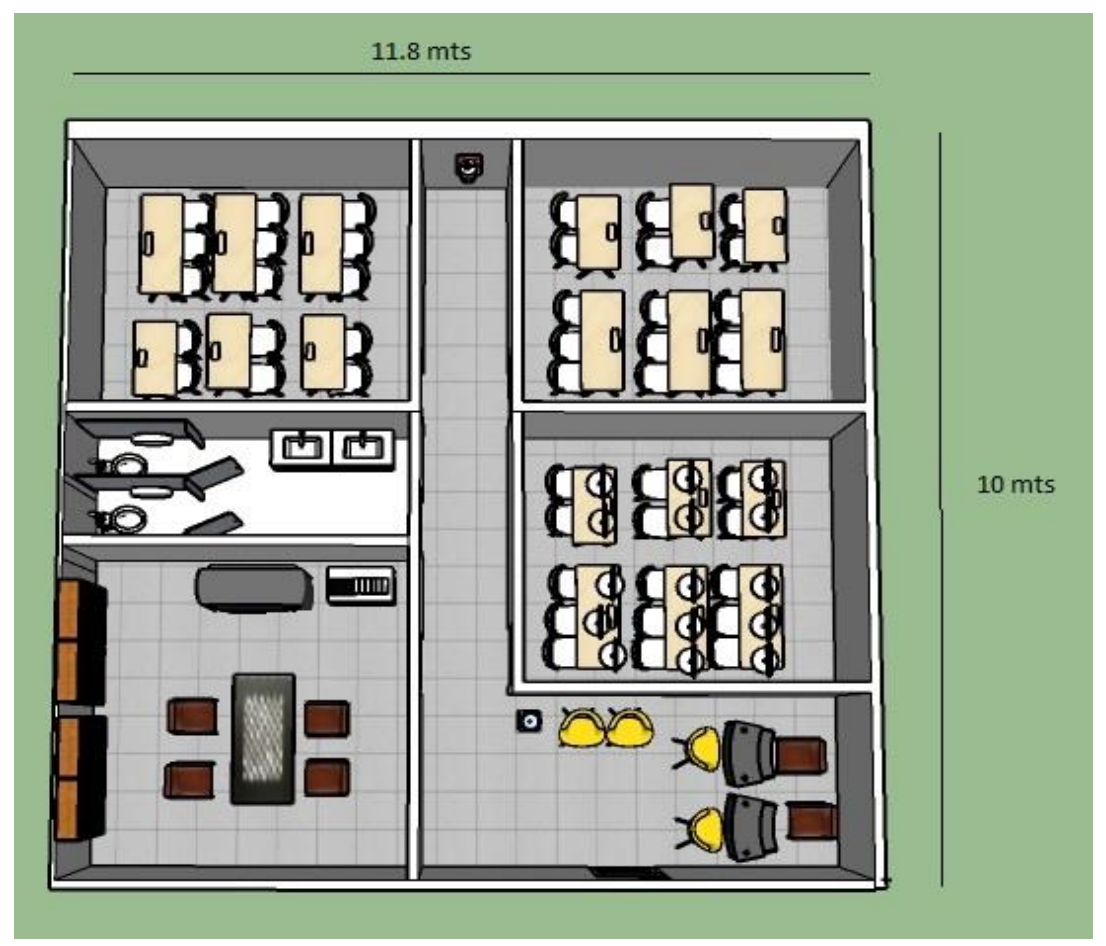

Figura 14. Plano del local. Escala 1:1000

\subsubsection{Distribución de equipos y maquinaria.}

El local estará dividido en cinco áreas (ver figura 15):

- Salón 1 y 2 que contarán con espacio para 15 alumnos y donde se dictarán las clases que no requieran equipos de cómputo.

- Laboratorio: Contará con 15 computadoras, Este salón se usará sobre todo en cursos que requieran uso intensivo de computadoras.

- Recepción y administración: En esta área funcionará el área de administración donde se hará la recepción de los alumnos. 
- Sala 1: En esta sala se dictarán las clases individuales.

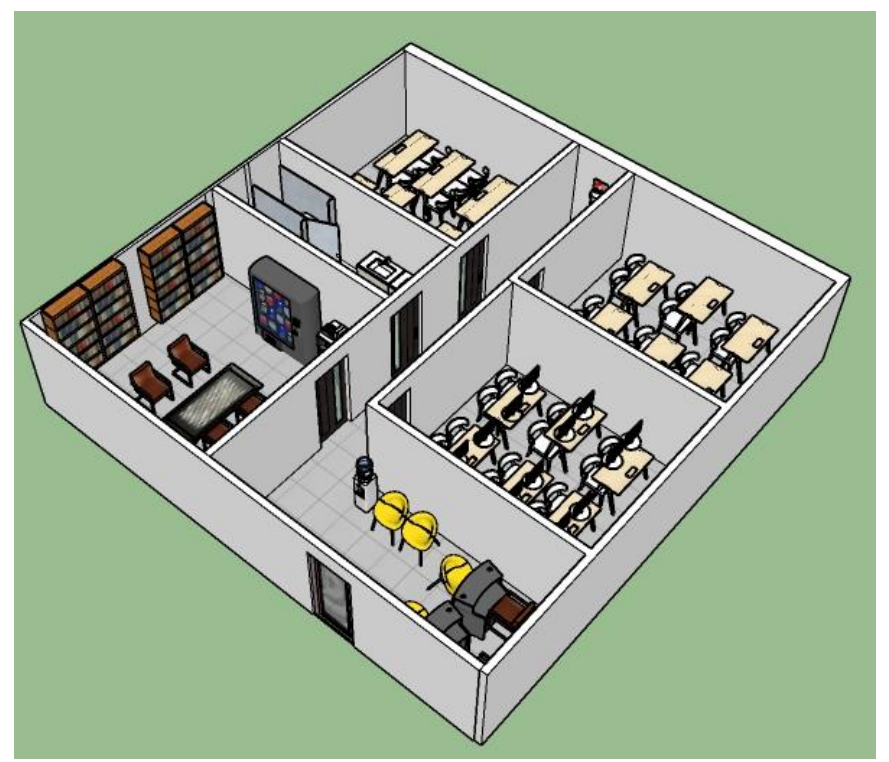

Figura 15. Distribución de Equipos y Muebles de la Escuela. Escala 1:1000

\subsection{Determinación del tamaño}

La Escuela brindará servicios de capacitación de lunes a sábado. Como cuenta con tres salones tienen una capacidad máxima de 45 personas de Aforo. Asimismo, podrá brindar hasta 10 cursos al mes como se describe en la tabla 49.

Tabla 49

Capacidad de cursos por Salón

\begin{tabular}{llllllll}
\hline Horario & Lunes & Martes & Miércoles & Jueves & Viernes & Horario & Sábado \\
\hline 9-12 am & Curso 1 & Curso 2 & Curso 1 & Curso 2 & $9-1 \mathrm{pm}$ & Curso 9 \\
\hline 1-3 pm & Curso 3 & Curso 4 & Curso 3 & Curso 4 & $2-6$ pm & Curso 10 \\
\hline 4-7 pm & Curso 5 & Curso 6 & Curso 5 & Curso 6 & & \\
\hline 7-10 pm & Curso 7 & Curso 8 & Curso 7 & Curso 8 & & \\
\hline
\end{tabular}


Al contar con tres salones la cantidad de cursos que se podrían brindar al mismo tiempo en un mes sería un máximo de 30 cursos, por lo que la capacidad máxima de alumnos que podrían estar matriculados al mismo tiempo sería de 450 alumnos.

De acuerdo con los resultados de la investigación de mercado y en base a la información obtenida en la entrevista con un experto se ha decidido durante la primera etapa solamente brindar clases en las mañanas, en las noches y sábados, lo que daría la cantidad de cursos mostrados en la tabla 50.

Tabla 50

Programación de cursos por salón

\begin{tabular}{llllllll}
\hline Horario & Lunes & Martes & Miércoles & Jueves & Viernes & Horario & Sábado \\
\hline 9-12 am & Curso 1 & Curso 2 & Curso 1 & Curso 2 & $9-1 \mathrm{pm}$ & Curso 5 \\
\hline 1-3 pm & & & & & $2-6$ pm & Curso 6 \\
\hline 4-7 pm & & & & & & \\
\hline 7-10 pm & Curso 3 & Curso 4 & Curso 3 & Curso 4 & & \\
\hline
\end{tabular}

Lo que permitiría una capacidad máxima de 18 cursos al mes con un número máximo de alumnos por mes de 270 alumnos. Esto quiere decir que la capacidad del local utilizada sería de un $60 \%$ de la capacidad total. 


\subsubsection{Proyección de crecimiento.}

Considerando que durante los primeros tres años no se llegará a utilizar la capacidad del local al 100\% no será necesario conseguir un local con más espacio ni más número de salones. Se planea seguir con el mismo personal. Lo único que crecería es el número de profesores conforme se vayan abriendo más cursos y se utilicen más horarios.

\subsubsection{Recursos.}

En base a las proyecciones de ventas se necesitarán la siguiente cantidad de horas de dictado para cubrir los cursos programados (ver tabla 51).

Tabla 51

Horas de dictado por mes

\begin{tabular}{|c|c|c|c|c|c|c|c|c|c|c|c|c|c|c|}
\hline Días & Horario & Salón & Ene & Feb & Mar & Abr & May & Jun & Jul & Ago & Sep & Oct & Nov & Dic \\
\hline Lun-Mie & Mañana & Lab & 0 & 0 & 0 & 0 & 0 & 0 & 0 & 0 & 0 & 0 & 0 & 0 \\
\hline Lun-Mie & Mañana & Aula 1 & 0 & 0 & 0 & 0 & 0 & 0 & 0 & 0 & 0 & 0 & 0 & 0 \\
\hline Lun-Mie & Mañana & Aula 2 & 0 & 0 & 0 & 0 & 0 & 0 & 0 & 0 & 0 & 0 & 0 & 0 \\
\hline Mar-Jue & Mañana & $\mathrm{Lab}$ & 0 & 18 & 18 & 18 & 18 & 18 & 18 & 18 & 18 & 18 & 18 & 18 \\
\hline Mar-Jue & Mañana & Aula 1 & 0 & 0 & 0 & 0 & 0 & 0 & 18 & 18 & 18 & 18 & 18 & 18 \\
\hline Mar-Jue & Mañana & Aula 2 & 0 & 0 & 0 & 0 & 0 & 0 & 18 & 18 & 18 & 18 & 18 & 18 \\
\hline Lun-Mie & Noche & Lab & 0 & 0 & 0 & 0 & 0 & 0 & 18 & 18 & 18 & 18 & 18 & 18 \\
\hline Lun-Mie & Noche & Aula 1 & 0 & 0 & 0 & 0 & 0 & 0 & 18 & 18 & 18 & 18 & 18 & 18 \\
\hline Lun-Mie & Noche & Aula 2 & 0 & 0 & 0 & 0 & 0 & 0 & 0 & 0 & 0 & 0 & 0 & 0 \\
\hline Mar-Jue & Noche & Lab & 0 & 18 & 18 & 18 & 18 & 18 & 18 & 18 & 18 & 18 & 18 & 18 \\
\hline Mar-Jue & Noche & Aula 1 & 0 & 18 & 18 & 18 & 18 & 18 & 18 & 18 & 18 & 18 & 18 & 18 \\
\hline Mar-Jue & Noche & Aula 2 & 0 & 0 & 0 & 0 & 0 & 0 & 18 & 18 & 18 & 18 & 18 & 18 \\
\hline Sábado & Mañana & $\mathrm{Lab}$ & 0 & 18 & 18 & 18 & 18 & 18 & 18 & 18 & 18 & 18 & 18 & 18 \\
\hline Sábado & Mañana & Aula 1 & 0 & 0 & 0 & 18 & 18 & 18 & 18 & 18 & 18 & 18 & 18 & 18 \\
\hline Sábado & Mañana & Aula 2 & 0 & 0 & 0 & 18 & 18 & 18 & 18 & 18 & 18 & 18 & 18 & 18 \\
\hline Sábado & Tarde & Lab & 0 & 0 & 0 & 0 & 0 & 0 & 18 & 18 & 18 & 18 & 18 & 18 \\
\hline Sábado & Tarde & Aula 1 & 0 & 0 & 0 & 0 & 0 & 0 & 0 & 0 & 0 & 0 & 0 & 0 \\
\hline Sábado & Tarde & Aula 2 & 0 & 0 & 0 & 0 & 0 & 0 & 18 & 18 & 18 & 18 & 18 & 18 \\
\hline & Personalizado & Sala A & 0 & 10 & 0 & 10 & 0 & 10 & 10 & 10 & 10 & 10 & 10 & 10 \\
\hline Total & Horas & & 0 & 82 & 72 & 118 & 108 & 208 & 244 & 244 & 244 & 244 & 244 & 244 \\
\hline
\end{tabular}




\subsubsection{Relación de Materiales.}

Para el dictado de las clases solamente se requerirían plumones, motas y los certificados que se van a brindar a los alumnos. A principio de año se comprar el material necesario para los certificados de todo el año.

En la tabla 52 se puede observar los materiales requeridos para el dictado de los cursos:

Tabla 52

Materiales por curso

\begin{tabular}{llrlrrr}
\hline & enero & & febrero & \multicolumn{3}{c}{ marzo } \\
\hline & & & & & & \\
Materiales directos (MD) & S/ & $1,044.80$ & S/ & 44.80 & S/ & 44.80 \\
Plumones & S/ & 36.00 & S/ & 36.00 & S/ & 36.00 \\
Motas & S/ & 8.80 & S/ & 8.80 & S/ & 8.80 \\
Certificados y otros & S/ & $1,000.00$ & & & & \\
\hline
\end{tabular}

\subsubsection{Requerimiento de Personal.}

En el siguiente cuadro se muestra el personal administrativo requerido y sus sueldos (ver tabla 53).

Tabla 53

Gastos de personal

\begin{tabular}{lccccccc}
\hline Cargo & Salario & Gratificación & CTS & Vacaciones & Es Salud & Comisión & Total Anual \\
\hline Recepcionista & & & & & & & \\
& $\mathrm{S} / .950 .00$ & $\mathrm{~S} / 158.33$ & $\mathrm{~S} / 79.17$ & $\mathrm{~S} / 79.17$ & $\mathrm{~S} / 93.87$ & $\mathrm{~S} / 93.00$ & $\mathrm{~S} / 1,453.54$ \\
\hline Gerente & $\mathrm{S} / 2,800.00$ & $\mathrm{~S} / 466.67$ & $\mathrm{~S} / 233.33$ & $\mathrm{~S} / 233.33$ & $\mathrm{~S} / 260.37$ & $\mathrm{~S} / 93.00$ & $\mathrm{~S} / 4,086.70$ \\
\hline Coordinador & $\mathrm{S} / 2,500.00$ & $\mathrm{~S} / 416.67$ & $\mathrm{~S} / 208.33$ & $\mathrm{~S} / 208.33$ & $\mathrm{~S} / 233.37$ & $\mathrm{~S} / 93.00$ & $\mathrm{~S} / 3,659.70$ \\
\hline Total & $\mathbf{S} / \mathbf{6 , 2 5 0 . 0 0}$ & $\mathbf{S} / \mathbf{1 , 0 4 1 . 6 7}$ & $\mathbf{S} / \mathbf{5 2 0 . 8 3}$ & $\mathbf{S} / \mathbf{5 2 0 . 8 3}$ & $\mathbf{S} / \mathbf{5 8 7 . 6 1}$ & $\mathbf{S} / \mathbf{2 7 9 . 0 0}$ & $\mathbf{S} / \mathbf{9 , 1 9 9 . 9 4}$ \\
\hline
\end{tabular}


7.2.2.3 Inversión activo intangible.

La inversión en activo intangible se refiere a los gastos necesarios para el lanzamiento de la empresa. En la tabla 54, se puede ver la inversión inicial en activo fijo e intangible.

\section{Tabla 54}

Inversión en activo intangible

\begin{tabular}{llc}
\hline Concepto & \multicolumn{2}{l}{ Inversión } \\
\hline Licencias software & S/ & 307.63 \\
\hline Gastos de alquiler & S/ & $24,532.20$ \\
\hline Acondicionamiento de local & S/ & $51,027.72$ \\
\hline
\end{tabular}

\subsubsection{Requerimiento de terceros.}

Este requerimiento se refiere a los profesores que van a dictar los cursos se acuerda a las ventas proyectadas. Se ha considerado pagar S/45.00 soles la hora y programar un total de 72 horas al mes. En la tabla 55 se muestra la planilla de pago por profesor.

\section{Tabla 55}

Pagos a profesores

\begin{tabular}{lccccccc}
\hline \multicolumn{1}{c}{ Personal } & \#horas & Sueldo x hora & $\begin{array}{c}\text { Sueldo } \\
\text { mensual }\end{array}$ & Gratificación & $\begin{array}{c}\text { Asignación } \\
\text { Familiar }\end{array}$ & Es Salud & Total \\
\hline $\begin{array}{l}\text { Profesor part } \\
\text { time }\end{array}$ & 72 & S/ 45.00 & S/ 3,240.00 & S/ 540.00 & S/ 93.00 & S/ 299.97 & S/ 4,172.97 \\
\hline
\end{tabular}




\subsubsection{Tecnología.}

Para el desarrollo de las clases presenciales se hará uso de laptops, televisores y pizarras. Para las clases online se desarrollará una página web a través de las cuales los alumnos puedan revisar y descargar los materiales, ver las clases online y dar exámenes de preguntas múltiples. A través de esta página web también se podrá visualizar las notas e inscribirse en futuros cursos.

\subsubsection{Flexibilidad.}

La Escuela de Marketing Digital tiene como una parte de su estrategia ofrecer más flexibilidad que la competencia. Para esto se considerarán los siguientes aspectos:

1. Días de atención: El horario normal de atención será durante días de semana de lunes a sábado.

2. Contenido del curso: En caso se contrate un curso individual, se podría configurar un curso a la medida del alumno.

3. Lugar: Las clases se darán normalmente en el local.

\section{Selección del tamaño ideal.}

Para calcular el tamaño ideal se han considerado los siguientes factores:

1 El número de personas por salón: Se ha considerado que 15 personas sería lo recomendable para que la clase sea didáctica por lo que los salones de la Escuela van a tener como máximo ese número de alumnos.

2 Nro. de salones: al realizar un análisis de la competencia mediante los cursos que dictan y la información obtenida de internet se ha determinado que cuentan con la siguiente cantidad de salones: Negzy (un salón), Mott (cuatro salones) y Pandemia (cinco salones). 
Considerando que es una escuela nueva se consideró que con tres salones es suficiente para cubrir la demanda. Con tres salones a su capacidad completa se puede llegar a tener un aforo máximo de 45 personas en un solo turno.

3 Nro. de Horarios: Si se utilizara el local en las mañanas, tarde y noches e incluso el sábado se podría acomodar hasta 10 cursos en el mes (ver tabla 49), por lo que se podría considerar una capacidad máxima de 450 personas. Sin embargo, se ha decidido no considerar el horario de las tardes (de 1 a $4 \mathrm{pm}$ y de 4 a 7 pm) ya que se considera que la demanda para estos horarios es sumamente baja. Por lo que el local contaría con una capacidad efectiva de seis cursos al mes lo que significa un máximo de 270 alumnos al mes.

Si se requiera brindar clases a un número mayor de 270 alumnos se pueden seguir las siguientes estrategias.

1. Evaluar la posibilidad de dictar cursos online.

2. Programar cursos en las tardes con el objetivo de incrementar la capacidad del local. Con el objetivo de incentivar a posibles clientes a que se inscriban en estos horarios se podría brindar descuentos especiales para las personas que estudien en las tardes.

Esta segunda estrategia no requeriría de mayor inversión en activos, sólo en las promociones o descuentos a aplicarse.

\subsection{Estudio de localización}

Según Sapag (2001), la localización de una empresa puede determinar el éxito o fracaso de un negocio. La decisión de localización es una decisión a largo plazo que puede tener repercusiones económicas importantes en la rentabilidad de un negocio. 


\subsubsection{Definición de factores locacionales.}

Para la Escuela de Marketing Digital se han considerado cuatro factores principales:

- Accesibilidad: La Escuela debe estar ubicada en un lugar de fácil acceso para los empleados y clientes. Debe ser fácil llegar a la escuela mediante transporte público y privado.

- Cercanía al público objetivo: Debe estar en una zona céntrica que sea de fácil acceso a la mayoría del público objetivo.

- Seguridad: La Escuela debe estar en una zona relativamente segura que no tenga un historial frecuente de asaltos. De preferencia en una zona que cuente con cámaras de vigilancia. Asimismo, el edificio donde se encuentre la empresa debe contar con servicio de vigilancia. La oficina debe cumplir con los reglamentos de defensa civil.

- Tamaño: La oficina contará con un metraje alrededor de $118 \mathrm{~m} 2$. Este metraje permitirá acondicionar los ambientes descritos en el plano. Asimismo, se debería poder contar con un aforo mínimo de 45 personas.

- Estacionamientos: La oficina deberá contar con un mínimo de dos estacionamientos para poder recibir a los clientes. Asimismo, debería estar cerca a algún estacionamiento público para los clientes que no lleguen a conseguir un espacio vacío en el estacionamiento asignado.

- Precio: El precio no deberá superar los \$3,000 dólares mensuales

\subsubsection{Macrolocalización.}

La oficina se encontrará en el distrito de Miraflores por los siguientes factores:

- En primer lugar, ha sido el distrito preferido en la encuesta realizada. 
- Es un distrito céntrico, de fácil acceso y relativamente seguro.

- De acuerdo con el análisis realizado como un factor crítico de éxito (ver figura 3), una gran cantidad de agencias, institutos educativos y empresas se encuentran en este distrito. Debido a que el público de la Escuela puede venir de cualquiera de estas tres entidades se consideró que es el distrito ideal para su ubicación.

A continuación, en la figura 16 y 17, se puede visualizar el plano del distrito obtenido de la Municipalidad de Miraflores (Municipalidad de Miraflores, 2013) y la leyenda de tipos de zonificación.

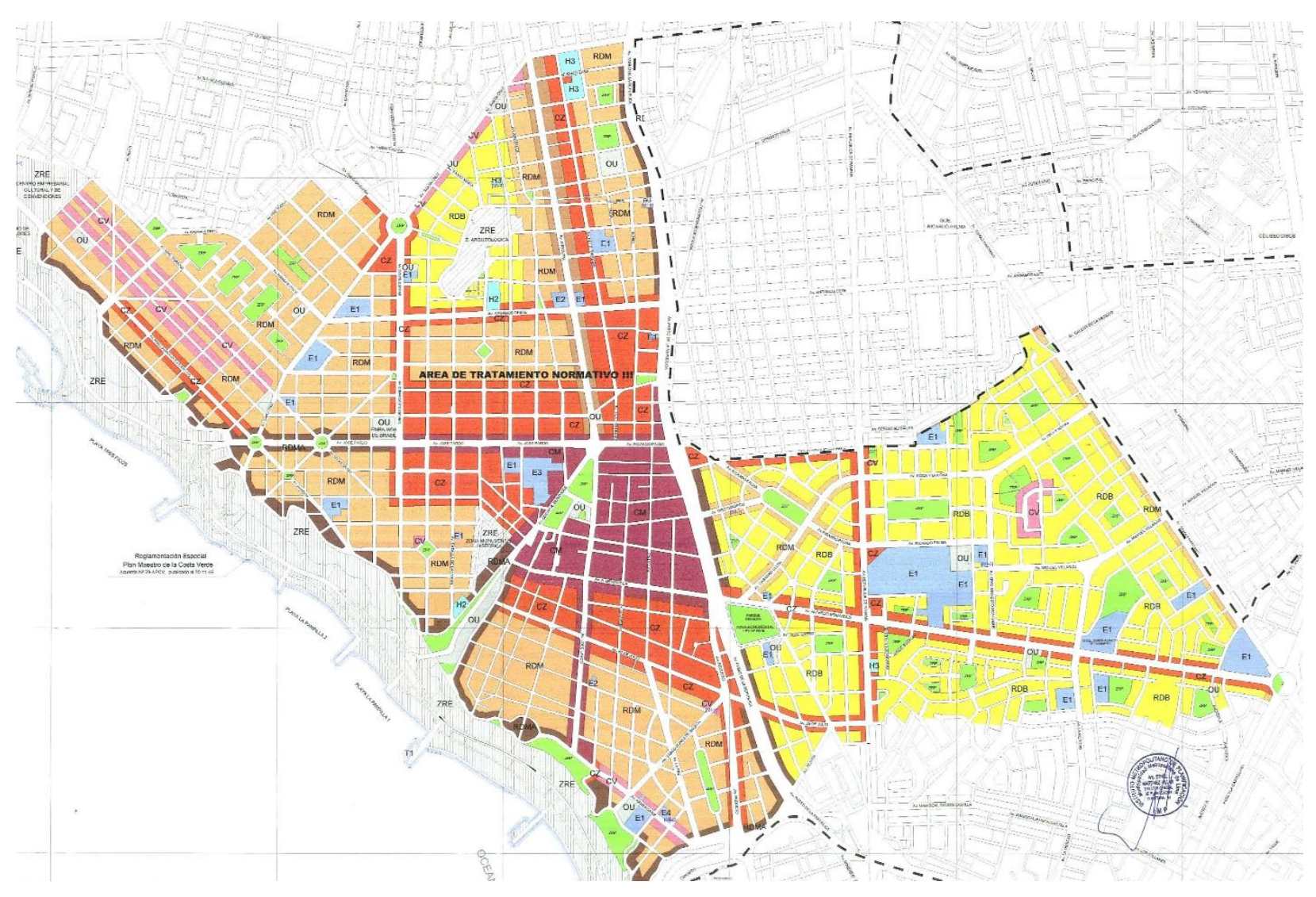

Figura 16. Plano de zonificación de Miraflores, por Municipalidad de Miraflores, 2013, Perú, Lima 
ZONAS RESIDENCIALES

RDB Residencial de Densidad Baja

RDM Residencial de Densidad Media

RDA Residencial de Densidad Alta

RDMA Residencial Densidad Muy Alta

ZONAS COMERCIALES

CV Comercio Vecinal

CZ Comercio Zonal

CM Comercio Metropolitano

Figura 17. Zonificación de Miraflores, por Municipalidad de Miraflores, 2013, Perú, Lima

El distrito de Miraflores se encuentra dividido por zonas. Se ha considerado que sería preferible que la Escuela se encuentre en una zona de comercio metropolitano o de comercio zonal ya que estas zonas son de fácil acceso debido a que varias rutas de transporte pasan por estas ubicaciones. Ejemplos de este tipo de zonas en Miraflores son: (a) Av. Del Ejército, (b) Av. Larco, (c) Av. Pardo, (d) Av. Benavides, (e) Toda la zona alrededor de parque Kennedy entre otras.

\subsubsection{Microlocalización.}

Con el objetivo de seleccionar la ubicación de la oficina se han considerado los seis factores descritos anteriormente. A cada factor se le ha asignado un peso en la evaluación de las alternativas. Asimismo, se evaluará cada factor asignándole una calificación desde cinco (Muy bueno) a uno (Muy Malo). En la tabla 56 se muestran los factores de localización y el rango de valoración del puntaje. 
Tabla 56

Factores de localización

\begin{tabular}{ll}
\hline Factor & \% de ponderación \\
\hline Accesibilidad & $20 \%$ \\
\hline Cercanía & $20 \%$ \\
\hline Seguridad & $10 \%$ \\
\hline Tamaño & $15 \%$ \\
\hline Estacionamientos & $10 \%$ \\
\hline Precio & $25 \%$ \\
\hline Total & $100 \%$ \\
\hline
\end{tabular}

Tabla 57

Valoración del puntaje

\begin{tabular}{ll}
\hline Valoración & Puntaje \\
\hline Muy Bueno & 5 \\
\hline Bueno & 4 \\
\hline Regular & 3 \\
\hline Malo & 2 \\
\hline Muy Malo & 1 \\
\hline
\end{tabular}


En la tabla 58 se muestran las ofertas de alquiler analizadas.

Tabla 58

Alternativas de alquiler

\begin{tabular}{lllll}
\hline Factor & Alternativa 1 & Alternativa 2 & Alternativa 3 & Alternativa 4 \\
\hline Accesibilidad & Lejos de & Cerca de & Cerca de & Cerca de \\
& transporte & transporte & transporte & transporte público \\
& público & público & público & \\
& Cerca de vía & Av. El Ejército & Av. Larco & Av. Larco \\
\hline Cercanía & expresa & & & \\
& No tiene & No tiene & No tiene & No tiene \\
\hline Seguridad & $117 \mathrm{~m} 2$ & $117.5 \mathrm{~m} 2$ & $120 \mathrm{~m} 2$ & $110 \mathrm{~m} 2$ \\
\hline Tamaño & & 2 & 5 & No tiene \\
\hline Estacionamientos & 2 & $\$ 2,478$ & $\$ 4,400$ & $\$ 7,900$ \\
\hline Precio & $\$ 3,910$ & & & \\
\hline
\end{tabular}

La información de los locales en alquiler se obtuvo de las siguientes páginas:

- Alternativa 1: https://urbania.pe/inmueble/alquiler-de-local-comercial-en-mirafloreslima-4172575

- Alternativa 2: https://www.adondevivir.com/propiedades/moderno-local-comercial-1175-m-sup2-miraflores-54109967.html

- Alternativa 3: https://urbania.pe/inmueble/alquiler-de-local-comercial-en-mirafloreslima-4171487 
- Alternativa 4: https://www.adondevivir.com/propiedades/exclusivo-local-en-miraflores55252683.html

Con la información obtenida se procedió a calcular la mejor alternativa, de acuerdo al puntaje acumulado (ver tabla 59).

Tabla 59

Ponderación de alternativas

\begin{tabular}{cccccccc}
\hline & Accesibilidad & Cercanía & Seguridad & Tamaño & Estacionamiento & Precio & Total \\
\hline Alternativa & $20 \%$ & $20 \%$ & $10 \%$ & $15 \%$ & $10 \%$ & $25 \%$ & $100 \%$ \\
/Ponderación & & & & & & & \\
\hline 1 & 3 & 4 & 3 & 5 & 3 & 4 & 3.75 \\
\hline 2 & 5 & 5 & 3 & 5 & 3 & 5 & 4.60 \\
\hline 3 & 5 & 5 & 3 & 5 & 5 & 3 & 4.30 \\
\hline 4 & 5 & 5 & 3 & 4 & 1 & 1 & 3.25 \\
\hline
\end{tabular}

La ponderación se realizó siguiendo los siguientes criterios:

- Accesibilidad: Se consideró a los locales ubicados en la Av. El Ejército y la Av. Larco, de alta accesibilidad, ya que existen líneas de transporte públicos que pasan por esas avenidas. El local de la Vía Expresa es más difícil de acceder.

- Cercanía: Todos los locales al encontrarse al encontrarse en pleno Miraflores están cercanos al público objetivo.

- Seguridad: Ninguno cuenta con seguridad propia del local por lo que se considera intermedia al ser un distrito relativamente seguro en comparación a otros distritos. 
- Tamaño: Todos los locales cumplen con el tamaño requerido en el plano de $118 \mathrm{~m}^{2}$, sin embargo, la alternativa cuatro tiene un tamaño ligeramente menor.

- Estacionamiento y Precio: Se realizó la puntuación en base al número de estacionamientos y en el caso del precio la más valorada fue la opción más económica.

En base al puntaje obtenido y teniendo en cuenta que el precio es un factor muy importante (25\%) se encontró que la mejor alternativa para el proyecto es la alternativa número dos.

\subsubsection{Consideraciones legales.}

En esta sección se considerará los trámites legales que se debe cumplir para implementar el proyecto.

\subsubsection{Identificación del marco legal.}

Licencia Municipal

Como la Escuela de Marketing Digital se va a encontrar en el distrito de Miraflores se procedió a averiguar los requerimientos para tramitar la licencia. Según la municipalidad de Miraflores (Municipalidad de Mirafloes, 2012) existen tres tipos de licencias:

- Categoría I: Para locales de hasta $100 \mathrm{~m}^{2}$.

- Categoría II: Para locales de más de $100 \mathrm{~m}^{2}$ hasta $500 \mathrm{~m}^{2}$, o hasta dos pisos o con un máximo de 20 computadoras.

- Categoría III: Para locales de más de $500 \mathrm{~m}^{2}$, o más de dos pisos, o con más de 20 computadoras 
En el caso de la Escuela de Marketing Digital se procedería con la categoría II. Para este tipo de categoría se solicita los siguientes requisitos:

- Solicitud de Licencia de Funcionamiento: Esta solicitud tiene carácter de declaración jurada e incluye número de RUC y DNI o carnet de extranjería de la persona que solicita.

- Vigencia de poder del representante legal en caso de personas jurídicas. Para personas naturales se requiere carta poder con firma legalizada.

- Cumplir con los requisitos para la inspección técnica de seguridad en defensa civil básica.

- Pago de una tasa por derecho de trámite que en el caso de la categoría II sería de S/415.89 soles.

En la figura 18, se puede observar el proceso de obtención de licencia de la municipalidad de Miraflores: 
PROCEDIMIENTO PARA OBTENER LA LICENCIA DE

FUNCIONAMIENTO DEFINITIVA

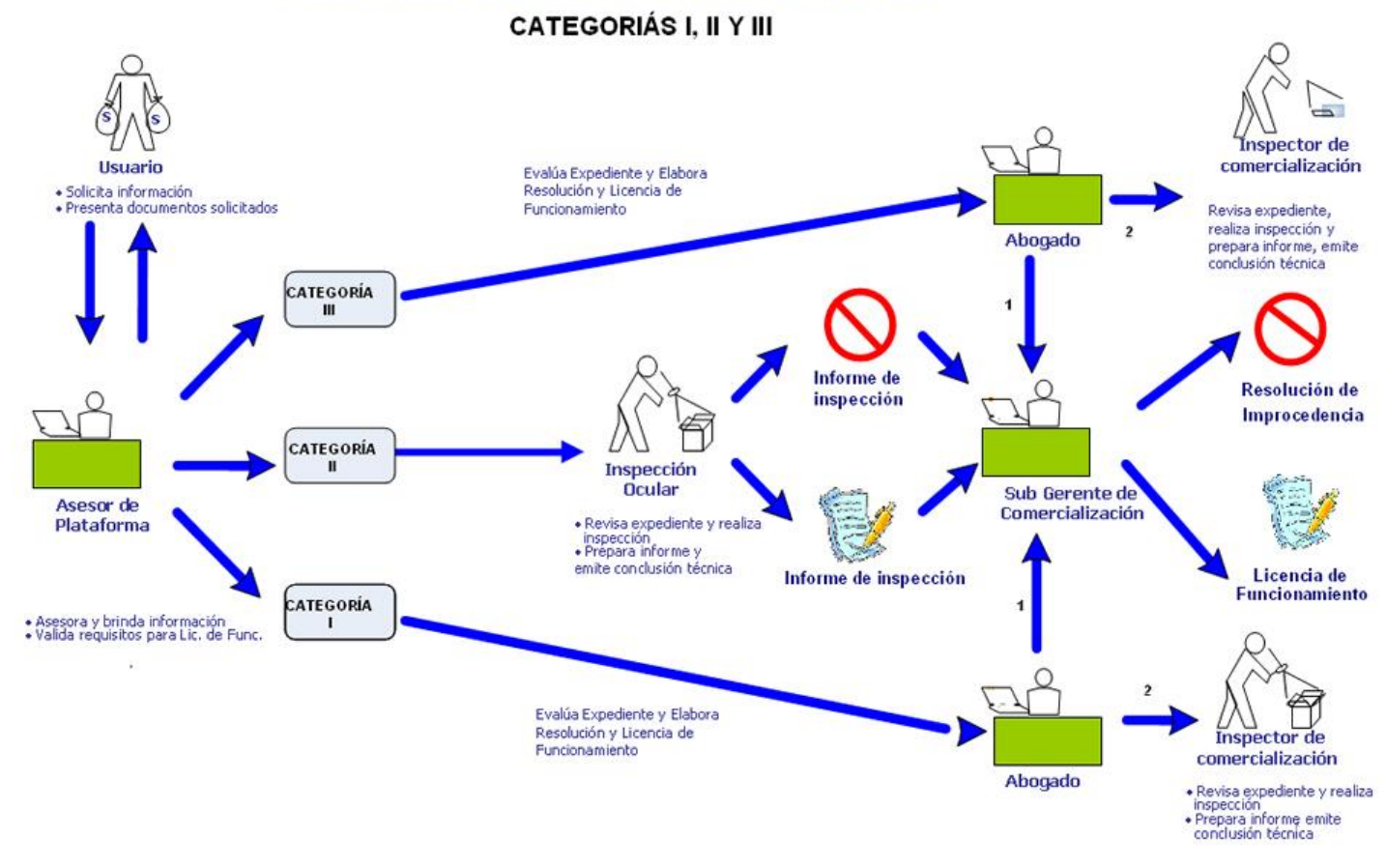

Figura 18. Proceso de obtención de licencia en Miraflores, por Blog de la Municipalidad de Miraflores, 2012, Perú, Lima

\section{Requisitos para la obtención de la Licencia:}

De acuerdo con la declaración jurada de cumplimiento de las condiciones de seguridad que se encuentra en la página web de la Municipalidad de Miraflores (2018), se requieren las siguientes medidas de seguridad para la obtención de la licencia:

- El local no debe encontrarse en proceso de construcción (obra terminada)

- Contar con servicios de agua, electricidad y demás servicios que resulten esenciales para el desarrollo de las actividades.

- Mobiliario básico e instalado para el desarrollo de la actividad. 
- Cuenta con los equipos o artefactos debidamente instalados o ubicados en los lugares de uso habitual.

- Las vías de evacuación (pasadizos, escaleras, accesos y salidas) del establecimiento presentan un ancho mínimo de 1.20 y permiten la evacuación de las personas de manera segura.

- Las vías de evacuación se encuentran libres de obstáculos.

- El establecimiento cuenta con señalización de seguridad tales como direcciones de salida, salida, zona segura en caso de sismo, riesgo eléctrico, extintores, entre otros.

- El establecimiento está equipado con luces de emergencia operativas.

- Las puertas que se utilizan como medios de evacuación abren en el sentido del flujo de los evacuantes o permanecen abiertas en el horario de atención.

- No cuenta con material combustible o inflamable debajo de las escaleras que sirven como medio de evacuación.

- El gabinete de la instalación eléctrica es de material metálico o resina termoplástica.

- Cuenta con interruptores termo magnéticos apropiados para la capacidad de corriente utilizada. Además, tiene un circuito eléctrico por cada interruptor magnético y no utiliza conductores flexibles (cable tipo mellizo)

- Los circuitos de tomacorrientes no están sobrecargados con extensiones o adaptadores.

- Contar con extintores operativos y en cantidad adecuada al riesgo existente en el establecimiento.

- Los extintores deben contar con tarjeta de control y mantenimiento actualizada y estar ubicados en lugares accesibles y protegidos de los elementos.

- Contar con plan de seguridad para hacer frente a los riesgos. 
- Contar con un sistema de detección y alarma de incendios.

- La cimentación o parte de ella no se encuentra expuesta o en peligro de colapso como consecuencia de filtraciones de agua, socavamiento entre otros.

- El tablero eléctrico se encuentra conectado a tierra y cuenta con placa de protección

- Las aberturas no usadas en tableros eléctricos se encuentran cerradas con tapas.

- Se cuenta con un certificado de medición de resistencia del pozo a tierra firmado por ingeniero o técnico electricista colegiado.

- Los conductores eléctricos utilizados se encuentran protegidos con tubos o canaletas de PVC.

- Las estructuras de soporte de equipos de aire acondicionado, condensadores y otros están adecuadamente fijas y en buen estado de conservación.

- Las puertas, ventanas, mamparas y otros elementos frágiles que se encuentren ubicados en áreas donde existe riesgo de rotura por impacto accidental deben ser de vidrio templado o laminado. En caso sean de vidrios primarios deben tener láminas de seguridad u otro sistema de protección en caso de rotura.

- Debe haber un espacio libre de no menos a un metro frente a tableros eléctricos, así como también, iluminación general y de emergencia en dicha zona.

\subsubsection{Ordenamiento jurídico de la empresa.}

Según Mi Empresa Propia (2016), los pasos que se deben seguir para la constitución y formalización de la empresa son los siguientes:

1. Elegir el tipo de empresa: En el Perú se pueden crear empresas bajo dos modalidades: 
1. Persona Natural: Bajo esta modalidad la empresa se forma por una sola persona $y$ esa persona tiene responsabilidades ilimitadas por las actividades de la empresa.

2. Persona Jurídica: Bajo esta modalidad se puede formar una empresa ya sea una o más personas. Este tipo de persona cuenta con varias opciones; Empresa Individual de responsabilidad limitada (E.I.R.L), Sociedad Anónima Cerrada (S.A.C.) entre otras. En este tipo de empresas los socios tienen responsabilidad limitada ya que el patrimonio de estos está separado del patrimonio del negocio. Para la Escuela de Marketing Digital se va a escoger la persona jurídica. Sería una sociedad anónima cerrada dado que son dos los socios que la conformarán.

2. Búsqueda de nombres: Antes de constituir la empresa se debe escoger el nombre de ésta, por lo que es importante la búsqueda de nombres. Los pasos para la búsqueda de nombres son los siguientes:

1 Acercarse a una de las oficinas de la SUNARP.

2 Realizar la búsqueda del nombre o los posibles nombres para escoger cuál de ellos está libre. El costo del trámite es de S/5.00 y los resultados se obtienen el mismo día.

3. Reserva de nombre: Una vez que se ha escogido el nombre se procede a reservarlo. La reserva tiene un coste de $\mathrm{S} / 18.00$ y permite inscribir la empresa con el nombre elegido hasta por 30 días.

4. Elaboración de la minuta de constitución: La minuta debe ser realizada por un abogado y en el contenido deben estar especificados los estatutos de la empresa. Los estatutos deben contener la siguiente información:

1. Distribución del aporte de capital de los socios. 
2. Las actividades económicas que va a realizar la empresa.

3. Especificar las funciones que va a realizar el representante legal y los gerentes

5. Apertura de una cuenta bancaria: Si el aporte de los socios es monetario se debería abrir una cuenta bancaria a nombre de la empresa y depositar el aporte. Si los aportes son no monetarios (bienes) es necesario firmar una declaración jurada de aporte de bienes.

6. Después de elaborarse la minuta es necesario darle formalidad a la misma a través de una escritura pública. Esta escritura debe estar autorizada por un notario que de fe del contrato. La escritura debe ser firmada por los integrantes de la empresa.

7. Una vez que se haya firmado la escritura ya sean los socios o el notario deberán proceder a inscribir a la empresa en la SUNARP

8. Una vez realizada la inscripción en registros públicos la notaria deberá entregar a los socios una copia registra certificada y el testimonio de la empresa.

9. Inscripción en la SUNAT: Para inscribirse en la SUNAT como persona jurídica es necesario que el representante legal lleve la siguiente información:

1. Documento de identidad del representante legal

2. Comprobante de servicios no mayor a dos meses de antigüedad

3. Partida registral certificada

10. Al momento de registrarse, el representante legal deberá brindar sus datos personales, indicar que actividades económicas desarrollará la empresa, declarar el domicilio fiscal y escoger el régimen tributario adecuado. Los regímenes tributarios por los que se puede optar son los siguientes:

1. Nuevo RUS

2. Régimen Especial 


\section{Régimen General}

11. Una vez que se haya entregado la información respectiva, dicha información será consignada en la ficha RUC y se entregará una constancia de información registrada (CIR).

12. A continuación, se debe solicitar la clave SOL. Dicha clave permitirá acceder a la plataforma de SUNAT de forma virtual para realizar operaciones tributarias.

13. En el caso de que se desee iniciar las operaciones económicas se deberá realizar los siguientes pasos:

1. En el caso del régimen especial o régimen general se deberá comprar libros u hojas contables, legalizarlos y entregarlos al contador para que registre las operaciones de forma permanente. Para el caso del RUS no se requiere el registro de libros contables.

2. Para comenzar a realizar las primeras ventas es necesario acercarse a una imprenta autorizada por la SUNAT para realice la impresión de las boletas o facturas.

14. Formalización Laboral: Es importante que desde el primer momento la empresa formalice la relación laboral con sus trabajadores. Para esto existen varios regímenes laborales, pero son dos los más utilizados.

1. Régimen Laboral General: este régimen tiene las siguientes características

i. El trabajador recibe una serie de beneficios laborales tales como CTS, Gratificaciones, 30 días de vacaciones, seguro social (Es Salud) entre otros. 
ii. El empleador deberá firmar un contrato de trabajo con el empleado, el cual deberá tener tres copias: Para la empresa, para el trabajador y la tercera se envía al ministerio de trabajo.

iii. La información laboral de los trabajadores se debe ingresar al T-Registro de la SUNAT

iv. Todos los meses se debe presentar la planilla de pagos usando el PDT Plame con la información de salarios, retenciones de impuestos de cuarta y quinta categoría, Es Salud, entre otros.

2. Régimen Laboral Especial: Según la ley MYPE una empresa pequeña puede formalizar a los trabajadores bajo este régimen. Este régimen permite a la empresa ofrecer un paquete menor de beneficios laborales tales como: 15 días de vacaciones anuales en vez de 30 días, la opción de afiliarlos al servicio integral de salud (SIS) en vez de Es Salud, la eliminación de la CTS y las gratificaciones entre otras características.

Según Sunat (2018) las empresas que podrían acogerse a esta ley deben cumplir estos ingresos que no superen las 1,700 UIT en el año.

La Escuela de Marketing Digital se inscribiría durante la primera etapa en este régimen.

\subsection{Determinación de la localización óptima}

En la tabla 59 se determinó que la localización óptima para la implementación de la Escuela de Marketing Digital es la alternativa dos, la cual está ubicada en Av. Del Ejército 490 y cuenta con las siguientes características: (A donde vivir, 2018)

- Área: $117 \mathrm{~m}^{2}$ 
- Condiciones de alquiler: dos meses de garantía y un mes de adelanto con un contrato de cinco años de alquiler y un incremento anual de $3 \%$

- Precio de Alquiler: \$2,478 dólares o S/8,115 soles mensuales

- Fecha de entrega: Diciembre 2018

- Antigüedad: A estrenar

En la figura 19 se puede observar la ubicación del local seleccionado.

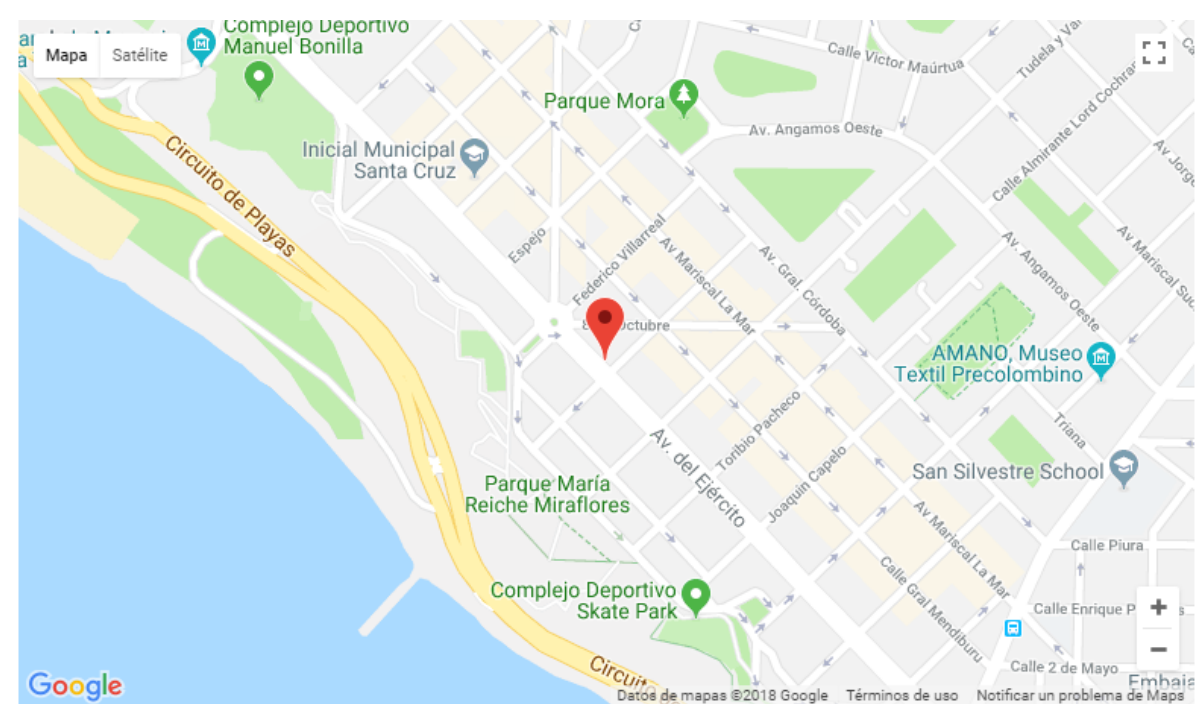

Figura 19. Local Comercial 117,5 $\mathrm{m}^{2}$ Miraflores, por A Donde Vivir, 2018, Perú, Lima

También se encontró información del mismo local en una página de Urbania (2018) donde se puede ver la distribución y los exteriores. Además, este local comparte cerca de 10 estacionamientos otros cinco locales lo que nos da un promedio de dos estacionamientos por local (ver figura 20 y 21). 


\section{Vistas Planos}

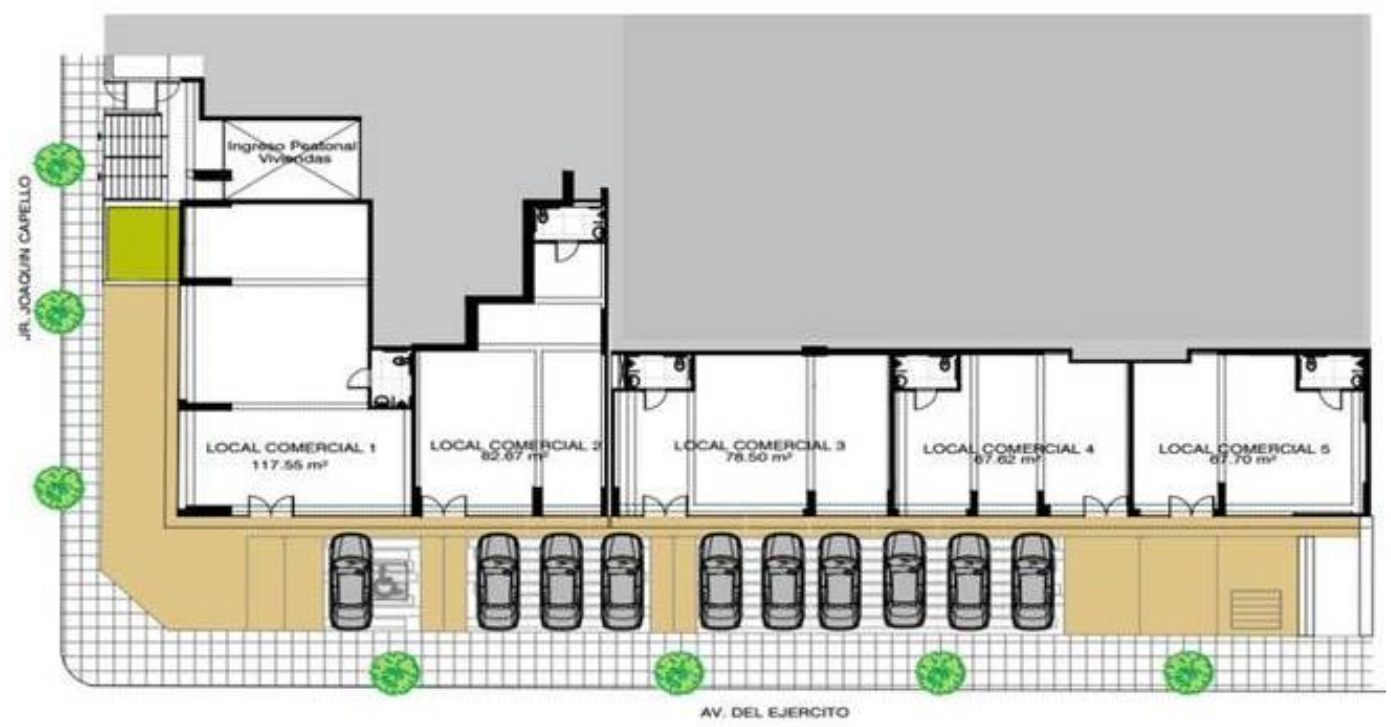

AT: $402.5 \mathrm{~m} 2$

Figura 20. Plano Local Comercial en Miraflores - Av. Del Ejército 490, por Urbania, 2018, Perú, Lima

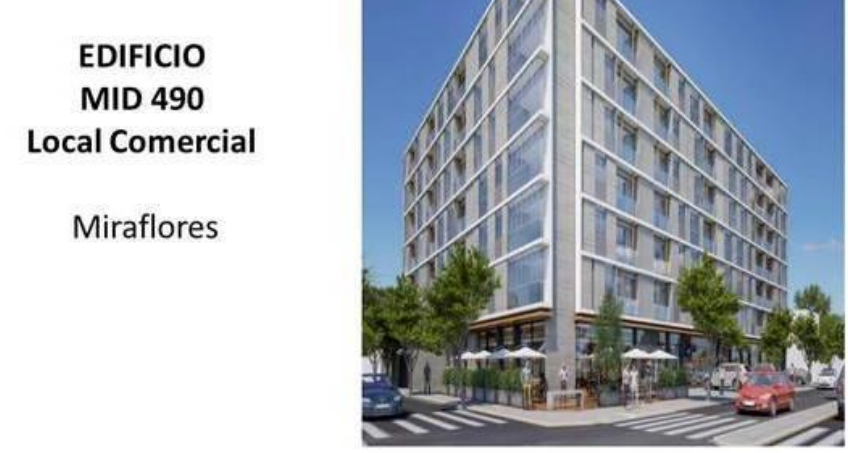

Figura 21. Edificio MID. Tomado de Alquiler de Local Comercial en Miraflores - Av. Del Ejército 490, por Urbania, 2018, Perú, Lima 
Ventajas del local

- Se encuentre en la esquina de una avenida comercial de fácil acceso.

- Cuenta con estacionamientos.

- Se encuentra ubicado en un edificio nuevo por lo que no hay problemas por antigüedad de la infraestructura.

- Área y distribución son adecuadas para el funcionamiento de la Escuela. 


\section{Capítulo VIII: Aspectos Organizacionales}

En el presente capítulo se desarrollan los aspectos organizacionales del estudio, tales como la misión, visión, estrategias de negocio y estructura organizacional.

\subsection{Caracterización de la cultura organizacional deseada}

Robins y Judge (2013) definen la cultura organizacional como un sistema que distingue a las organizaciones, unas de otras. La cultura organizacional describe la manera como se hacen las cosas dentro de una organización, como se comportan las personas dentro de ella. La cultura les da un sentido de identidad a los miembros de la organización, genera un compromiso que guía a todos hacia un mismo objetivo. La cultura se origina en la manera de pensar y actuar de los fundadores de la organización y es uno de los criterios que se toman en cuenta al momento de seleccionar a los empleados.

\subsubsection{Visión.}

Para David (2013) la visión es aquello en lo que la organización aspira a convertirse. Según Reuben Mark (David, 2013), ex CEO de Colgate, "la visión debe ser algo que haga sentir mejor a la gente, que le dé la sensación de formar parte de algo".

Los nueve criterios para evaluar una visión según D’Alessio (2015) se muestran en la tabla 60 . 
Tabla 60

Criterios para evaluar la visión

\begin{tabular}{|c|c|c|c|}
\hline 1 & $\begin{array}{l}\text { ¿Contiene la ideología central de la } \\
\text { organización? }\end{array}$ & Sí & Incluye el valor de la excelencia, el \\
\hline 2 & ¿Está redactada en tiempo futuro? & Sí & $\begin{array}{l}\text { Está enfocada a lo que se espera alcanzar } \\
\text { en el } 2021 .\end{array}$ \\
\hline 3 & ¿Es simple, clara y comprensiva? & Sí & Está redactada en un lenguaje sencillo \\
\hline 4 & ¿Es ambiciosa, convincente y realista? & Sí & $\begin{array}{l}\text { Indica el reconocimiento que espera } \\
\text { alcanzar al } 2021 \text { Está circunscrita sólo al } \\
\text { campo del marketing digital. }\end{array}$ \\
\hline 5 & $\begin{array}{l}\text { ¿Está definida en un horizonte de } \\
\text { tiempo que permita los cambios? }\end{array}$ & Sí & Se contempla un plazo de 3 años. \\
\hline 6 & ¿Está proyecta a un alcance geográfico? & Sí & $\begin{array}{l}\text { Se proyecta el reconocimiento a nivel } \\
\text { nacional }\end{array}$ \\
\hline 7 & ¿Es conocida por todos? & Sí & $\begin{array}{l}\text { Se encontrará publicada en la recepción } \\
\text { del local. Se incluirá el tema en el proceso } \\
\text { de inducción del personal. }\end{array}$ \\
\hline 8 & $\begin{array}{l}\text { ¿Está expresada de tal manera que } \\
\text { permite crear un sentido de urgencia? }\end{array}$ & Sí & $\begin{array}{l}\text { Se establece una meta y un plazo para } \\
\text { alcanzarla. }\end{array}$ \\
\hline 9 & $\begin{array}{l}\text { ¿Da una idea clara desarrollada sobre } \\
\text { adónde desea ir la organización? }\end{array}$ & Sí & $\begin{array}{l}\text { Se indica que se aspira a ofrecer una } \\
\text { formación de excelencia y a ser } \\
\text { reconocida a nivel nacional. }\end{array}$ \\
\hline
\end{tabular}


La visión de la Escuela de Marketing Digital al 2021 es:

"Ser al 2021 una institución reconocida a nivel nacional por su ofrecer a sus alumnos una formación de excelencia en el campo del marketing digital.”

\subsubsection{Misión.}

De acuerdo con David (2013), la misión es el pilar, el punto de partida de todos los planes, estrategias y tareas dentro de una organización. La misión es la descripción del negocio, la razón de para qué existe la organización, debe ser amplia y conciliatoria. Son nueve los componentes que debe tener en cuenta la misión (ver tabla 61): 
Tabla 61

Nueve componentes de la misión

1 Clientes Los clientes de la Escuela de Marketing Digital son los alumnos y en algunos casos los padres de estos.

2 Producto o servicio La Escuela de Marketing Digital brindará el servicio de enseñanza.

3 Mercados El mercado objetivo de la Escuela está conformado (en el aspecto geográfico)

por habitantes de los distritos de: Miraflores, San isidro, San Borja Surco, La Molina, Jesús María, Lince, Pueblo Libre, Magdalena y San Miguel. Pero se espera que se posicione y alcance reconocimiento a nivel nacional.

$4 \quad$ Tecnología

$5 \quad$ Preocupación por la

supervivencia, el

crecimiento y la

rentabilidad
La Escuela contará con equipos modernos y con cursos actualizados de acuerdo con las tendencias del mercado.

La Escuela será una organización competitiva y buscará ser un negocio rentable para sus accionistas.
$6 \quad$ Filosofía

$7 \quad$ Auto concepto
La filosofía de la escuela se basará en el respeto por las personas y sus ideas, la excelencia académica, la innovación y el respeto por el medio ambiente. enseñanza de calidad, a través de profesores reconocidos, una metodología de enseñanza personalizada, la flexibilidad de sus cursos y la fácil aplicación de estos en el ámbito laboral.

8 Preocupación por la La Escuela mantendrá una imagen pública de respeto hacia las personas y el imagen pública medio ambiente. Así también buscará el reconocimiento como una institución educativa de calidad.

9 Preocupación por los La Escuela contará con colaboradores valiosos y talentosos, con experiencia y empleados entusiasmo para realizar sus funciones. 
La misión de la Escuela de Marketing Digital se ha establecido como sigue: "Mossaiqo es una escuela de marketing digital conformada por un equipo con experiencia y talento. Es una institución que contribuye al bienestar de la sociedad a través de la capacitación de personas, a las cuales dota de competencias que les permiten desenvolverse de manera exitosa en el área de marketing u otra relacionada a esta, dentro de cualquier organización”.

\subsubsection{Principios.}

Según Jones (2008), los valores de una organización persiguen establecer el tipo de comportamiento esperado de parte de aquellos quienes conforman la organización.

La Escuela de Marketing Digital, se regirá por los siguientes principios o valores:

- Respeto por las personas y sus ideas: respeto por el ser humano, miembro o no de la institución, por su dignidad, sus creencias y sus distintas formas de pensar.

- Excelencia académica: en todos los aspectos del proceso educativo, tales como la elaboración de los sílabos, la metodología de enseñanza y el sistema de evaluación.

- Innovación: se buscará la mejora, modernización y renovación en los procesos.

- Respeto por el medio ambiente: a través de la implementación de políticas institucionales como el ahorro y reciclaje de papel, uso inteligente de la energía eléctrica, el uso de productos no tóxicos para la limpieza de las instalaciones. 


\subsection{Formulación de Estrategias del Negocio.}

Las empresas gastan recursos y sacrifican oportunidades al optar por determinadas estrategias. Dichas estrategias deben diseñarse con el fin de alcanzar los objetivos que se ha fijado la organización. Generalmente las estrategias y objetivos establecen para un periodo de cinco años. (David, 2013)

La formulación e implementación de estrategias es una tarea prioritaria de la administración. Una estrategia bien diseñada y efectivamente implementada puede ser una ventaja competitiva, puede hacer felices a los clientes y mejorar la rentabilidad de la organización. (Thompson, Peteraf, Gamble, \& Strickland, 2012)

Según los autores, son cinco las estrategias competitivas más comunes:

- Estrategia de costos bajos: llegar a muchos clientes manejando bajos costos con respecto de la competencia.

- Estrategia de diferenciación amplia: atraer el mayor número posible de clientes a través de la oferta de un producto o servicio diferenciado.

- Estrategia dirigida de bajo costo: ofrecer productos de bajo costo a un pequeño segmento de consumidores.

- Estrategia dirigida de diferenciación: se enfoca en conseguir un segmento específico de compradores, siendo la ventaja frente a los rivales el ofrecer un producto que satisfaga gustos y necesidades específicas de dicho segmento.

- Estrategia de mejores costos del proveedor: esta estrategia trata de brindar mayor valor por el monto que está adquiriendo el bien o el servicio esto se puede dar a través del incremento de atributos o características adicionales al producto que no generen costos elevados en comparación de la competencia. 
La estrategia seleccionada para la Escuela de Marketing Digital será la de diferenciación basada en:

- Alto nivel de servicio al cliente: atención personalizada, grupos pequeños de alumnos por curso, clases individuales en horarios que el alumno elija, posibilidad de estudiar sólo los módulos del curso que el alumno desee.

- Inversión en promoción y publicidad para el lanzamiento de la Escuela y para su posicionamiento en el mercado como la primera en ofrecer un servicio personalizado.

- Generación de alianzas con empresas para ofrecer a los alumnos la oportunidad de crear campañas de marketing digital que puedan implementarse en la realidad.

\subsection{Determinación de las ventajas competitivas críticas.}

Con el aumento de la competencia en el sector servicio, es una necesidad diferenciarse frente a los clientes. Una organización exitosa es esa que los clientes consideran como la mejor proveedora del servicio que están buscando contratar. Por lo tanto, las organizaciones deben atender a los clientes a quienes estén en capacidad de satisfacer de mejor manera, es decir, deben enfocarse en un segmento determinado del mercado. (Lovelock \& Wirtz, 2010) Según Thompson et al. (2012), la ventaja competitiva es aquella que se enfoca en satisfacer las necesidades de los consumidores, de la manera más eficaz.

Los planteamientos estratégicos que garantizarán una ventaja competitiva sustentable serán:

- Ser una Escuela especializada en Marketing Digital. Sólo se dictarán cursos relacionados a esta área.

- Mantenerse siempre a la vanguardia, ofreciendo los cursos de última tendencia a nivel mundial. 
- Contar con profesores de alto nivel académico, con experiencia comprobada en el área de marketing digital.

- Establecer una metodología de enseñanza que conjugue la teoría con la práctica, un método de enseñanza dinámico y eficaz.

La ventaja competitiva de la Escuela consistirá en:

- Ofrecer un producto diferenciado: cursos en dos distintas modalidades (regulares o grupales y personalizados).

- Contar una metodología propia, enfocada en brindar clases dinámicas, donde se fomente la participación del alumno y se le motive a poner en práctica lo aprendido.

- Poner a disposición del alumno un ambiente agradable y adecuado para el desarrollo de las clases presenciales.

Para la elaboración de la matriz VRIO (ver tabla 62) se consideró las preguntas establecidas por Barney y Griffin en 1992 (Vega, s.f.) 
Tabla 62

Matriz VRIO

\begin{tabular}{|c|c|c|c|c|c|}
\hline Recurso & ¿Es valioso? & $\begin{array}{l}\text { ¿Es raro, } \\
\text { único o } \\
\text { escaso? }\end{array}$ & $\begin{array}{l}\text { ¿Es difícil } \\
\text { de imitar? }\end{array}$ & $\begin{array}{l}\text { ¿La } \\
\text { organización } \\
\text { está alineada } \\
\text { con los } \\
\text { recursos? }\end{array}$ & Implicancia \\
\hline $\begin{array}{l}\text { Personalización } \\
\text { del servicio }\end{array}$ & SI & SI & SI & SI & $\begin{array}{l}\text { Ventaja } \\
\text { competitiva }\end{array}$ \\
\hline $\begin{array}{l}\text { Escuela } \\
\text { especializada } \\
\text { en marketing } \\
\text { digital }\end{array}$ & SI & SI & $\mathrm{NO}$ & SI & $\begin{array}{l}\text { Ventaja } \\
\text { competitiva } \\
\text { temporal }\end{array}$ \\
\hline $\begin{array}{l}\text { Clases } \\
\text { individuales }\end{array}$ & SI & SI & $\mathrm{NO}$ & SI & $\begin{array}{l}\text { Ventaja } \\
\text { competitiva } \\
\text { temporal }\end{array}$ \\
\hline $\begin{array}{l}\text { Grupos } \\
\text { pequeños }\end{array}$ & SI & SI & $\mathrm{NO}$ & SI & $\begin{array}{l}\text { Ventaja } \\
\text { competitiva } \\
\text { temporal }\end{array}$ \\
\hline $\begin{array}{l}\text { Personal } \\
\text { docente } \\
\text { capacitado }\end{array}$ & SI & SI & $\mathrm{NO}$ & SI & $\begin{array}{l}\text { Ventaja } \\
\text { competitiva } \\
\text { temporal }\end{array}$ \\
\hline $\begin{array}{l}\text { Capacidad de } \\
\text { ofrecer cursos } \\
\text { nuevos según } \\
\text { tendencias }\end{array}$ & SI & $\mathrm{NO}$ & SI & SI & $\begin{array}{l}\text { Ventaja } \\
\text { competitiva } \\
\text { temporal }\end{array}$ \\
\hline Ubicación & SI & NO & $\mathrm{NO}$ & SI & $\begin{array}{l}\text { Igualdad } \\
\text { competitiva }\end{array}$ \\
\hline $\begin{array}{l}\text { Ambiente de } \\
\text { estudio } \\
\text { adecuado }\end{array}$ & SI & $\mathrm{NO}$ & $\mathrm{NO}$ & SI & $\begin{array}{l}\text { Igualdad } \\
\text { competitiva }\end{array}$ \\
\hline $\begin{array}{l}\text { Variedad de } \\
\text { horarios }\end{array}$ & SI & $\mathrm{NO}$ & $\mathrm{NO}$ & SI & $\begin{array}{l}\text { Igualdad } \\
\text { competitiva }\end{array}$ \\
\hline $\begin{array}{l}\text { Variedad de } \\
\text { cursos }\end{array}$ & SI & $\mathrm{NO}$ & $\mathrm{NO}$ & SI & $\begin{array}{l}\text { Igualdad } \\
\text { competitiva }\end{array}$ \\
\hline
\end{tabular}

Nota: En base a las preguntas establecidas por Barney y Griffin en 1992 (Vega, s.f.) 


\subsection{Diseño de la estructura organizacional deseada}

A continuación, se presenta el organigrama de la organización (ver figura 22). Se encuentra a la cabeza el gerente general, quien tiene bajo su supervisión al coordinador de la Escuela. El coordinador es el encargado de supervisar tanto a la recepcionista como a los profesores.

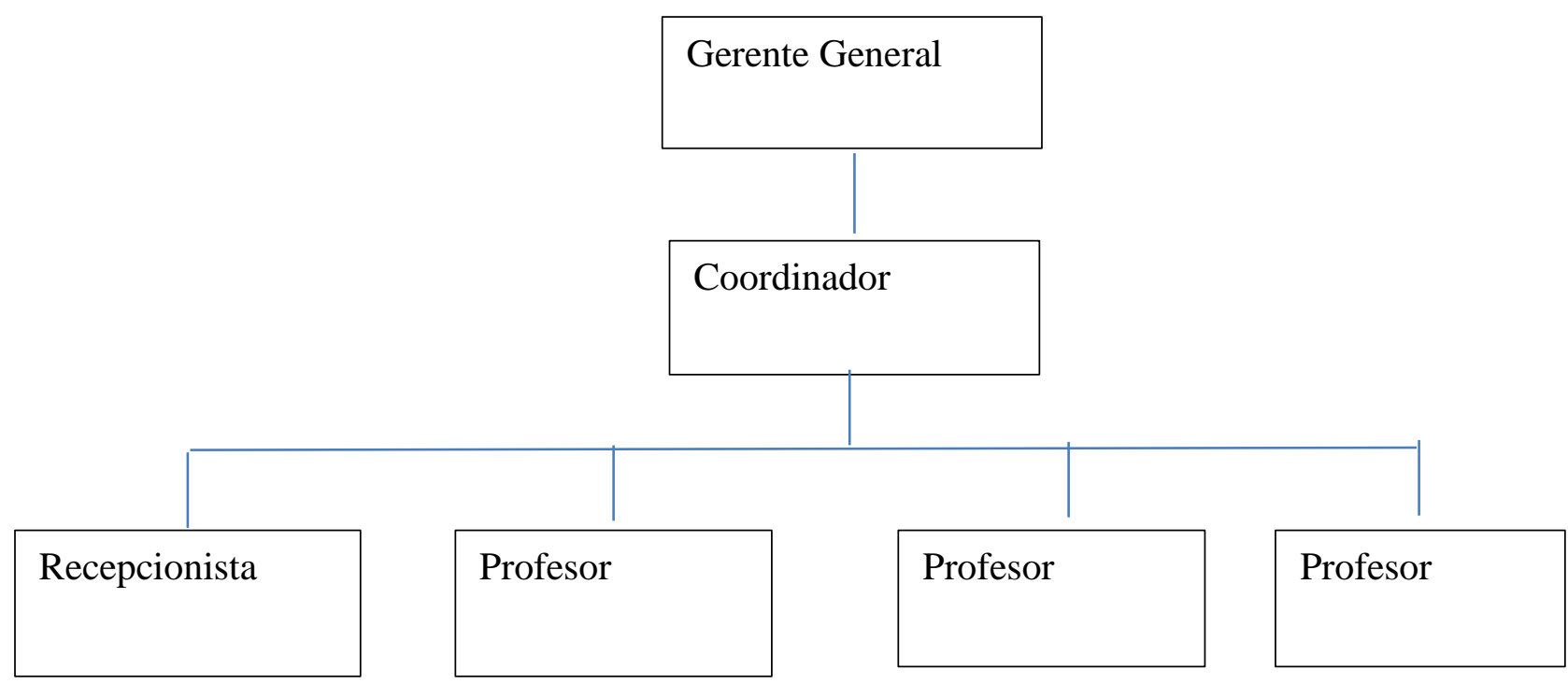

Figura 22. Organigrama

Se estará tercerizando al personal de limpieza, así como también el servicio contable y servicio de marketing.

\subsection{Diseño de los perfiles de puestos clave}

Los docentes deberán ser profesionales que trabajen en agencias o hayan tenido experiencia en empresas grandes en el área de marketing digital. En cuanto a su formación académica, será un requerimiento que hayan estudiado publicidad, comunicaciones, marketing, administración o informática (ver tabla 63). Es deseable que también cuenten con certificaciones (especialmente las de Google). 
Para el caso del Gerente General, se requiere una persona con conocimientos financieros, pues se encargará de manejar las finanzas de la empresa, además de revisar y aprobar el trabajo del outsourcing que maneje la contabilidad (ver tabla 64).

En el caso del Coordinador se necesita una persona que cuente con experiencia tanto en la parte administrativa como académica, así como también en servicio al cliente, pues además de encargarse del buen desarrollo de las clases, será quien tenga que resolver reclamos en caso estos se presentaran (ver tabla 65).

En cuanto a la Recepcionista, dado que su principal función será la atención a los clientes, así como las ventas, debe ser una persona con perfil comercial, con estudios de marketing digital y de preferencia con una carrera técnica en secretariado (ver tabla 66). Tabla 63

\section{Perfil del docente}

Características Funciones

- Más de 5 años de experiencia - Preparación de sílabos en conjunto con el en el rubro coordinador.

- Experiencia en medios

- Preparación de clases. importantes.

- Dictado de clases.

- Certificado en Google.

- Evaluar a los alumnos.

- Experiencia docente en - Llenar los reportes de notas. instituciones de prestigio.

- Carrera: Comunicaciones, Marketing o Administración 
Tabla 64

Perfil del gerente

Características $\quad$ Funciones

- Más de 3 años de anejo de las finanzas de la empresa.

experiencia en el rubro $\quad$ - Supervisión de outsourcing contable.

- Certificado en Google. - Representar legalmente a la empresa.

- Experiencia docente. $\quad$ - Atención de reclamos que no pudiesen ser resueltos

- Carrera: Marketing o por la coordinación.

Administración

Tabla 65

Perfil del coordinador

Características $\quad$ Funciones

Carrera: Administración, - Control de asistencia del personal docente y

Marketing o afines. administrativo.

Estudios adicionales: $\quad$ - Control de los pagos a proveedores y planillas.

Atención al cliente. $\quad$ - Elaborar o revisar los sílabos de los cursos.

Otros Conocimientos _ - Atender consultas de los docentes.

(Opcionales): inglés ㄴ Supervisar el mantenimiento de las instalaciones de

intermedio/avanzado la empresa

- Preparar informe mensual de ventas

- Atención de reclamos 
Tabla 66

Perfil de recepcionista/agente de ventas

\begin{tabular}{|c|c|}
\hline Características & Funciones \\
\hline Carrera: Marketing a nivel & - Gestionar matrículas. \\
\hline técnico. Secretariado. & - $\quad$ Atención al cliente (Informes y Consultas) \\
\hline Deseable: Atención al & - Envío y respuesta de correos masivos \\
\hline \multirow[t]{8}{*}{ cliente. } & (Recordatorio de pagos, Información de cambios, \\
\hline & solicitudes, campañas, nuevos cursos, encuestas y \\
\hline & fichas de datos.). \\
\hline & - Emisión de Boletas de ventas, facturas y cheques \\
\hline & - $\quad$ Apoyo al Administrador \\
\hline & - $\quad$ Registro de alumnos interesados en los cursos \\
\hline & - Resolver consultas a través de las redes sociales. \\
\hline & - $\quad$ Manejo de caja chica. \\
\hline
\end{tabular}

\subsection{Remuneraciones, compensaciones e incentivos}

Remuneración es aquello que una persona recibe como compensación por la ejecución de las tareas encomendadas (Chiavenato, 2009). Se ha determinado que las remuneraciones del personal de la Escuela serán fijas y los pagos se realizarán mensualmente, el último día útil de cada mes.

En el caso del Gerente General, el Coordinador y la Recepcionista, estos trabajarán a tiempo completo, mientras que los docentes estarán en modalidad part-time. Esto último debido a que los cursos se dictan sólo algunas horas al mes por lo que no es necesario que permanezcan 
en la oficina, además esta modalidad les permite a los docentes conjugar la docencia con sus actividades en empresas comerciales.

En la tabla 67 se muestran las remuneraciones consideradas para el personal a tiempo completo.

Tabla 67

Remuneración bruta mensual del personal

\begin{tabular}{lc}
\hline \multicolumn{1}{c}{ Cargo } & Remuneración Bruta \\
\hline Gerente General & $2,800.00$ \\
\hline Coordinador & $2,500.00$ \\
\hline Recepcionista & 950.00 \\
\hline
\end{tabular}

En el caso de los docentes, se ha establecido una tarifa de S/45 por hora. Además, al estar en planilla en todos los casos gozarán de los beneficios sociales que les correspondan, tales como gratificaciones, Essalud, entre otros. Se ha contemplado además un aumento del $8 \%$ anual para todo el personal.

\subsection{Política de recursos humanos}

La política de recursos humanos se basará en la gestión del talento, la gestión de la calidad y la gestión del clima laboral de la organización.

Se establecerán los objetivos estratégicos para cada una de estas áreas, así como también indicadores de gestión para controlar los resultados.

Para controlar la calidad del servicio se aplicarán encuestas a los alumnos y también se implementará un programa de cliente incógnito para medir la calidad del servicio ofrecido por el personal de recepción y asesores comerciales. 


\section{Capítulo IX: Planificación Financiera}

En el presente capítulo se presentarán la inversión, presupuestos base y presupuestos de resultados.

\subsection{La Inversión.}

La inversión es el procedimiento mediante el cual se calculan los gastos de la preoperación, el diseño de la empresa, constitución de la misma, muebles y equipos de oficina, maquinaria, contratación de personal, entre otros; que en función al tipo de proyecto se puede considerar antes del funcionamiento y puesta en marcha (Sapag, 2011).

\subsubsection{Inversión pre operativa.}

En la tabla 68 a continuación se puede ver el detalle de la inversión pre-operativa:

Tabla 68

Inversión pre-operativa

\begin{tabular}{|c|c|c|}
\hline \multirow{2}{*}{$\begin{array}{l}\text { Concepto } \\
\text { Activo fijo }\end{array}$} & \multicolumn{2}{|c|}{ Monto } \\
\hline & & \\
\hline Muebles & S/ & $16,077.97$ \\
\hline Equipos & $\mathrm{S} /$ & $40,616.10$ \\
\hline \multicolumn{3}{|l|}{ Activo intangible } \\
\hline Licencias software & S/ & 307.63 \\
\hline Garantía alquiler de local & S/ & $24,532.20$ \\
\hline Acondicionamiento de local & S/ & $51,027.72$ \\
\hline Subtotal- Inversión en activos & S/ & $132,561.61$ \\
\hline \multicolumn{3}{|l|}{ Otros gastos (PCGE 63- 65) } \\
\hline Gastos de constitución de la empresa & $\mathrm{S} /$ & $3,500.00$ \\
\hline Gastos de lanzamiento-marketing & $\mathrm{S} /$ & $6,065.00$ \\
\hline Subtotal gastos pre-operativos & S/ & $9,565.00$ \\
\hline Total & S/ & $142,126.61$ \\
\hline
\end{tabular}


Según la NIC 38, los gastos de promoción y pre-operativos no se reconocen como activos intangibles. Se reconocen como gasto en el periodo en que se incurran, dentro de las cuentas 63 o 65 del estado de Resultados. (Ministerio de Economía y Finanzas, 2016)

\subsubsection{Inversión en capital de trabajo.}

El capital de trabajo se desarrolla a fin de determinar el éxito o el fracaso de un negocio; para estimarlo, uno de los métodos más utilizados es el del máximo déficit acumulado que resulta más exacto debido a que se evalúa el máximo déficit entre los ingresos y egresos. (Sapag, 2001)

Se determinó que el máximo déficit se alcanza en el primer mes, siendo este de S/. 23,614.53. en los siguientes dos meses el saldo continúa en negativo. Pero a partir del cuarto mes ya se produce un resultado positivo. La empresa puede operar con los ingresos que genera (ver tabla 69). 
Tabla 69

Cálculo del capital de trabajo según el método del máximo déficit acumulado:

\begin{tabular}{|c|c|c|c|c|c|c|c|c|c|c|c|c|}
\hline & enero & febrero & marzo & abril & mayo & junio & Julio & agosto & setiembre & octubre & noviembre & diciembre \\
\hline Ingresos & S/ & S/ 20,900.00 & $\mathrm{S} / 20,250.00$ & S/ 27,650.00 & S/ 27,000.00 & S/ 27,650.00 & S/ $63,650.00$ & S/ $\quad 63,650.00$ & S/ $\quad 63,650.00$ & S/ $\quad 63,650.00$ & S/ $\quad 63,650.00$ & S/ $\quad 63,650.00$ \\
\hline Egresos & S/ $23,614.53$ & S/ 12,049.53 & S/ 12,049.53 & S/ 12,049.53 & S/ 12,049.53 & S/ 14,049.53 & S/ $12,049.53$ & S/ $\quad 12,049.53$ & S/ $\quad 12,049.53$ & S/ $12,049.53$ & S/ $\quad 12,049.53$ & S/ $12,049.53$ \\
\hline Saldo & $-\mathrm{S} / 23,614.53$ & S/ $8,850.47$ & S/ $8,200.47$ & S/ $15,600.47$ & S/ 14,950.47 & S/ 13,600.47 & S/ $51,600.47$ & S/ $\quad 51,600.47$ & S/ $\quad 51,600.47$ & S/ $\quad 51,600.47$ & S/ $\quad 51,600.47$ & S/ $51,600.47$ \\
\hline $\begin{array}{l}\text { Saldo } \\
\text { acumulado }\end{array}$ & $-\mathrm{S} / 23,614.53$ & $-S / 14,764.06$ & $-S / \quad 6,563.60$ & S/ $9,036.87$ & S/ 23,987.34 & $\mathrm{S} / 37,587.81$ & S/ 89,188.28 & S/ $140,788.75$ & S/ $192,389.22$ & S/ $243,989.68$ & S/ $295,590.15$ & S/ 347,190.62 \\
\hline
\end{tabular}




\subsubsection{Costo del proyecto.}

El costo del proyecto resulta de la suma de la inversión inicial más el capital de trabajo, como se observa en la tabla 70.

Tabla 70

Inversión inicial

\begin{tabular}{lrr}
\hline Inversión inicial & S/ & $132,561.61$ \\
Capital de trabajo & S/ & $23,614.53$ \\
\hline Total & S/ & $156,176.15$ \\
\hline
\end{tabular}

\subsubsection{Inversiones futuras.}

Para los siguientes años se consideró invertir en la compra de licencias para las computadoras (ver tabla 71). Las licencias son anuales.

Tabla 71

Inversiones futuras

\begin{tabular}{llll}
\hline & Año 1 & Año 2 & Año 3 \\
\hline TOTAL & S/ 307.63 & S/ 307.63 & S/ 307.63 \\
\hline
\end{tabular}

\subsection{Financiamiento}

El proyecto se financiará con S/.50,000.00 de un préstamo bancario y los socios aportarán la diferencia en partes iguales, es decir S/53,088.07.

\subsubsection{Endeudamiento y condiciones.}

El préstamo por $\mathrm{S} / 50,000.00$ se tomaría a tres años con cuotas fijas de $\mathrm{S} / .1,826.83$ y una TEA de $20.46 \%$. Se consultó el portal de la SBS (Superintendencia de Banca, s.f.) y se tomó como referencia el banco Interbank para préstamos a más de 360 días (ver figura 23). 
SIMULADOR FINANCIERO

\begin{tabular}{|c|c|c|c|c|c|c|c|c|c|c|}
\hline \multirow{2}{*}{\multicolumn{4}{|c|}{ Detalles de la operación financiera }} & & & & & & & \\
\hline & 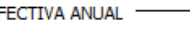 & TIPO DE & & FORMAD & & & 「 Nún & MERO DE CUOTAS & $\Gamma$ IMPORTE & A EVALUAR \\
\hline TEA & $20.460 \%$ & O Cuo & is Crecientes & $\begin{array}{l}\text { Diario } \\
\text { Semanal }\end{array}$ & Trimestral & Semestral & $\Delta$ & 36 & 50,0 & 00.00 \\
\hline${ }^{*}{ }_{F i j}$ & e del tipo de tasa & Ocuo & is Decrecientes & & Tetramestral 0 & Dnual & & & & \\
\hline Com & siones y gastos & & Detalles del & anciamiento & & & Io the di & señado por: & & \\
\hline S.d & gravamen $(\mathrm{x}$ periodo & $0.000 \%$ & Tasa Efectiva & ual (TEA) & $20.46 \%$ & & & & & \\
\hline Otro & Cargos (Portes) & - & Tasa Efectiva & ensual & $1.56 \%$ & & & & & \\
\hline ITF ( & & $0.005 \%$ & Total costo $\mathrm{E}$ & tivo Anual & $20.46 \%$ & & & & & m \\
\hline & & & ${ }^{*}$ No modifiq & nada de estos $\mathrm{co}$ & conceptos & Total In & reses & $15,762.52$ & Total a Pagar & $65,765.81$ \\
\hline Cuota & Deuda & $\begin{array}{c}\text { Factor (Cuotas } \\
\text { Crecientes) }\end{array}$ & Amortización & Interés & $\begin{array}{c}\text { S. Desgravamen } \\
0.00 \%\end{array}$ & $\begin{array}{r}\text { Otros C } \\
\text { Por }\end{array}$ & & $\begin{array}{c}\text { Cuota por } \\
\text { Financiamiento }\end{array}$ & \begin{tabular}{c|} 
I.T.F. \\
$0.005 \%$
\end{tabular} & $\begin{array}{c}\text { Cuota Total a } \\
\text { Pagar }\end{array}$ \\
\hline 0 & $50,000.00$ & & & & & & & & & - \\
\hline 1 & $48,954.93$ & - & $1,045.07$ & 781.66 & - & & - & $1,826.74$ & 0.09 & $1,826.83$ \\
\hline 2 & $47,893.51$ & - & $1,061.41$ & 765.32 & - & & - & $1,826.74$ & 0.09 & $1,826.83$ \\
\hline 3 & $46,815.51$ & - & $1,078.01$ & 748.73 & - & & - & $1,826.74$ & 0.09 & $1,826.83$ \\
\hline 4 & $45,720.65$ & - & $1,094.86$ & 731.88 & - & & - & $1,826.74$ & 0.09 & $1,826.83$ \\
\hline 5 & $44,608.67$ & - & $1,111.97$ & 714.76 & - & & - & $1,826.74$ & 0.09 & $1,826.83$ \\
\hline 6 & $43,479.31$ & - & $1,129.36$ & 697.38 & - & & - & $1,826.74$ & 0.09 & $1,826.83$ \\
\hline 7 & $42,332.30$ & - & $1,147.01$ & 679.72 & - & & - & $1,826.74$ & 0.09 & $1,826.83$ \\
\hline 8 & $41,167.35$ & - & $1,164.95$ & 661.79 & - & & - & $1,826.74$ & 0.09 & $1,826.83$ \\
\hline 9 & $39,984.20$ & - & $1,183.16$ & 643.58 & - & & - & $1,826.74$ & 0.09 & $1,826.83$ \\
\hline 10 & $38,782.54$ & - & $1,201.65$ & 625.08 & - & & - & $1,826.74$ & 0.09 & $1,826.83$ \\
\hline 11 & $37,562.10$ & - & $1,220.44$ & 606.30 & - & & - & $1,826.74$ & 0.09 & $1,826.83$ \\
\hline 12 & $36,322.58$ & - & $1,239.52$ & 587.22 & - & & - & $1,826.74$ & 0.09 & $1,826.83$ \\
\hline 13 & $35,063.69$ & - & $1,258.90$ & 567.84 & - & & - & $1,826.74$ & 0.09 & $1,826.83$ \\
\hline 14 & $33,785.11$ & - & $1,278.58$ & 548.16 & - & & - & $1,826.74$ & 0.09 & $1,826.83$ \\
\hline 15 & $32,486.54$ & - & $1,298.57$ & 528.17 & - & & - & $1,826.74$ & 0.09 & $1,826.83$ \\
\hline 16 & $31,167.68$ & - & $1,318.87$ & 507.87 & - & & - & $1,826.74$ & 0.09 & $1,826.83$ \\
\hline 17 & $29,828.19$ & - & $1,339.48$ & 487.25 & - & & - & $1,826.74$ & 0.09 & $1,826.83$ \\
\hline 18 & $28,467.77$ & - & $1,360.43$ & 466.31 & - & & - & $1,826.74$ & 0.09 & $1,826.83$ \\
\hline 19 & $27,086.07$ & - & $1,381.69$ & 445.04 & - & & - & $1,826.74$ & 0.09 & $1,826.83$ \\
\hline 20 & $25,682.78$ & - & $1,403.29$ & 423.44 & - & & - & $1,826.74$ & 0.09 & $1,826.83$ \\
\hline 21 & $24,257.55$ & - & $1,425.23$ & 401.50 & - & & - & $1,826.74$ & 0.09 & $1,826.83$ \\
\hline 22 & $22,810.03$ & - & $1,447.51$ & 379.22 & - & & - & $1,826.74$ & 0.09 & $1,826.83$ \\
\hline 23 & $21,339.89$ & - & $1,470.14$ & 356.59 & - & & - & $1,826.74$ & 0.09 & $1,826.83$ \\
\hline 24 & $19,846.77$ & - & $1,493.12$ & 333.61 & - & & - & $1,826.74$ & 0.09 & $1,826.83$ \\
\hline 25 & $18,330.30$ & - & $1,516.47$ & 310.27 & - & & - & $1,826.74$ & 0.09 & $1,826.83$ \\
\hline 26 & $16,790.13$ & - & $1,540.17$ & 286.56 & - & & - & $1,826.74$ & 0.09 & $1,826.83$ \\
\hline 27 & $15,225.87$ & - & $1,564.25$ & 262.48 & - & & - & $1,826.74$ & 0.09 & $1,826.83$ \\
\hline 28 & $13,637.17$ & - & $1,588.71$ & 238.03 & - & & - & $1,826.74$ & 0.09 & $1,826.83$ \\
\hline 29 & $12,023.62$ & - & $1,613.54$ & 213.19 & - & & - & $1,826.74$ & 0.09 & $1,826.83$ \\
\hline 30 & $10,384.85$ & - & $1,638.77$ & 187.97 & - & & - & $1,826.74$ & 0.09 & $1,826.83$ \\
\hline 31 & $8,720.47$ & - & $1,664.39$ & 162.35 & - & & - & $1,826.74$ & 0.09 & $1,826.83$ \\
\hline 32 & $7,030.06$ & - & $1,690.41$ & 136.33 & - & & - & $1,826.74$ & 0.09 & $1,826.83$ \\
\hline 33 & $5,313.23$ & - & $1,716.83$ & 109.90 & - & & - & $1,826.74$ & 0.09 & $1,826.83$ \\
\hline 34 & $3,569.55$ & - & $1,743.67$ & 83.06 & - & & - & $1,826.74$ & 0.09 & $1,826.83$ \\
\hline 35 & $1,798.62$ & - & $1,770.93$ & 55.80 & - & & - & $1,826.74$ & 0.09 & $1,826.83$ \\
\hline 36 & 0.00 & - & $1,798.62$ & 28.12 & - & & - & $1,826.74$ & 0.09 & $1,826.83$ \\
\hline
\end{tabular}

Figura 23. Simulación préstamo. Tomado de www.excelnegocios.com 


\subsubsection{Capital y costo de oportunidad.}

El costo de oportunidad se calcula con la finalidad de determinar cuál es el beneficio que se deja de percibir al invertir en un negocio en lugar de otro. (Sapag, 2011). Se realizó el siguiente cálculo correspondiente, el cual se muestra en la tabla 72, concluyéndose que el costo de capital para el proyecto es de $16.96 \%$.

Tabla 72

Costo de capital

\section{Cálculo de Costo de}

Capital

\begin{tabular}{lr}
\hline Tasa bonos USA - Rf & $2.06 \%$ \\
Riesgo País (al 1 ${ }^{\circ}$ oct '18) & $1.34 \%$ \\
Rm & $10.84 \%$ \\
Rm-Rf & $8.78 \%$ \\
Beta del sector educación & 1.15 \\
Beta apalancado & 1.54 \\
\hline Costo Capital & $16.96 \%$ \\
\hline
\end{tabular}

Nota: Recuperado de https://www.investing.com/rates-bonds/u.s.-3-year-bond-yieldhistorical-data,

https://estadisticas.bcrp.gob.pe/estadisticas/series/diarias/resultados/PD04709XD/html,

https://espanol.spindices.com/indices/equity/sp-500 y http://pages.stern.nyu.edu/ adamodar/.

La fórmula utilizada fue: $\mathrm{Ke}=\mathrm{Rf}+\beta(\mathrm{Rm}-\mathrm{Rf})+$ Riesgo país

\subsubsection{Costo de capital promedio ponderado.}

Se calculó que para el presente proyecto el costo de capital promedio ponderado o WACC es de $21.80 \%$ (ver tabla 73 ).

Tabla 73

Cálculo del WACC

\section{WACC}

\begin{tabular}{lrr} 
Wd & $33 \% \mathrm{Kd}$ & $45.00 \%$ \\
$\mathrm{We}$ & $67 \% \mathrm{Ke}$ & $16.96 \%$ \\
\hline Wacc & $21.80 \%$ & \\
\hline
\end{tabular}




\subsection{Presupuestos base}

El presupuesto es una estimación anticipada de los ingresos y egresos de una actividad económica a realizarse, en un periodo determinado. (Meneses, 2004)

\subsubsection{Presupuesto de ventas.}

Para determinar los ingresos del negocio, se debe elaborar el presupuesto de ventas. Con este fin se debe establecer el volumen de ventas por producto, por año y sus respectivos precios unitarios, para la vida útil del proyecto. (Meneses, 2004)

En la tabla 74 se muestra el presupuesto de ventas elaborado.

Tabla 74

Presupuesto de ventas por año

\begin{tabular}{lccc}
\hline & Año 1 & Año 2 & Año 3 \\
\hline Clases grupales & & & \\
Cantidad de alumnos & $1,110.00$ & $2,340.00$ & $3,060.00$ \\
Precio de matrícula & 450.00 & 450.00 & 472.50 \\
Ingreso por clases grupales & $499,500.00$ & $1,053,000.00$ & $1,445,850.00$ \\
Clases personalizadas & & & \\
Cantidad de alumnos & 9.00 & 24.00 & 36.00 \\
Precio de matrícula & 650.00 & 650.00 & 682.50 \\
Ingresos por clases personalizadas & $5,850.00$ & $15,600.00$ & $24,570.00$ \\
\hline Ingresos totales & $505,350.00$ & $1,068,600.00$ & $1,470,420.00$ \\
\hline
\end{tabular}

En el caso de los cursos regulares o grupales, teniendo en cuenta los resultados de obtenidos del estudio de mercado se proyectó mayor demanda por las noches, seguida de los sábados y finalmente las mañanas (ver tabla 75).

Tabla 75

Alumnos por horario

\begin{tabular}{lrrr}
\hline Horario & Año 1 & Año 2 & Año 3 \\
\hline Cursos regulares noches & 485 & 960 & 1,080 \\
Cursos regulares sabatinos & 365 & 660 & 900 \\
Cursos regulares mañanas & 260 & 720 & 1,080 \\
\hline Total & $\mathbf{1 , 1 1 0}$ & $\mathbf{2 , 3 4 0}$ & $\mathbf{3 , 0 6 0}$ \\
\hline
\end{tabular}




\subsubsection{Presupuesto de costos de producción.}

En la tabla 76 se puede observar el presupuesto de los costos de producción:

Tabla 76

Costos de producción

\begin{tabular}{|c|c|c|c|c|c|c|}
\hline & \multicolumn{2}{|r|}{ Año 1} & \multicolumn{2}{|r|}{ Año 2} & \multicolumn{2}{|r|}{ Año 3} \\
\hline Materiales directos (MD) & $\mathrm{S} /$ & $1,537.60$ & $\mathrm{~S} /$ & $2,124.00$ & $\mathrm{~S} /$ & $2,874.00$ \\
\hline Plumones & S/ & 432.00 & $\mathrm{~S} /$ & 518.40 & $\mathrm{~S} /$ & 518.40 \\
\hline Motas & $\mathrm{S} /$ & 105.60 & $\mathrm{~S} /$ & 105.60 & S/ & 105.60 \\
\hline Certificados y otros & S/ & $1,000.00$ & $\mathrm{~S} /$ & $1,500.00$ & $\mathrm{~S} /$ & $2,250.00$ \\
\hline $\begin{array}{l}\text { Mano de obra por el servicio } \\
\text { (MOD) }\end{array}$ & $\mathrm{S} /$ & $118,929.65$ & $\mathrm{~S} /$ & $238,860.80$ & $\mathrm{~S} /$ & $263,242.63$ \\
\hline Profesores & $\mathrm{S} /$ & $118,929.65$ & $\mathrm{~S} /$ & $238,860.80$ & S/ & $263,242.63$ \\
\hline Costos indirectos (CIF) & $\mathrm{S} /$ & $150,129.74$ & $\mathrm{~S} /$ & $165,708.66$ & $\mathrm{~S} /$ & $179,006.23$ \\
\hline sueldo coordinador & $\mathrm{S} /$ & $21,958.22$ & $\mathrm{~S} /$ & $23,714.88$ & S/ & $25,612.07$ \\
\hline Alquileres & $\mathrm{S} /$ & $88,315.9$ & $\mathrm{~S} /$ & $90,965.4$ & $\mathrm{~S} /$ & $93,694.4$ \\
\hline luz, agua y teléfono & S/ & $12,063.60$ & $\mathrm{~S} /$ & $12,666.78$ & $\mathrm{~S} /$ & $13,300.12$ \\
\hline Seguros & $\mathrm{S} /$ & 252.00 & $\mathrm{~S} /$ & 264.60 & S/ & 277.83 \\
\hline Mantenimiento de edificio & $\mathrm{S} /$ & $6,000.00$ & $\mathrm{~S} /$ & $6,300.00$ & S/ & $6,615.00$ \\
\hline Arbitrios & $\mathrm{S} /$ & $1,140.00$ & $\mathrm{~S} /$ & $1,197.00$ & $\mathrm{~S} /$ & $1,256.85$ \\
\hline $\begin{array}{l}\text { Limpieza y mantenimiento } \\
\text { (personal y productos de aseo) }\end{array}$ & $\mathrm{S} /$ & $20,400.00$ & $\mathrm{~S} /$ & $30,600.00$ & S/ & $38,250.00$ \\
\hline Total & $\mathbf{S}$ & $270,596.99$ & $\mathbf{S} /$ & $106,693.46$ & $\mathbf{S} /$ & $445,122.86$ \\
\hline
\end{tabular}

\subsubsection{Presupuesto de compras.}

Se determinó que los siguientes serían los insumos a comprar (ver tabla 77).

Tabla 77

Compra de insumos

\begin{tabular}{lrrrrrr}
\hline & \multicolumn{2}{c}{ Año 1 } & & \multicolumn{1}{c}{ Año 2 } & \multicolumn{1}{c}{ Año 3 } \\
\hline Plumones & S/ & 432.00 & S/ & 518.40 & S/ & 518.40 \\
Motas & S/ & 105.60 & S/ & 105.60 & S/ & 105.60 \\
Certificados y otros & S/ & $1,000.00$ & S/ & $1,500.00$ & S/ & $2,250.00$ \\
\hline
\end{tabular}




\subsubsection{Presupuesto de costo de ventas.}

Se estimó el costo de ventas para los tres primeros años, que comprenden el horizonte del proyecto (ver tabla 78).

Tabla 78

Costo de ventas

\begin{tabular}{|c|c|c|c|c|c|c|}
\hline & \multicolumn{2}{|r|}{ Año 1} & \multicolumn{2}{|r|}{ Año 2} & \multicolumn{2}{|r|}{ Año 3} \\
\hline Ventas & $\mathrm{S} /$ & $505,350.00$ & $\mathrm{~S} /$ & $1,068,600.00$ & $\mathrm{~S} /$ & $1,470,420.00$ \\
\hline Costo de ventas & $\mathrm{S} /$ & $270,596.99$ & $\mathrm{~S} /$ & $406,693.46$ & $\mathrm{~S} /$ & $445,122.86$ \\
\hline
\end{tabular}

\subsubsection{Presupuesto de gastos administrativos.}

Se incluyeron en el presupuesto de gastos administrativos los sueldos del personal administrativo (sólo 50\% en el caso del coordinador), los alquileres, servicios, mantenimiento de la plataforma online, útiles de oficina y en el primer año, los gastos de constitución, tal como se puede observar en la tabla 79.

Tabla 79

Presupuesto de gastos administrativos

\begin{tabular}{lrrrrrr}
\hline Gasto & \multicolumn{2}{c}{ Año 1 } & & Año 2 & & Año 3 \\
\hline Recepcionista & S/ & $17,442.44$ & S/ & $18,837.84$ & S/ & $20,344.86$ \\
Gerente & S/ & $49,040.44$ & S/ & $52,963.68$ & S/ & $57,200.77$ \\
Coordinador & S/ & $10,979.11$ & $\mathrm{~S} /$ & $11,857.44$ & $\mathrm{~S} /$ & $12,806.03$ \\
Alquileres & $\mathrm{S} /$ & $9,812.88$ & $\mathrm{~S} /$ & $10,107.27$ & $\mathrm{~S} /$ & $10,410.48$ \\
Luz, agua y teléfono & $\mathrm{S} /$ & $1,340.40$ & $\mathrm{~S} /$ & $1,407.42$ & $\mathrm{~S} /$ & $1,477.79$ \\
Servicios contables & $\mathrm{S} /$ & $18,000.00$ & $\mathrm{~S} /$ & $18,900.00$ & $\mathrm{~S} /$ & $19,845.00$ \\
Útiles de oficina & $\mathrm{S} /$ & 600.00 & $\mathrm{~S} /$ & 630.00 & $\mathrm{~S} /$ & 661.50 \\
Plataforma Online & $\mathrm{S} /$ & - & $\mathrm{S} /$ & $4,000.00$ & $\mathrm{~S} /$ & $4,000.00$ \\
Gastos de constitución & $\mathrm{S} /$ & $3,500.00$ & & & & \\
\hline Total & $\mathrm{S} /$ & $110,715.27$ & $\mathrm{~S} /$ & $118,703.64$ & $\mathrm{~S} /$ & $126,746.44$ \\
\hline
\end{tabular}




\subsubsection{Presupuesto de marketing y ventas.}

En el presupuesto de ventas (ver tabla 80) se consideran los gastos de marketing, así como el $25 \%$ del sueldo del Coordinador.

Tabla 80

Presupuesto de marketing

\begin{tabular}{lllllll}
\hline Gasto & & Año 1 & & Año 2 & & Año 3 \\
\hline Gastos de marketing & S/ & $36,465.00$ & S/ & $40,600.00$ & S/ & $42,600.00$ \\
\% Sueldo coordinador & S/ & $10,979.11$ & S/ & $11,857.44$ & S/ & $12,806.03$ \\
\hline Total & S/ & $47,444.11$ & S/ & $52,457.44$ & S/ & $55,406.03$ \\
\hline
\end{tabular}

\subsubsection{Presupuesto de gastos financieros.}

Se han considerado los siguientes gastos financieros (ver tabla 81).

Tabla 81

Gastos financieros

\begin{tabular}{lccc}
\hline Gasto & Año 1 & Año 2 & Año 3 \\
\hline Interés de la deuda & $\mathrm{S} / 8,243.43$ & $\mathrm{~S} / 5,445.02$ & $\mathrm{~S} / 2,074.07$ \\
ITF & $\mathrm{S} / 13.20$ & $\mathrm{~S} / 13.20$ & $\mathrm{~S} / 13.20$ \\
\hline Total & $\mathrm{S} / 8,256.63$ & $\mathrm{~S} / 5,458.22$ & $\mathrm{~S} / 2,087.27$ \\
\hline
\end{tabular}

\subsection{Presupuestos de resultados}

\subsubsection{Estado de ganancias y pérdidas proyectado.}

Es un estado financiero, el primero que debe ser elaborado. En él se muestra la gestión económica de una organización durante un tiempo determinado. En este informe se resumen todos los ingresos y gastos en los que ha incurrido durante el periodo. Con este informe se pueden obtener los ratios que permiten ver la rentabilidad contable de la organización. (Beltrán \& Cueva, 2009) 
A continuación se puede ver el Estado de Resultados proyectado (ver tabla 82) para los tres primeros años del presente proyecto. Este se calculó en base a los presupuestos de ventas, costo de producción, compras, costo de ventas, gastos administrativos, de marketing y gastos financieros desarrollados en la primera parte de este capítulo.

Tabla 82

Estado de ganancias y pérdidas proyectado

\begin{tabular}{|c|c|c|c|}
\hline & Año 1 & Año 2 & Año 3 \\
\hline Ventas & $\mathrm{S} / 505,350.00$ & $\mathrm{~S} / 1,068,600.00$ & $\mathrm{~S} / 1,470,420.00$ \\
\hline Costo de ventas & $\mathrm{S} / 270,596.99$ & $\mathrm{~S} / 406,693.46$ & $\mathrm{~S} / 445,122.86$ \\
\hline Utilidad bruta & $\mathrm{S} / 234,753.02$ & S/661,906.54 & $\mathrm{S} / 1,025,297.14$ \\
\hline $\begin{array}{l}\text { Gastos administrativos } \\
\text { Gastos de ventas (gastos de mkt+ } \% \\
\text { coordinador) }\end{array}$ & $\begin{array}{l}\text { S/110,715.27 } \\
\text { S/47,444.11 }\end{array}$ & $\begin{array}{l}\text { S/118,703.64 } \\
\text { S/52,457.44 }\end{array}$ & $\begin{array}{l}\text { S/126,746.44 } \\
\text { S/55,406.03 }\end{array}$ \\
\hline EBITDA & S/76,593.64 & $\mathrm{S} / 490,745.47$ & $\mathrm{~S} / 843,144.67$ \\
\hline Depreciación + amortización & $\mathrm{S} / 34,071.16$ & $\mathrm{~S} / 34,071.16$ & $\mathrm{~S} / 34,071.16$ \\
\hline Utilidad operativa -EBIT & $\mathrm{S} / 42,522.47$ & $\mathrm{~S} / 456,674.31$ & $\mathrm{~S} / 809,073.51$ \\
\hline $\begin{array}{l}\text { Interés de la deuda } \\
\text { Otros gastos financieros }\end{array}$ & $\begin{array}{c}\mathrm{S} / 8,243.43 \\
\mathrm{~S} / 13.20\end{array}$ & $\begin{array}{c}\mathrm{S} / 5,445.02 \\
\mathrm{~S} / 13.20\end{array}$ & $\begin{array}{c}\mathrm{S} / 2,074.07 \\
\mathrm{~S} / 13.20\end{array}$ \\
\hline Utilidad antes de impuestos & $\mathrm{S} / 34,265.84$ & $\mathrm{~S} / 451,216.09$ & S/806,986.24 \\
\hline Impuesto a la renta $(0.295)$ & $S / 10,108.42$ & $\mathrm{~S} / 133,108.75$ & $\mathrm{~S} / 238,060.94$ \\
\hline Utilidad neta & $\mathrm{S} / 24,157.42$ & $\mathrm{~S} / 318,107.34$ & $\mathrm{~S} / 568,925.30$ \\
\hline
\end{tabular}




\subsubsection{Balance proyectado.}

Según Sapag (2001) el balance general representa el valor contable de la empresa en un momento determinado. El balance está dividido en tres partes: en el lado izquierdo se ubican los activos y en el derecho, los pasivos más el capital de la empresa. Ambos lados deben mostrar el mismo resultado total. En el balance se pueden ver los activos con los que cuenta la empresa, así como también como está financiada (ver tabla 83).

Tabla 83

Balance proyectado

\begin{tabular}{|c|c|c|c|c|}
\hline & Año 0 & Año 1 & Año 2 & Año 3 \\
\hline \multicolumn{5}{|l|}{ ACTIVO } \\
\hline \multicolumn{5}{|l|}{ Activo corriente } \\
\hline Efectivo y equivalente de efectivo & $\mathrm{S} / 23,614.53$ & $\mathrm{~S} / 57,803.18$ & $\mathrm{~S} / 383,143.35$ & $\mathrm{~S} / 955,930.52$ \\
\hline Pago garantía alquiler local & $\mathrm{S} / 24,532.20$ & $\mathrm{~S} / 24,532.20$ & $\mathrm{~S} / 24,532.20$ & $\mathrm{~S} / 24,532.20$ \\
\hline Impuesto pagado $\mathrm{x}$ adelantado & & $\mathrm{S} / 10,054.89$ & S/20,109.77 & $\mathrm{S} / 30,164.66$ \\
\hline \multicolumn{5}{|l|}{ Activo Fijo } \\
\hline \multicolumn{5}{|l|}{ Inv. Muebles y Equipo de } \\
\hline Comunicación & S/16,077.97 & S/16,077.97 & S/16,077.97 & S/16,077.97 \\
\hline \multicolumn{5}{|l|}{ Depreciación Acumulada Muebles } \\
\hline y Equipo & $\mathrm{S} / 0.00$ & $\mathrm{~S} / 3,215.59$ & $\mathrm{~S} / 6,431.19$ & $\mathrm{~S} / 9,646.78$ \\
\hline Neto Muebles & S/16,077.97 & $\mathrm{S} / 12,862.37$ & $\mathrm{~S} / 9,646.78$ & $\mathrm{~S} / 6,431.19$ \\
\hline Inv. Equipo de Computo & $\mathrm{S} / 40,616.10$ & $\mathrm{~S} / 40,616.10$ & $\mathrm{~S} / 40,616.10$ & $\mathrm{~S} / 40,616.10$ \\
\hline \multicolumn{5}{|l|}{ Depreciación Acumulada Equipo de } \\
\hline Computo & $\mathrm{S} / 0.00$ & $\mathrm{~S} / 13,538.70$ & $\mathrm{~S} / 27,077.40$ & $\mathrm{~S} / 40,616.10$ \\
\hline Neto Equipo de Computo & $\mathrm{S} / 40,616.10$ & $\mathrm{~S} / 27,077.40$ & $\mathrm{~S} / 13,538.70$ & $\mathrm{~S} / 0.00$ \\
\hline \multicolumn{5}{|l|}{ Activo Intangible } \\
\hline Licencias software & S/307.63 & $\mathrm{S} / 615.25$ & $\mathrm{~S} / 615.25$ & $\mathrm{~S} / 615.25$ \\
\hline Amortización de licencias software & & $\mathrm{S} / 307.63$ & $\mathrm{~S} / 307.63$ & $\mathrm{~S} / 307.63$ \\
\hline Neto licencias software & S/307.63 & $\mathrm{S} / 307.63$ & $\mathrm{~S} / 307.63$ & $\mathrm{~S} / 307.63$ \\
\hline Acondicionamiento de local & $\mathrm{S} / 51,027.72$ & $\mathrm{~S} / 51,027.72$ & $\mathrm{~S} / 51,027.72$ & $\mathrm{~S} / 51,027.72$ \\
\hline Amortización acondicionamiento & $\mathrm{S} / 0.00$ & $\mathrm{~S} / 17,009.24$ & $\mathrm{~S} / 34,018.48$ & $\mathrm{~S} / 51,027.72$ \\
\hline Neto Acondicionamiento & $\mathrm{S} / 51,027.72$ & $\mathrm{~S} / 34,018.48$ & $\mathrm{~S} / 17,009.24$ & $\mathrm{~S} / 0.00$ \\
\hline Total activo & $\mathrm{S} / \mathbf{1 5 6 , 1 7 6 . 1 5}$ & $\mathrm{S} / \mathbf{1 6 6 , 6 5 6 . 1 5}$ & $\mathrm{S} / 468,287.67$ & $\mathrm{~S} / \mathbf{1 , 0 1 7 , 3 6 6 . 1 9}$ \\
\hline \multicolumn{5}{|l|}{ PASIVO } \\
\hline \multicolumn{5}{|l|}{ Pasivo corriente } \\
\hline Préstamo a 3 años & $\mathrm{S} / 50,000.00$ & $\mathrm{~S} / 36,322.58$ & $\mathrm{~S} / 19,846.76$ & $\mathrm{~S} / 0.00$ \\
\hline \multicolumn{5}{|l|}{ PATRIMONIO NETO } \\
\hline Capital & S/106,176.15 & S/106,176.15 & S/106,176.15 & $\mathrm{S} / 106,176.15$ \\
\hline Resultados del ejercicio & & $\mathrm{S} / 24,157.42$ & $\mathrm{~S} / 318,107.34$ & $\mathrm{~S} / 568,925.30$ \\
\hline Resultados Acumulados & & & $\mathrm{S} / 24,157.42$ & $\mathrm{~S} / 342,264.76$ \\
\hline Total Patrimonio Neto & S/106,176.15 & $\mathrm{S} / 130,333.57$ & $\mathrm{~S} / 448,440.91$ & $\mathrm{~S} / 1,017,366.20$ \\
\hline Total Pasivo y Patrimonio & $\mathrm{S} / \mathbf{1 5 6 , 1 7 6 . 1 5}$ & $\mathrm{S} / \mathbf{1 6 6 , 6 5 6 . 1 5}$ & $\mathrm{S} / 468,287.67$ & $\mathrm{~S} / \mathbf{1 , 0 1 7 , 3 6 6 . 1 9}$ \\
\hline
\end{tabular}




\subsubsection{Flujo de caja proyectado.}

En la tabla 84 a continuación se muestra el flujo de caja proyectado, en el cual se consideraron tres indicadores, el flujo de caja operativo, el flujo de caja libre y el flujo de caja del accionista. En el flujo de caja operativo se puede ver que es positivo desde el primer año de operaciones y muestra una tendencia de crecimiento para los siguientes dos años. En el caso de los flujos de caja libre y del accionista, si bien al iniciar el año 1 el flujo es negativo, al final de año 1 ya este se vuelve positivo y mantiene la tendencia de crecimiento en los siguientes dos años.

Tabla 84

Flujo de caja proyectado

\begin{tabular}{|c|c|c|c|c|}
\hline & Año 0 & Año 1 & Año 2 & Año 3 \\
\hline \multicolumn{5}{|l|}{ Ingreso operativo } \\
\hline Ventas & & $\mathrm{S} / 505,350.00$ & $\mathrm{~S} / 1,068,600.00$ & $\mathrm{~S} / 1,470,420.00$ \\
\hline \multicolumn{5}{|l|}{ Egresos operativos } \\
\hline MD & & $S / 1,537.60$ & $\mathrm{~S} / 2,124.00$ & $\mathrm{~S} / 2,874.00$ \\
\hline MOD & & S/118,929.65 & $\mathrm{S} / 238,860.80$ & $S / 263,242.63$ \\
\hline CIF (s/deprec) & & $S / 150,129.74$ & $S / 165,708.66$ & S/179,006.23 \\
\hline Gastos adm & & S/110,715.27 & $S / 118,703.64$ & $S / 126,746.44$ \\
\hline Gasto de vtas & & $\mathrm{S} / 47,444.11$ & $S / 52,457.44$ & $\mathrm{~S} / 55,406.03$ \\
\hline Total egresos & & $\mathrm{S} / 428,756.37$ & $\mathrm{~S} / 577,854.53$ & $\mathrm{~S} / 627,275.33$ \\
\hline Ingresos-egresos & & $S / 76,593.64$ & $S / 490,745.47$ & $\mathrm{~S} / 843,144.67$ \\
\hline Imp. Renta & & $\mathrm{S} / 22,595.12$ & $\mathrm{~S} / 144,769.91$ & $\mathrm{~S} / 248,727.68$ \\
\hline Flujo de caja operativo & & $\mathrm{S} / \mathbf{5 3 , 9 9 8 . 5 1}$ & $\mathrm{S} / 345,975.55$ & $\mathrm{~S} / \mathbf{5 9 4 , 4 1 6 . 9 9}$ \\
\hline Inversiones & $-S / 132,561.61$ & $-S / 307.63$ & $-S / 307.63$ & $-S / 307.63$ \\
\hline Capital de trabajo & $-\mathrm{S} / 23,614.53$ & $\mathrm{~S} / 0.00$ & & \\
\hline Flujo de caja libre & $-S / 156,176.15$ & $\mathrm{~S} / \mathbf{5 3 , 6 9 0 . 8 9}$ & $\mathrm{S} / 345,667.93$ & $\mathrm{~S} / \mathbf{5 9 4 , 1 0 9 . 3 6}$ \\
\hline Préstamo & $\mathrm{S} / 50,000.00$ & $-S / 13,677.42$ & $-S / 16,475.82$ & $-S / 19,846.77$ \\
\hline Int & & $-\mathrm{S} / 8,243.43$ & $-\mathrm{S} / 5,445.02$ & $-\mathrm{S} / 2,074.07$ \\
\hline Itf & & $-\mathrm{S} / 13.20$ & $-S / 13.20$ & $-S / 13.20$ \\
\hline Escudo fiscal & & $\mathrm{S} / 2,431.81$ & $\mathrm{~S} / 1,606.28$ & $\mathrm{~S} / 611.85$ \\
\hline Flujo de caja del accionista & $-S / 106,176.15$ & $\mathrm{~S} / \mathbf{3 4 , 1 8 8 . 6 5}$ & $\mathrm{S} / \mathbf{3 2 5 , 3 4 0 . 1 7}$ & $\mathrm{S} / \mathbf{5 7 2 , 7 8 7 . 1 7}$ \\
\hline
\end{tabular}




\section{Capítulo X: Evaluación Económico Financiera}

\subsection{Evaluación financiera}

\subsubsection{TIR.}

La tasa interna de retorno (TIR) es un criterio de evaluación financiera que se utiliza para medir la rentabilidad de un proyecto como porcentaje. Una TIR mayor o igual a la tasa exigida por el inversionista indica que el proyecto es viable. La máxima tasa exigible es aquella que iguala el VAN a cero. (Sapag, 2011).

Para el presente proyecto la TIR económica resultó ser 117\% por lo cual, se considera que el proyecto es rentable.

\subsubsection{VAN.}

El valor actual neto (VAN) mide la rentabilidad de un proyecto una vez que se ha recuperado la inversión. Para ello se utiliza la tasa de descuento del accionista y el resultado del flujo de caja. El proyecto se considera rentable sólo cuando el VAN es mayor o igual que cero (Sapag, 2011).

Para el presente proyecto se determinó un VAN de S/520, 380.29 que fue calculado con una tasa de descuento del accionista de $16.85 \%$, por lo tanto, el proyecto resulta rentable.

\subsubsection{ROE.}

La Rentabilidad Neta del Patrimonio (ROE) es un ratio que se calcula sobre el patrimonio promedio y mide la rentabilidad del proyecto en el tiempo (Stickney, Weil, Schipper \& Francis, 2012). En la tabla 85 se muestra la ROE de los 3 años del proyecto. Tabla 85

ROE

\begin{tabular}{lrrr}
\hline RATIOS & Año 1 & Año 2 & Año 3 \\
\hline ROE & $19 \%$ & $71 \%$ & $56 \%$ \\
\hline
\end{tabular}


Analizando la rentabilidad, para el presente proyecto se tiene un ROE de $19 \%$ en el primer año, mientras que, en el segundo, $71 \%$; lo cual muestra una tendencia positiva y muy rentable para los accionistas.

\subsubsection{Ratios.}

Los ratios financieros (ver tabla 86) son cocientes comúnmente utilizados para la evaluación de proyectos, con ellos se puede medir y conocer la rentabilidad, eficiencia y en general, la situación financiera de una empresa. Los ratios se dividen en cuatro grupos: de liquidez, de gestión, de solvencia o endeudamiento y de rentabilidad.

- Los ratios de liquidez muestran la capacidad que tiene la empresa para cubrir sus deudas en el corto plazo.

- En cuanto a los índices de solvencia, éstos se utilizan para medir la capacidad de endeudamiento de la empresa.

- Finalmente, los índices de rentabilidad son aquellos que evalúan la capacidad de una empresa para generar utilidades. (Stickney, Weil, Schipper \& Francis, 2012).

Tabla 86

Ratios

\begin{tabular}{lccc}
\hline Ratios & Año 1 & Año 2 & Año 3 \\
\hline Liquidez: & & & \\
Liquidez Corriente & 2.54 & 21.55 & \\
Prueba Ácida & 1.6 & 19.3 & \\
Capital de Trabajo, \$000 & S/56,067.69 & S/407,938.56 & S/1,010,627.39 \\
Rentabilidad: & & & \\
Margen Bruto & $46 \%$ & $62 \%$ & $70 \%$ \\
Margen Operativo & $8 \%$ & $43 \%$ & $55 \%$ \\
Margen EBITDA & $15 \%$ & $46 \%$ & $57 \%$ \\
Margen Neto & $5 \%$ & $30 \%$ & $39 \%$ \\
ROE & $19 \%$ & $71 \%$ & $56 \%$ \\
ROA & $14 \%$ & $68 \%$ & $56 \%$ \\
Solvencia: & & & \\
Deuda / Patrimonio & 0.3 & 0.0 & 0.0 \\
\hline
\end{tabular}


Analizando los ratios de la empresa cuenta con exceso de liquidez por lo que se podría considerar invertir en ampliar el negocio para los siguientes años. En cuanto al margen neto, este nos muestra que hay un crecimiento notorio a partir del segundo año. Sobre la deuda, el monto de esta disminuye hasta cero en el año tres, fecha en la que se termina de cancelar el préstamo.

\subsection{Análisis de riesgo}

\subsubsection{Análisis de punto de equilibrio.}

El punto de equilibrio es ese punto de actividad en el que no se produce ganancia ni pérdida (Sapag, 2011). Para el cálculo del punto de equilibrio en unidades, se calculó primero el monto de los costos variables (ver tabla 87):

Tabla 87

Costos variables

Año 1

Año 2

Año 3

\begin{tabular}{|c|c|c|c|}
\hline Costo variables & $\mathrm{S} / 133,871.25$ & S/ $255,059.00$ & S/ $280,894.54$ \\
\hline Profesores & S/ $118,929.65$ & S/ $238,860.80$ & S/ $263,242.63$ \\
\hline luz, agua y teléfono & S/ $\quad 13,404.00$ & $14,074.20$ & $14,777.91$ \\
\hline Motas & 105.60 & 105.60 & 105.60 \\
\hline Plumones & 432.00 & 518.40 & 518.40 \\
\hline Certificados y otros & $1,000.00$ & $1,500.00$ & $2,250.00$ \\
\hline
\end{tabular}

Con estos datos y los precios se obtuvo el costo de venta unitario (CVU) y se pudo determinar el punto de equilibrio en unidades, el cual se muestra en la tabla 88:

Tabla 88

Punto de equilibrio en unidades

Margen Punto de

\begin{tabular}{lllllccc} 
Producto & Demanda & C. variable & Precio & Margen & Ponderado equilibrio \\
\hline C. grupales & $99 \%$ & S/ & 119.63 & S/ 450.00 & 330.37 & 327.71 & $\mathbf{8 7 1}$ \\
C. individuales & $1 \%$ & S/ & 119.63 & S/ 650.00 & 530.37 & 4.27 & $\mathbf{7}$ \\
\hline
\end{tabular}


Para el cálculo del punto de equilibrio financiero se igualó el VAN del accionista a cero, de esta manera se pudo estimar hasta cuánto pueden bajar los flujos de caja sin que se produzca pérdida (En este caso hasta el 16.95\%). En la tabla 89 se muestra el resultado: Tabla 89

Punto de equilibrio financiero

\begin{tabular}{cccc}
\hline & Año 1 & Año 2 & Año 3 \\
\hline$-S / 106,176.15$ & $\mathrm{~S} / 5,793.60$ & $\mathrm{~S} / 55,132.09$ & $\mathrm{~S} / 97,064.42$ \\
\hline
\end{tabular}

\subsubsection{Análisis de sensibilidad.}

El análisis de sensibilidad es utilizado por los inversionistas antes de tomar una decisión sobre determinado proyecto. (Sapag, 2011).

Para el análisis de sensibilidad del presente proyecto, se trabajó con dos variables: ventas y costos fijos. Se trabajó con una variación en ventas del $+20 \%,+10 \%,-10 \%$ y $-20 \%$ con una variación en costos fijos de $+10 \%,+5 \%,-5 \%$ y $-10 \%$. Del análisis se puede concluir, que aun cuando las ventas resultaran $10 \%$ menores a lo proyectado y los gastos fijos, el VAN continuaría siendo positivo (ver tabla 90).

Tabla 90

Análisis de sensibilidad

Ventas

$20 \% \quad 10 \% \quad-10 \% \quad-20 \%$
\begin{tabular}{l|lllll} 
G. Fijos & S/520,380.29 & S/606,420.00 & S/555,885.00 & S/454,815.00 & S/404,280.00
\end{tabular}
$10 \% \quad \mathrm{~S} / \mathbf{3 2 4 , 3 7 3 . 6 3} \quad S / 563,568.41 \quad S / 600,156.27 \quad S / 559,909.62 \quad \mathrm{~S} / 487,465.65$
$5 \% \quad S / 309,629.38 \quad S / 535,635.42 \quad S / 570,408.52 \quad S / 532,158.11 \quad S / 463,307.36$
$\begin{array}{llllll}-5 \% & \mathbf{S} / \mathbf{2 8 0 , 1 4 0 . 8 6} & S / 528,662.64 & S / 561,711.00 & S / 525,357.80 & S / 459,922.05\end{array}$
$\begin{array}{llllll}-10 \% & \mathbf{S} / \mathbf{2 6 5 , 3 9 6 . 6 1} & S / 531,792.55 & S / 563,201.71 & S / 528,651.63 & S / 466,461.49\end{array}$ 


\subsubsection{Análisis de escenarios.}

El análisis de escenarios es una herramienta que se utiliza para evaluar el riesgo de un proyecto. Haciendo este análisis se determina la rentabilidad de un proyecto en distintos escenarios, buscando de esta manera cubrir la incertidumbre. (Sapag, 2011).

Para el presente proyecto se calculó el VAN y la TIR en tres escenarios distintos: optimista, normal y pesimista, en cada uno de ellos la variable que se modificó fueron las ventas. En el escenario optimista se asumió que las ventas aumentaban $10 \%$ y en el pesimista que éstas disminuían en 10\%. A partir de esta evaluación se presenta la tabla 91:

\section{Tabla 91}

Análisis de escenarios

\begin{tabular}{lcc}
\hline Escenario & VAN & TIR \\
\hline Optimista Ventas $+10 \%$ & S/617,022.66 & $143 \%$ \\
Proyectado & S/520,380.29 & $117 \%$ \\
Pesimista Ventas -10\% & S/369,737.92 & $90 \%$ \\
\hline
\end{tabular}

Como puede observar en la tabla 91 anterior, aún en el escenario pesimista, en el que las ventas cayeran, el proyecto se mantiene rentable. 


\section{Conclusiones y Recomendaciones}

Luego de realizado todo el trabajo se obtuvieron las conclusiones y recomendaciones descritas a continuación.

\section{Conclusiones}

- Según los antecedentes revisados se ha registrado en los últimos años un aumento del uso del Internet principalmente a través de equipos móviles como los teléfonos celulares. Este aumento ha llevado a las empresas a tomar la decisión de invertir en marketing digital. En base a esta tendencia se considera que las empresas van a invertir un mayor porcentaje de su presupuesto publicitario en este rubro, por lo que la demanda de profesionales formados en marketing digital va a seguir aumentando.

- Si bien en el mercado existen instituciones que ofrecen cursos de marketing digital, estas aún no cubren el total de la creciente demanda, por lo cual existe la oportunidad de crear una nueva Escuela de Marketing Digital. El marketing digital está en constante cambio. De forma constante se lanzan nuevas redes sociales, aplicaciones móviles y formatos de pauta publicitaria por lo que un factor importante para que la escuela destaque sobre la competencia es que el personal tanto administrativo como académico se encuentre actualizado en las nuevas tendencias.

- La Escuela se orientará a personas que estén relacionadas al marketing digital por cuestiones de estudio o trabajo cuyas edades estén entre 18 y 49 años y que vivan en los distritos de Jesús María, La Molina, Lince, Magdalena, Pueblo Libre, Miraflores, San Borja, San Isidro, San Miguel y Surco.

- La Escuela se diferenciará de otras instituciones por ofrecer cursos a grupos reducidos de máximo 15 alumnos por aula, así como también por ofrecer cursos individuales, a los que se llamará personalizados. En el caso de estos cursos, el alumno determinará 
el horario y los días en los que se realizarán sus clases, de igual modo elegirá los temas que sean de su interés.

- Luego de realizado el análisis financiero se determinó que el proyecto es viable, obteniéndose un VAN del accionista de S/. 520,380.29.

\section{Recomendaciones}

- Con base en los resultados obtenidos, se recomienda ejecutar el plan de negocio.

- Se recomienda que en el segundo año, en que ya hay un aumento de caja, analizar la posibilidad de abrir un segundo local.

- Asimismo se recomienda las siguientes acciones para que la escuela destaque sobre la competencia y mantenga su vigencia:

- Evaluar la posibilidad de dictar cursos en provincia y considerar colocar un local en alguna ciudad con alta tasa de crecimiento.

- Una vez que la empresa este consolidada en el mercado evaluar la opción de licenciar el modelo de negocio como lo realiza actualmente la empresa Pandemia.

- Ser los primeros en brindar cursos de temas nuevos, como en su momento lo realizó la empresa Pandemia con el tema de los Chatbots. Este punto es importante ya que posicionaría a la Escuela como una de las más innovadoras del medio.

- Considerar la opción de ampliar la oferta de cursos a temas relacionados a Marketing Digital tales como: Diseño Gráfico, Animación por computadora, Programación, Redacción, entre otros. 


\section{Referencias}

Andina Agencia Peruana de Noticias (11 de Octubre de 2018). CCL: inestabilidad política afecta dinámica económica e inversiones. Obtenido de Andina Agencia Peruana de Noticias: https://andina.pe/agencia/noticia-ccl-inestabilidad-politica-afecta-dinamicaeconomica-e-inversiones-728181.aspx

Ansoff, H.Igor. (1976) La Estrategia de la Empresa. Ediciones Universidad de Navarra, Barcelona.

A donde vivir. (2018). Moderno Local Comercial 117,5 m2 Miraflores. Recuperado de https://www.adondevivir.com/propiedades/moderno-local-comercial-117-5-m-sup2miraflores-54109967.html

América Noticias. (17 de enero de 2017). americatv.com.pe. Recuperado de https://www.americatv.com.pe/noticias/actualidad/odebrecht-empresa-investigadacorrupcion-opera-peru-desde-hace-30-anos-n261653

Banco Mundial. (6 de Julio de 2018). Inflación - Precios al consumo. Recuperado de https://www.google.com.pe/publicdata/explore?ds=d5bncppjof8f9_\&met_y=ny_gdp_

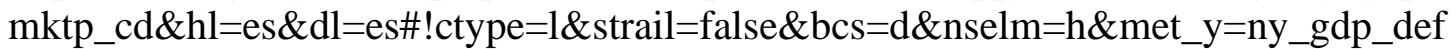
1_kd_zg\&fdim_y=inflation_type:1\&scale_y=lin\&ind_y=false\&rdim=region\&idim $=\mathrm{c}$ ountry:PER\&ifdim=region\&tdim=true

BBVA Research. (24 de Enero de 2019). Situación Perú 1T19. Recuperado de https://www.bbvaresearch.com/wp-content/uploads/2019/01/Presentacion_SituacionPeru_1T19.pdf

Beltrán, A. \& Cueva, H. (2009). Evaluación privada de proyectos. Centro de Investigación de Universidad del Pacífico.

Cámara Americana de Comercio de la República Dominicana. (Agosto de 2016). Comprendiendo los retos al desarrollo del e-Commerce en la República Dominicana. Recuperado de http://amcham.org.do/images/pdf/AMCHAMDR\%20-eCommerce.pdf

Chiavenato, I. (2009). Gestión del Talento Humano. México: Mc Graw Hill Educación.

Collins, J. (2011). Empresas que sobresalen. Deusto.

Compañía Peruana de Estudios de Mercados y Opinión Pública. (Enero de 2018). Inversiones Publicitarias 2017. Recuperado de http://cpi.pe/images/upload/paginaweb/archivo/26/mr_inversion_publicitaria_201801. pdf

D’Alessio, F. (2015). El proceso estratégico: Un enfoque de gerencia. Lima: Pearson.

David, F. (2013). Conceptos de administración estratégica (Catorce ed.). México D.F.: Pearson Educación.

El Comercio. (17 de febrero de 2019). elcomercio.pe. Recuperado de https://elcomercio.pe/politica/encuesta-comercio-ipsos-respaldo-martin-vizcarra-cae5-puntos-noticia-608484

El Comercio Perú. (2 de Julio de 2017a). La publicidad digital movió S/268 millones en el Perú durante el 2016. Recuperado de https://elcomercio.pe/economia/publicidaddigital-movio-s-268-millones-peru-2016-439158

El Comercio Perú. (8 de Mayo de 2017b). Posgrados: Tres grandes tendencias en educación para ejecutivos. Recuperado de https://elcomercio.pe/economia/dia-1/posgrados-tresgrandes-tendencias-educacion-ejecutivos-419112 
El Economista América. (23 de Febrero de 2018). Tendencias de enseñanza incluye cursos online. Recuperado de http://www.eleconomistaamerica.pe/actualidad-eAmperu/noticias/8961501/02/18/Tendencias-de-ensenanza-incluye-cursos-online.html

Excel Total. (s.f.). La función Pronóstico en Excel. Recuperado de https://exceltotal.com/lafuncion-pronostico-en-excel/

Eyzaguirre, M. (22 de Junio de 2016). Formación en marketing digital. Recuperado de http://semanaeconomica.com/hagamosclic/2016/06/22/formacion-en-marketingdigital/

Facebook. (30 de Septiembre de 2018). MOTT Fanpage. Recuperado de https://www.facebook.com/mott.pe/

Fernandez Nogales, A. (1999). Investigación de Mercados: Obtención de Información. Madrid: Gráficas Rogar.

Ferreyro, R. R. (Abril de 2008). Universidad de Guadalajara. Recuperado de Del Pizarrón a las TIC:

http://www.udgvirtual.udg.mx/apertura/index.php/apertura4/article/viewFile/65/74

Gestión. (4 de Octubre de 2012). Stansa: Reducir el gasto de papel en 40\% genera ahorros de $15 \%$ en costos operativos. Recuperado de https://gestion.pe/economia/empresas/stansa-reducir-gasto-papel-40-genera-ahorros15-costos-operativos-21554

Gestión. (13 de febrero de 2019). gestion.pe. Recuperado de https://gestion.pe/peru/politica/corte-suprema-confirma-anulacion-indulto-albertofujimori-nndc-258603

GFK. (2017). GfK Kit de planeamiento digital Perú 2017. Recuperado de https://cdn2.hubspot.net/hubfs/2405078/Landing_Pages_PDF/Peru/GfK\%20uso\%20d e\%20internet\%202016\%20-\%20Short.pdf

GoDaddy. (2018). Herramienta de búsqueda de nombre de dominios. Recuperado de https://pe.godaddy.com/domains/searchresults.aspx?isc=goflpe34\&checkAvail=1\&tm skey=1dom_03_godaddynb\&domainToCheck=mossaiqo

Google Maps. (1 de Octubre de 2018). agencia de marketing digital - Google Maps.

Recuperado de

https://www.google.com.pe/maps/search/agencia+de+marketing+digital/@ $12.0964021,-77.0551807,12.75 \mathrm{z} /$ data $=! 4 \mathrm{~m} 4 ! 2 \mathrm{~m} 3 ! 5 \mathrm{~m} 2 ! 4 \mathrm{e} 3 ! 10 \mathrm{e} 1$

Hernández, Ronald M.; Orrego Cumpa, Rosalina; Quiñones Rodriguez, Sonia. (05 de Octubre de 2018). Propósitos y Representaciones. Recuperado de Nuevas formas de aprender: La formación docente frente al uso de las TIC: http://revistas.usil.edu.pe/index.php/pyr/article/view/248/520

INEI. (2015). Población total al 30 de junio, por grupos quinquenales de edad, según departamento, provincia y distrito. Recuperado de https://www.inei.gob.pe/media/MenuRecursivo/indices_tematicos/cuadro001_1.xls

INEI. (2016a). Perú: Estructura Empresarial 2016. Lima: INEI. Recuperado de https://www.inei.gob.pe/media/MenuRecursivo/publicaciones_digitales/Est/Lib1445/1 ibro.pdf

INEI. (Noviembre de 2016b). Planos Estratificados de Lima Metropolitana a Nivel de Manzana 2016. Recuperado de https://www.inei.gob.pe/media/MenuRecursivo/publicaciones_digitales/Est/Lib1403/1 ibro.pdf

INEI. (Junio de 2018). Perú: Indicadores de Educación por departamento, 2007-2017.

Recuperado de https://www.inei.gob.pe/media/MenuRecursivo/publicaciones_digitales/Est/Lib1529/1 ibro.pdf 
Internet Archive. (30 de Septiembre de 2018). Wayback Machine - Mott.pe. Recuperado de https://web.archive.org/web/*/https://mott.pe/

IPAE. (2018). minedu.gob.pe. Recuperado de repositorio.minedu.gob.pe/bitstream/handle/MINEDU/6057/Transformemos\%20el\%2 0sistema\%20educativo\%20YA\%20CADE\%20Educación\%202018.pdf?sequence=1\& isAllowed $=\mathrm{y}$

Jones, G. (2008). Teoría Organizacional: Diseño y cambio en las organizaciones. México D.F.: Pearson Educación.

Kotler, P., \& Armstrong, G. (2012). Marketing (Decimocuarta ed.). México: Pearson Education.

Kotler, P., Kartajaya, H., \& Setiawan, I. (2017). Marketing 4.0: Moving from Traditional to Digital. New Jersey: John Wiley \& Sons.

La República. (27 de Julio de 2016). La ruta que marcó PPK para la educación en el siguiente quinquenio. Recuperado de https://larepublica.pe/politica/787491-la-rutaque-marco-ppk-para-la-educacion-en-el-siguiente-quinquenio

Lovelock, C., \& Wirtz, J. (2015). Marketing de servicios - personal, tecnología y estrategia (Séptima ed.). México D.F.: Pearson Educación de México.

Lovelock, C., Huete, L., \& Reynoso, J. (2010). Administración de servicios: Estrategias para la creación de valor en el nuevo paradigma de los negocios. México: Pearson Educación.

McDaniel, C., \& Gates, R. (2016). Investigación de Mercados. México: Cengage Learning.

Merino, M. J., Pintado, T., Sanchez, J., \& Grande, I. (2015). Introducción a la investigación de mercados. Madrid: ESIC Editorial.

Mi Empresa Propia. (2016). Guía Mi Empresa Propia 2016. Recuperado de https://mep.pe/wp-archivos/pdf/guiamep2016.pdf

Ministerio de Educación. (1 de Octubre de 2018). ¿Dónde estudio? - Observatorio de Educación y Empleo. Recuperado de https://www.ponteencarrera.pe/dondeestudio?p_p_id=Buscador+PEC\&p_p_lifecycle=0\&p_p_col_id=column$1 \&$ p_p_col_pos $=1 \&$ p_p_col_count $=7 \&$ tipo $=1 \&$ ca $=\&$ in $=\&$ re $=$

Ministerio de Trabajo y Promoción del Empleo. (2016). ¿Cuánto ganan los jóvenes profesionales técnicos? Recuperado de https://www.ponteencarrera.pe/como-va-elempleo\#cuanto-ganan

Municipalidad de Miraflores. (12 de Junio de 2012). ¿Cómo obtener una licencia de funcionamiento? Recuperado de http://blogs.miraflores.gob.pe/larco400/2012/06/como-obtener-una-licencia-defuncionamiento-en-miraflores/

Municipalidad de Miraflores. (2013). Plano Zonificación Miraflores. Recuperado de http://www.miraflores.gob.pe/Gestorw3b/files/img/5949-6561-plano-zonificacionactualizado-ene.2013.jpg

MINSA (2015) Población estimada por edades simples y grupos de edad, según provincia y distrito. Recuperado de: http://www.minsa.gob.pe/estadisticas/estadisticas/Poblacion/PoblacionMarcos.asp?15

Nuñez, G. (2017). Yo soy, el shopper peruano digitalizado. Recuperado de https://www.ipsos.com/sites/default/files/201705/YoSoyElShopperPeruanoDigitalizado.pdf

Ochoa, C. (29 de Mayo de 2015). Muestreo no probabilístico: muestreo por conveniencia. recuperado de https://www.netquest.com/blog/es/blog/es/muestreo-por-conveniencia

Osiptel. (2016). Propuesta tarifaria de la red de transporte y acceso de los proyectos regionales de internet de banda ancha. Recuperado de 
https://www.osiptel.gob.pe/repositorioaps/data/1/1/1/par/erestel-2016-serviciostelecomunicaciones-hogares/ERESTEL\%202016.pdf

Porter, M. E. (2009). Ser Competitivo. Grupo Planeta.

Realinfluencers. (20 de Noviembre de 2017). Revolución en las aulas: 5 tendencias educativas protagonistas en 2018. Recuperado de https://www.realinfluencers.es/2017/11/20/5-tendencias-seran-claves-educacion2018/

Revista Gestión. (11 de Septiembre de 2017). Casi 2 millones de peruanos realizan sus compras online desde su celular. Recuperado de https://gestion.pe/tendencias/2millones-peruanos-realizan-compras-online-celular-143284

Robbins, S., \& Judge, T. (2013). Comportamiento Organizacional (Decimoquinta ed.). México: Pearson.

Rodríguez, C. A. (26 de Octubre de 2002). Teoría de segmentación de mercados. Recuperado de https://www.gestiopolis.com/teoria-segmentacion-mercados/

RPP Noticias. (16 de febrero de 2019). rpp.pe. Recuperado de https://rpp.pe/politica/gobierno/martin-vizcarra-acuerdo-con-odebrecht-causainsomnio-a-involucrados-en-corrupcion-noticia-1181253

Sapag, N. (2001). Evaluación de Proyectos de Inversión en la Empresa. Argentina: Pearson Education.

Sapag, N. (2011). Proyectos de Inversión: Formulación y Evaluación (Segunda ed.). México: Pearson.

Similar Web. (30 de Septiembre de 2018). Mott.pe Analysis. Recuperado de https://www.similarweb.com/website/mott.pe\#overview

Stanton, W., Etzel, M., \& Walker, B. (2007). Fundamentos de Marketing (Treceava ed.). Mc Graw Hill.

Stickney, C. P., Weil, R. L., Schipper, K., Francis, J., \& Alecchi, B. A. (2012). Contabilidad Financiera - Una introducción a conceptos, métodos y usos. Buenos Aires: Cengage Learning Argentina.

Sunat. (30 de Septiembre de 2018). Consulta RUC. Recuperado de https://econsultaruc.sunat.gob.pe/cl-ti-itmrconsruc/jcrS00Alias

SUNAT. (09 de Abril de 2018). Régimen MYPE Tributario - RMT. Recuperado de http://emprender.sunat.gob.pe/regimen-mype

Superintendencia de Banca, S. y. (s.f.). www.sbs.gob.pe. Recuperado de http://www.sbs.gob.pe/app/pp/EstadisticasSAEEPortal/Paginas/TIActivaTipoCredito Empresa.aspx?tip=B

Superintendencia Nacional de Educación Superior Universitaria. (27 de Septiembre de 2018). Postulantes por universidad y sexo - Ciencias de la comunicacion. Obtenido de https://www.sunedu.gob.pe/sibe/

Thompson, Peteraf, Gamble, \& Strickland. (2012). Administración estratégica (18ava ed.). México: Editorial McGraw Hill.

Universia Perú. (26 de Octubre de 2017). Dónde estudiar Marketing y Publicidad en Perú. Recuperado de http://noticias.universia.edu.pe/educacion/noticia/2016/07/08/1141647/dondeestudiar-marketing-publicidad-peru.html

Urbania. (2018). Alquiler de Local Comercial en Miraflores - Av. Del Ejército 490.

Recuperado de https://urbania.pe/inmueble/alquiler-de-local-comercial-en-mirafloreslima-4044898

Vega, E. G. (s.f.). Fases para el diseño y análisis de la Cadena de Valor en las Organizaciones. Recuperado de https://revistas.up.edu.pe/index.php/business/article/download/28/29/ 
Velásquez, K. (29 de Noviembre de 2017). ¿Qué sabes del Marketing Digital?: Hablamos de su definición, historia y tendencias. Recuperado de https://marketing4ecommerce.mx/marketing-digital-definicion-historia/ 


\section{Apéndices}

\section{Apéndice 1}

\section{Estudio preliminar - Muestra de profesionales en LinkedIn dedicados al marketing digital}

Análisis de los profesionales

Se analizó el perfil de 100 personas en LinkedIn que están trabajando en el área de marketing digital y se obtuvo los siguientes resultados:

De los profesionales que están trabajando actualmente en el rubro la mayoría estudio como primera carrera comunicaciones. Sin embargo, se puede observar profesionales que vienen de carreras aparéntenme no relacionadas con el marketing como informática. Esto, debido a las necesidades de capacidades tecnológicas para el marketing digital.

\begin{tabular}{ll}
\hline & Nro. De \\
Carrera que estudio & Profesionales \\
\hline Comunicaciones & 38 \\
\hline Administración & 12 \\
\hline Publicidad & 11 \\
\hline Marketing & 11 \\
\hline Informática & 6 \\
\hline Periodismo & 5 \\
\hline Diseño & 3 \\
\hline Economía & 3 \\
\hline No Especifica & 2 \\
\hline Bibliotecología & 2 \\
\hline Estadística & 1 \\
\hline Soporte Técnico & 1 \\
\hline Contabilidad & 1 \\
\hline Química & 1 \\
\hline Ingeniería & 1 \\
\hline Literatura & 1 \\
\hline Hotelería & 1 \\
\hline Total general & $\mathbf{1 0 0}$ \\
\hline
\end{tabular}

De los profesionales actuales en el mercado el 93\% trabaja en Lima. Estos nos da un indicio que todavía hay un crecimiento por aprovechar en provincias. 


\begin{tabular}{ll}
\hline & Nro. De \\
Ciudad donde trabaja & Profesionales \\
\hline Lima & 93 \\
\hline Piura & 2 \\
\hline Arequipa & 2 \\
\hline Trujillo & 1 \\
\hline Ayacucho & 1 \\
\hline No especifica & 1 \\
\hline Total general & $\mathbf{1 0 0}$ \\
\hline
\end{tabular}

El $43 \%$ de los profesionales que están trabajando en el rubro del marketing digital no han llevado ningún programa o curso directamente relacionado al marketing digital por lo que el mercado potencial para una escuela de marketing no solo se encuentra en los profesionales que desean incorporarse a este rubro sino los que ya están en el mismo y quieren formalizar sus conocimientos u obtener certificaciones.

\begin{tabular}{lll}
\hline $\begin{array}{l}\text { Nro. De programas de marketing } \\
\text { digital que estudio }\end{array}$ & $\begin{array}{l}\text { Nro. De } \\
\text { profesionales }\end{array}$ & $\begin{array}{l}\% \text { de } \\
\text { profesionales }\end{array}$ \\
\hline 0 & 43 & $43 \%$ \\
\hline 1 & 33 & $33 \%$ \\
\hline 2 & 20 & $20 \%$ \\
\hline 3 & 3 & $3 \%$ \\
\hline 4 & 1 & $1 \%$ \\
\hline Total general & $\mathbf{1 0 0}$ & $100 \%$ \\
\hline
\end{tabular}

Los programas más antiguos que se han encontrado en los perfiles datan del 2010, siendo este el año en que se lanzaron los primeros programas al mercado.

\begin{tabular}{ll}
\hline $\begin{array}{l}\text { Año en que llevo su primer } \\
\text { programa }\end{array}$ & Cuenta de Nombre \\
\hline 2010 & 4 \\
\hline 2011 & 5 \\
\hline 2012 & 6 \\
\hline 2013 & 9 \\
\hline 2014 & 11 \\
\hline 2015 & 14 \\
\hline 2016 & 5 \\
\hline 2017 & 2 \\
\hline No especifico & 1 \\
\hline Total general & $\mathbf{5 7}$ \\
\hline
\end{tabular}


Se realizó un análisis de las instituciones donde habían estudiado estos profesionales obteniéndose la siguiente información:

\begin{tabular}{|c|c|c|c|c|c|c|c|c|c|c|}
\hline INSTITUCIÓN & 2010 & 2011 & 2012 & 2013 & 2014 & 2015 & 2016 & 2017 & 2018 & TOTAL \\
\hline $\begin{array}{l}\text { Universidad Peruana de Ciencias } \\
\text { Aplicadas }\end{array}$ & & & & & & 1 & & & & $\mathbf{1}$ \\
\hline $\begin{array}{l}\text { Universidad Peruana de Ciencias } \\
\text { Aplicadas }\end{array}$ & 2 & 1 & 1 & 2 & & & & & & 6 \\
\hline Instituto San Ignacio de Loyola & & & 1 & & 2 & 2 & & & 1 & 6 \\
\hline Instituto San Ignacio de Loyola & & & & & & 1 & & & & 1 \\
\hline EAE Business School & 1 & 1 & & 2 & 2 & & & & & 7 \\
\hline Universidad de Piura & & & & 3 & 2 & 1 & & 1 & & 7 \\
\hline Universidad del Pacifico & & & & & & 5 & & & & 6 \\
\hline IEBS Business School & & & 2 & & & 1 & & 2 & & 5 \\
\hline Neo Consulting (Consultora) & & & & & & & & 1 & & 1 \\
\hline Neo Consulting (Consultora) & & & 1 & & & & & & & 1 \\
\hline Neo Consulting (Consultora) & & & 1 & & & & & & & 1 \\
\hline Coursera (cursos online) & & & 1 & 1 & & & & & & 2 \\
\hline Coursera (cursos online) & & & & & & & & 1 & & 1 \\
\hline Universidad de Barcelona & & 1 & & & 1 & & & & & 2 \\
\hline Universidad Católica San Pablo & & & & & 1 & & 1 & & & 2 \\
\hline Instituto Toulouse Lautrec & & & 1 & & & & & & & 1 \\
\hline Instituto Toulouse Lautrec & & & & & & & & 1 & & 1 \\
\hline Instituto Peruano de Arte y Diseño & & & & & 1 & 1 & & & & 2 \\
\hline Zegel IPAE & & & & 1 & 1 & & & & & 2 \\
\hline Universidad CEU Cardenal Herrera & & & & & & 1 & & & & 1 \\
\hline ENEB Business School & & & & & & & 1 & & & 1 \\
\hline Kei Web Enterprises & 1 & & & & & & & & & 1 \\
\hline Goobec Perú - Cursos & 1 & & & & & & & & & 1 \\
\hline $\begin{array}{l}\text { MOTT Centro de Especialización } \\
\text { Digital }\end{array}$ & & & & & & & 1 & & & 1 \\
\hline Universidad de Lima & & & & & & & & 1 & & 1 \\
\hline Google (cursos gratuitos) & & & & & & & & 1 & & 1 \\
\hline Universidad del Pacifico & & & & & 1 & & & & & 1 \\
\hline Universidad de Nueva York & & & & & & & 1 & & & 1 \\
\hline ESIC Escuela de Negocios & & & & & & & 1 & & & 1 \\
\hline Neximotion - Agencia consultora & & & & & & & 1 & & & 1 \\
\hline Universidad Camilo José Cela & & & & & & 1 & & & & 1 \\
\hline $\begin{array}{l}\text { Universidad de San Martin de } \\
\text { Porres }\end{array}$ & & & & & 1 & & & & & $\mathbf{1}$ \\
\hline IAB Perú & & & & 1 & & & & & & 1 \\
\hline APEM - Escuela de Marketing & & & & & & & & 1 & & 1 \\
\hline Universidad de Palermo & & & & & & 1 & & & & 1 \\
\hline $\begin{array}{l}\text { Pandemia (Escuela de Marketing } \\
\text { Digital) }\end{array}$ & & & & & & 1 & & & & 1 \\
\hline Esden Perú - Escuela Superior & & 1 & & & & & & & & 1 \\
\hline PROMPERÚ & & & & & & 1 & & & & 1 \\
\hline Universidad Nacional de Trujillo & & & 1 & & & & & & & 1 \\
\hline Universidad Ricardo Palma & & & & 1 & & & & & & 1 \\
\hline The Atomic Garden - Escuela & & & & & 1 & & & & & 1 \\
\hline Instituto Peruano de Marketing & & 1 & & & & & & & & 1 \\
\hline Underground School of Creativity & & & & & & 1 & & & & 1 \\
\hline
\end{tabular}




\begin{tabular}{lllllllllll}
\hline $\begin{array}{l}\text { Universidad Autónoma de } \\
\text { Barcelona }\end{array}$ & & 1 & & & & & & & 1 \\
\hline OM Latam Academy & 1 & & & & & & & $\mathbf{1}$ \\
\hline Total general & $\mathbf{5}$ & $\mathbf{6}$ & $\mathbf{1 0}$ & $\mathbf{1 1}$ & $\mathbf{1 3}$ & $\mathbf{1 8}$ & $\mathbf{6}$ & $\mathbf{9}$ & $\mathbf{1}$ & $\mathbf{7 9}$ \\
\hline
\end{tabular}




\section{Apéndice 2}

\section{Ficha de Reclutamiento para Focus Group}

Presentación: Somos alumnos de la Escuela de Posgrado de la USIL, estamos organizando un Focus Group como parte de nuestro trabajo académico para graduarnos, por ello solicitamos su participación, y antes de iniciar la reunión le haremos unas preguntas de interés sólo para nosotros. Agradecemos que haya venido y le invitamos a compartir una tarde (mañana, noche) agradable.

\section{Filtro \#1: Aspectos Comportamentales}

1. ¿Usted estudia o trabaja en alguna de las siguientes áreas: publicidad, relaciones públicas, ventas, marketing, imagen institucional?
a) Sí
b) No (terminar)

2. ¿Con qué frecuencia toma cursos que sean útiles para su desarrollo profesional?
a) Nunca
b) Una vez al año
c) Dos veces al año
d) Más de 3 veces al año

3. ¿Ha tomado Ud. cursos de marketing digital como SEO, SEM, Community Manager, etc.?
a) Sí
b) $\mathrm{No}$

4. ¿Estaría interesado en tomar cursos de marketing digital?
a) Sí
b) No (terminar)

5. ¿Qué aspectos considera determinantes al momento de elegir dónde estudiar?
a) Ubicación
b) Prestigio
c) Precio
d) Horario

\section{Filtro \#2: NIVEL SOCIOECONOMICO}

1. Ingreso mensual (Nuevos Soles)

2. Distrito de residencia 
Datos de control

Nombre:

Correo electrónico:

Ocupación:

Teléfono:

Edad: 


\section{Apéndice 3}

\section{FOCUS GROUP}

\section{Guía de Indagación o Guía de Tópicos o Guía de preguntas}

\section{Introducción}

\section{Saludo y Presentación}

Muy buenos días/tardes/noches, somos dos alumnos de la Maestría en Ciencias Empresariales de la USIL que estamos realizando una investigación de mercados con el objetivo de determinar la demanda para la creación de una escuela de marketing digital.

Por tal motivo, el día de hoy nos encontramos reunidos en esta sala con el fin de conversar con Uds. acerca de los cursos de marketing digital y las instituciones donde se dictan. Les pedimos unos minutos de su tiempo para conversar acerca de este tema y por favor, siéntanse con libertad de dar su opinión sin ninguna restricción, ya que todo lo que Uds. nos digan será tratado de manera confidencial. No hay respuestas buenas ni malas. Les damos las gracias por su participación.

Reglas de Juego: Relajarse, No tema estar en desacuerdo, Grabación y audio.

Calentamiento: Breve presentación de los participantes.

1. Descripción del proceso de contratación del servicio (7 minutos) Hablemos del proceso de elección de un instituto o escuela: Al momento de elegir dónde estudiar un curso de marketing digital ¿cómo es el proceso de elección de la institución? ¿Qué factores son considerados en el proceso de elección? ¿Por qué? ¿Nos pueden indicar los tres más importantes? ¿Qué factor (factores) es (son) determinante (s) para la matrícula en determinada institución? ¿Por qué? ¿Quién es la persona encargada de definir la institución? ¿Ud. mismo, otro decisor o ambos? ¿Por qué? ¿En qué medios busca información con respecto de institutos o escuelas? ¿Por qué? ¿Con qué frecuencia se matricula en cursos? ¿Por qué? ¿A cuánto asciende su gasto promedio en cursos o capacitaciones? 
2. Hábitos de consumo ( 7 minutos) Hablemos en forma general de los cursos de marketing digital: ¿Qué tipo de cursos prefiere? ¿Cuánto tiempo debería durar cada uno de estos cursos? ¿Qué curso relacionado al marketing digital le interesa, pero aún no ha encontrado en los institutos o escuelas actuales? ¿En qué horario le gustaría estudiar? ¿Qué modalidades de estudio conoce? ¿Qué cursos le interesaría llevar próximamente? ¿Por qué? ¿Con qué frecuencia se inscribe a cursos relacionados con su carrera?

3. Evaluación de la competencia (7 minutos) ¿Qué institutos o escuelas de marketing digital conoce? ¿Cuál considera el mejor instituto o escuela para llevar un curso de marketing digital? ¿Por qué? ¿Qué ventajas tiene? ¿Cuáles son las desventajas de estudiar en ella? ¿En qué institución definitivamente no estudiaría? ¿Por qué?

4. Acerca de La Empresa, ¿Estudiaría en una escuela nueva? ¿Qué características debería ésta tener para que se anime a estudiar en ella?

Nuestra propuesta es una Escuela de Marketing Digital, en la cual se dictarán cursos cortos de un mes de duración. La Escuela no estará regida por la Ley General de Educación, por lo que no emitirá certificados a nombre de la nación si no a nombre propio. Los cursos serán dictados por especialistas en las materias capaces de adaptar los cursos de acuerdo a las necesidades del alumno.

Los cursos se ofrecerán en tres modalidades:

- Cursos regulares, en nuestro local, para grupos pequeños de entre 5 a 15 personas en horarios previamente establecidos.

- Cursos individuales, donde el alumno compra un paquete de un número de horas para que un profesor le enseñe sólo temas específicos que el alumno requiera, el horario será establecido por el alumno quien deberá comunicarlo con anticipación a la escuela para hacer las coordinaciones necesarias.

- Cursos blended, es decir que el alumno estudiará por su cuenta a través de una plataforma virtual, asistiendo de manera presencial sólo una vez a la semana a la escuela para asesorías o prácticas. 
5. Acerca de los cursos ( 7 minutos) ¿Le parecería una ventaja que esta escuela ofrezca cursos personalizados, diseñados especialmente para Ud., con lo que Ud. Desea o necesita aprender?, ¿en el horario que Ud. Elija? ¿Que lo motivaría a llevar un curso de este tipo? En cuanto a los cursos blended, ¿le parecen interesantes o útiles? ¿Qué ventajas tienen estos cursos? La escuela también ofrecerá cursos regulares, grupales y presenciales ¿Le interesaría llevarlo?

6. Acerca de los precios y forma de pago ( 5 minutos) ¿Cuánto considera que debería ser el precio de los cursos en cada una de las modalidades que ofrece la escuela?

7. Acerca del local y horario de atención (5 minutos) ¿En qué distrito se debería ubicar la escuela de marketing digital? ¿Cuáles serían las ventajas de esta ubicación? ¿Cuál podría ser una buena alternativa a esta ubicación? ¿En qué horario debería funcionar la escuela? ¿Qué ambientes debería tener? ¿Qué equipamiento? ¿Qué esperaría de la plataforma online para los cursos blended?

8. Acerca de la metodología (5 minutos) ¿Qué le parece que en esta nueva escuela se utilice la gamificación (explicar gamificación) como método para motivar a los alumnos a estudiar y continuar capacitándose? ¿Qué opina de llevar cursos cortos, con pocas sesiones? ¿Qué le parecería poder elaborar una propuesta de campaña a una empresa real?

9. Intención de Compra (5 minutos) ¿Se matricularía en esta nueva escuela? ¿En qué modalidad de curso? ¿Qué ventajas le encontraría a estudiar en esta escuela? ¿Si no se matriculara, por qué razón sería? 


\section{Apéndice 4}

\section{Resultados del primer Focus Group}

\section{Descripción del proceso de contratación del servicio}

\begin{tabular}{|c|c|c|c|c|c|c|c|c|}
\hline Variable & Respuestas & Oma & Car & Luc & Edu & Kar & Vic & Att \\
\hline \multirow{4}{*}{$\begin{array}{l}\text { ¿Qué es lo que } \\
\text { valora en una } \\
\text { institución? }\end{array}$} & Prestigio & $\mathrm{X}$ & $\mathrm{X}$ & & $\mathrm{X}$ & & $\mathrm{X}$ & $\mathrm{X}$ \\
\hline & Ubicación & & $\mathrm{X}$ & $\mathrm{X}$ & & & & \\
\hline & Horarios & $\mathrm{X}$ & & & & & & \\
\hline & Precio & $\mathrm{X}$ & $\mathrm{X}$ & & & $X$ & $\mathrm{X}$ & \\
\hline $\begin{array}{l}\text { ¿Quién es el } \\
\text { decisor? }\end{array}$ & Yo & $\mathrm{X}$ & $\mathrm{X}$ & $\mathrm{X}$ & $\mathrm{X}$ & $\mathrm{X}$ & $\mathrm{X}$ & $\mathrm{X}$ \\
\hline $\begin{array}{l}\text { ¿En qué medios } \\
\text { busca información } \\
\text { con respecto de } \\
\text { institutos o } \\
\text { escuelas? }\end{array}$ & Internet / Buscadores & $\mathrm{X}$ & $\mathrm{X}$ & & $\mathrm{X}$ & & & \\
\hline $\begin{array}{l}\text { ¿Co que frecuencia } \\
\text { se matricula en } \\
\text { cursos? }\end{array}$ & Una vez al año & $\mathrm{X}$ & $\mathrm{X}$ & & $\mathrm{X}$ & & & \\
\hline \multirow{2}{*}{$\begin{array}{l}\text { ¿Cuál es su } \\
\text { presupuesto para } \\
\text { capacitarse? }\end{array}$} & Cursos Gratis & & $\mathrm{X}$ & & & $\mathrm{X}$ & & \\
\hline & Menos de 500 & & & & $\mathrm{X}$ & & & \\
\hline
\end{tabular}

\section{Hábitos de consumo}

\begin{tabular}{|c|c|c|c|c|c|c|c|}
\hline Variable & Respuestas & Oma Car & Luc & Edu & Kar & Vic & Att \\
\hline $\begin{array}{l}\text { ¿Qué cursos de } \\
\text { marketing digital } \\
\text { les interesaría } \\
\text { llevar? }\end{array}$ & Adwords & $\mathrm{X}$ & & & & $X$ & $X$ \\
\hline $\begin{array}{l}\text { ¿Qué duración } \\
\text { debería tener el } \\
\text { curso? }\end{array}$ & 3 a 4 meses & & & & $\mathrm{X}$ & & $\mathrm{X}$ \\
\hline
\end{tabular}

\begin{tabular}{|c|c|c|c|c|c|c|c|}
\hline $\begin{array}{l}\text { ¿Algún curso de } \\
\text { marketing digital } \\
\text { que les interese, } \\
\text { pero no han } \\
\text { encontrado en } \\
\text { ningún instituto? }\end{array}$ & $\begin{array}{l}\text { Los cursos son muy } \\
\text { teóricos, no hay mucha } \\
\text { práctica. }\end{array}$ & $X$ & $\mathrm{X}$ & & & $\mathrm{X}$ & \\
\hline \multirow{2}{*}{$\begin{array}{l}\text { ¿Qué horario } \\
\text { prefiere para } \\
\text { estudiar? }\end{array}$} & Fin de semana & $X$ & $X$ & $\mathrm{X}$ & $X$ & $X$ & $X$ \\
\hline & $\begin{array}{l}\text { En la noche (día de } \\
\text { semana) }\end{array}$ & $\mathrm{X}$ & $\mathrm{X}$ & $X$ & $\mathrm{X}$ & $\mathrm{X}$ & \\
\hline \multirow{3}{*}{$\begin{array}{l}\text { ¿Qué modalidades } \\
\text { de estudio } \\
\text { conocen? }\end{array}$} & Online & & $X$ & & $\mathrm{X}$ & $\mathrm{X}$ & \\
\hline & Mixto & & $X$ & & $X$ & $X$ & \\
\hline & Presencial & & $\mathrm{X}$ & & $X$ & $X$ & \\
\hline $\begin{array}{l}\text { ¿Con que } \\
\text { frecuencia se } \\
\text { inscriben a cursos } \\
\text { relacionados a su }\end{array}$ & Después de 4 a 5 años & & & & & $\mathrm{X}$ & \\
\hline
\end{tabular}


carrera?

\begin{tabular}{|c|c|c|c|c|c|c|c|c|}
\hline \multicolumn{9}{|c|}{ Evaluación de la competencia } \\
\hline Variable & Respuestas & Oma & Car & Luc & Edu & Kar & Vic & Att \\
\hline \multirow{6}{*}{$\begin{array}{l}\text { ¿Qué instituto o } \\
\text { escuela de } \\
\text { marketing digital } \\
\text { conoce? }\end{array}$} & ISIL & & & & $\mathrm{X}$ & & & \\
\hline & IPP & & $\bar{X}$ & & $\mathrm{X}$ & & $\bar{X}$ & \\
\hline & IPAD & $X$ & & & & & & \\
\hline & MOTT & & & & $\mathrm{X}$ & & & \\
\hline & Domestika & & & $\mathrm{X}$ & & & & \\
\hline & Atomic Garden & & $\mathrm{X}$ & & & $\mathrm{X}$ & & \\
\hline \multirow[b]{2}{*}{$\begin{array}{l}\text { ¿Cuál consideran } \\
\text { que es el mejor } \\
\text { instituto/escuela } \\
\text { para llevar un curso } \\
\text { de marketing } \\
\text { digital? }\end{array}$} & MOTT & & & & $\mathrm{X}$ & & & \\
\hline & Atomic Garden & & & & & $\mathrm{X}$ & & \\
\hline \multirow[t]{2}{*}{$\begin{array}{l}\text { ¿Por qué consideran } \\
\text { que son los } \\
\text { mejores? }\end{array}$} & $\begin{array}{l}\text { Los que dictan clases } \\
\text { trabajan en el medio } \\
\text { tienen mucha } \\
\text { experiencia. }\end{array}$ & & & & & $\mathrm{X}$ & & \\
\hline & $\begin{array}{l}\text { Algunos son } \\
\text { influencers }\end{array}$ & & & $\mathrm{X}$ & & & & \\
\hline $\begin{array}{l}\text { ¿Alguna desventaja } \\
\text { que tendría estudiar } \\
\text { en una de estas } \\
\text { escuelas? }\end{array}$ & $\begin{array}{l}\text { No estoy segura, pero } \\
\text { fácil el precio }\end{array}$ & & & $\mathrm{X}$ & & & & \\
\hline
\end{tabular}

Acerca de los cursos

\begin{tabular}{|c|c|c|c|c|c|c|c|c|}
\hline Variable & Respuestas & Oma & Car & Luc & Edu & Kar & Vic & Att \\
\hline $\begin{array}{l}\text { ¿Qué les parece la } \\
\text { opción de los cursos } \\
\text { personalizados? }\end{array}$ & Si es interesante & $\mathrm{X}$ & $\mathrm{X}$ & $\mathrm{X}$ & $\mathrm{X}$ & $\mathrm{X}$ & $\mathrm{X}$ & $\mathrm{X}$ \\
\hline \multirow{3}{*}{$\begin{array}{l}\text { ¿Qué les motivaría a } \\
\text { llevar un curso de } \\
\text { este tipo? }\end{array}$} & Que sea personalizado & & & & & $\mathrm{X}$ & & \\
\hline & $\begin{array}{l}\text { Que podamos elegir } \\
\text { nuestros horarios }\end{array}$ & & & & & $\mathrm{X}$ & & \\
\hline & $\begin{array}{l}\text { Me interesa que tenga } \\
\text { un certificado }\end{array}$ & & & & $\mathrm{X}$ & & & \\
\hline $\begin{array}{l}\text { ¿Cuánto creen que } \\
\text { debería durar los } \\
\text { cursos presenciales? } \\
\text { (En la modalidad } \\
\text { mixta) }\end{array}$ & Una vez por semana & $\mathrm{X}$ & $\mathrm{X}$ & $\mathrm{X}$ & $\mathrm{X}$ & $\mathrm{X}$ & $\mathrm{X}$ & $\mathrm{X}$ \\
\hline $\begin{array}{l}\text { ¿Y cuánto deberían } \\
\text { durar en el caso de } \\
\text { la modalidad de } \\
\text { cursos regulares? }\end{array}$ & $\begin{array}{l}\text { Máximo } 2 \text { veces por } \\
\text { semana }\end{array}$ & $\mathrm{X}$ & $\mathrm{X}$ & $\mathrm{X}$ & $\mathrm{X}$ & $\mathrm{X}$ & $\mathrm{X}$ & $X$ \\
\hline
\end{tabular}




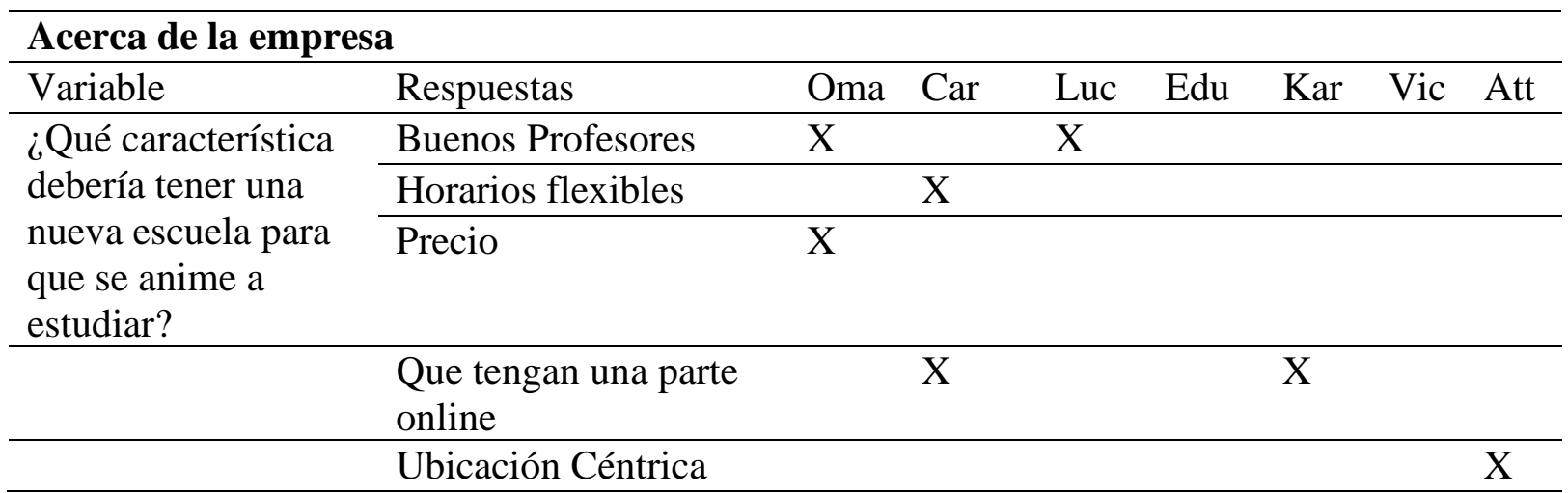

\begin{tabular}{|c|c|c|c|c|c|c|c|c|}
\hline \multicolumn{9}{|c|}{ Acerca de los precios y forma de pago } \\
\hline Variable & Respuestas & Oma & Car & Luc & Edu & Kar & Vic & Att \\
\hline \multirow{3}{*}{$\begin{array}{l}\text { ¿Cuál consideraría } \\
\text { que debe ser el } \\
\text { precio de los } \\
\text { cursos? }\end{array}$} & $\begin{array}{l}\text { Debería brindarse un } \\
\text { precio de introducción } \\
\text { al mercado }\end{array}$ & & & & & & & $\mathrm{X}$ \\
\hline & 250 soles mensuales & & & & $\mathrm{X}$ & & & \\
\hline & 300 soles mensuales & & $\mathrm{X}$ & & & & & \\
\hline \multirow{2}{*}{$\begin{array}{l}\text { ¿Y cuánto debería } \\
\text { ser la tarifa de un } \\
\text { curso } \\
\text { personalizado? }\end{array}$} & $\begin{array}{l}\text { Entre } 30 \text { a } 50 \$ \text { por } \\
\text { hora }\end{array}$ & & $\mathrm{X}$ & & & & & \\
\hline & 100 soles por hora & $\mathrm{X}$ & & & & & & \\
\hline \multirow{3}{*}{$\begin{array}{l}\text { ¿Cuántas horas } \\
\text { debería ser la } \\
\text { asesoría } \\
\text { personalizada? }\end{array}$} & Una vez al mes & & $\mathrm{X}$ & $\mathrm{X}$ & & & & \\
\hline & Cada 15 días & & $\mathrm{X}$ & & & $\mathrm{X}$ & & \\
\hline & $\begin{array}{l}2 \text { o } 3 \text { veces por semana } \\
\text { para una asesoría para } \\
\text { un nuevo proyecto }\end{array}$ & & & & & & & $\mathrm{X}$ \\
\hline
\end{tabular}

\begin{tabular}{|c|c|c|c|c|c|c|c|c|}
\hline \multicolumn{9}{|c|}{ Acerca del local y horario de atención } \\
\hline Variable & Respuestas & Oma & Car & Luc & Edu & Kar & Vic & Att \\
\hline \multirow{2}{*}{$\begin{array}{l}\text { ¿En qué distrito de } \\
\text { debería ubicar la } \\
\text { escuela? }\end{array}$} & Miraflores & & & & & & & \\
\hline & $\begin{array}{l}\text { Un distrito céntrico } \\
\text { cualquiera }\end{array}$ & & & & & & & \\
\hline \multirow[t]{3}{*}{$\begin{array}{l}\text { ¿Qué horario sería } \\
\text { el ideal? }\end{array}$} & $\begin{array}{l}\text { Dia se semana en la } \\
\text { noche }\end{array}$ & & & & & & & \\
\hline & Sábado en la mañana & & & & & & & \\
\hline & Domingo en la mañana & & & & & & & \\
\hline
\end{tabular}

\section{Acerca de la metodología}

\begin{tabular}{|c|c|c|c|c|c|c|c|}
\hline Variable & Respuestas & Oma Car & Luc & Edu & Kar & Vic & Att \\
\hline $\begin{array}{l}\text { ¿Qué les parecería } \\
\text { el uso de la } \\
\text { gamificación? }\end{array}$ & Si me interesa & & & & & & \\
\hline $\begin{array}{l}\text { ¿Qué les parece la } \\
\text { opción de que todos }\end{array}$ & $\begin{array}{l}\text { Los cursos deben ser } \\
\text { intensos }\end{array}$ & $\mathrm{X}$ & & & & & \\
\hline
\end{tabular}




\begin{tabular}{|c|c|c|c|c|c|c|c|c|}
\hline $\begin{array}{l}\text { los cursos sean } \\
\text { cursos cortos? }\end{array}$ & $\begin{array}{l}\text { Los cursos deben ser } \\
\text { puntuales }\end{array}$ & & $\mathrm{X}$ & & & & & \\
\hline $\begin{array}{l}\text { ¿Qué les parece la } \\
\text { opción de que } \\
\text { tengan convenios } \\
\text { con empresas } \\
\text { reales? }\end{array}$ & Si me interesa & $\mathrm{X}$ & $\mathrm{X}$ & $\mathrm{X}$ & $\mathrm{X}$ & $\mathrm{X}$ & $\mathrm{X}$ & $\mathrm{X}$ \\
\hline
\end{tabular}

\begin{tabular}{|c|c|c|c|c|c|c|c|c|}
\hline \multicolumn{9}{|c|}{ Intención de compra } \\
\hline Variable & Respuestas & Oma & Car & Luc & Edu & Kar & Vic & Att \\
\hline \multirow{2}{*}{$\begin{array}{l}\text { ¿Se matricularía en } \\
\text { esta nueva escuela? }\end{array}$} & $\mathrm{Si}$ & $\mathrm{X}$ & $\mathrm{X}$ & & $\mathrm{X}$ & $\mathrm{X}$ & $\mathrm{X}$ & $\mathrm{X}$ \\
\hline & $\begin{array}{l}\text { Sí, pero primero } \\
\text { tendríamos que ver el } \\
\text { precio }\end{array}$ & & & $X$ & & & & \\
\hline $\begin{array}{l}\text { ¿En qué modalidad } \\
\text { de los cursos que } \\
\text { hemos } \\
\text { mencionado? }\end{array}$ & $\begin{array}{l}\text { De la que armas tu } \\
\text { curso }\end{array}$ & $\mathrm{X}$ & $\mathrm{X}$ & $\mathrm{X}$ & $\mathrm{X}$ & $\mathrm{X}$ & $\mathrm{X}$ & $\mathrm{X}$ \\
\hline $\begin{array}{l}\text { ¿Qué ventajas le } \\
\text { encontrarían a } \\
\text { estudiar en una } \\
\text { escuela así? }\end{array}$ & Ganar tiempo & & & & $\mathrm{X}$ & & & \\
\hline \multirow[t]{3}{*}{$\begin{array}{l}\text { ¿Y si no se } \\
\text { matriculan en esta } \\
\text { escuela porque } \\
\text { razón seria? }\end{array}$} & $\begin{array}{l}\text { Por la falta de } \\
\text { trayectoria }\end{array}$ & & $\mathrm{X}$ & & & & & \\
\hline & Porque es nueva & $\mathrm{X}$ & $\mathrm{X}$ & $\mathrm{X}$ & $\mathrm{X}$ & $\mathrm{X}$ & $\mathrm{X}$ & $\mathrm{X}$ \\
\hline & Por el precio & & & & $\mathrm{X}$ & & & \\
\hline
\end{tabular}




\section{Apéndice 5}

\section{Resultados del segundo Focus Group}

\section{Descripción del proceso de contratación del servicio}

\begin{tabular}{|c|c|c|c|c|c|c|}
\hline Variable & Respuestas & Art & May & Pie & Gia & Eli \\
\hline \multirow{9}{*}{$\begin{array}{l}\text { ¿Qué es lo que valora } \\
\text { en una institución? }\end{array}$} & Años en el mercado & & $X$ & & & \\
\hline & $\begin{array}{l}\text { Referencias en redes } \\
\text { sociales }\end{array}$ & $\mathrm{X}$ & $\mathrm{X}$ & & & \\
\hline & Opiniones o comentarios & & $\mathrm{X}$ & $X$ & & \\
\hline & Si tiene una promoción & & $\mathrm{X}$ & & & \\
\hline & Precio & & $\mathrm{X}$ & $\mathrm{X}$ & & \\
\hline & Profesores & & $\mathrm{X}$ & $\mathrm{X}$ & $\mathrm{X}$ & \\
\hline & $\begin{array}{l}\text { Reputación de la } \\
\text { institución }\end{array}$ & & & $\mathrm{X}$ & & \\
\hline & $\begin{array}{l}\text { Manejo optimo del } \\
\text { marketing digital en la } \\
\text { propia empresa }\end{array}$ & $\mathrm{X}$ & & & & \\
\hline & $\begin{array}{l}\text { Cursos alineados con las } \\
\text { tendencias o cambios }\end{array}$ & $\mathrm{X}$ & & & $\mathrm{X}$ & \\
\hline ¿Quién es el decisor? & Yo & $\mathrm{X}$ & $\mathrm{X}$ & $\mathrm{X}$ & $\mathrm{X}$ & \\
\hline \multirow{6}{*}{$\begin{array}{l}\text { ¿Cuál es su } \\
\text { presupuesto para } \\
\text { capacitarse? }\end{array}$} & Menos de 800 & & & & & \\
\hline & Entre 800 y 1,000 & $\mathrm{X}$ & & & & \\
\hline & Entre 1,000 y 2,000 & & & & $\mathrm{X}$ & \\
\hline & Entre 2,000 y 3,000 & & $\mathrm{X}$ & & & \\
\hline & Entre 3,000 y 5,000 & & & $\mathrm{X}$ & & \\
\hline & Más de 5,000 & & & & & \\
\hline
\end{tabular}

\begin{tabular}{|c|c|c|c|c|c|c|}
\hline \multicolumn{7}{|l|}{ Hábitos de consumo } \\
\hline Variable & Respuestas & Art & May & Pie & Gia & Eli \\
\hline \multirow{5}{*}{$\begin{array}{l}\text { ¿Qué cursos de } \\
\text { marketing digital les } \\
\text { interesaría llevar? }\end{array}$} & Analítica (Métricas) & $\mathrm{X}$ & $X$ & $\mathrm{X}$ & & \\
\hline & Publicidad Digital & $\mathrm{X}$ & & $\mathrm{X}$ & & \\
\hline & Generación de contenido & & & $\mathrm{X}$ & & \\
\hline & Estrategia digital & & & & $\mathrm{X}$ & \\
\hline & Adwords & $\mathrm{X}$ & & & & \\
\hline \multirow{2}{*}{$\begin{array}{l}\text { ¿Qué tan seguido } \\
\text { llevan este tipo de } \\
\text { cursos? }\end{array}$} & Uno al año & $\mathrm{X}$ & & & & \\
\hline & Cada 3 meses & & & & $X$ & \\
\hline $\begin{array}{l}\text { ¿Qué horario prefiere } \\
\text { para estudiar? }\end{array}$ & Noche & $\mathrm{X}$ & $\mathrm{X}$ & $\mathrm{X}$ & $\mathrm{X}$ & \\
\hline
\end{tabular}

\begin{tabular}{lllllll}
\hline Evaluación de la competencia & Respuestas & Art & May & Pie & Gia & Eli \\
\hline Variable & Esan & & X & X & X & \\
\cline { 2 - 7 } $\begin{array}{l}\text { ¿Qué instituto o } \\
\text { escuela de marketing }\end{array}$ & UPC & X & X & X & \\
\hline
\end{tabular}




\begin{tabular}{lllllll}
\hline digital conoce? & IPAD & & $\mathrm{X}$ & $\mathrm{X}$ & \\
\cline { 2 - 7 } & Universidad de Piura & & & $\mathrm{X}$ & $\mathrm{X}$ \\
\cline { 2 - 7 } & MOTT & $\mathrm{X}$ & & & $\mathrm{X}$ \\
\hline Acerca de la empresa & & & & & & \\
\hline Variable & Respuestas & Art & May & Pie & Gia & Eli \\
\hline $\begin{array}{l}\text { ¿Qué característica } \\
\text { debería tener una } \\
\text { nueva escuela para } \\
\text { que se anime a } \\
\text { estudiar? }\end{array}$ & Buenos Profesores & $\mathrm{X}$ & & $\mathrm{X}$ & $\mathrm{X}$ & $\mathrm{X}$ \\
\cline { 2 - 7 } & Cursos relevantes & $\mathrm{X}$ & & & $\mathrm{X}$ & \\
\cline { 2 - 7 } & Que apliquen el & & $\mathrm{X}$ & & & \\
\hline
\end{tabular}

\begin{tabular}{lllllll}
\hline Acerca de los cursos & & & & & & \\
\hline Variable & Respuestas & Art & May & Pie & Gia & Eli \\
\hline \multirow{2}{*}{$\begin{array}{l}\text { ¿Qué les parece la } \\
\text { opción de los cursos } \\
\text { personalizados? }\end{array}$} & Me interesaría bastante & & X & & & X \\
\cline { 2 - 7 } & Si es interesante & X & & X & X & \\
\hline
\end{tabular}

\begin{tabular}{|c|c|c|c|c|c|c|}
\hline \multicolumn{7}{|c|}{ Acerca de los precios y forma de pago } \\
\hline Variable & Respuestas & Art & May & Pie & Gia & Eli \\
\hline \multirow{5}{*}{$\begin{array}{l}\text { ¿Cuál consideraría } \\
\text { que debe ser el precio } \\
\text { de los cursos? }\end{array}$} & $\begin{array}{l}\text { Debería brindarse un } \\
\text { precio promocional }\end{array}$ & & & $\mathrm{X}$ & & \\
\hline & $\begin{array}{l}\text { Los precios tendrían que } \\
\text { ser modulares de acuerdo } \\
\text { con los temas }\end{array}$ & $\mathrm{X}$ & & & & \\
\hline & Entre 500 a 800 soles & & $\mathrm{X}$ & & & \\
\hline & Entre 1000 a 1500 soles & & & & $\mathrm{X}$ & \\
\hline & Entre 400 a 500 soles & & & & & $\mathrm{X}$ \\
\hline
\end{tabular}

\begin{tabular}{|c|c|c|c|c|c|c|}
\hline \multicolumn{7}{|c|}{ Acerca del local y horario de atención } \\
\hline Variable & Respuestas & Art & May & Pie & Gia & Eli \\
\hline \multirow{2}{*}{$\begin{array}{l}\text { ¿En qué distrito de } \\
\text { debería ubicar la } \\
\text { escuela? }\end{array}$} & Miraflores & $\mathrm{X}$ & & $\mathrm{X}$ & $\mathrm{X}$ & \\
\hline & $\begin{array}{l}\text { Un distrito céntrico } \\
\text { cualquiera }\end{array}$ & & $\mathrm{X}$ & & & \\
\hline \multirow{3}{*}{$\begin{array}{l}\text { ¿Qué horario sería el } \\
\text { ideal? }\end{array}$} & Día se semana en la noche & $\mathrm{X}$ & $\mathrm{X}$ & $\mathrm{X}$ & $\mathrm{X}$ & $\mathrm{X}$ \\
\hline & Sábado en la mañana & $\mathrm{X}$ & & $\mathrm{X}$ & & \\
\hline & Domingo en la mañana & & $\mathrm{X}$ & & & $\mathrm{X}$ \\
\hline
\end{tabular}

\begin{tabular}{|c|c|c|c|c|c|c|}
\hline \multicolumn{7}{|c|}{ Acerca de la metodología } \\
\hline Variable & Respuestas & Art & May & Pie & Gia & Eli \\
\hline $\begin{array}{l}\text { ¿Qué les parecería el } \\
\text { uso de la } \\
\text { gamificación? }\end{array}$ & No lo veo relevante & & & $\mathrm{X}$ & $\mathrm{X}$ & \\
\hline \multirow{2}{*}{$\begin{array}{l}\text { ¿Y la opción de } \\
\text { descuentos o } \\
\text { seminarios por }\end{array}$} & Si me interesa & & $\mathrm{X}$ & & & $\mathrm{X}$ \\
\hline & $\begin{array}{l}\text { Es interesante pero no } \\
\text { forma parte de mi factor }\end{array}$ & & & $\mathrm{X}$ & & \\
\hline
\end{tabular}




\begin{tabular}{|c|c|c|c|c|c|c|}
\hline \multirow{2}{*}{$\begin{array}{l}\text { obtener buenas notas } \\
\text { o certificaciones? }\end{array}$} & \multicolumn{6}{|l|}{ de decisión } \\
\hline & No precisa / Indiferente & $\mathrm{X}$ & & & $\mathrm{X}$ & \\
\hline \multirow{3}{*}{$\begin{array}{l}\text { ¿Qué les parece la } \\
\text { opción de hacer } \\
\text { campañas para una } \\
\text { empresa real? }\end{array}$} & $\begin{array}{l}\text { La experiencia práctica es } \\
\text { la más útil }\end{array}$ & $\mathrm{X}$ & & & $\mathrm{X}$ & $\mathrm{X}$ \\
\hline & $\begin{array}{l}\text { Me influenciaría en la } \\
\text { toma de decisiones }\end{array}$ & & $\mathrm{X}$ & & & \\
\hline & $\begin{array}{l}\text { Es más interesante que la } \\
\text { gamificación }\end{array}$ & $\mathrm{X}$ & & & & \\
\hline \multicolumn{7}{|l|}{ Intención de compra } \\
\hline Variable & Respuestas & Art & May & Pie & Gia & Eli \\
\hline \multirow{2}{*}{$\begin{array}{l}\text { ¿Se matricularía en } \\
\text { esta nueva escuela? }\end{array}$} & $\mathrm{Si}$ & $X$ & $\mathrm{X}$ & $X$ & $X$ & \\
\hline & $\begin{array}{l}\text { Y además se } \\
\text { recomendaría }\end{array}$ & & & & & $\mathrm{X}$ \\
\hline
\end{tabular}




\section{Apéndice 6}

\section{Guía para la entrevista en profundidad}

\section{ENTREVISTA EN PROFUNDIDAD}

Entrevistador: $\quad$ Fecha:

Entrevistado:

Introducción

Buenos días/tardes, mi nombre es Ricardo Llanos. Quiero agradecerle por el tiempo que nos está brindando y quisiera pedirle por favor responder con toda confianza las preguntas, ya que la información que usted nos otorgue será estrictamente confidencial.

\section{OBJETIVO DEL ESTUDIO}

Obtener información sobre temas académicos y comerciales referentes a la creación de una escuela de marketing digital.

\section{PREGUNTAS}

\section{A. Conocimiento de la persona (5 min.)}

1. Podría comentarme sobre su cargo y su experiencia laboral

\section{B. Sobre la escuela de Marketing digital}

(25 $\min )$

\section{Se explica en qué consiste el proyecto}

\section{a) Sobre los cursos:}

1. ¿Cuáles son los cursos más dictados actualmente?

2. ¿Cuáles son las nuevas tendencias en cursos de marketing digital o relacionados con éste?

3. ¿Qué herramientas considera necesarias para el dictado de los cursos?

b) Sobre los alumnos:

1. ¿Cuál considera que es el perfil del alumno?

\section{c) Sobre la competencia:}

1. Hablando, sobre los institutos en los que ha trabajado, ¿en qué horarios considera que hay mayor alumnado?

2. ¿Cuáles son las características que tienen en común otros institutos? 
3. ¿Qué mejoraría Ud. en estas instituciones?

4. ¿Qué consideraciones hay que tener al momento de contratar un docente?

\section{Datos Básicos}

Nombre de la Empresa:

Ubicación:

Cargo del entrevistado:

Número de trabajadores en la compañía:

\section{Muchas Gracias por su participación}




\section{Apéndice 7}

\section{Transcripción de la entrevista con Marcos Fonruge}

- Entrevistador: Primero cuéntame sobre tu experiencia profesional.

- Marcos: Mi familia es de artes gráficas. Egrese en el 92 con diseño gráfico, en ese entonces no había digitalización en absoluto. Empecé haciendo diseño gráfico publicitario y como fui uno de los primeros en esta disciplina, rápidamente fui contactado por agencias de publicidad y del propio contacto con las agencias de publicidad fui llegando al marketing. Después de eso en el 99 tengo la oportunidad de meterme en el medio digital porque me contactan para diseñar el primer diario digital del mundo en español. Es en el primero que es $100 \%$ digital. Estoy haciendo ahí dirección de contenidos casi 10 años. Entre otras cosas porque evoluciono lo suficiente para convertirse en una factoría y portal de diseño de contenido para otras empresas. Nos contactaron varias empresas Después de eso me dedico $100 \%$ a agencia de publicidad digital. Era una de las cinco primeras agencias de publicidad digital en Europa y la primera en España. Y ahí continuando con el tema de publicidad y marketing digital hasta que llega el 2012. El 2012 es cuando me reclaman para iniciar el primer diplomado de Community Management para la Toulouse. Y desde el 2012 trabajando en agencias o diseñando los contenidos en Instituciones Educativas: Toulouse, Orval, UPC e IPP. Desde que estoy aquí para lo que me han utilizado es para renovar los currículos de Educación Digital. Tuve durante un año un programa de televisión con emprendedores TV, hacíamos todo lo que es medios sociales para pequeñas y medianas empresas

- Entrevistador: ¿Cuáles consideras que son los cursos que hay más demanda en marketing digital? 
- Marcos Fonruge: Lo que más está demandando la gente es marketing digital, todo el tema de Community Management y también a la hora de manejar pauta publicitaria. Todo lo que es emprendimiento digital o creación de apps o promoción de negocios en medios digitales está bastante solicitado. Dentro de la comunicación en redes digitales y medios sociales lo que la gente quiere es Community Management y manejo de pauta publicitaria.

Aquí en Perú la gente tiene la tendencia a hacer auto emprendimiento. Hay muchísima gente que tiene un negocio y ha descubierto que una inversión publicitaria en medios tradicionales está fuera de su alcance y sin embargo hacer inversión digital y emprendimiento digital, le resulta más sencilla. Todo lo que es emprendimiento digital, diseño de aplicaciones. No tanto páginas web. Fíjate lo que te diría, hay mucha gente que pretende que con su Facebook y redes sociales no tienen problemas para continuar a menos que quieran vender online. Pero por encima del diseño web, diseño para medios digitales, motion graphics para hacer memes, animaciones, cosas rápidas y todo lo que es manejo de redes sociales, marketing digital e incluso ahora recientemente comunicación política para medios digitales.

- Entrevistador: ¿Qué curso dirías que se demanda pero todavía no se enseña?

- Marcos: Pues fíjate algo tan sencillo como hacer memes, es una cosa tan sencilla como el storytelling, el problema no es la técnica, el problema es que casi todas las empresas e instituciones que dictan se centran en la parte técnica, si te enseñan adobe premiere, si te enseñan a manejar after effects pero les falta el saber enseñar contar historias a la gente, por ejemplo les falta fotografía y video, es una práctica que no se enseña mucho cuando le enseñan a alguien a ser community manager y sin embargo casi todo lo que es comunicación en medios digitales consiste en contar historias a través de tecnología y la primera son el video y la fotografía que más impacto provocan. 
Resulta que hay muy pocos community que sepan generar su propio contenido. Entonces todo lo que son disciplinas para generar contenido: storytelling, cursos de fotografía (...), el hacer un meme, saber contar una historia en 15 segundos, redacción creativa es algo que no se dicta mucho y queda un poco en el aire. Y los community si saben manejar la red, utilizar su Photoshop para hacer una gráfica rápida. Pero a la hora de redactar les cuesta muchísimo redactar en menos de 120 caracteres, les cuesta muchísimo hacer un call to action o llamadas que imperan la agente a compartir, a involucrarse. La carencia principal la veo en eso en habilidades de redacción y habilidades de creación de contenido.

- Entrevistador: Se cubre más la parte tecnológica o técnica pero no la parte creativa

- Marcos: Efectivamente. Pensemos en todo momento que aquí tenemos dos figuras, uno es el community que quiere trabajar a sueldo de alguien y normalmente ese alguien para quien está trabajando no tiene idea de nada. El community es un gestor, pero se espera que sea un gestor y un creador de contenidos. No se puede pretender aquí en Perú que un community sea solo community a menos que la empresa que lo reciba tenga área de creatividad también y área de generación de contenido y área de diseño. Y eso no suele ser muy habitual. Generalmente una empresa contrata a un community para que le lleve las redes y espera que le haga todo.

Y luego tienen la otra: yo estudio marketing digital para llevar mi propio negocio por lo tanto no tengo un gestor de contenidos, un equipo de diseño, no tengo tal. Soy yo mismo la persona que estoy intentando sacar mi emprendimiento. En ambos casos para mí la carencia es esa. El community tiene que tener parte de creatividad, redacción creativa, capacidad de síntesis y tienen que ser un poco práctico para contar historias y generar experiencias. No puede ser solo un operador que mueve palancas para colocar las cosas 
en su sitio ya que muchas veces el mismo tiene que generar experiencias para que la gente se enganche con la página

- Entrevistador: ¿Que tendencias vez a futuro, por ejemplo, temas que vayan a salir?

- Marcos: Por ejemplo, temas que están saliendo. Lo primero es que se están micro fragmentando las redes sociales. Hasta ahora todo el mundo miraba únicamente Facebook, únicamente YouTube, Twitter e Instagram y aquí Twitter con mucho cuidado ya que Twitter se utiliza cuando hay futbol o hay política. Ahora estalló y dentro de 10 días se volverá a calmar.

Hay gente que está buscando la micro especialización en las redes. Cada vez hay redes que están especializadas en un rubro o gremio concreto. Y también están mucho las redes efímeras, es decir el contenido que desparece rápidamente por lo tanto no son redes repositorio como por ejemplo Pinterest que tú puedes ver contenido de hace un año o más, sino que el contenido se adecúa mucho a lo que los millenials han preparado y a lo que los millenials también están siguiendo que es el contenido inmediato, consumo rápido de contenido, desechar rápido el contenido, es decir aprende rápido olvida pronto. Entonces las redes inmediatas, los temas de usar los medios de mensajería como canal publicitario también, hay una tendencia muy fuerte a que la gente abandona redes más o menos tradicionales y cada vez se utilizan más los sistemas de mensajería como núcleo o como una red propia. En caso tienes WhatsApp, empezó siendo un sistema de mensajería y ahora prácticamente es una red social a nivel de micro grupos. Entonces la publicidad en sistemas de mensajería también es tendencia. Más tendencias, Facebook quiero convertir su plataforma en una zona de ventas y tiene su propia tarjeta de divisa, de cambio, de moneda de crédito. Entonces va a suceder. Hay mucha tendencia a que las grandes redes se queden únicamente para marketeros y no sea tanto para el flujo de información y demás. 
Ejemplo: influencers y los micro influencers, no se está buscando el influencer de 20,000 millones de seguidores, se buscan los micro influencer y hay mucha tendencia a que la gente crea su propio contenido y tiene área de influencia muy fuerte y cada vez más concretas y reducidas. Es decir, casi todo el mundo antes quería ser famoso. La gente ya que no quiere ser famosa en televisión, quiero abrir un canal de YouTube, hablar de un tema concreto y tener un monto de seguidores. Entonces eso está bastante fuerte pero ya no influencer de tengo 10 millones de seguidores sino tengo un millón de seguidores solo para el tema de recetas de cocina o tengo un millón de seguidores solo para asuntos domésticos. Y otra tendencia bastante fuerte es el gaming, antes la gente intentaba hacer dinero con YouTube y ahora en medios digitales lo que está vendiendo muy fuerte es el tema de gaming, el adver gaming y también el ganar dinero a través de competiciones online

Entrevistador: Ahí entra bastante el Twitch, ¿no?

- Marcos: Y Fornite está pegando muy fuerte y el E3 cada vez promueve más competencia entre grupos que son prácticamente el prime time de lo que antes era ver la Super Bowl y ahora sin embargo hay 30 o 40 millones de personas conectadas viendo un combate de Fornite. Entonces es algo que las marcas también tienen que tener en cuenta

- Entrevistador: ¿Y qué opinas el tema de la automatización, Chatbots?

- Marcos: Es que eso ya no es tendencia. Mira aquí se ve como tendencia, pero ya está súper implementado en otras partes. El tema de los Chatbots ya tendría que haber estado hace un año y pico totalmente asentado. El problema es que las compañías que utilizan la automatización de contenido o de comentarios no saben cuál es su discurso. No tienen parametrizada su ruta de discurso y no han hecho un análisis lógico tipo árbol de diagrama de que sucede cuando dices si cuando dices no. Pero en si lo que son los 
Chatbots lo que es la comunicación a través de inteligencia artificial está prácticamente desplazando a todo lo demás.

Yo hace mucho que veo que como figura el community no existe, por eso te insisto tanto que es el cuenta cuentos tradicional de toda la vida el que ahora tiene un papel en medios digitales ya que contestar como community, lo que antiguamente se conocía como community que un tipo que solamente contesta y solamente dice déjame tu teléfono eso ya lo hace un chatbot. ¿Qué es lo que pienso? Pues si se trabaja sobre ello y se enseña a la gente a programar Chatbots probablemente se le hará mucho más versátil. Una escuela que enseñe a la gente a programar chatbot y a generar herramientas de conversación automatizada probablemente sería una asignatura muy demandada porque no mucha gente sabe hacerlo y sin embargo todo el mundo está deseando aplicarlo.

- Entrevistador: ¿Para dictar un curso de marketing digital que consideras que son los factores más importantes?

- Marcos Fonruge: Lo primero no empezar por lo digital. Fíjate yo soy un tecnócrata hasta la medula, pero la mayoría de la gente ha aprovechado la terminología digital para darle un aspecto de grandilocuencia ... Si la persona que va no ha hecho absolutamente nada de marketing antes ni tiene idea de lo que es marketing empezamos mal. Para empezar el problema es que mucha gente confunde marketing con publicidad. Punto 1. Una cosa es que planes voy a hacer yo de marketing para conseguir tales beneficios y otra cosa es como lo voy a comunicar. Hay mucha gente que se apunta cursos de marketing digital cuando lo que quiere es publicidad en redes sociales que es indistinto. No es que yo quiero vender mi producto online, eso es publicidad no es marketing. Marketing es un plan mucho más profundo que implica tener un buen SEM, un buen SEO, tener una buena estructura. Ver cuáles son tus objetivos de marketing digital y luego los de comunicación y publicidad. 
Entonces primer paso para tener una escuela de marketing: Que enseñen las bases de marketing. Las escuelas de marketing digital tienen que ser una vía de acceso rápido al mercado laboral porque es lo que busca la gente, no buscan cursos de nueve meses. Un diplomado de nueve meses en marketing digital no va a tener tanto impacto como un diplomado de ocho semanas. Pero en esas semanas hay que enseñarles los fundamentos del marketing, deben de saber segmentar a su público objetivo, tienen que saber muy bien lo que es un insight, lo que es un objetivo de marketing y lo que es un objetivo de comunicación que los confunden constantemente. Tiene que saber lo que es un embudo de conversión, conocer rudimentos básicos como la pirámide de Maslow. Darle una base de marketing y analogías que le hagan entender como eso se traduce en el medio digital y darle una vía de acceso rápido.

- Entrevistador: ¿Cuál consideras que son las principales diferencias entre las escuelas, institutos y universidades para enseñanza de marketing digital?

- Marcos: La universidad te da el titulo o cartón de la universidad y en algunos entornos laborales eso pesa bastante. El problema que tiene una universidad es que son muchos más lentos reaccionando y para cuando sales tienes docentes de mucho peso, pero lamentablemente cuando has acabado ese año tienes un equipaje muy grande pero una salida laboral no tan grande. En el tiempo que una universidad ha hecho un diplomado de un año, MOTT ha hecho tres diplomados cortos y el IPP ha hecho dos. Para mí el equilibrio es algo como el IPP. Una universidad para mi es una tortuga, es lenta en sus procesos, tarda mucho en cambiar el currículo. En el tiempo que se está dictando ese diplomado puede que haya evoluciones o cambios que no se asimilan en el currículo. Las pequeñas como MOTT a mi gusto son eminentemente técnicas. Si no tienes una formación previa de marketing o no conoces mucho el medio te acabo de convertir en un operador, pero no en un creador en un desarrollador. Instituciones tipo IPP que tienen las 
carreras largas pero que extraen de ahí un diplomado corto me parecen más interesantes porque si te enseñan las bases, si te enseñan la parte técnica pero también te dan un acceso rápido al mercado laboral. No estas esperando ni un año y pico para acabar ni es tampoco enseñarte a usar Facebook y a subir posts sin decirte para qué.

- Entrevistador: ¿Cuándo se lanza un curso que tanto considera que se puede llenar los salones?

- Marcos: Se llenan bastante, lo que he notado es que los alumnos generalmente se fían más del capital humano que tiene la empresa que de la propia empresa. La gente no va por la institución sino más por el docente.

- Entrevistador: ¿Y como ves la demanda en marketing digital? ¿Cuánto crees que vaya a crecer la demanda de este año al siguiente?

- Marcos: mucho, es que la inversión ha crecido un montón y es que estamos hablando de tener un $8 \%$ de inversión a un $14 \%$ de inversión. No te voy a decir que el crecimiento sea exponencial, pero si es un crecimiento geométrico... Ahora mismo podrían abrirse cinco escuelas más y las cinco tendrían gente solo que hay que saber que segmento atacar, por ejemplo, los conos están muy abandonados... y en provincias ya no te quiero ni contar, están desesperados. Tú abres ahora mismo una escuela de marketing digital en Huancayo y te comes toda la región de Junín.

- Entrevistador: ¿Cual consideras que es el perfil típico del estudiante de marketing digital?

- Marcos: Tengo varios perfiles: Uno es el chico joven hasta 26 a 27 años, que tiene una carrera y quiere saber de esto. Te hablo del típico chaval que está egresando de empresariales, comunicaciones y quiere complementar con esto. Tienes otro que es el emprendedor, que generalmente viene de un estrato socioeconómico un poco más bajo que en los otros perfiles. Este emprendedor quiere hacerlo el mismo y se ha dado cuenta que es una forma más barata que en medios tradicionales y luego tienes el tercer perfil 
que es un profesional que trabaja en el medio y necesita actualizarse. Muchas de las personas que han solicitado mi servicio de capacitación se encuentran entre los 30 a 35 años y generalmente o estén en el rubro de gastronomía, moda o servicios a terceros como coach o cosas de ese estilo. Esas personas son las que tratan de realizar las campañas ellos mismos. Si yo tuviera que lanzarme a atacar dos perfiles de forma muy fuerte, uno seria recién egresados y otro para emprendedores

- Entrevistador: ¿Dentro de lo que son los cursos cuales son los horarios que más te demandan?

- Marcos: Nocturnos, la gente antes de las siete de la noche no se mete en algo sobre todo los emprendedores y otro sería el intensivo de fin de semana, el sábado desde las 8am a $1 \mathrm{pm}$, un break para almorzar y luego de 3 a $5 \mathrm{pm}$ y el domingo desde las $8 \mathrm{am}$ a la $1 \mathrm{pm}$. Y muchos prefieren este intensivo de un fin de semana a llevar un curso de cuatro meses. Con el grupo de estudiantes hay más flexibilidad de horarios, pero en las mañanas va a estar vacío. Una escuela empieza a moverse a partir de las 2pm y a partir de las 7 a 10 pm revientas de público. Los únicos que se meterían en la mañana son los que no estudian ni trabajan que es un porcentaje muy bajo.

- Entrevistador: ¿En base a tu experiencia cual dirías que es el porcentaje que se llenaría en cada turno?

- Marcos: El de noche lleno absoluto. Si consideramos el de la noche con un $100 \%$ de demanda, un curso de 5 a 7 podría tener un 50 a 55\% de demanda. Y en la mañana si preparas un curso de 10 a 1pm la demanda bajaría por debajo del 30\% según mis cálculos. Y esto no tiene que ver con el fin de semana, tú abres un curso el sábado por la mañana o por la tarde y se te llena. 


\section{Apéndice 8}

\section{Transcripción de la entrevista con Miguel Calderón}

- Entrevistador: Nos podría decir su nombre y cargo.

- Miguel: Soy Miguel Calderón. Soy director general de educación superior tecnológica. A la pregunta, nosotros somos competentes para la autorización de lo que son institutos y escuelas tecnológicas de educación superior tecnológica y básicamente hay dos procesos que se cumplen para poder dar el servicio educativo. Uno es la creación y el otro el licenciamiento que se dan al mismo tiempo. Para lo que me preguntas específicamente que es oferta privada existe la figura de un promotor. El promotor puede ser una persona natural o jurídica que se constituye para poder frente al ministerio de educación, frente a nosotros, crear o licenciar un instituto o escuela tecnológica.

Ahora la denominación es absolutamente libre ya que se regula por la ley de sociedades, toda esa normativa. Lo que nosotros autorizamos es la denominación del instituto o escuela tecnológica que ellos proponen para el licenciamiento. Entonces tú puedes tener una promotora de una denominación con la terminología SAC y este promotor es el que viene al ministerio de educación y propone la creación de un instituto con determinadas carreras y para ser licenciado tiene que cumplir ciertos requisitos. Una vez que ha sido licenciado ya puede brindar el servicio educativo. Evidentemente un instituto como el instituto superior tecnológico Le Cordon Bleu, no necesariamente su promotor en registros públicos tiene el mismo nombre. El nombre puede ser servicios generales o servicios de gastronomía SAC o cualquier figura que vaya por ese lado. Lo que sí es indispensable para brindar el servicio educativo es que ese instituto o escuela tenga un licenciamiento, tenga la licencia del ministerio de educación. Ese es otro documento normativo. La licencia se da al instituto o escuela que se ha creado sin embargo el 
responsable del instituto es el promotor. Si hay algún tipo de falta se sanciona al instituto y se sigue al promotor que es el verdadero dueño de la institución. Esa es la figura en la parte privada.

- Entrevistador: ¿Y todo centro que de clases necesita estar validado por el ministerio de educación o hay empresas privadas que podrían dar clases y no necesitarían una validación?

- Miguel: La iniciativa empresarial es libre, yo puedo constituirme como SAC y dar clases de inglés, de nivelación de escolares, puedo hacer cursos técnicos, enseñar cocina, etc. Pero si das algún tipo de certificado, algún tipo de constancia es a nombre propio y no tiene ninguna validez en el sistema educativo. Hay muchas asociaciones o instituciones que dan cursos culturales, ejemplo cine francés, etc., que es absolutamente libre.

Cualquier asociación, cualquier empresa puede tener una oferta de formación. Lo que no pueden hacer es dar títulos a nombre de la nación ni dar certificados oficiales a nombre del ministerio de educación. Cuando tú quieres dar una carrera de técnico o profesional técnico tienes que estar licenciado por el ministerio. Cumples ciertos requisitos, hay una duración en términos de créditos, de horas que tú tienes que cumplir, hay procedimientos que tienes que registrar en el ministerio de educación. Entonces para eso es el licenciamiento. Si tú te licencias tienes la posibilidad de dar esa oferta con un título a nombre de la nación. Pero para dar cursos de capacitación, de extensión, de actualización, cualquier tipo de oferta, uno empresarialmente es libre de hacerlo. Lo que no puedes hacer es ofertar con publicidad engañosa. Te pongo un caso concreto: hay una asociación universitaria iberoamericana, que era el nombre de una SAC que utilizaba el término de universidad en su nombre. Entonces eso llevaba a muchas personas a confusión pensando que era una asociación de nivel universitario. Ahí Indecopi tiene clara la denominación de este tema de la publicidad engañosa. Por ejemplo, que tú ofertes algo con reconocimiento 
oficial que puede ser cualquier cosa. Entonces te engaña porque con eso se puede inferir de que hay un reconocimiento por parte del ministerio de educación. Esos son los límites que permiten las normas.

- Entrevistador: Entonces constancia seria lo único que se podría emitir

- Miguel: O diplomas a nombre de la empresa. Por ejemplo, Nestlé es una empresa que da cursos de cocina entonces en sus certificados dice Nestlé reconoce que esta persona ha estudiado 6 horas de cocina en microondas. Es totalmente válido y licito. Es un reconocimiento propio de la actividad privada en este caso, pero eso no tiene valor oficial.

- Entrevistador: ¿Y para la actividad privada estos cursos no están sujetos a ningún reglamento?

- Miguel: Es totalmente libre, por ejemplo, las academias universitarias, no necesitan autorización. La única autorización que tramitan es del municipio para funcionar como un establecimiento que va a congregar a determinada cantidad de personas. Las academias universitarias al igual que el caso de Nestlé imparten clases para prepararse para un centro y eso no está regulado ni tiene porque estar regulado. Es libre, cualquier persona puede hacer eso. Tú puedes tener una empresa y ofrecer un curso de cinco años y si alguien te lo compra bien.

- Entrevistador: ¿Y el nombre de los cursos por ejemplo diplomados lo puede poner cualquier empresa o está restringido?

- Miguel: Si está restringido oficialmente para las universidades. Las universidades, en la ley universitaria, señala que brindan diplomados. Porque estos si están regulados en lo que es la formación continua. Lo mismo que el termino licenciatura, bachillerato. Ahora una cosa es un diplomado como un programa regular pero el dar diplomas, el diploma no es un grado académico, suele ser más libre en el mercado. 
- Entrevistador: Yo me refería que la competencia brindaba cuatro o cinco cursos de seis meses y decía diplomado de marketing digital.

- Miguel: Si, ósea lo puedes dar, pero no tiene un valor oficial.

- Entrevistador: Ah, pero si se puede poner el nombre, ¿el nombre no está restringido?

- Miguel: El nombre no está restringido. Se menciona en la ley universitaria como restrictivo para la universidad

- Entrevistador: ¿Pero la empresa privada si puede ponerle cualquier nombre?

- Miguel: Si

- Entrevistador: En la competencia que hemos visto una de ellas se nombra en internet como escuela, otro como centro de especialización y otro como Social Media Academy. ¿Esos nombres también estarían restringidos?

- Miguel: No estarían restringidos, lo que está restringido es el uso de nombre de universidad porque eso es solo para instituciones que están bajo la tutela de la ley universitaria. Tú puedes usar instituto o escuela porque lo que nosotros registramos como exclusivo y es oficial es instituto de educación superior como si fuera una sola palabra. Por ejemplo: escuela de educación superior tecnológica, pero la palabra escuela se usa indistintamente. Por ejemplo, hay escuela de choferes y no te da un título de valor universitario.

- Entrevistador: Por ejemplo ¿se podría nombrar instituto de redes de marketing digital y sería totalmente valido?

- Miguel: Lo que no se puede usar es el mismo nombre que usan en las leyes para instituciones oficiales, que te digo: universidad, escuela de educación superior tecnológica, escuela de educación superior pedagógica, escuela superior de formación artística, instituto de educación superior. Esos están restringidos 
- Entrevistador: Y por ejemplo uno de estos competidores habían formado una escuela y vimos que estaban formando franquicias. ¿Una franquicia educativa la puede brindar una organización privada?

- Miguel: Si, porque eso está regulado por la ley general de sociedades. Tú puedes hacer con tu empresa privada lo que quieras salvo: no puedes dar títulos a nombre de la nación ni parecerte absolutamente a nada oficial

- Entrevistador: ¿Que ventaja se tendría si se creara una escuela de marketing digital como si fuera un instituto?

- Miguel: Es el valor oficial, porque tú puedes dar carreras de uno, dos o tres años autorizadas por el ministerio de educación. Ahora el proceso de licenciamiento no es lo que era antes. Ahora tenemos por ley hasta 90 días hábiles para dar respuesta a los privados que ya se están licenciando ahora. Ya no es un procedimiento tan complicado como antes que duraba años, eran proceso que te demoraban dos, tres años en autorizar un instituto.

Un instituto que tiene por ejemplo marketing digital o administración de empresas, por ejemplo, tiene esas carreras bajo la regulación del ministerio que al final te dan un título a nombre de la nación pero también los institutos están habilitados a dar formación continua, esto quiere decir libre y a nombre propio. Estamos viendo que cursos de formación continua en el futuro puedan ser validados con cursos de las carreras. Por ejemplo tú puedes tener en la carrera un curso de ofimática y al mismo tiempo lo puedes dar como formación continua a cualquier persona que quiera estudiar solamente office. De tal forma que este curso se pueda convalidar en el futuro como parte de la carrera.

- Entrevistador: Y en el caso de la empresa privada que comience dictando cursos y luego quiere licenciarse, ¿lo puede hacer sin ningún problema?

- Miguel: Sí, el promotor es libre de crear y licenciar un instituto cuando quiera 
- Entrevistador: ¿Y hay algún requisito como un mínimo de alumnos? ¿Qué requisitos principales existen?

- Miguel: Los requisitos son: primero los institucionales, la autorización de funcionamiento, del municipio, la constitución del promotor y todos estos instrumentos institucionales básicos. Luego hay requerimientos de infraestructura, de equipamiento, de perfiles docentes, de programas porque tienes que cumplir un determinado número de créditos, de horas, de estructura que es básicamente similar para toda la educación superior que es básicamente una formación general, tipo estudios generales, la parte de especialidad y las prácticas y hay una cantidad mínimo de créditos que debes de tener en cada tema. Eso es básicamente los requisitos, una vez que pasas el proceso y te autorizan las metas los pones tú y eso depende de tu aforo, de cuanta gente puede estar al mismo tiempo en una institución.

- Entrevistador: ¿Y puede ser algo muy pequeño?

- Miguel: Totalmente. Nosotros hemos visto institutos que tenían como meta iniciar con 40 o 60 alumnos. Eso es totalmente iniciativo de cada persona.

- Entrevistador: ¿Y la forma como se hacen los syllabus, los cursos, eso es netamente decisión de la empresa?

- Miguel: El ministerio te pide algo así como nosotros le llamamos el itinerario: la competencia, el módulo, tus cursos, las horas, en que ciclo lo dictas y todo el programa asociado al equipamiento y la infraestructura que vas a utilizar y los perfiles de los docentes. Lo que tu colocas lo tienes que cumplir no es que el ministerio te ponga un estándar mínimo del docente. Lo que pones tiene valor de declaración jurada, lo mismo con las condiciones de infraestructura.

- Entrevistador: Quizás la mayor complicación de pasar de una empresa privada a un instituto es el compromiso. Lo que uno se compromete a hacer y hacerlo. 
- Miguel: Si, nosotros exigimos un mínimo de existencia para iniciar el servicio educativo y de proyección ya sea a través del plan de implementación o del plan de inversiones a futuro.

- Entrevistador: Y fuera del tema de que un instituto licenciado brindaría título a nombre la nación, ¿hay algún otro beneficio, de repente por el lado tributario que también convengan licenciarse?

- Miguel: Eso es previsto en la ley, pero está en debate con el ministerio de economía y finanzas. Por eso si mal no recuerdo hace cuatro o cinco años ese beneficio caduco. Tenía que restituirse con la nueva ley. Se ha restituido pero la misma ley manda que el ministerio de economía regule este tributo. Es política del ministerio de economía no dar ese tipo de exoneraciones tributarias así que está en pleno debate.

- Entrevistador: Y hay algún asesoramiento o algún otro beneficio.

- Miguel: No, no hay mayor beneficio por parte del ministerio de educación excepto que los licenciados pueden participar en beca 18 si son calificados. Hay institutos en los cuales el $50 \%$ de sus ingresos están basados en beca 18, lo cual es peligroso ya que se acaba beca 18 y te queda un vacío en tus ingresos. 


\section{Apéndice 9}

\section{Cuestionario}

Buenos días/tardes, somos alumnos de la Escuela de Postgrado de la EPG USIL y estamos realizando una investigación acerca del potencial que existe para la creación de una Escuela de Marketing Digital en Lima. Por favor, le pedimos responder las siguientes preguntas, cuyas respuestas serán tratadas de manera confidencial y global. Gracias por su participación.

1.- ¿Cuántos años tiene?
a. Menor de 18 (Si está en este rango, fin de la encuesta. Gracias.)
b. Entre 15 y 18
c. Entre 18 y 25
d. Entre 26 y 30
e. Entre 31 y 35
f. Entre 36 y 45
g. Entre 46 y 49
h. Mayor de 45 (Si está en este rango, fin de la encuesta. Gracias.)

2.- ¿En qué distrito vive?
a. Jesús María
e. Pueblo Libre
h. San Miguel
b. La Molina
f. Miraflores
i. Surco
c. Lince
g. San Borja
j. Otro
d. Magdalena
h. San Isidro

Si la respuesta es OTRO, fin de la encuesta. Gracias.

3.- ¿Estudia una carrera relacionada con el marketing digital o trabaja en un puesto relacionado con el marketing (por ejemplo: administración, ventas, diseño, publicidad, comunicaciones)?
Sí
No

Si la respuesta es NO, fin de la encuesta. Gracias.

4.- ¿Qué escuelas de marketing digital conoce?
a. MOTT
b. Pandemia
c. Negzy
d. Otra (¿cuál?)
e.

Ninguna

5.- ¿Cuál es el factor más importante al momento de decidir estudiar en determinada escuela o instituto? 

a. Prestigio de la institución
b. Prestigio de los profesores
c. Ubicación
d. Precio de los cursos
e. Horarios de estudio

6.- ¿Cuántas veces al año toma cursos de capacitación?
a. Una vez
b. Dos veces
c. Tres o más
d. Nunca

6.1. ¿De estos cursos cuántos se relacionan con el marketing digital? (sin considerar cursos gratuitos)

EXPLICACIÓN: Nuestra propuesta es una Escuela de Marketing Digital, en la cual se dictarán cursos cortos (de un mes de duración). Las clases serán personalizadas, es decir se adaptarán a las necesidades de los alumnos y serán dictadas en un ambiente cómodo y agradable por profesionales reconocidos en el medio.

Los cursos se ofrecerán en tres modalidades:

- Cursos regulares, en nuestro local, para grupos pequeños de entre 5 a 15 personas en horarios previamente establecidos.

- Cursos individuales, donde el alumno compra un paquete de un número de horas para que un profesor le enseñe sólo temas específicos que el alumno requiera, el horario será establecido por el alumno.

- Cursos blended, es decir que el alumno estudiará por su cuenta a través de una plataforma virtual, asistiendo de manera presencial sólo una vez a la semana.

7.- ¿Estaría dispuesto a estudiar en esta escuela de marketing digital?

\begin{tabular}{|l|l|}
\hline Definitivamente sí & \\
\hline Probablemente sí & \\
\hline Indeciso & \\
\hline Probablemente no & \\
\hline Definitivamente no & \\
\hline
\end{tabular}

Si la respuesta ES PROBABLEMENTE NO o DEFINITIVAMENTE NO, fin de la encuesta. Gracias.

7.1. ¿En cuál de las modalidades que ofrece la escuela de marketing digital le gustaría estudiar?
a. Regular
b. Personalizado
c. Blended 
8.- ¿Cuánto estaría dispuesto a pagar mensualmente por un curso en la modalidad elegida?
a. Menos de S/. 200
b. Entre S/. 200 y S/. 300
c. Entre S/. 301 y S/. 400
d. Entre S/. 401 y S/ 500
e. Entre S/. 501 y S/.600
f. De S/.601 a más

9.- ¿En qué horarios tiene disponibilidad para estudiar?
a. En las mañanas (entre lunes y viernes)
b. En las tardes (entre lunes y viernes)
c. En las noches (entre lunes y viernes)
d. Sábados
e. Domingos

10.- ¿En qué distrito de Lima Metropolitana le gustaría que se encuentre ubicada la escuela?
a. Miraflores
b. San Isidro
c. Surco
d. Lince
e. Otro:

11. ¿Qué características debería tener el local de esta nueva escuela de marketing digital? Marque las 3 más importantes para usted.

_ Computadoras modernas

Estacionamiento para los alumnos

Local eco amigable

Fácil acceso

Cafetería

__Otra. ¿Cuál? 
12. ¿Qué característica deberían tener los profesores de la institución?

Amplia experiencia en el área de marketing

Reconocidos en el medio

Graduados de instituciones de prestigio

Experiencia en la docencia

Otra. ¿Cuál?

13.- ¿Qué cursos le gustaría que se dicten en la escuela?
a. SEO y SEM
b. Publicidad digital
c. AdWords
d. Social Media
e. Analítica web
f. Diseño de contenidos
g. Otros. ¿Cuáles?

14.- ¿En qué medios debería anunciar la nueva escuela de marketing digital?
a. Redes sociales
b. Radio
c. Revistas o diarios
d. Mailing

\section{DATOS DEL ENCUESTADO}
Sexo:
1. Femenino
2. Masculino

¿Cuánto es el ingreso promedio por persona en su hogar?

a) Mayor o igual a $\mathrm{S} / .1330 .10$

b) Menor a $S / .1330 .10$ 


\section{Apéndice 10}

\section{Planos estratificados a nivel manzana por ingreso per cápita del hogar por distrito}
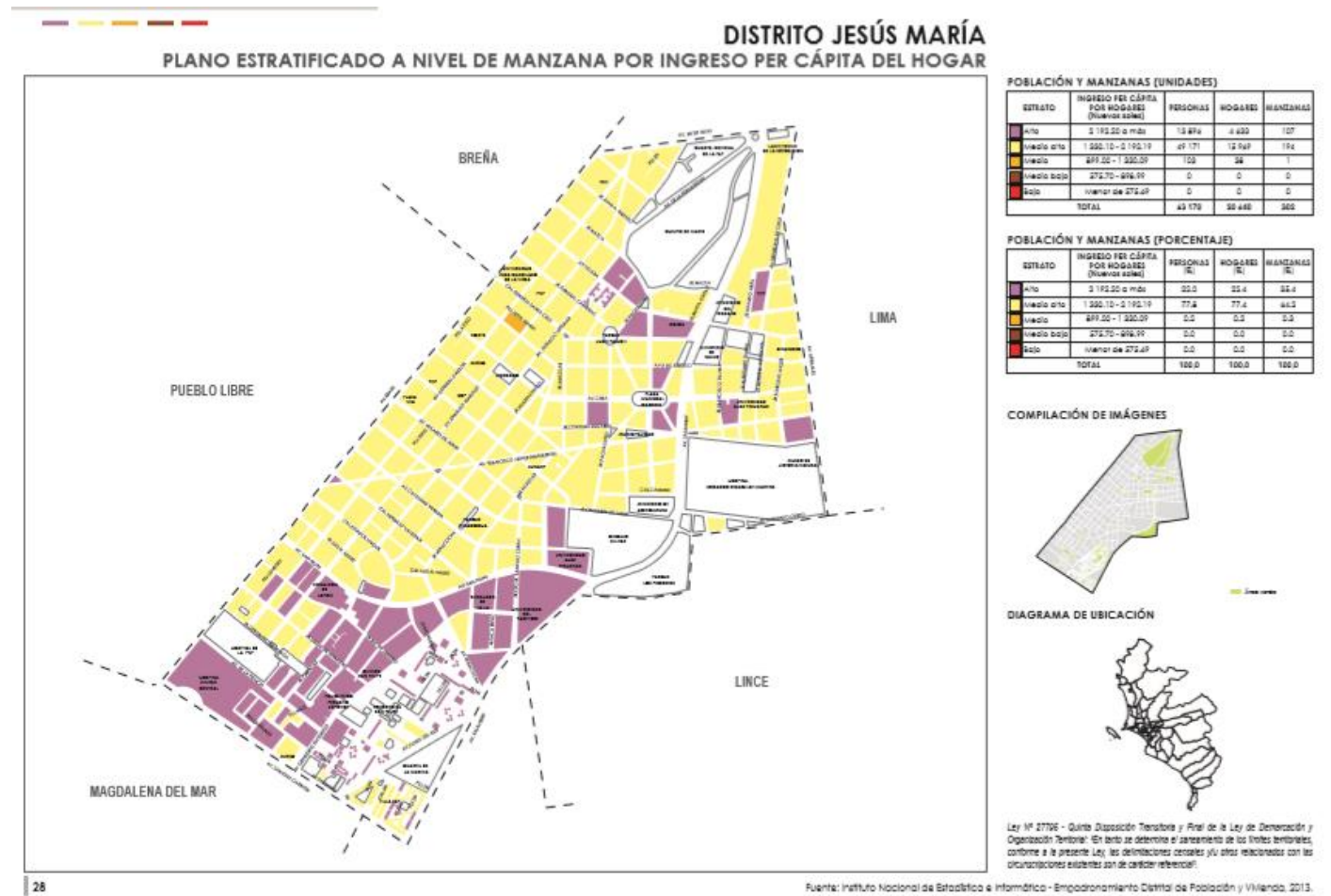

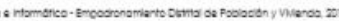
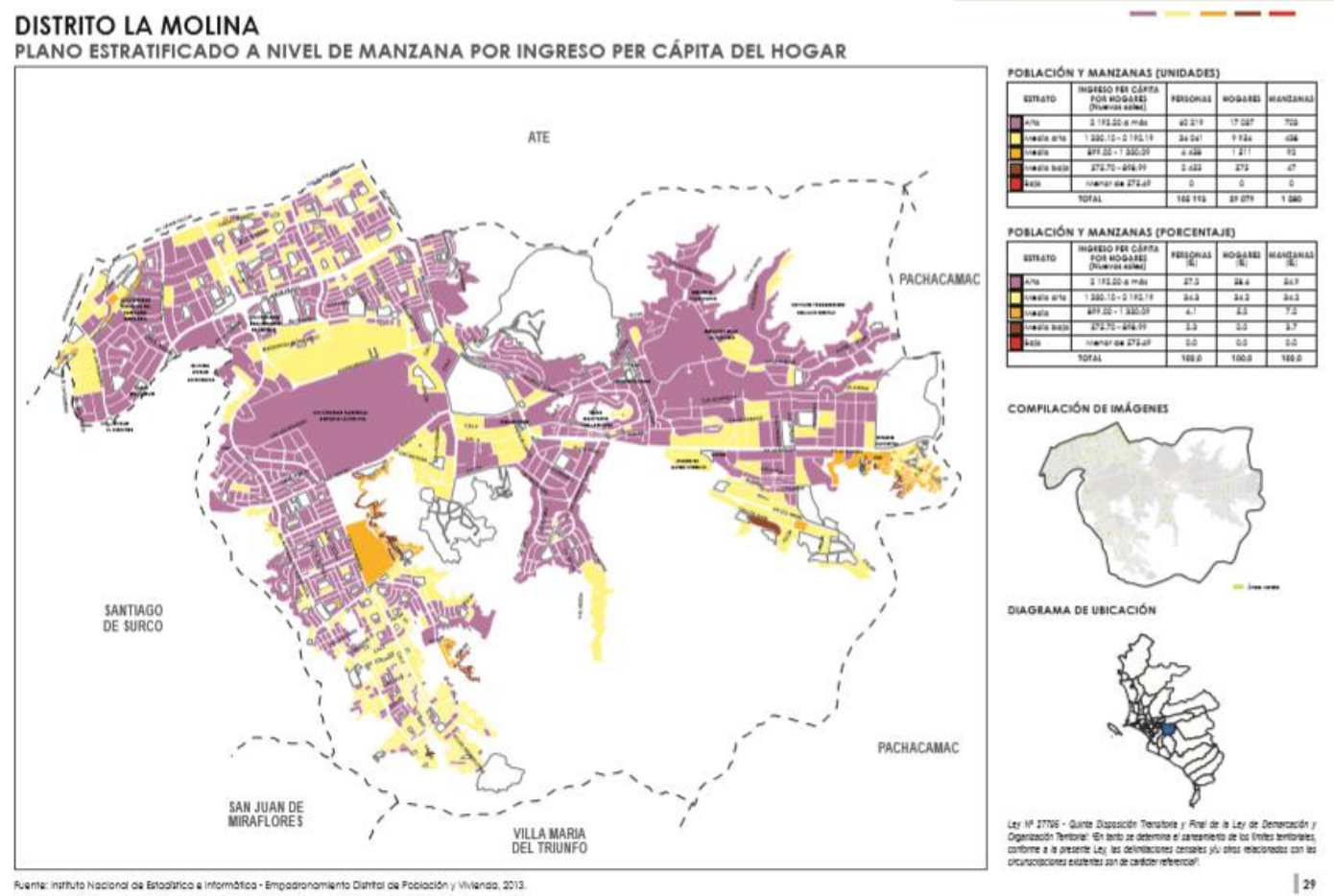

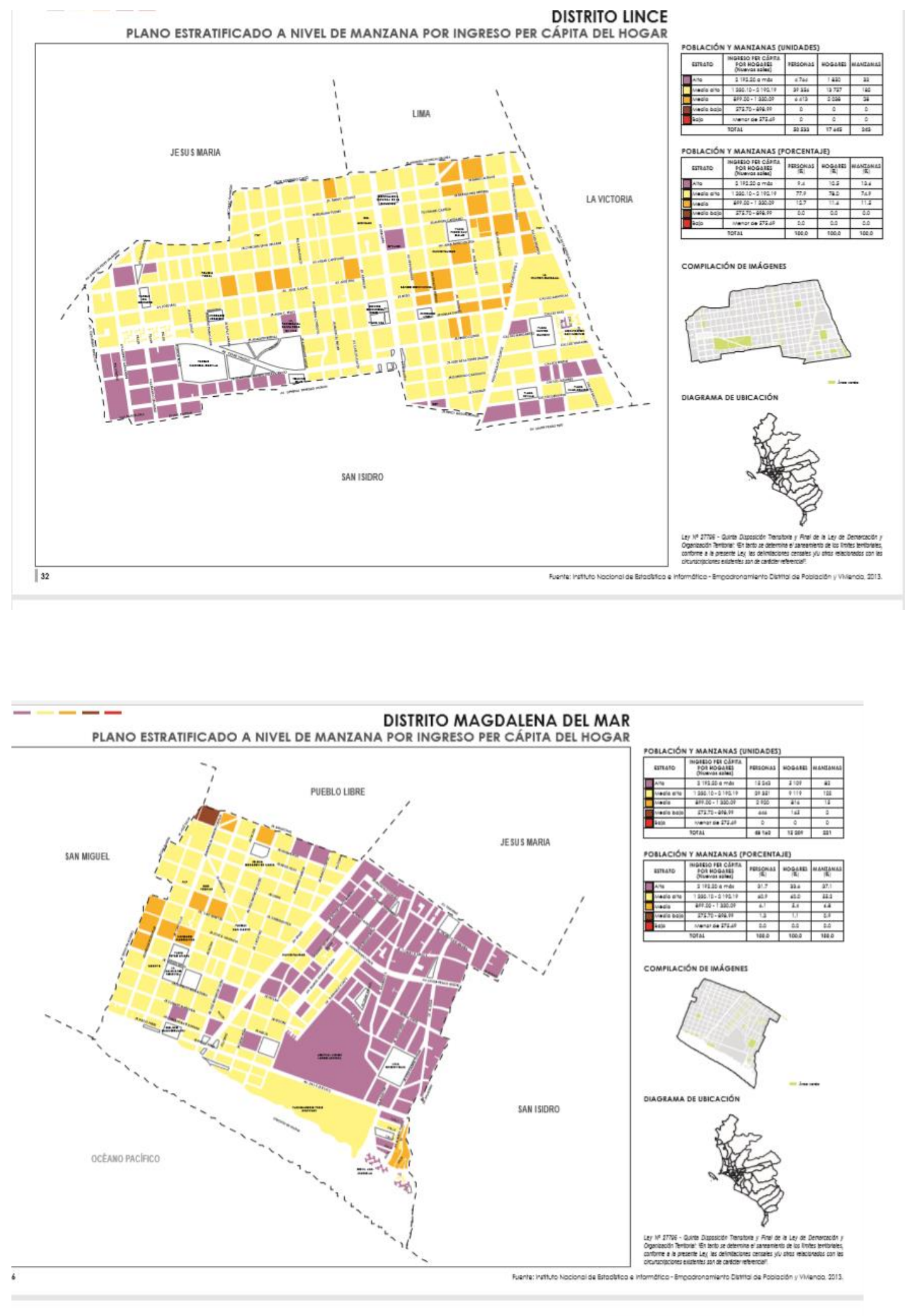
DISTRITO MAGDALENA VIEJA

PLANO ESTRATIFICADO A NIVEL DE MANZANA POR INGRESO PER CÁPITA DEL HOGAR
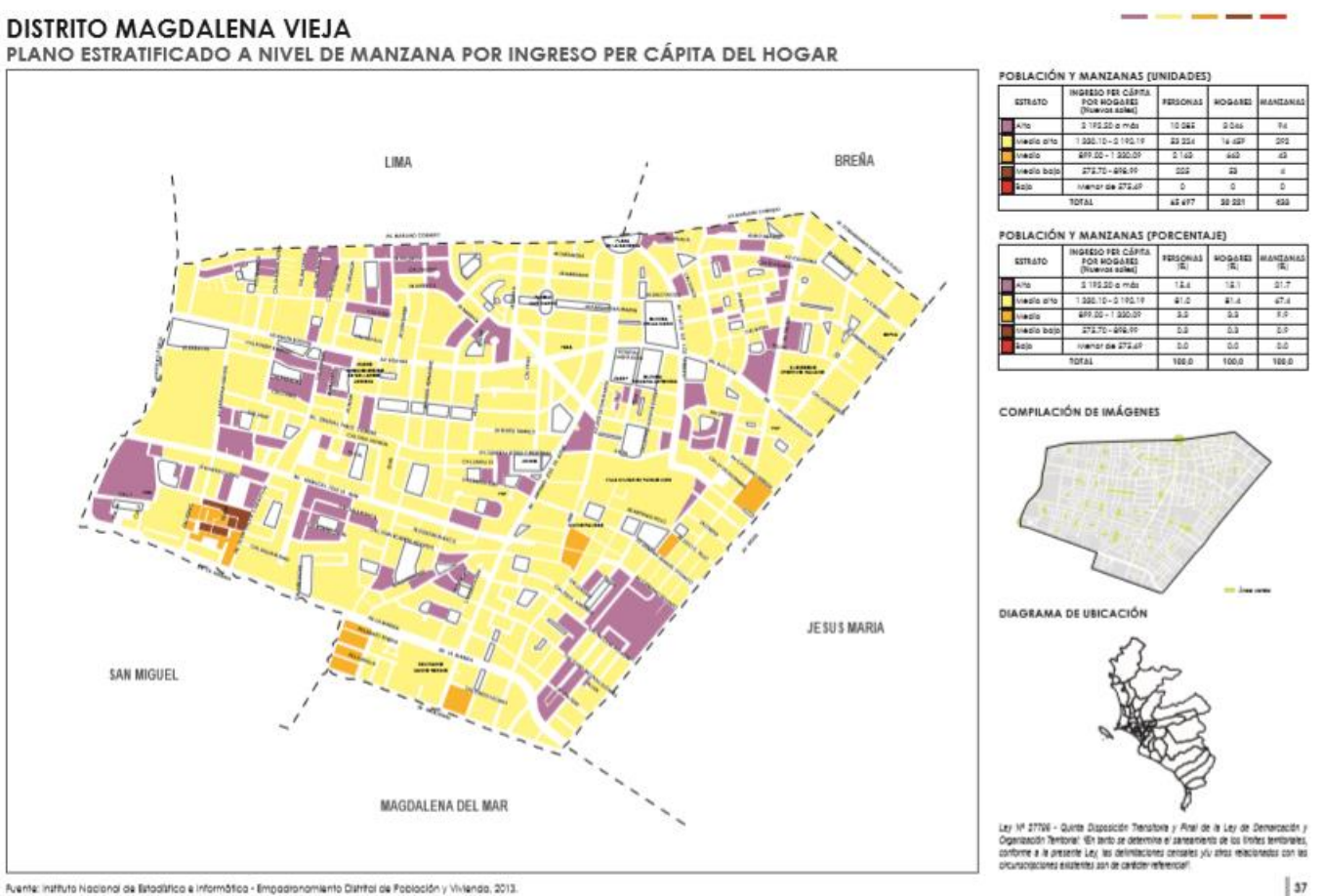

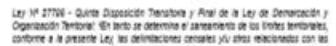
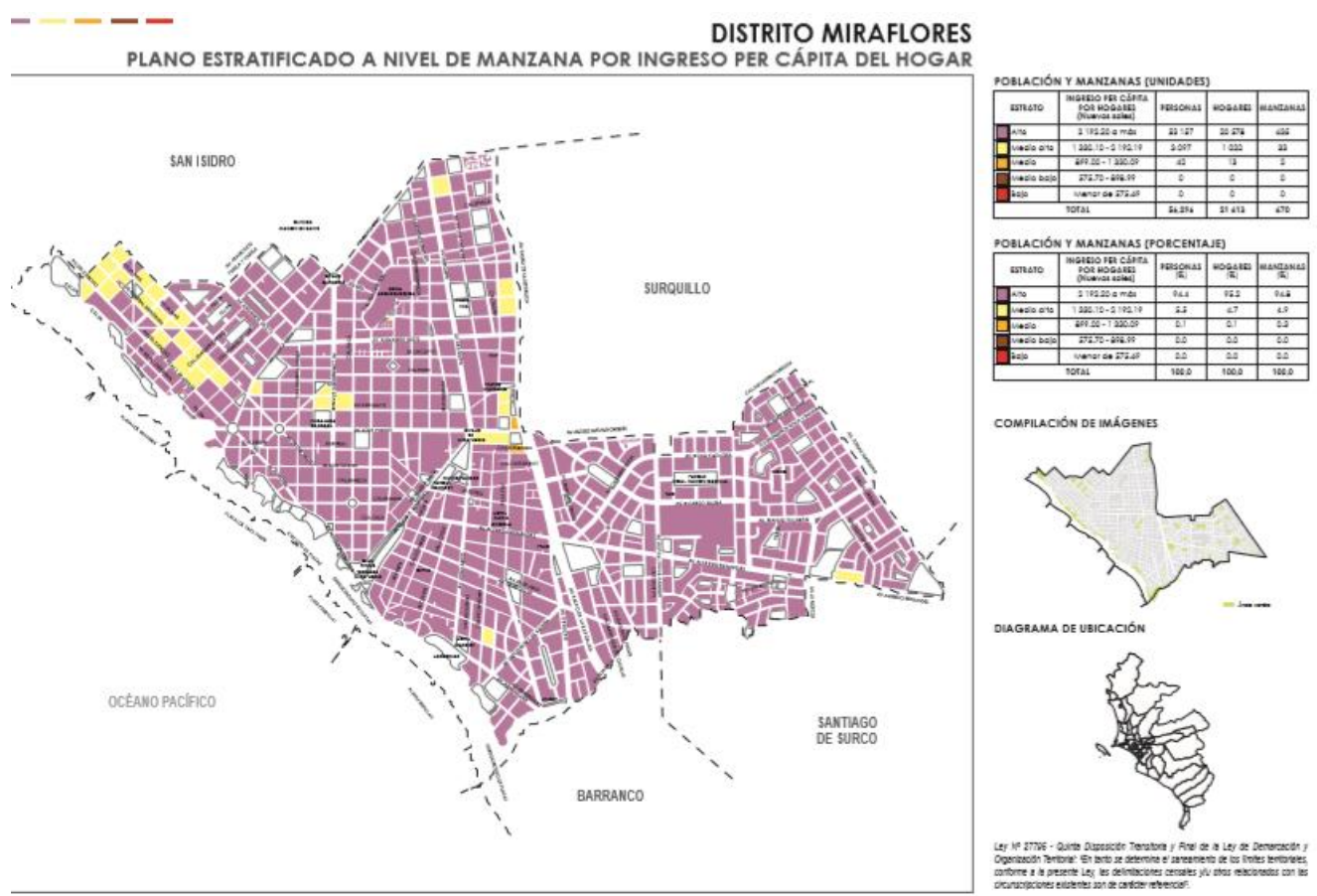

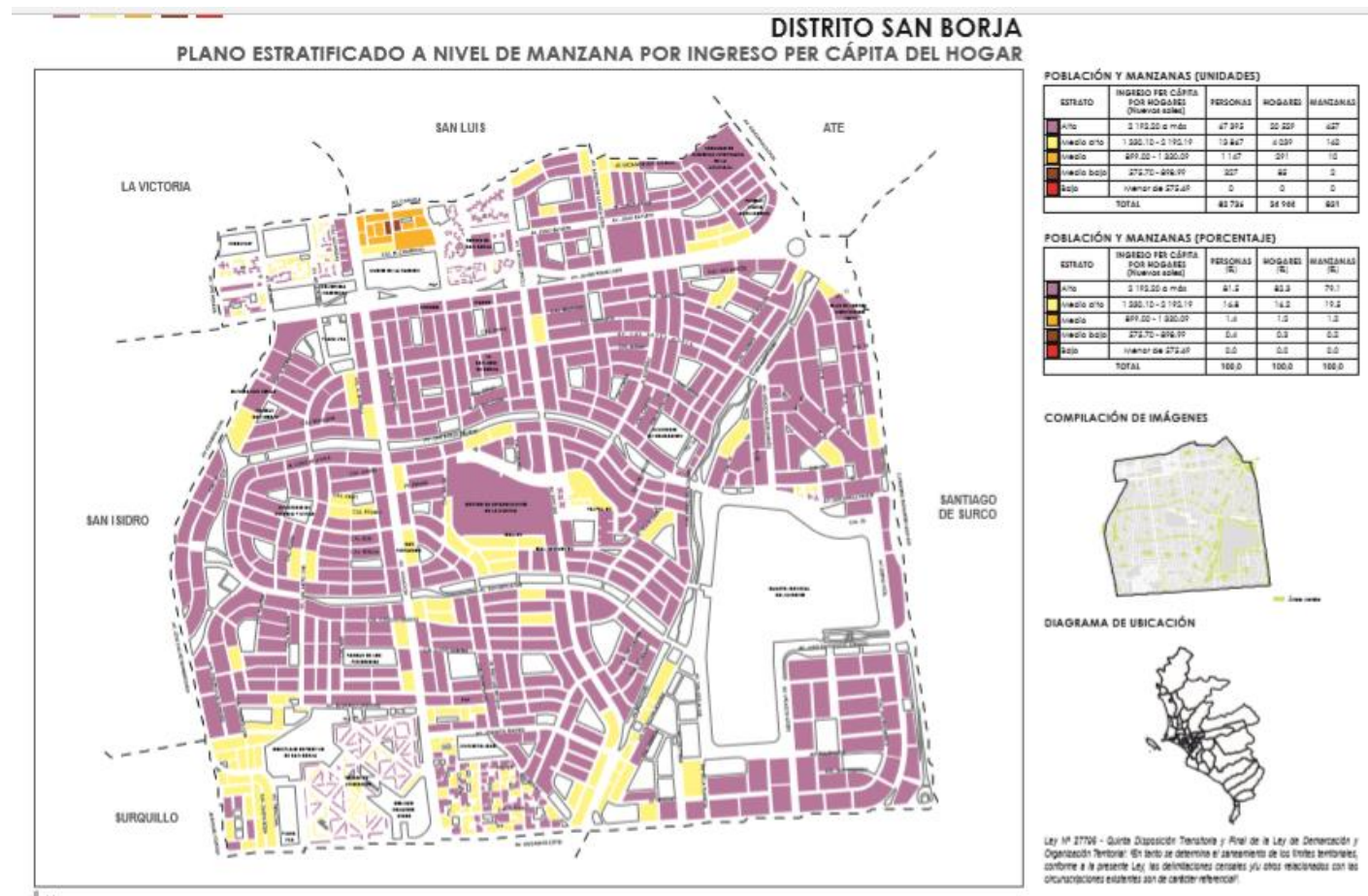

oragrama de UEicación

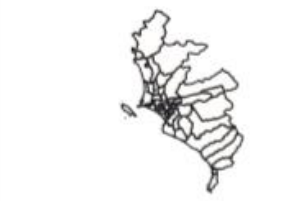

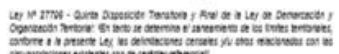

46

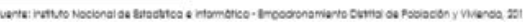

DISTRITO SAN ISIDRO

PLANO ESTRATIFICADO A NIVEL DE MANZANA POR INGRESO PER CÁPITA DEL HOGAR

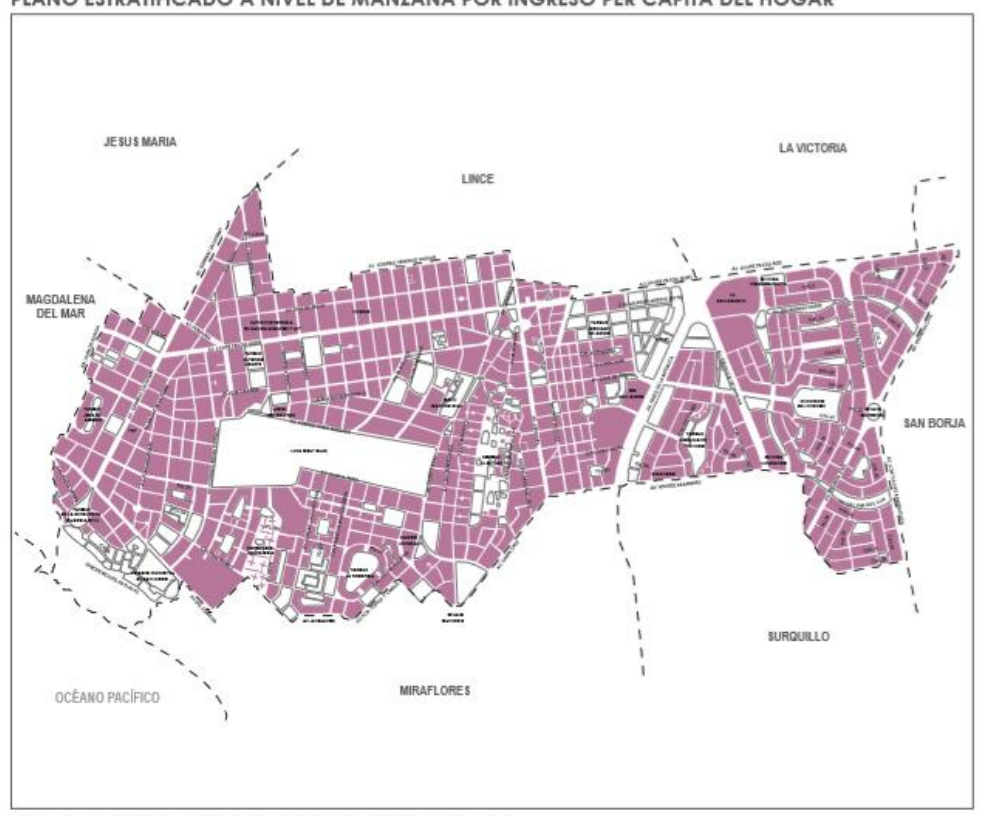

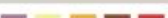

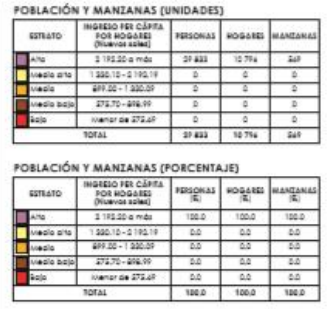

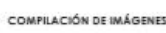

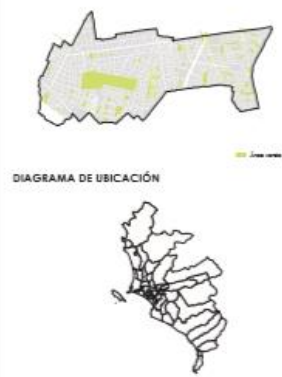

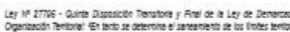

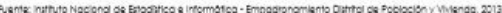



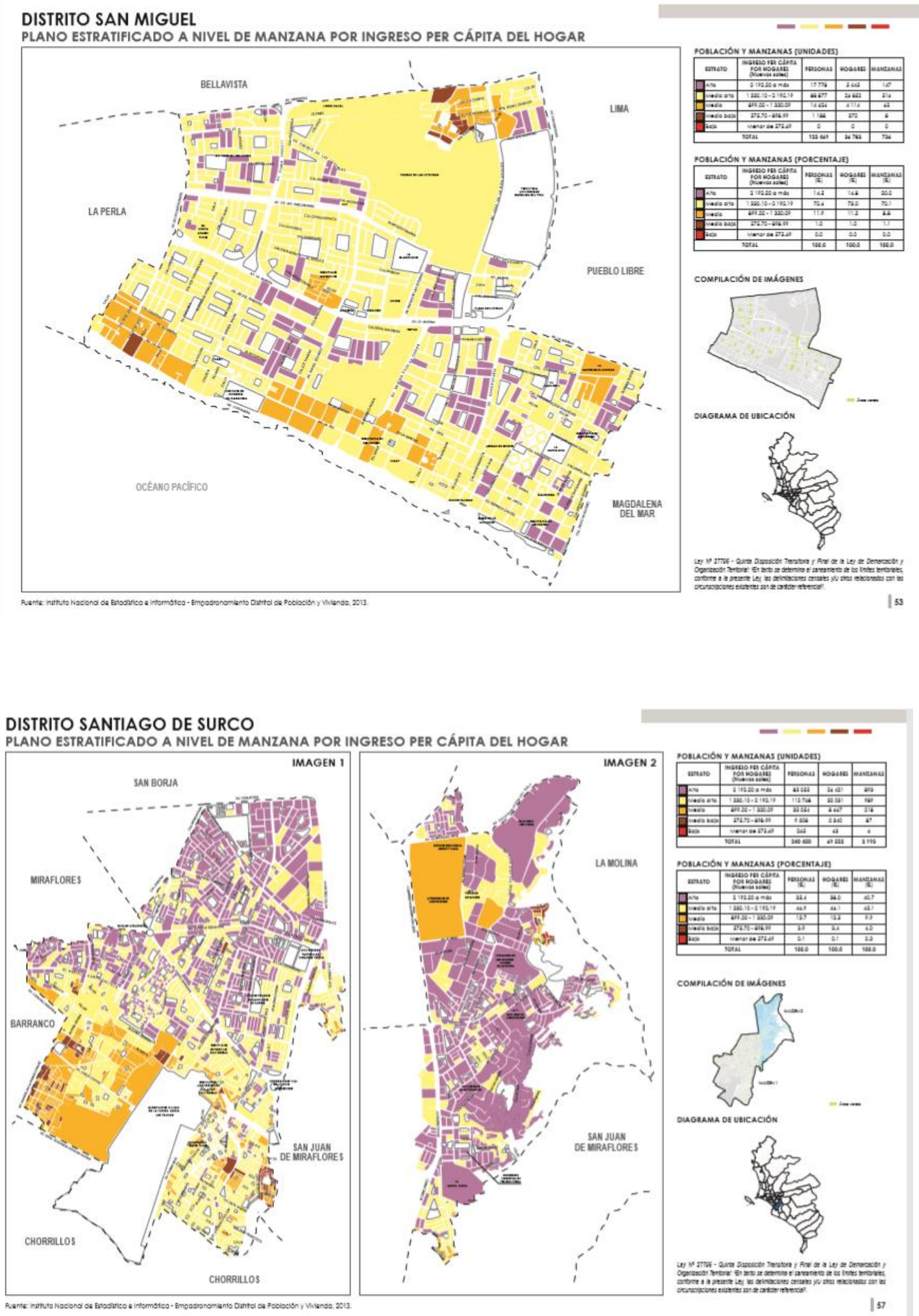